Eduardo Machado de Almeida

\title{
Estrutura da População, Crescimento e Reprodução de Maurolicus stehmanni Parin \& Kobyliansky, 1993 (Teleostei: Sternoptychidae) na Zona Econômica Exclusiva do Sul e Sudeste do Brasil.
}

Dissertação de Mestrado apresentada ao Instituto Oceanográfico da Universidade de São Paulo, como parte dos requisitos para obtenção do Título de Mestre em Ciências, área de Oceanografia Biológica.

Orientadora: Profa. Dra. Carmen L. D. B. Wongtschowski

São Paulo 


\title{
Universidade de São Paulo \\ Instituto Oceanográfico
}

\section{Estrutura da População, Crescimento e Reprodução de Maurolicus stehmanni Parin \& Kobyliansky, 1993 (Teleostei: Sternoptychidae) na Zona Econômica Exclusiva do Sul e Sudeste do Brasil.}

\begin{abstract}
Eduardo Machado de Almeida
Dissertação de Mestrado apresentada ao Instituto Oceanográfico da Universidade de São Paulo, como parte dos requisitos para obtenção do Título de Mestre em Ciências, área de Oceanografia Biológica.
\end{abstract}

Aprovada em ______ por:

Profa. Dra. Carmen Lucia Del Bianco Wongtschowski Instituto Oceanográfico da Universidade de São Paulo

Dra. June Ferrraz Dias

Instituto Oceanográfico da Universidade de São Paulo

Dra. Maria Cristina Cergole

IBAMA São Paulo 


\section{Índice}

Índice de tabelas

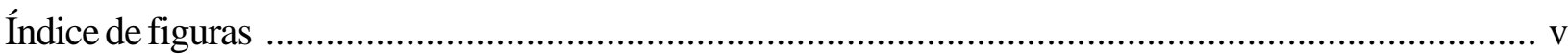

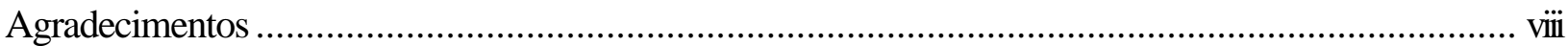

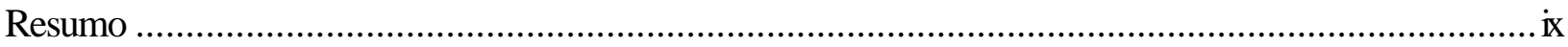

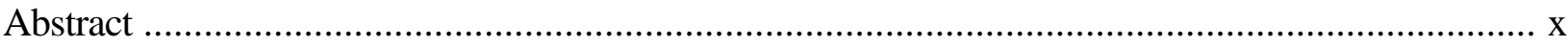

Capítulo I. Introdução ao estudo ............................................................................................. 1

I. 1: O gênero Maurolicus .......................................................................................... 1

I. 1a: O papel ecológico de Maurolicus ..................................................................... 2

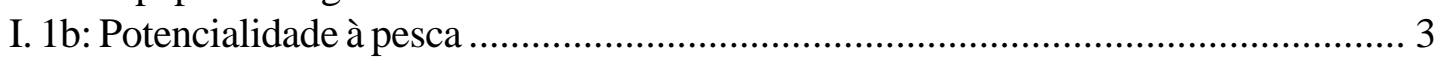

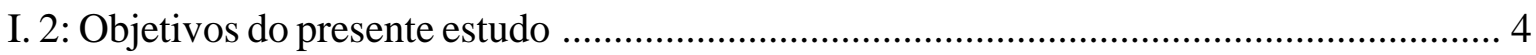

I. 3: Caracterização da área ……………………………………………………..... 5

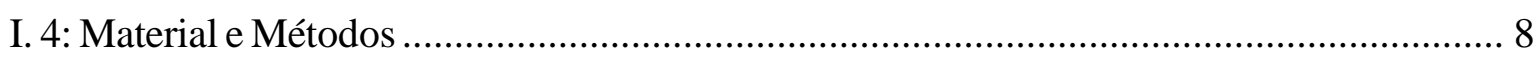

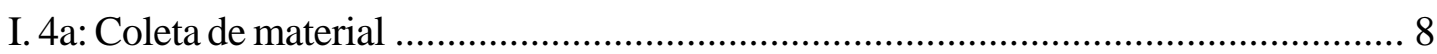

I. 4b: Obtenção de dados .................................................................................. 9

Capítulo II. A espécie ……………………………………………………………………..... 10

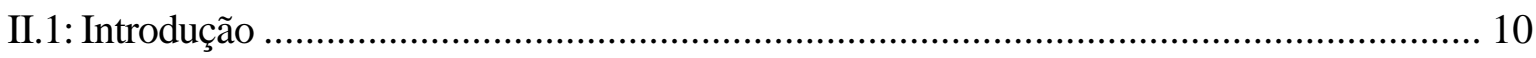

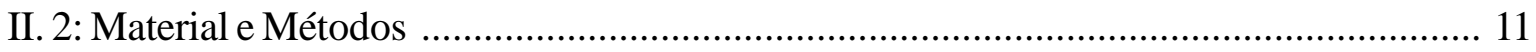

II. 2a: Características morfológicas ......................................................................... 11

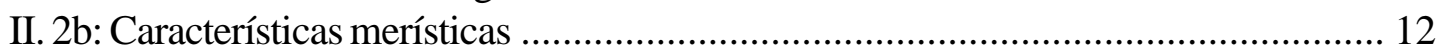

II. 2c: Identificação da espécie ................................................................................... 13

II. 3: Resultados e Discussão …………………………………...................................... 14

II. 3a: Características morfológicas ...................................................................... 14

II. 3b: Características merísticas ............................................................................ 19

II. 3c: Identificação da espécie …………………………………………………. 23

Capítulo III. Estrutura termohalina e distribuição de Maurolicus stehmanni na área.............................26

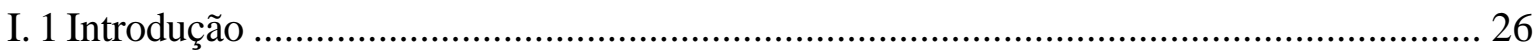

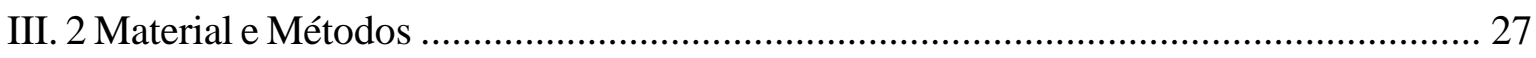

III. 2a: Condições oceanográficas da área durante os cruzeiros ………………………. 27

III. 2b: Distribuição espaço-temporal de M. stehmanni ................................................. 28

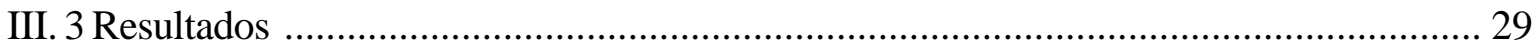

III. 3a: Condições oceanográficas na área durante os cruzeiros ..................................... 29

III. 3b: Distribuição espaço-temporal de M. stehmanni .................................................. 33

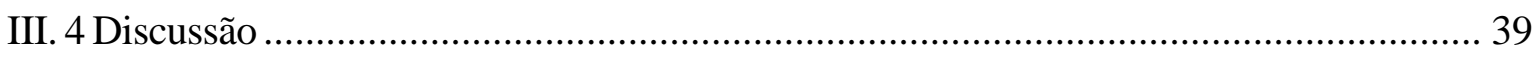

Capítulo IV. Estrutura da população e reprodução de Maurolicus stehmanni ................................... 42

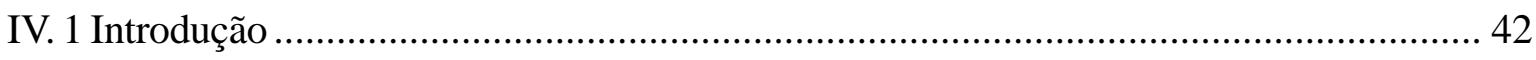

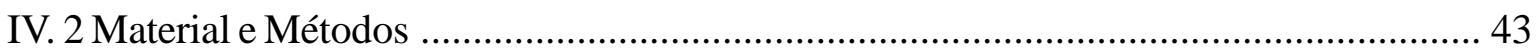

IV. 2a: Captura e composição da população ................................................................. 43 
IV. 2b: Relação entre o peso total e o comprimento padrão e fator de condição ............ 44

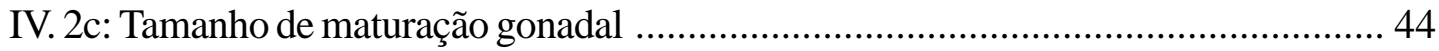

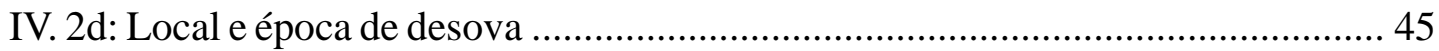

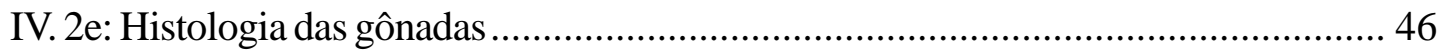

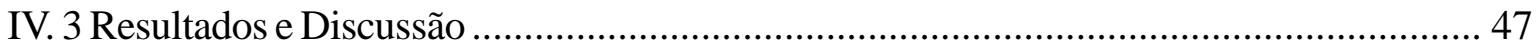

IV. 3a: Captura e composição da população .......................................................... 47

IV. 3b: Relação entre o peso total e o comprimento padrão (Wt/Cp) ............................ 56

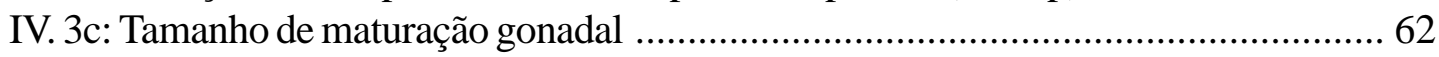

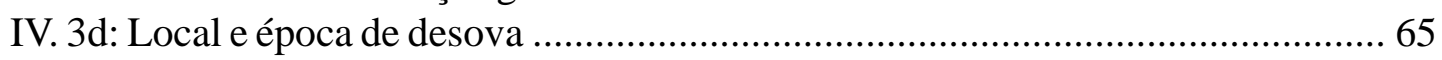

IV. 3e: Histologia das gônadas ........................................................................ 75

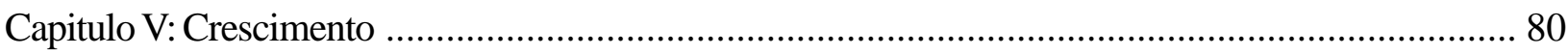

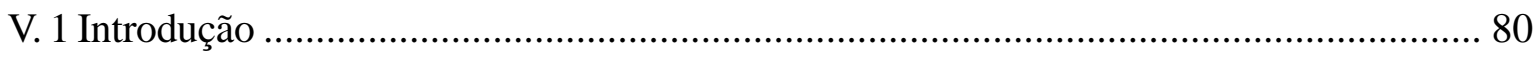

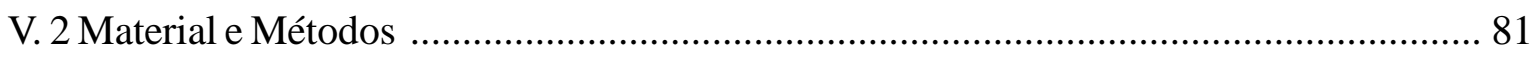

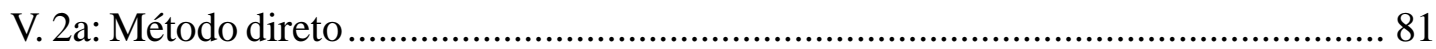

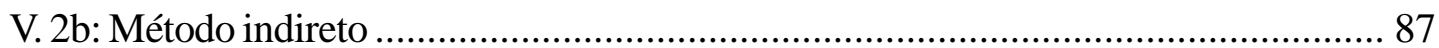

V. 2c: Comparação entre os resultados deste estudo e os da literatura ........................... 88

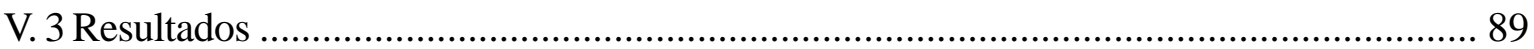

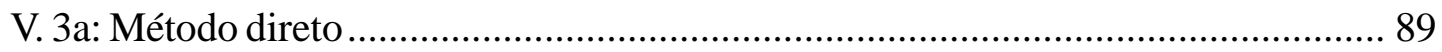

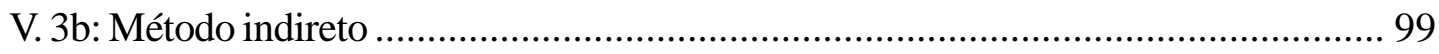

V. 3c: Comparação entre os métodos direto, indireto e resultados da literatura ............. 104

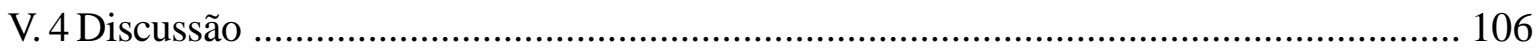

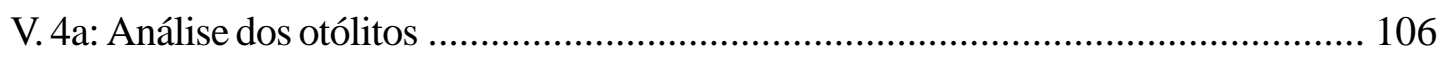

V. 4b: Parâmetros de crescimento ................................................................... 108

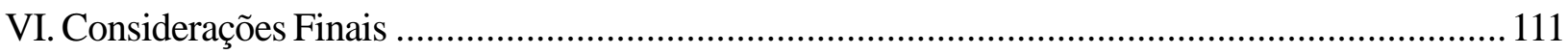

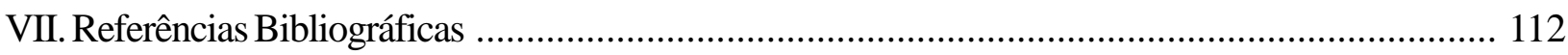




\section{ÍNDICE de TABELAS}

Tabela II.1. Resultado do teste de comparação múltipla de médias (Tukey) das proporções entre o comprimento da cabeça e o comprimento padrão $(\mathrm{Cc} / \mathrm{Cp})$ e entre o diâmetro da órbita e o comprimento padrão (Dho/Cp), considerando-se cada lance de pesca, machos e fêmeas separadamente. As células em cinza representam as estações nas quais a diferença entre as médias foi significativamente diferente $(5 \%)$. O número de exemplares na amostra está indicado entre parênteses.

Tabela II.2. Maurolicus: Valores dos parâmetros das regressões lineares entre o comprimento da cabeça e o comprimento padrão $(\mathrm{Cc} / \mathrm{Cp})$, entre a altura do corpo e o comprimento padrão $(\mathrm{Ac} / \mathrm{Cp})$ e entre o diâmetro da órbita e o comprimento padrão (Dho/Cp).

Tabela II.3. Maurolicus: valores médios e intervalos de confiança $(a=0,05)$ do comprimento da cabeça $(\mathrm{Cc})$, altura do corpo (Ac) e diâmetro da órbita (Dho) em relação ao comprimento padrão, por lance de pesca.

Tabela II.4. Valores das características merísticas e morfométricas obtidos neste trabalho e aqueles apresentados na revisão de Parin \& Kobyliansky (1996). Os números representam as médias e os valores entre parênteses os valores máximos e mínimos. V - vértebras; RB - rastros do $1^{\circ}$ arco brânquial; FAC - fotóforos caudais; RNP - raios da nadadeira peitoral; $\mathrm{Cc} / \mathrm{Cp}$ - relação (\%) entre comprimento da cabeça e o comprimento padrão; Dho/Cp - relação (\%) entre o diâmetro da órbita e o comprimento padrão; Ac/Cp - relação (\%) entre altura do corpo e o comprimento padrão; Tmax. tamanho máximo e L - localidade pesquisada.

Tabela IV.1. Captura e tamanho da amostra de Maurolicus stehmanni referente aos cruzeiros I, II e III (inverno de 1996, outono de 1997 e primavera de 1997, respectivamente). Na - número de exemplares amostrados; Nc - número estimado de indivíduos capturados; P - peso total capturado; $\mathrm{Nl}$ - número de lances com ocorrência de M. stehmanni. * Ausência de sobressaco ao aparato de pesca.

Tabela IV.2. Valores numéricos e proporção sexual de peixes adultos de M. stehmanni, por lance de pesca e época do ano. * - Lances de pesca com proporção sexual significativamente diferente de 1:1 $(\mathrm{p}=0,05)$.

Tabela IV.3. Parâmetros (a e b) da relação Wt/Cp e o coeficiente de determinação $\mathrm{r}^{2}$, para as épocas de coleta.

Tabela IV.4. Tamanhos (comprimento padrão) máximos $\left(\mathrm{T}_{\max }\right)$ e mínimos $\left(\mathrm{T}_{\min }\right)$ de machos e fêmeas com gônadas maduras de espécies do gênero Maurolicus deste estudo e outros localizados em diferentes áreas. $\mathrm{Cp}_{\max }$ é o comprimento padrão máximo encontrado. Notar que os trabalhos foram publicados antes da última revisão do gênero (Parin \& Kobyliansky, 1993 e 1996), exceto a publicação de Rasmunsen \& Giske (1994).

Tabela IV.5. Valores médios e desvios padrões de $\mathrm{RGS}_{1}$ e $\mathrm{RGS}_{2}$ das fêmeas em maturação (B) e maduras (C) de M. stehmanni, para as três épocas de amostragem.

Tabela IV.6. Características das fases de desenvolvimento ovocitário de M. stehmanni observadas neste estudo.

Tabela V.1. M. stehmanni: Valores médios de comprimento padrão e raio dos otólitos por grupo de anel. $\mathrm{N}$ - número de otólitos analisados em cada grupo; $\mathrm{Cp}$ - comprimento padrão médio; Ro - raio médio do otólito e dp - desvios padrão.

Tabela V.2. Porcentagem de borda opaca (\% o) e de borda translúcida (\% t) nos otólitos de $M$. stehmanni por grupo de anel (G0, G1, G2 e G3) para as três épocas de análise; n é o número de otólitos analisados.

Tabela V.3. M. stehmanni: Valores de comprimento padrão retrocalculados pelos métodos BPH e SPH para cada grupo de anel G1, G2 e G3. Cpi é o comprimento padrão médio retrocalculado que o peixe teria na formação do anel i, e foi calculado para todos os peixes. 
Tabela V.4. M. stehmanni: Parâmetros de crescimento estimados através de diferentes métodos: 1) valores médios de comprimento padrão por grupo de anel e 2) valores retrocalculados. $\Phi$ - índice de performance.

Tabela V.5. Parâmetros de crescimento $\left(\mathrm{L} \infty, \mathrm{k}, \mathrm{t}_{0}\right)$ e o índice de performance $(\Phi)$ de M. stehmanni estimados pela rotina ELEFAN I para a mostra total e por época de coleta.

Tabela V.6. Valores médios de comprimento padrão (mm) das coortes de M. stehmanni estimados pelo método Bhattacharya.

Tabela V.7. Parâmetros de crescimento $\left(\mathrm{L} \infty, \mathrm{k}, \mathrm{t}_{0}\right)$ e o índice de performance $(\Phi)$ de $M$. stehmanni estimados pela método Bhattacharya para a amostra total. 


\section{ÍNDICE de FIGURAS}

Figura I.1. Área de prospecção (hachuriada) e sua localização na América do Sul. 5

Figura I.2. Localização das estações oceanográficas do Cruzeiro III. Nos Cruzeiros I e II as estações foram deslocadas 5 milhas para o sul. O retângulo representa a área prospectada nos Cruzeiros IV e V.

Figura II.1. Localização dos lances de pesca do material estudado para a identificação da espécie. 11

Figura II.2. Medidas utilizadas nas análises. $\mathrm{Cp}$ - comprimento padrão; $\mathrm{Cc}$ - comprimento da cabeça; Dho - diâmetro da órbita; Ac - altura do corpo. Modificada de Ribeiro (1996).

Figura II.3. Série de fotóforos caudais (AC) utilizados na identificação da espécie e série de fotóforos branquioestegais (BR) utilizados na identificação do gênero. Modificada de Ribeiro (1996).

Figura II.4. Diagramas de dispersão dos dados de comprimento da cabeça (A), altura do corpo (B) e diâmetro da órbita (Dho) x comprimento padrão de Maurolicus, entre $22^{\circ}$ e $35^{\circ} \mathrm{S}$, dos lances 259 , 340, 364 e 386. F - fêmeas e M - machos.

Figura II.5. Maurolicus: Variação, em porcentagem, da relação entre o comprimento da cabeça (A), altura do corpo (B) e diâmetro da órbita (C) e o comprimento padrão em função do tamanho do peixe.

Figura II.6. Maurolicus: Variação do número de fotóforos caudais, número de rastros branquiais e número de vértebras em função do comprimento do corpo, para machos e fêmeas separadamente. ...

Figura II.6. (cont.) Maurolicus: Variação do número de raios da nadadeira dorsal, número de raios da nadadeira ventral e número de raios da nadadeira peitoral em função do comprimento do corpo, para machos e fêmeas separadamente.

Figura II.7. Maurolicus: resultados das análises sobre características merísticas para os quatro lances de pesca. Os valores ao lado das barras horizontais representam o número de peixes analisados. A cruz preta representa o valor mais freqüente.

Figura II.8. Variação das características merísticas para as espécies do gênero Maurolicus apresentadas por Parin \& Kobyliansky (1996) e neste trabalho. A cruz preta representa o valor mais frequiente.

Figura III.1. Localização das radiais 1, 2, 3 e 4, para as quais foram traçados os perfis verticais de temperatura e salinidade.

Figura III.2. Perfil vertical da temperatura de uma estação oceanográfica. As setas indicam o início da termoclina (tc) e a isoterma de $18^{\circ} \mathrm{C}(\mathrm{t} 18)$.......

Figura III.3. Distribuição vertical de temperatura e salinidade para as radiais 1, 2, 3 e 4 no cruzeiro de inverno.

Figura III.4. Distribuição vertical de temperatura e salinidade para as radiais 1, 2, 3 e 4 no cruzeiro de outono.

Figura III.5. Distribuição vertical de temperatura e salinidade para as radiais 1, 2, 3 e 4 no cruzeiro de primavera.

Figura III.6. Distribuição dos cardumes de M. stehmanni, a partir das análises dos registros hidroacústicos durante os cruzeiros de estudo. Figura fornecida pelo Laboratório de Hidroacústica, do Departamento de Oceanografia da Fundação Universidade do Rio Grande.

Figura III.7. Distribuição dos lances de pesca com ocorrência de M. stehmanni para os três cruzeiros realizados.

Figura III.8. Profundidade e horário de operação de todos os lances de pesca, com presença $(\cdot)$ ou ausência (o) de M. stehmanni. 
Figura III.9. Profundidade de operação da rede $(\bullet)$; profundidade do início da termoclina $(+)$; isoterma de $18{ }^{\circ} \mathrm{C}(\mathbf{x})$ e o momento do dia em que foi efetuada a captura ( ) - noite; $\mathbf{D}$ - nascer do sol; $\not \mathfrak{a}$ - dia e $\mathbf{O}$ - pôr-do-sol), por lance de pesca, para os três cruzeiros (o número ao lado da profundidade de operação representa o lance de pesca)..

Figura IV.1. Distribuição de freqüência de classes de comprimento padrão (Cp) de M. stehmanni para os cruzeiros I, II e III em conjunto.

Figura IV.2. Distribuição de freqüência de classes de comprimento padrão (Cp) de M. stehmanni para as três épocas de estudo.

Figura IV.3. Distribuição de freqüência de classes de comprimento padrão (Cp) de M. stehmanni, por lance de pesca, para o inverno de 1996.

Figura IV.4. Distribuição de freqüência de classes de comprimento padrão (Cp) de M. stehmanni, por lance de pesca, para o outono de 1997.

Figura IV.5. Distribuição de freqüência de classes de comprimento padrão (Cp) de M. stehmanni, por lance de pesca, para a primavera de 1997.

Figura IV.6. Porcentagem de machos e fêmeas de M. stehmanni, por classe de comprimento padrão (Cp).

Figura IV.7. Proporção entre jovens e adultos de M. stehmanni por época de coleta. 55

Figura IV.8. Proporção de peixes adultos de M. stehmanni, por lance de pesca, para o inverno de 1996. 57

Figura IV.9. Proporção de peixes adultos de M. stehmanni, por lance de pesca, para o outono de 1997. 58

Figura IV.10. Proporção de peixes adultos de $M$. stehmanni, por lance de pesca, para a primavera de 1997.

Figura IV.11. Valores de peso total (Wt) e comprimento padrão $(\mathrm{Cp})$ de $M$. stehmanni. A equação representa a relação entre estas variáveis.

Figura IV.12. Representação gráfica das curvas das relações entre o peso total (Wt) e o comprimento padrão (Cp) de M. stehmanni, por época do ano.

Figura IV.13. Valores do fator de condição (K) em função do comprimento padrão de M. stehmanni. A reta tracejada representa o valor de "a" da relação peso/comprimento.

Figura IV.14. Valores médios do fator de condição $(\mathrm{K})$ de $M$. stehmanni por época do ano. A reta tracejada representa o valor de "a" da relação peso/comprimento.

Figura IV.15. Porcentagem de indivíduos adultos por classe de comprimento padrão (Cp) para $M$. stehmanni. $\mathrm{L}_{50}$ - Tamanho médio de início de primeira maturação gonadal; X - Valores amostrados; a curva foi traçada segundo King (1996).

Figura IV.16. Freqüência relativa (em porcentagem) dos estádios de maturidade gonadal de $M$. stehmanni, por época do ano. A - peixes imaturos (jovens); B - peixes em maturação (adultos) e C peixes maduros (adultos).

Figura IV.17. Frequiência dos estádios de maturidade gonadal M. stehmanni por local de coleta no inverno de 1996.

Figura IV.18. Freqüência dos estádios de maturidade gonadal M. stehmanni por local de coleta no outono de 1997.

Figura IV.19. Freqüência dos estádios de maturidade gonadal M. stehmanni por local de coleta na primavera de 1997.

Figura IV.20. Valores individuais de RGS1 de M. stehmanni para peixes de todos os lances de pesca. A barra horizontal representa o valor médio encontrado.

Figura IV.21. Valores de RGS1 em relação ao comprimento padrão (Cp) dos indivíduos em maturação de M. stehmanni, para os diferentes sexos e por estádios de maturidade. 
Figura IV.22. Valores médios de $\Delta$ RGS das fêmeas adultas (B e C) de M. stehmanni, por época de coleta. As barras verticais representam os intervalos de confiança $(\mathrm{p}=0,05)$.

Figura IV.23. Valores médios de $\Delta \mathrm{K}$ para fêmeas em maturação (B) e maduras (C), por época do ano. As

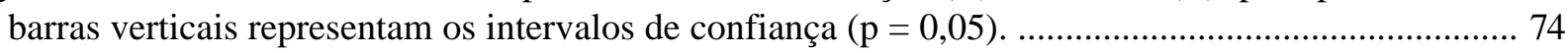

Figura IV.24. Cortes de ovários de fêmeas de M. stehmanni ................................................................... 77

Figura IV.24. (cont.): Cortes de ovários de fêmeas de M. stehmanni ....................................................... 78

Figura V.1. M. stehmanni: Esquema da face externa do otólito sagitta. ................................................ 81

Figura V.2. Otólito de M. stehmanni. A reta representa o eixo de leitura adotado. ................................. 82

Figura V.3. Otólitos de M. stehmanni mostrando diferentes grupos de anéis. A - 0 anéis, $\mathrm{Cp}=29 \mathrm{~mm}$ e B

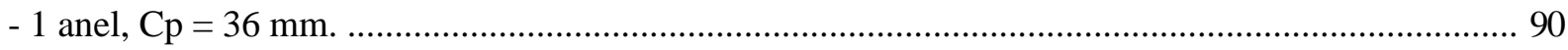

Figura V.3. (continuação) Otólitos de M. stehmanni mostrando diferentes grupos de anéis. C- 2 anéis, Cp $=41 \mathrm{~mm}$ e D -3 anéis, $\mathrm{Cp}=42 \mathrm{~mm}$. 91

Figura V.4. Raio dos anéis em função do comprimento padrão (Cp). n - tamanho da amostra para $M$. stehmanni.

Figura V.5. Valores médios do incremento marginal (IM) dos otólitos de M. stehmanni para os grupos de 1,2 e 3 anéis, considerando-se fêmeas, machos e a amostra total, por época de coleta. Os números em itálico indicam o tamanho da amostra.

Figura V.6. Valores médios do índice de incremento marginal (G) dos otólitos de M. stehmanni para os grupos de 2 e 3 anéis, considerando-se fêmeas, machos e a amostra total, por época de coleta. Os números em itálico indicam o tamanho da amostra.

Figura V.7. Comprimento padrão $(\mathrm{Cp})$ médio de M. stehmanni por época do ano para os grupos de anéis, considerando-se fêmeas, machos e a amostra total. Os números em itálico indicam o tamanho da amostra.

Figura V.8. M. stehmanni: Fator de condição (K) por época do ano. A reta tracejada representa o valor de "a " da relação peso/comprimento.

Figura V.9. M. stehmanni: Representação gráfica das relações entre o raio do otólito (Ro) e o comprimento padrão $(\mathrm{Cp})$ de machos e fêmeas.

Figura V.10. M. stehmanni: Relação entre o raio do otólito (Ro) e o comprimento padrão (Cp).

Figura V.11. M. stehmanni: Curvas de crescimento ajustadas aos dados de comprimentos padrão médios por anel. FW: método Ford-Walford; B: método de Baylay; vB: método de von Bertalanffy.

Figura V.12. Curvas de crescimento de M. stehmanni ajustadas aos dados de comprimentos padrão médios retrocalculados. FW: método Ford-Walford; B: método de Baylay; vB: método de von Bertalanffy.

Figura V.13. Histograma dos valores de freqüência de comprimento padrão, curvas de crescimento e os parâmetros de crescimento obtidos pela rotina ELEFAN I utilizando os dados de cada cruzeiro. ......102

Figura V.14. Histograma dos valores de freqüência de comprimento padrão, curvas de crescimento e os parâmetros de crescimento obtidos pela rotina ELEFAN I utilizando os dados agrupados.

Figura V.15. Grade auximétrica do índice de performance $(\Phi)$ sobre a relação entre a taxa de crescimento (k) e o Lo. - - Valores da literatura: NO1- Noruega, mar aberto (Gjøsæter, 1981); NF1 - Noruega, fiordes (Gjøsæter, 1981); NO2 - Noruega, mar aberto (Kristoffersen \& Salvanes, 1996); NF2 - Noruega, fiordes (Kristoffersen \& Salvanes, 1996); J - Japão (Yuuki, 1984); o - Este estudo, dados de comprimento médio por grupo de anel; - Este estudo, dados retrocalculados por grupo de anel (1 - FordWalford, 2 - Bayley e 3 - von Bertalanffy); $\Delta$ - Este estudo, ELEFAN I e $\quad$ - Este estudo, Bhattacharya. 


\section{AGRADECIMENTOS}

$\mathcal{A}$ Professora Carmen por todo apoio e confiança dispensados.

Ao CXNPq pe la bols a de estudos.

Ao Programa REVIZEE - SCORE/S ul, pela disponibilização dos dados.

À tripulação do $\mathcal{N} / O c$. "Atlântico Sul" cujo trabalho permitiu que es te e studo fosse realizado.

Ao Prof Lauro Madure ira e sua equipe de trabalho; Tony, Dirceu, Hugo, Charles, André e Tina

À Dra $g$ une Dias pelo auxilio prestado durante o trabalho e suges tões no trabalho final.

Ao Dr. Roberto Ávila Bernardes pelo acompanthamento do trabalho des de o seu inicio e incentivo.

À Dra Maria Cristina Cergole pelas sugestões e às "meninas da Cris": Tuca, Fabiane e, especialmente, à Cintfia pela re visão da tese.

Ao Prof. Dr. Iosé Lima Figue ire do do Muse u de Zoologia da US P pela revisão do capitulo 2 e pelas importantes sugestões.

Aos camaradas do laboratório de Ictiofauna: Alê, Andressa laliás, be líssimo desenho do otólito), Mônica, Re nata, Concha, Amanda, Marilza, D. Cida, André, Eduardo Tavares, Iô, Miguel e Gianmarco por todo auxílio prestado e amizade, sempre acompanfados de muito bom humor.

À Profa Lucy e suas "me ninas": Maria He le na, Raquel, Corrine, Dóris e Fúlvia e, particularmente, à Kỉka pelos "cafézinhos", Gate-papos, amizade e valiosas sugestões.

Ao prof. Mario $\mathcal{K}$ e suas "meninas": I une (de novo), Elô e Cacá, também pelos "cafézinhos", Gate -papos, amizade e sugestões.

Ao pessoalda biblioteca, que sem exceção, sempre foram atenciosos, profissionais e simpáticos.

Aos de mais companheiros de IO:S usuki, Masami, Toninho (manutenção), g ean, Fabiano, Walter, Rodrigo, Amaro, I orge, Márcia Cohen, Maisa, Felipe Pime nta, Be tinfo, Cris e Marcelo e muitos outros que por motivo de espaço não foram citados, pelo convívio gostoso destes últimos anos.

À Emília do ICB - USP e à bióloga Elisa da Faculdade de Odontologia - USP pelo auxilio nas pre parações fis tológic as.

Ao me u amigo Daniel Cohenca pelo ine stimável auxílio e m tudo que se refere à informática.

À tia Vera é Cia. pela amizade e "bols a alimentação".

À $\mathcal{T}$ annia por aturar as minhas manias e por todo carinfo.

À toda minha familia, desde o pequenino Caio até a D. Yolanda, passando pelo casal Gilberto e Ele nice, agradeço pela camaradagem e pelos momentos (muitos) felizes que passamos (e passaremos) juntos.

Muito obrigado. 


\section{RESUMO}

Maurolicus é um gênero representado por peixes mesopelágicos, com elevada biomassa na Zona Econômica Exclusiva sudeste sul brasileira. O material deste estudo provém de arrastos com rede de meia água efetuados com o N/Oc. Atlântico Sul, entre as isóbatas de 100 e 1500 m e entre as latitudes $22^{\circ}$ e $35^{\circ} \mathrm{S}$, realizados no inverno de 1996; outono de 1997 e primavera de 1997. A análise das características merísticas e morfológicas de 120 exemplares, coletados em 4 pontos distintos, indicou que na região ocorre M. stehmanni Parin \& Kobyliansky, 1993. Através da análise da distribuição vertical e horizontal das capturas, verificou-se que a espécie está associada à região de quebra de plataforma continental, permanecendo em profundidades maiores que 200 metros durante o dia, migrando para camadas superiores a noite, com a diminuição da intensidade luminosa. Pela distribuição de frequiência de comprimento e proporção entre jovens e adultos constatou-se que ocorreu recrutamento em todos os períodos estudados. A partir da análise da proporção entre peixes jovens e adultos por comprimento estimou-se $\mathrm{o}_{50 \text { médio }}$ em $32 \mathrm{~mm}$. As análises da relação gonadossomática, da freqüência dos estádios de maturidade gonadal e do $\Delta \mathrm{K}$ (diferença entre o fator de condição total e somático) indicaram que a espécie apresentou atividade reprodutiva em todas as áreas e épocas analisadas. A relação entre o raio do otólito e o tamanho dos indivíduos é linear, porém não foi possível identificar a periodicidade de formação dos anéis, impossibilitando estimativas adequadas dos parâmetros de crescimento. Aplicandose a rotina ELEFAN I, do pacote computacional FISAT, aos dados de freqüência de comprimento foi estimado o Lo em $53 \mathrm{~mm}$ e $\mathrm{k} \mathrm{em} 0,9$ ano $^{-1}$, indicando que a espécie atinge o tamanho médio da $1^{\mathrm{a}}$ maturação gonadal em torno do $1^{\circ}$ ano de vida. 


\begin{abstract}
Maurolicus is a genus of mesopelagic fish very abundant in the south-eastern and south Brazilian Economic Exclusive Zone. The material of this study was sampled by mid water trawl during cruises of R/V Atlântico Sul in winter of 1996, autumn of 1997 and spring of 1997, between 100 and 1500 meters depth, from latitudes of $22^{\circ}$ to $35^{\circ} \mathrm{S}$. The meristic and morphological analysis of 120 specimens collected in 4 distinctive points, has indicated the occurrence of M. stehmanni Parin \& Kobyliansky, 1993 in the area. Through the vertical and horizontal distribution of the catches it was verified that this species is associated with the shelf break, staying in depths higher than $200 \mathrm{~m}$ during the day, migrating to lower depths at night as the luminous intensity falls. The length frequency and the proportion between youngs and adults showed that the recruitment occured during the periods surveyed. By means of young-adult proportion by length a value of $\mathrm{L}_{50}$ about $32 \mathrm{~mm}$ was estimated. The study of gonadossomatic relationship, gonadal maturity frequency and $\Delta \mathrm{K}$ (difference between total and somatic condition factor) indicated that $M$. stehmanni presented reproductive activity in the area during all the sampled seasons. There is a linear relationship between the standard length and the otolith radius, however the periodicity of the zone formation was not identified, which did not permit appropriate estimates of the growth parameters. The L $\infty$ of 53 $\mathrm{mm}$ and $\mathrm{k}$ of 0,9 year $^{-1}$ were estimated using ELEFAN I routine (FISAT) based on length frequency data, indicating that $M$. stehmanni attains maturity around its first year of life.
\end{abstract}




\section{CAPÍTULO I. INTRODUÇÃO AO ESTUDO}

O Programa Nacional de Avaliação do Potencial Sustentável dos Recursos Vivos da Zona Econômica Exclusiva ("REVIZEE”) se originou a partir do compromisso assumido pelo Brasil quando da ratificação da CONVEMAR (1985), que atribuiu aos países costeiros direitos e responsabilidades em relação à exploração, conservação e gestão dos recursos vivos da Zona Econômica Exclusiva (“'ZEE').

Este estudo faz parte do subprojeto "Prospecção Pesqueira dos Recursos Pelágicos", inserido no "PROGRAMA REVIZEE" - SCORE/SUL, que engloba as regiões sudeste e sul do Brasil e visa inventariar os recursos vivos da “ZEE”, verificar as características ambientais de suas ocorrências, estimar suas biomassas e estabelecer o potencial pesqueiro dos principais recursos pesqueiros pelágicos detectados. Nos três primeiros cruzeiros efetuados por este subprojeto, entre Cabo de São Tomé e Arroio Chuí, entre as isóbatas de 100 e 1500 metros, o gênero com maior ocorrência e abundância foi Maurolicus. Neste sentido, o presente trabalho se propõe a estudar aspectos do ciclo de vida deste potencial pesqueiro.

\section{1: O GÊENERO Maurolicus}

Maurolicus (Gmelin, 1789) é um gênero representado por peixes mesopelágicos que pertencem aos Stomiiformes, ordem com alta representatividade na comunidade íctiica de meia água oceânica (Ahlstrom et al., 1984).

Em 1964, Grey transferiu o gênero Maurolicus e os demais da família Maurolicidae para a família Gonostomatidae. Weitzman (1974) recolocou o gênero em questão na família Sternoptychidae, em função de um apurado estudo sobre a osteologia e as relações evolutivas dos gêneros da ordem Stomiiformes. Esta ordem é constituída por duas infraordens: Gonostomata e Photichthya, sendo que a família Sternoptychidae está incluída na primeira, junto com a família Gonostomatidae (Ahlstrom et al., 1984).

Ahlstrom et al. (1984), revisando a ordem Stomiiformes também utilizou os estudos realizados por Bassot (1966, apud Ahlstrom et al., op.cit.) sobre anatomia dos fotóforos (órgãos bioluminescentes) e confirmou que Maurolicus pertence à família Sternoptychidae que apresenta fotóforos do tipo alfa, enquanto que a família Gonostomatidae apresenta o tipo beta.

Grey (1964), ao estudar espécimes de Gonostomatidae de várias regiões do globo, não observou diferenças regionais no número de fotóforos, mas notou uma pequena variação no número de rastros do primeiro arco branquial. Concluiu, então, que a variabilidade observada para as diferentes espécies de peixes das distintas áreas do globo era pequena e, até aquele momento, insuficiente para discriminar diferentes espécies.

Mais recentemente, Parin \& Kobyliansky (1996) apresentaram uma chave de identificação para as espécies do gênero Maurolicus, sugerindo a ocorrência de, pelo menos, 15 espécies, alopátricas e distribuídas ao redor do globo. Entre os exemplares examinados foram constatadas diferenças nos caracteres merísticos (número de vértebras e número de rastros do 
primeiro arco branquial) e morfológicos (relações diâmetro da órbita ocular/comprimento padrão, tamanho da cabeça/comprimento padrão e profundidade do corpo).

\section{1a: O papel ecológico de Maurolicus}

A importância do gênero na cadeia trófica pelágica tem sido apresentada por uma série de autores e, mais recentemente, por Kaartvedt et al. (1998), na Noruega e Ribeiro (1996), no Brasil. Segundo estes autores, Maurolicus se alimenta de zooplâncton (predominantemente eufasiáceos e copépodas) e, serve como alimento para lulas e grandes peixes pelágicos, constituindo um importante elo intermediário entre os componentes iniciais e finais da rede trófica de mar aberto. Estes animais vivem na proximidade do talude continental e apresentam migração vertical diária: permanecem em profundidades maiores que 200m (zona mesopelágica) durante o dia e sobem para áreas mais rasas (zona pelágica) durante o escurecer, para se alimentar.

Nesta migração Maurolicus pode experimentar variações de temperatura de até $10{ }^{\circ} \mathrm{C}$, sendo que Caldeira (1999) observou sua ocorrência em temperaturas que variaram entre 12,4 e $21,4{ }^{\circ} \mathrm{C}$.

Por sua vez, estudos sobre a dieta de peixes de grande porte e elevado valor comercial, realizados nesta mesma área, comprovaram a relevância desta espécie para sua alimentação (Zavalla-Camin, 1981; Ankenbrandt, 1985; Haimovici et al., 1994), ficando evidente a sua importância na trofodinâmica do ecossistema de quebra de plataforma.

Zavalla-Camin (op. cit.), ao analisar os conteúdos estomacais de atuns e afins, entre as isóbatas de $160 \mathrm{~m}$ e $600 \mathrm{~m}$, na costa Sudeste-Sul brasileira, mostrou que Maurolicus é o item alimentar mais abundante e de maior ocorrência entre os teleósteos. O autor assinalou a presença de Maurolicus na dieta dos peixes capturados em quase todos os dias de pesca.

Ankenbrandt (op. cit.), ao estudar o hábito alimentar do Scombridae Katsuwonus pelamis (bonito-listrado) no Atlântico sudoeste, verificou que Maurolicus muelleri e o crustáceo Euphausia similis eram os principais itens encontrados, sendo que o consumo de Maurolicus aumentou com o crescimento do predador.

Um estudo realizado na região sul do Brasil, na área do talude continental, para avaliar a composição faunística de peixes ósseos demersais, mostrou que Maurolicus esteve presente em cerca de $25 \%$ dos arrastos e que a espécie estava associada a águas com temperaturas baixas e a partir da isóbata de 400m (Haimovici et al., op. cit.). Os autores ainda relataram que foi frequente a ocorrência de Maurolicus no conteúdo estomacal dos peixes bentopelágicos amostrados. 


\section{1b: Potencialidade à pesca}

Quanto à potencialidade pesqueira de Maurolicus, Gjøsæter \& Kamaguchi (1980) sugerem que, devido à grande explotação dos estoques pesqueiros convencionais e mesmo à sobrepesca dos mesmos, novos recursos devem ser pesquisados, entre eles os peixes mesopelágicos. Os estoques destes peixes estão distribuídos ao redor do globo, do Ártico à Antártica, com valores de produção mais elevados nas regiões tropicais e subtropicais.

Os mesmos autores expõem que a captura de peixes mesopelágicos, para fins comerciais (produção de ração, farinha de peixe e óleo) se dá, ainda que em pequenas proporções, na África do Sul com a captura de Lampanyctodes hectoris. Na Austrália a pesca experimental de Maurolicus e L. hectoris resultou em uma captura pequena, porém estudos de prospecção a descrevem como promissora (Anon, 1977; 1977a, apud Gjøsæter \& Kamaguchi, op. cit.).

Shelton \& Davies (1979, apud Prosch, 1991) mostraram que a biomassa de Maurolicus na África do Sul é bastante alta e, embora represente um potencial pesqueiro lucrativo, existem problemas relacionados ao aparato de pesca e barcos apropriados para sua captura.

Greig (2000), após um estudo da distribuição e abundância de Maurolicus, realizado na primavera de 1997, utilizando prospecção hidroacústica e dentro do mesmo projeto deste estudo, estimou uma biomassa da ordem de 1 milhão de toneladas para a espécie.

Ribeiro (1996) apresenta a importância de Maurolicus com relação ao seu papel na transferência de energia na cadeia trófica pelágica, ao lado de vários outros pequenos peixes mesopelágicos (Myctophidae, Gonostomatidae, Sternoptychidae, Gempylidae e outros), e adverte que, a explotação pesqueira destes recursos deve ser precedida de estudos sobre distribuição e abundância e suas variabilidades sazonais e anuais, crescimento, reprodução e relações tróficas, pois não se sabe qual seria a resposta destes estoques à pressão de pesca.

Salvanes \& Stockley (1996) expõem que, devido ao ciclo de vida curto, maturação precoce e alta fecundidade, esta espécie pode reagir mais rapidamente às alterações no ecossistema (especialmente em termos de composição da comunidade) do que as espécies com um ciclo de vida longo. Assim, diferenças e similaridades nos parâmetros do ciclo de vida de Maurolicus, em diferentes áreas, podem ser respostas às variações na disponibilidade de alimentos e/ou abundância dos predadores, incluindo a pesca. 


\section{2: OBJETIVOS DO PRESENTE ESTUDO}

No Brasil estudos sobre Maurolicus são restritos, estando disponíveis apenas os trabalhos de Ribeiro (1996) sobre desenvolvimento larval e distribuição de ovos e larvas na região sudeste e Weiss et al. (1988) sobre a distribuição de ovos e larvas na região sul. Recentemente, dentro do mesmo projeto e área deste trabalho, Caldeira (1999) realizou uma análise sobre a distribuição da espécie em relação às condições ambientais e Greig (2000) estimou a biomassa e distribuição da espécie, através de dados hidroacústicos.

Estudos sobre a biologia do adulto de Maurolicus na costa brasileira eram, até a realização do presente trabalho, inexistentes.

Neste sentido, o objetivo deste estudo foi dar subsídios à avaliação do estoque deste recurso, mais especificamente:

- Verificar qual (is) espécie (s) de Maurolicus ocorre(em) na ZEE SudesteSul brasileira;

- Obter informações sobre a distribuição de Maurolicus ao longo da área, em três épocas de pesquisa;

- Estimar a composição da população em comprimento, em relação a proporção sexual e proporção entre jovens e adultos;

- Estimar o comprimento médio de primeira maturação;

- Verificar as possíveis áreas e épocas de desova da(s) espécie(s);

- Obter informações sobre o crescimento da(s) espécie(s), na área. 


\section{3: CARACTERIZAÇÃo DA ÁREA}

A região prospectada abrangeu a Zona Econômica Exclusiva (ZEE) SudesteSul brasileira situada entre Cabo de São Tomé (RJ) e Arroio Chuí (RS), entre as profundidades de 100 a 1500 m (figura I.1.), sobre a Plataforma Continental (PC), a Quebra de Plataforma (QB) e o Talude Continental (TC).
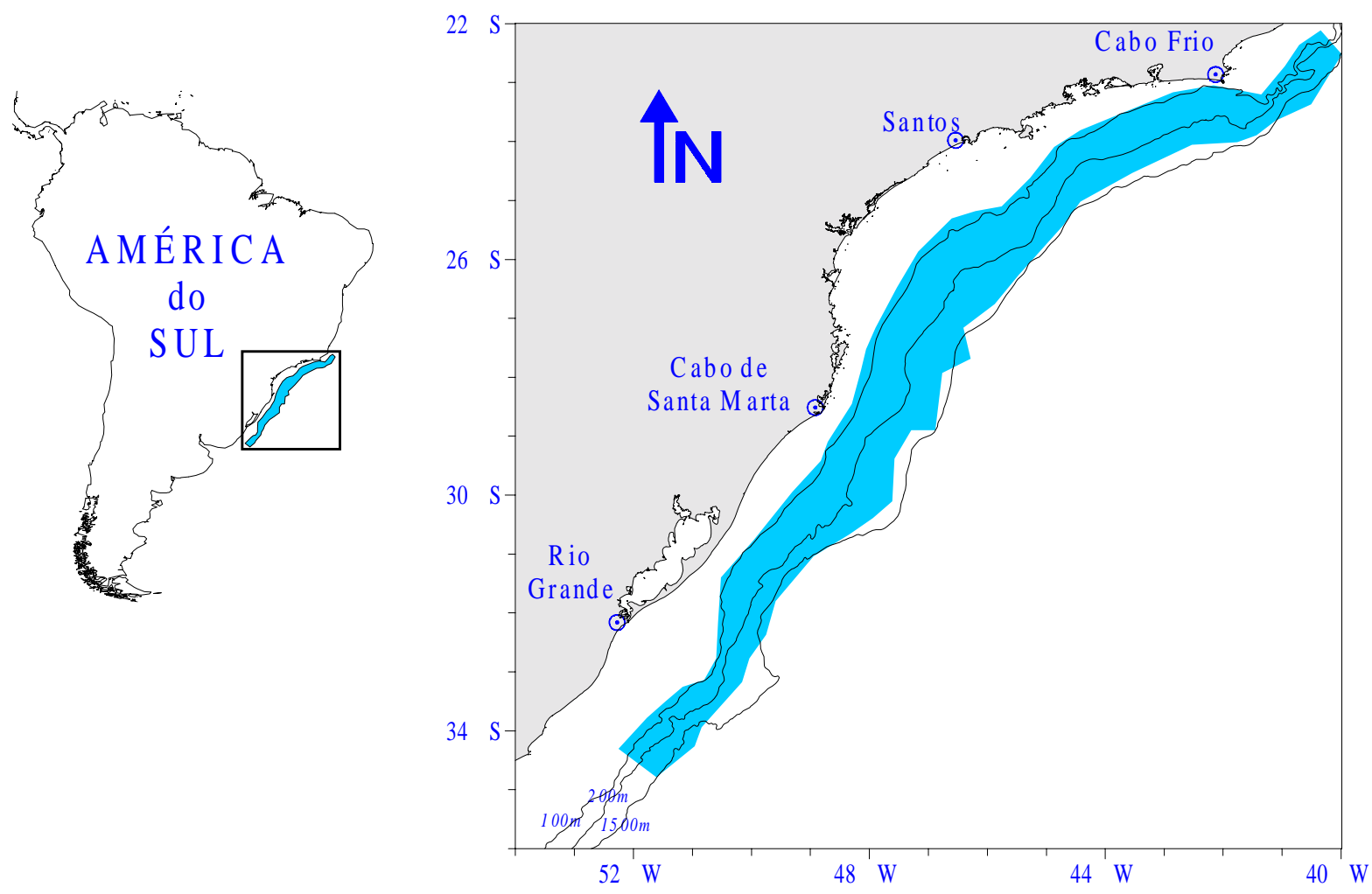

Figura I.1. Área de prospecção (hachuriada) e sua localização na América do Sul.

Toda a área sofre influência da circulação superficial oceânica de larga escala gerada pelo regime de ventos do Atlântico Sul. Ao longo do talude continental flui a Corrente do Brasil (CB), porção oeste do giro subtropical (que no hemisfério sul tem sentido anticiclônico), se originando da bifurcação da Corrente Sul Equatorial (a aproximadamente $8^{\circ} \mathrm{S}$ ) e seguindo em direção sul até a Convergência Subtropical (CS) (ao redor de $42^{\circ} \mathrm{S}$ ). Neste ponto, a CB encontra-se com a Corrente das Malvinas (CM), formando a Confluência Brasil-Malvinas, que flui para leste (Cirano, 1995).

A região sudeste, entre Cabo de São Tomé $\left(22^{\circ} \mathrm{S}\right)$ e Cabo de Santa Marta (28 $\mathrm{S})$, apresenta a forma de uma baía. Em seus extremos norte e sul a plataforma é estreita, com menos de $100 \mathrm{~km}$, enquanto que no centro, ao largo de Santos (SP), ela é extensa, com cerca de $200 \mathrm{~km}$ (Miranda \& Katsuragawa, 1991). Na altura de Cabo Frio (230 S) a direção da linha de costa sofre uma brusca mudança de direção, alterando-se de norte/sul para leste/oeste (Campos et al., 2000).

$\mathrm{Na}$ região sudeste ocorrem três massas de água com as seguintes características 
(Silva, 1995; Castro-Filho, 1996 e Campos et al., op. cit.):

- Água Tropical (AT) com maiores valores de temperatura e salinidade (T > 20 $\mathrm{C}$ e $\mathrm{S}>36,4)$ e que tem origem em baixas latitudes. Esta massa de água flui de norte para sul na camada superior da $\mathbf{C B}$ e tem alta contribuição volumétrica sobre a PC. É caracterizada pela baixa concentração de nutrientes, e alta concentração de oxigênio dissolvido.

- Água Central do Atlântico Sul (ACAS) origina-se na CS e tem valores de temperatura e salinidade inferiores a 20 e $36,4^{\circ} \mathrm{C}$, respectivamente. Flui na porção inferior da CB formando a termoclina; no verão pode penetrar na $\mathbf{P C}$ e ter uma elevada contribuição volumétrica. É rica em sais nutrientes e pobre em oxigênio dissolvido.

- Água Costeira (AC), apresenta baixa salinidade devido à influência continental; sua importância volumétrica sobre a ZEE é menor que a das demais massas de água, acima citadas.

Nos meses de primavera e verão, devido à prevalência de ventos nordeste na região, pode ocorrer ressurgência costeira, principalmente próximo a Cabo Frio. O regime de ventos NE promove o transporte de Ekman, que carrega águas superficiais costeiras para leste ("offshore"), gerando uma divergência ao longo da costa que permite a penetração da ACAS, pelo fundo, sobre a plataforma, até o seu afloramento à superfície. Este fenômeno tem uma característica sazonal e mesmo nas épocas propícias a sua ocorrência pode apresentar alta variabilidade, pois depende basicamente das condições metereológicas (Pires-Vanin \& Matsuura, 1993; Matsuura \& Kitahara, 1995; Matsuura, 1996).

Assim, quando há a penetração da ACAS sobre a plataforma forma-se uma termoclina sazonal devido à baixa temperatura desta massa de água. Analogamente, se o fenômeno não ocorrer, a temperatura da água sobre a plataforma permanece verticalmente homogênea. A ACAS apresenta uma alta concentração de sais nutrientes e o encontro desta massa de água com a zona eufótica promove um aumento na produção primária fitoplanctônica. Por sua vez, esta alta produtividade sustenta uma maior biomassa de herbívoros, acarretando condições adequadas para o desenvolvimento de larvas de peixes e da fauna bentônica (Pires-Vanin \& Matsuura, 1993).

Outra característica importante da área é a presença de vórtices frontais na quebra da plataforma. Próximo a Cabo Frio, a CB, que flui ao longo do talude de norte para o sul, sofre uma mudança de direção para sudoeste, causando meandramentos que podem provocar a formação de vórtices ciclônicos ao longo de todo o ano. O resultado destes fenômenos é a ascensão de águas mais frias e ricas em nutrientes às áreas superficiais e é denominado ressurgência de Quebra de Plataforma (Campos, 1995; Campos et. al.,1999; Matsuura, 1996;). Campos et al. (2000) consideram que a ação destes vórtices permite que a ACAS penetre e permaneça sobre a borda da plataforma continental durante o ano e que o fenômeno de ressurgência costeira ocorre devido à combinação deste fenômeno com a 
predominância de ventos NE que bombeiam esta água para a região costeira.

A região sul (entre Cabo de Santa Marta e Arroio Chuí) é caracterizada pela presença da Convergência Subtropical (CS). Na verdade, é uma interface das regiões subtropical e temperada (Haimovici et al., 1994).

A CS é um fenômeno que ocorre devido ao encontro de duas correntes: a $\mathbf{C B}$, transportando AT, flui para o sul e a Corrente das Malvinas (CM), transportando Água Subantártica (ASA, $\mathrm{T}<15^{\circ} \mathrm{C}$ e $\mathrm{S}<34$ e rica em sais nutrientes), flui em direção norte. $\mathrm{O}$ encontro destas duas correntes ocorre, aproximadamente, em $42^{\circ} \mathrm{S}$ (podendo variar entre 35 e $45^{\circ} \mathrm{S}$ ). Desse encontro forma-se a ACAS, também denominada Água Subtropical, que se dirige a camadas mais profundas e realiza um giro anti-horário, podendo alcançar a PC (Haimovici et al., 1994; Garcia, 1997 e Castello et al., 1997).

Sobre a PC, flui em direção norte um ramo costeiro da $\mathbf{C M}$, transportando a ASA, entre as isobátas de 50 e $100 \mathrm{~m}$ até aproximadamente $32^{\circ} \mathrm{S}$, mas podendo alcançar latitudes menores no inverno (Haimovici et al., 1994). Piola et al. (1999) mostram que nesta latitude há a formação de uma frente subtropical (Subtropical Shelf Front, STSF) onde a ASA se encontra com a AT, tratando-se de uma zona estreita com altas variações de temperatura e salinidade. Estes autores afirmam que esta frente seria uma extensão da $\mathbf{C S}$ sobre a PC, que impede a ASA de continuar fluindo em direção norte e a AT de prosseguir em direção sul.

Assim, a região sul sofre forte influência das duas correntes (CB e $\mathbf{C M})$, há uma tendência de variação sazonal na intensidade das mesmas, acarretando o deslocamento da CS e uma maior importância volumétrica de uma massa de água em relação a outra. Ou seja, no inverno a predominância de frentes frias e o enfraquecimento do vento sudeste promovem o deslocamento da CB para áreas mais oceânicas e sobre a $\mathbf{P C}$ há uma maior penetração da ASA, ocorrendo sobre a PC uma forte estratificação termohalina. Analogamente, no verão, devido à prevalência de ventos nordeste, que deslocam a $\mathbf{C S}$ para sul e sobre a PC, ocorre uma penetração maior da AT, causando homogeneidade termohalina sobre a PC (Garcia, 1997).

A influência da $\mathbf{A C}$ sobre a área é menor que a das demais massas de água e varia sazonal e anualmente, como uma função da descarga de água doce do Rio da Prata e da Lagoa dos Patos (Garcia, 1997). Piola et al. (1999) sugerem que as plumas do Rio da Prata e da Lagoa dos Patos podem penetrar até baixas latitudes no inverno sobre a PC interna, a qual sofre altas variações de temperatura durante o ano $\left(<13^{\circ} \mathrm{C}\right.$, no inverno e $>20^{\circ} \mathrm{C}$, no verão).

Processos de ressurgência costeira ocorrem nas épocas de primavera e verão nas proximidades do Cabo de Santa Marta. Ressurgência de Quebra de Plataforma ocorre durante o ano todo, com maior intensidade nos meses de inverno (Haimovici et al., 1994; Garcia, 1997). 


\section{4: MATERIAL E MÉTODOS}

\section{4a: Coleta de material}

O material para este trabalho foi proveniente de 5 cruzeiros oceanográficos realizados com o N/Oc. "Atlântico Sul", visando a "Prospecção Pesqueira de Recursos Pelágicos. Tais cruzeiros fizeram parte do Programa “REVIZEE" das regiões sudeste e sul, entre Cabo de São Tomé (RJ) e Arroio Chuí (RS).

Os períodos dos cruzeiros foram os seguintes:

- Cruzeiro I (inverno) - julho/agosto/setembro de 1996;

- Cruzeiro II (outono) - abril/maio de 1997;

- Cruzeiro III (primavera) - novembro/dezembro de 1997;

- Cruzeiro IV - maio de 1999 e

- Cruzeiro V - outubro de 1999.

Estes dois últimos foram realizados em uma área restrita, em frente de Itajaí (figura I.2.).

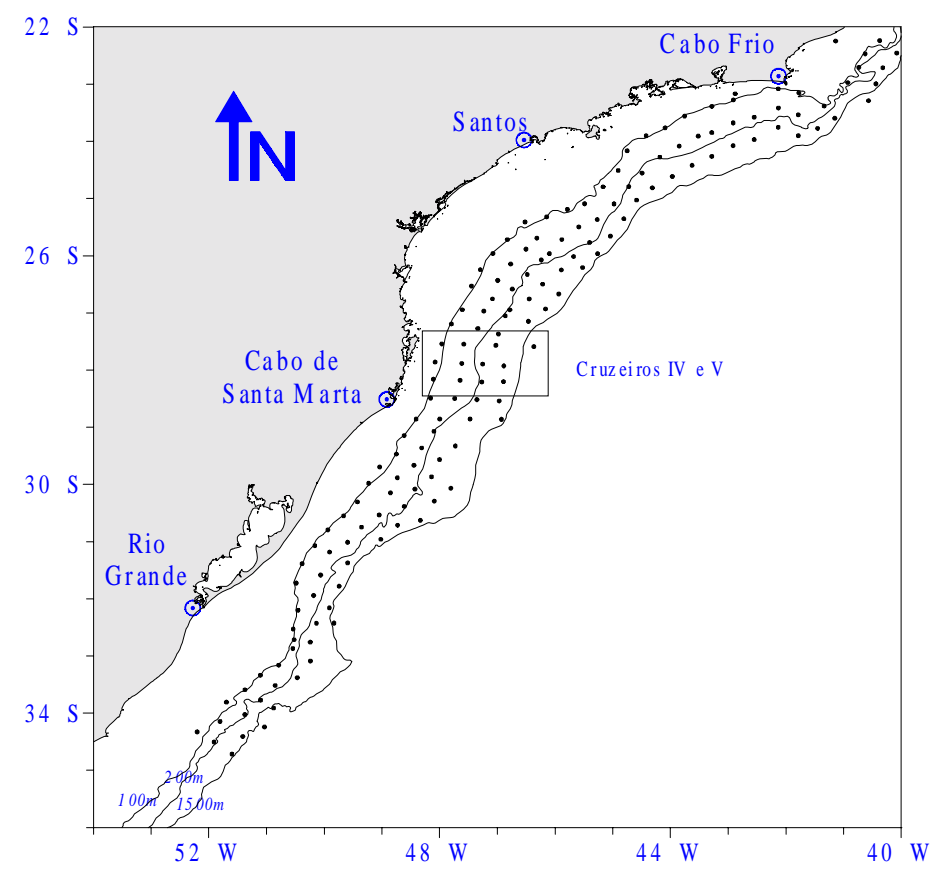

Figura I.2. Localização das estações oceanográficas do Cruzeiro III. Nos Cruzeiros I e II as estações foram deslocadas 5 milhas para o sul. $O$ retângulo representa a área prospectada nos Cruzeiros IV e V.

O maior esforço amostral foi efetuado entre as isóbatas de 100 e 1500m, em 34 radiais aproximadamente perpendiculares à costa. Ao longo do percurso foram realizadas varreduras acústicas e ecointegração, com uma Ecossonda Sinrad EK 500, devidamente calibrada.

Em paralelo à varredura acústica foram efetuados lances de pesca com rede de arrasto de meia água a fim de coletar a fauna aí presente para estudo da composição e proporção de espécies nos cardumes. Os exemplares para este estudo foram provenientes 
destes lances. A rede utilizada foi desenhada especialmente para o N/Oc. "Atlântico Sul", visando a captura de clupeídeos, engraulídeos e lulas. Apresenta 269 metros de circunferência, com malhas de $400 \mathrm{~mm}$ na boca e nas asas, diminuindo gradualmente até $50 \mathrm{~mm}$ no túnel e $20 \mathrm{~mm}$ no saco. As portas responsáveis pela abertura da rede medem $3 \mathrm{~m}$ x 1,35m e pesam $380 \mathrm{~kg}$ cada uma. Nos cruzeiros II a V foi acrescentado à rede de pesca um sobressaco.

As condições hidrográficas foram monitoradas através de lançamento de CTD em estações oceanográficas a cada 20 milhas náuticas (figura I.2.).

\section{4b: Obtenção de dados}

A bordo, sempre que possível, os peixes coletados foram identificados e separados por espécie sendo que, de cada espécie, foram obtidos o peso total e o número de indivíduos, os quais foram congelados. No caso da captura de espécies muito numerosas apenas uma subamostra foi retirada. Neste caso, o número de indivíduos capturados foi estimado a partir do peso e do número de exemplares desta subamostra e do peso total da espécie capturada.

Os espécimes de Maurolicus foram identificados a bordo através da análise de uma série de fotóforos branquioestegais (6 pares de fotóforos) (figura II.3.) como indicado por ZavallaCamin (1981) em sua dissertação. No laboratório, a identificação dos espécimes de Maurolicus foi confirmada com a utilização dos manuais de identificação de peixes da FAO (Fischer, 1978), porém, foi necessário utilizar a chave da família Gonostomatidae, pois os manuais disponíveis não estavam atualizados (Maurolicus pertence à família Sternoptychidae). Cerca de 150 exemplares de Maurolicus de cada lance de pesca, coletados aleatoriamente, foram medidos (comprimento total e comprimento padrão) e pesados. Destes, sessenta tiveram suas características biológicas anotadas, isto é: com o auxílio de um estereomicroscópio, foram retirados e devidamente acondicionados o estômago, o par de otólitos Sagitta e as gônadas; estas foram pesadas e conservadas em formalina por 24 horas sendo, posteriormente, transferidas para álcool a $70 \%$.

No Cruzeiro I não foram tomadas as medidas de comprimento padrão (Cp), estes valores foram estimados a partir da tranformação dos valores de comprimento total $(\mathrm{Ct})$ pela equação de regressão entre os valores de $\mathrm{Cp}$ e $\mathrm{Ct}$ (abaixo) obtida com os dados de peixes dos cruzeiros II e III, pelo método dos mínimos quadrados.

$$
\mathrm{Cp}=\mathrm{Ct}^{*} \mathbf{0 , 8 6 2 1}-\mathbf{1 , 5 2 7 7}
$$

O sexo foi identificado e o estádio de maturidade das gônadas foi classificado sob estereomicroscópio, adotando-se a escala proposta por Vazzoler (1996), que apresenta os estádios: A - imaturo, B - em maturação, C - maduro, D - esvaziado (em recuperação) e E - em repouso.

$\mathrm{O}(\mathrm{s})$ método(s) de análise dos dados estão detalhados nos próximos capítulos, conforme o assunto abordado. 


\section{CAPÍTULO II. A ESPÉCIE}

\section{II.1: INTRODUÇÃ̃}

Até o momento os estudos realizados no sudoeste do Atlântico referiam-se à espécie aí presente como Maurolicus muelleri, podendo-se citar Zavala-Camim (1981); Ankenbrandt (1985); Weiss et al. (1988); Bonecker \& Hubold (1990); Haimovici et al. (1994); Ribeiro (1996), Caldeira (1999) e Greig (2000).

Entretanto, Parin \& Kobyliansky (1993 e 1996) fizeram uma revisão do gênero Maurolicus, examinando material do mundo todo. Concluíram pela existência de 15 espécies alopatricamente distribuídas, sendo que para a diagnose destas espécies estes autores utilizaram o número de vértebras, o número de rastros branquiais, o número de raios da nadadeira dorsal, o diâmetro do olho, o comprimento da cabeça e a altura do corpo. Com base em material disponível para as latitudes entre $34^{\circ}$ e $40^{\circ} \mathrm{S}$ ao largo da costa sudeste da América do Sul, os autores descreveram uma espécie nova, Maurolicus stehmanni.

Como o material estudado no presente trabalho provém de área adjacente a esta $\left(22^{\circ}\right.$ a $35^{\circ} \mathrm{S}$ ), e por haver muita sobreposição de número de características merísticas entre as espécies propostas por Parin \& Kobyliansky ( $o p$. cit.), foi feito um estudo taxonômico comparativo com o objetivo de identificar a (s) espécie (s) que ocorre(m) na ZEE brasileira entre $22^{\circ} \mathrm{e}$ $35^{\circ} \mathrm{S}$. 


\section{2: MATERIAL E MÉTODOS}

Para cumprir este objetivo foram utilizados exemplares provenientes de 4 lances de pesca distintos, realizados ao longo da área e distribuídos da seguinte forma: ao norte, lance 259 $\left(24^{\circ} \mathrm{S}\right)$; na região central, lances $340\left(26^{\circ} \mathrm{S}\right)$ e $364\left(28^{\circ} \mathrm{S}\right)$ e ao sul lance $386\left(33^{\circ} \mathrm{S}\right)$ (figura II 1). No laboratório, após descongelamento, os peixes foram fixados em formalina. Deste material, cerca de 30 exemplares de cada um dos 4 lances de pesca foram separados, em função da qualidade do material, procurando-se contemplar a maior amplitude possível de comprimentos do corpo.

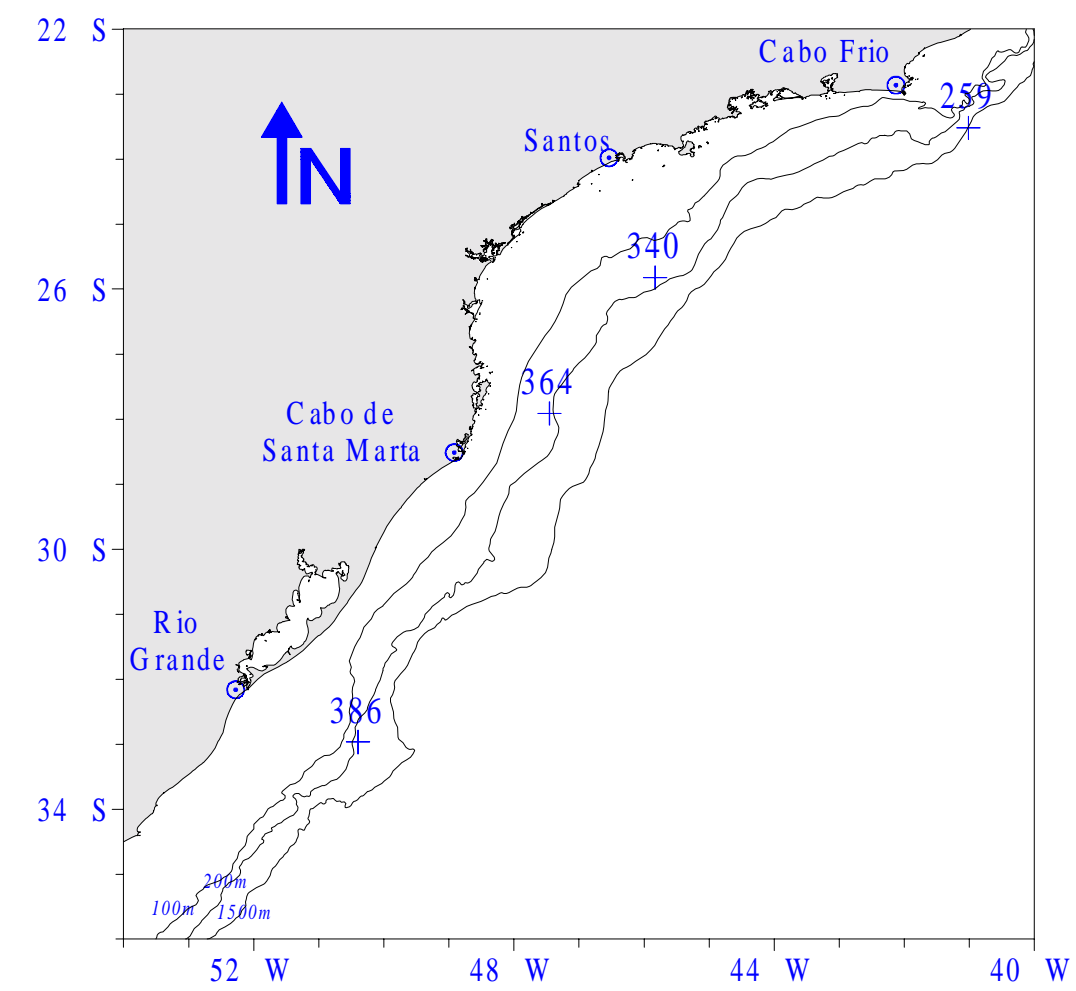

Figura II.1. Localização dos lances de pesca do material estudado para a identificação da espécie.

Para averiguar a ocorrência de dimorfismo sexual nas características analisadas o sexo de cada exemplar foi anotado, após observação das gônadas, com o auxílio de um estereomicroscópio.

\section{2a: Características morfológicas:}

Com a utilização de um paquímetro, foram tomadas, por três vezes, e obtidas as médias das medidas descritas abaixo (figura II.2.):

- Comprimento padrão $(\mathrm{Cp})$ : distância da ponta do focinho à porção distal do pedúnculo caudal (base dos raios da nadadeira caudal);

- Comprimento da cabeça $(\mathrm{Cc})$ : distância da ponta do focinho à margem posterior do opérculo; 


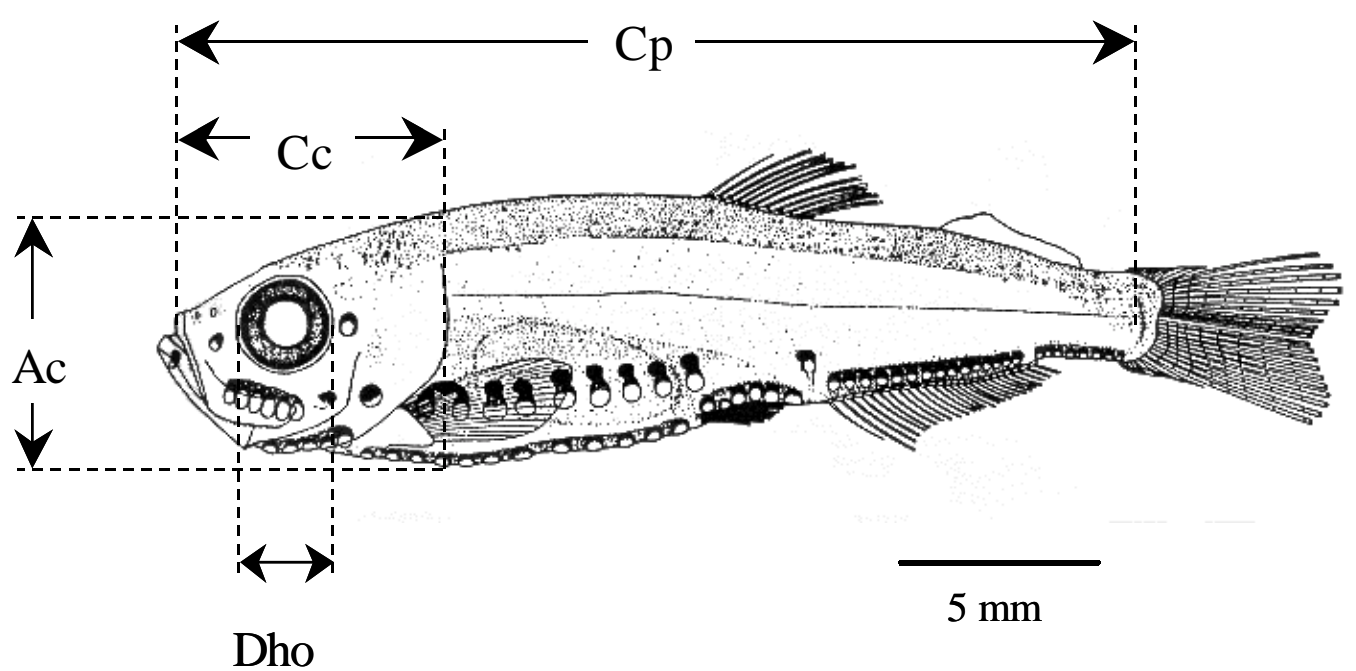

Figura II.2. Medidas utilizadas nas análises. $\mathrm{Cp}$ - comprimento padrão; Cc comprimento da cabeça; Dho - diâmetro da órbita; Ac - altura do corpo. Modificada de Ribeiro (1996).

- Altura do corpo (Ac): distância vertical, em ângulo reto com o eixo longitudinal do peixe, entre os contornos dorsal e ventral do corpo, na altura da inserção da nadadeira peitoral;

- Diâmetro da órbita (Dho): medida horizontal da cavidade ocular.

Com estas medidas foram feitas as seguintes análises:

1) Gráficos de dispersão entre a altura do corpo e o comprimento padrão (Ac x Cp), o diâmetro do olho e o comprimento padrão (Dho x $\mathrm{Cp}$ ) e o comprimento da cabeça e o comprimento padrão ( $\mathrm{Cc} \times \mathrm{Cp}$ ), levando-se em conta o valor médio individual de cada medida, o sexo e o lance de pesca.

2) Teste $F$ (nível de significância de 5\%) entre as médias das proporções das medidas $\mathrm{Ac} / \mathrm{Cp}, \mathrm{Cc} / \mathrm{Cp}$ e Dho/Cp, considerando-se os quatro lances de pesca e o sexo. Nestas análises, os machos do lance 364 foram excluídos devido ao baixo número amostral (n=3). Quando o resultado do teste mostrou que as médias eram significativamente diferentes foi aplicado o teste de Tukey (comparação múltipla).

3) Cálculo das regressões lineares entre Ac x Cp, Cc x Cp e Dho x Cp para ambos os sexos, pelo método dos mínimos quadrados, após verificação de não existência de dimorfismo sexual e tipo de relação entre as medidas.

4) Diagramas de dispersão dos valores das proporções (em porcentagem) entre Ac/ $\mathrm{Cp}, \mathrm{Cc} / \mathrm{Cp}$ e Dho/Cp, em função do comprimento padrão.

\section{2b: Características merísticas:}

Com o auxílio de um estereomicroscópio contou-se o número de raios das nadadeiras peitoral, dorsal, caudal e ventral; o número de rastros branquiais do $1^{\circ}$ arco branquial, o número 


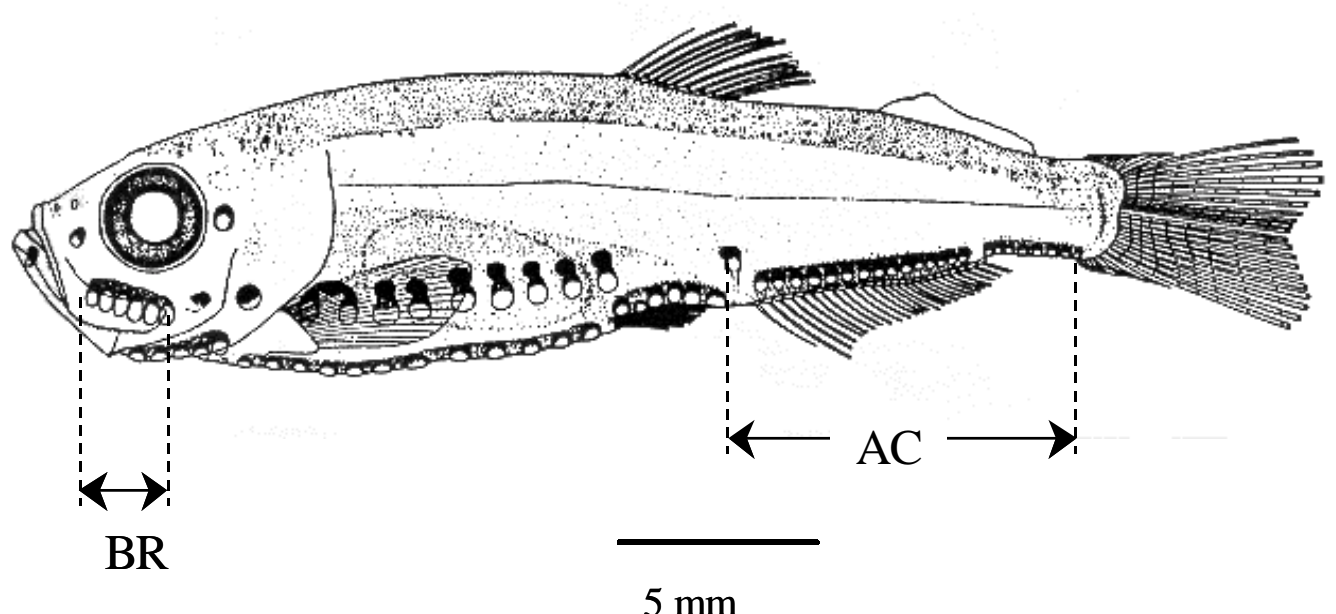

Figura II.3. Série de fotóforos caudais (AC) utilizados na identificação da espécie e série de fotóforos branquioestegais (BR) utilizados na identificação do gênero. Modificada de Ribeiro (1996).

de vértebras e o número de fotóforos da série de fotóforos caudais (ou pós-ventrais), localizados posteriormente ao ânus (figura II.3.).

Os valores de cada característica foram lançados em diagramas de dispersão, em função do comprimento padrão. Inicialmente as análises foram feitas para os sexos separadamente, com o objetivo de verificar se havia dimorfismo sexual. Constatado não haver diferença entre sexos, nestas características, os valores de machos e fêmeas foram agrupados. A amplitude de variação e o valor mais freqüente encontrado foram comparados por lance de pesca através de gráficos.

\section{2c: Identificação da espécie:}

Os dados das características merísticas (valores máximos, mínimos e mais freqüentes) e morfológicas (valores máximos, mínimos e médios) obtidos foram comparados aos de quatro espécies apresentadas nos trabalhos de Parin \& Kobyliansky (1993 e 1996) por meio de uma tabela.

Como o gênero Maurolicus é considerado pseudo-oceânico, isto é, está associado ao talude continental dos oceanos (Grey, 1964; Gjøsæter, 1981; Clarke, 1982; Rasmunssen \& Giske, 1994; Goodson et al., 1995 e Salvanes \& Stockley, 1996), os dados do material estudado foram comparados com aqueles das espécies geograficamente mais próximas M. stehmanni, M. weitzmani e M. parvipinnis (Valliant, 1889), e também com os dados de M. muelleri, que ocorre no Atlântico Norte oriental (Parin \& Kobyliansky, 1993 e 1996), uma vez que esta era a espécie relatada para a costa Sudeste-Sul do Brasil. 


\section{3: RESULTADOS E DISCUSSÃO}

\section{3a: Características morfológicas:}

As figuras II.4A, B e C apresentam os diagramas de dispersão das variações do tamanho da cabeça, altura do corpo e diâmetro da órbita em relação ao comprimento padrão, considerando-se o sexo, dos peixes dos quatro lances amostrados. Verifica-se que não há, nestes aspectos, qualquer evidência de dimorfismo sexual, existindo tendência de uma relação linear entre o comprimento do corpo e as medidas analisadas.

$\mathrm{O}$ teste $\mathrm{F}$ não rejeitou a hipótese de que as médias fossem iguais para a relação $\mathrm{Ac} / \mathrm{Cp}$ de machos e fêmeas; em contrapartida, a mesma hipótese foi rejeitada para as relações $\mathrm{Cc} / \mathrm{Cp}$ e Dho/Cp. Na tabela II.1. apresenta-se os resultados do teste de Tukey aplicado, constatandose que:

- Não houve diferença entre machos e fêmeas de uma mesma estação e, portanto, a espécie não apresentou dimorfismo sexual quanto às características morfológicas analisadas.

- Houve diferença significativa entre as médias do lance 340 com as dos lances 364 e 386 na relação $\mathrm{Cc} / \mathrm{Cp}$, entretanto, as médias entre estes dois últimos não foram diferentes.

- Nas relações Dho/Cp houve diferença significativa entre as médias do lance 386 com os demais lances, exceto entre fêmeas deste lance em relação às fêmeas do lance 340.

Na tabela II.2. são apresentados os parâmetros ( $\mathrm{a}$ e b) obtidos das regressões lineares Ac x Cp, Dho x Cp e Cc x Cp e os respectivos valores do coeficiente de determinação $\left(\mathrm{r}^{2}\right)$; estes valores foram elevados (maiores que 0,8 ) com exceção do lance 386, representado pelos maiores indivíduos amostrados e com maior dispersão de valores. A comparação das regressões entre as amostras não foi possível, devido à não sobreposição das amplitudes de tamanho dos peixes constituintes das mesmas.

As porcentagens de $\mathrm{Ac} / \mathrm{Cp}$, Dho/Cp e Cc/Cp, em relação ao comprimento padrão, não variaram com o crescimento do peixe a partir dos $25 \mathrm{~mm}$ de comprimento padrão, tamanho do menor peixe analisado (figuras II.5A, B, e C).

Os valores médios destas relações (em porcentagem), por lance de pesca, e para o total constam da tabela II.3. Apesar destes valores serem significativamente diferentes entre alguns lances de pesca (como visto acima), considerou-se toda a amostra para calcular o valor médio para a espécie, na área, pois as diferenças existentes entre os lances foram menores que as descritas por Parin e Kobyliansky ( op. cit.) entre diferentes espécies, como pode ser verificado, em parte, na tabela II.4. Desta forma considerou-se que na área foi coletada uma única espécie, para a qual as médias das relações foram: $\mathrm{Cc} / \mathrm{Cp} 30,8 \%$; Dho/Cp 9,4 \% e Ac/Cp 22,4\%. 
A

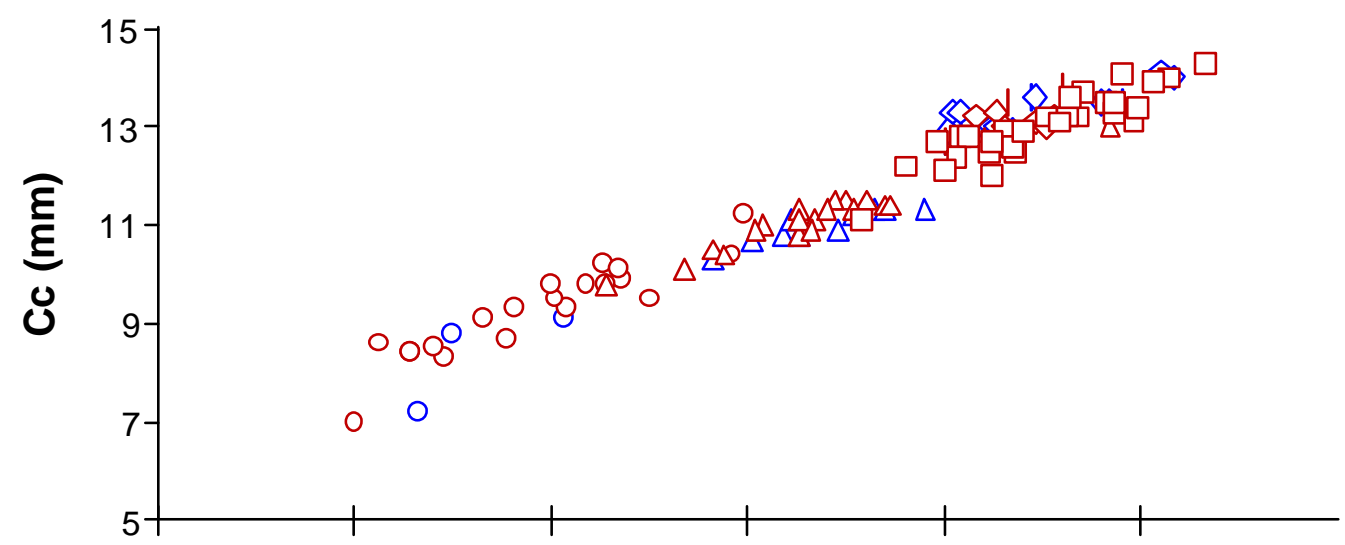

B

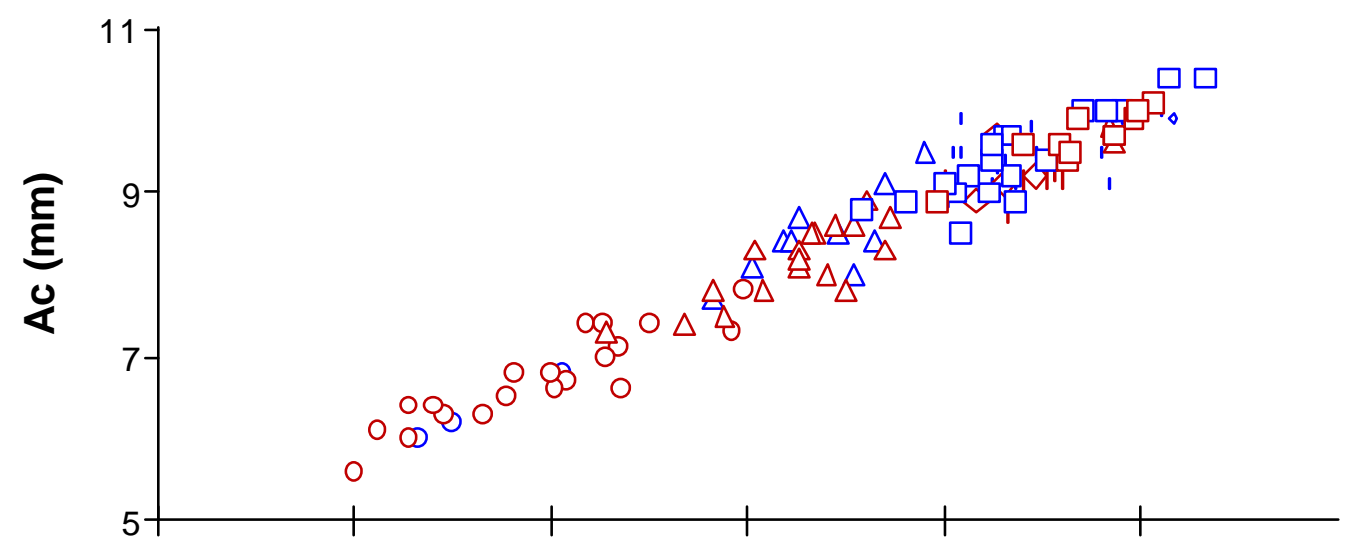

C

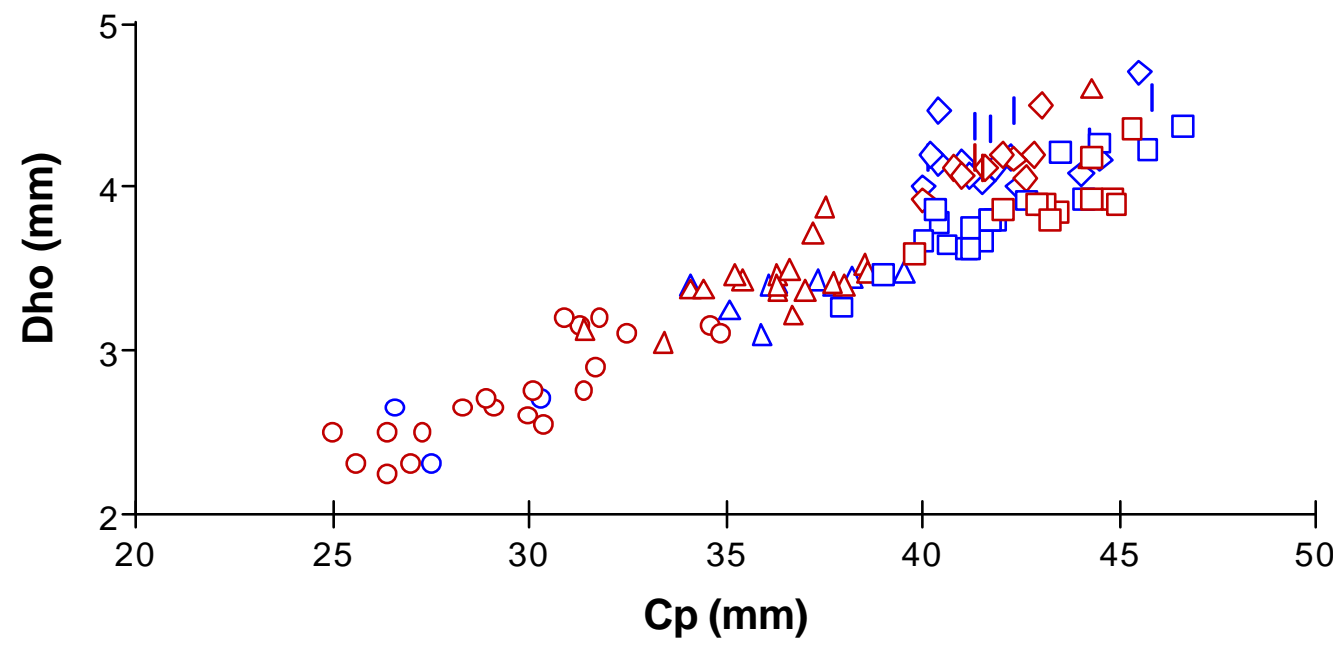
$259 \mathrm{~F}$
$\triangle 340 \mathrm{~F}$
O $364 \mathrm{~F}$
$>386 \mathrm{~F}$
$259 \mathrm{M}$
$\triangle 340 \mathrm{M}$
○ $364 \mathrm{M}$
$386 \mathrm{M}$

Figura II.4. Diagramas de dispersão dos dados de comprimento da cabeça (A), altura do corpo (B) e diâmetro da órbita (Dho) x comprimento padrão de Maurolicus, entre $22^{\circ}$ e $35^{\circ} \mathrm{S}$, dos lances 259, 340, 364 e 386. F fêmeas e M - machos. 
Tabela II.1. Resultado do teste de comparação múltipla de médias (Tukey) das proporções entre o comprimento da cabeça e o comprimento padrão (Cc/Cp) e entre o diâmetro da órbita e o comprimento padrão (Dho/ Cp), considerando-se cada lance de pesca, machos e fêmeas separadamente. As células em cinza representam as estações nas quais a diferença entre as médias foi significativamente diferente (5\%). $\mathrm{O}$ número de exemplares na amostra está indicado entre parênteses.

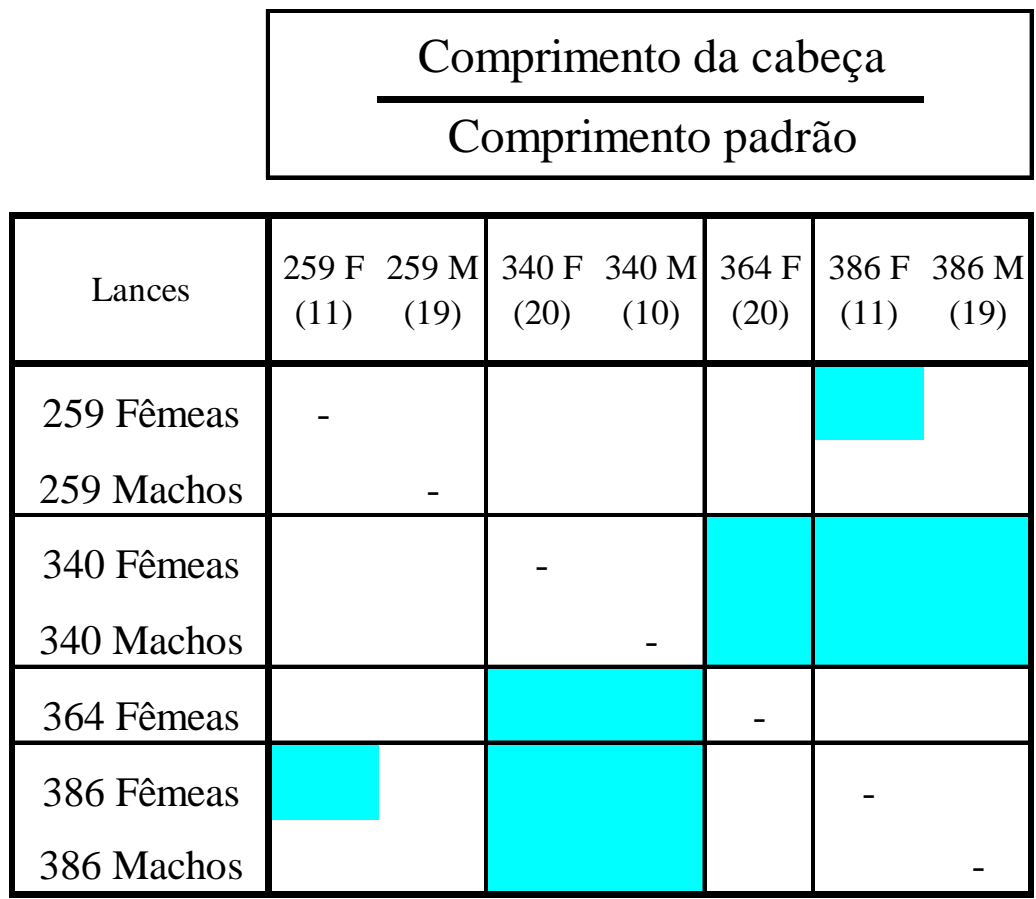

\begin{tabular}{|c|c|c|c|c|}
\hline & \multicolumn{4}{|c|}{$\frac{\text { Comprimento da órbita ocular }}{\text { Comprimento padrão }}$} \\
\hline Lances & $\begin{array}{cc}259 \mathrm{~F} & 259 \mathrm{M} \\
(11) & (19)\end{array}$ & $\begin{array}{cc}340 \mathrm{~F} & 340 \mathrm{M} \\
(20) & (10)\end{array}$ & $\begin{array}{l}364 \mathrm{~F} \\
(20)\end{array}$ & $\begin{array}{cc}386 \mathrm{~F} & 386 \mathrm{M} \\
(11) & (19)\end{array}$ \\
\hline $\begin{array}{l}259 \text { Fêmeas } \\
259 \text { Machos }\end{array}$ & - & & & \\
\hline $\begin{array}{l}340 \text { Fêmeas } \\
340 \text { Machos }\end{array}$ & & - & & \\
\hline 364 Fêmeas & & & - & \\
\hline $\begin{array}{l}386 \text { Fêmeas } \\
386 \text { Machos }\end{array}$ & & & & - \\
\hline
\end{tabular}


Tabela II.2. Maurolicus: Valores dos parâmetros das regressões lineares entre o comprimento da cabeça e o comprimento padrão $(\mathrm{Cc} / \mathrm{Cp})$, entre a altura do corpo e o comprimento padrão $(\mathrm{Ac/Cp})$ e entre o diâmetro da órbita e o comprimento padrão (Dho/Cp).

\begin{tabular}{|c|c|c|c|c|}
\cline { 2 - 5 } \multicolumn{1}{c|}{} & Lances & $\mathrm{a}$ & $\mathrm{b}$ & $\mathrm{r}^{2}$ \\
\hline & 259 & 0,560 & 0,293 & 0,814 \\
Cc x Cp & 340 & 1,706 & 0,255 & 0,924 \\
& 364 & $-0,557$ & 0,330 & 0,838 \\
& 386 & 5,090 & 0,193 & 0,582 \\
\hline \multirow{4}{*}{ Ac x Cp } & 259 & 0,890 & 0,203 & 0,778 \\
& 340 & 1,009 & 0,199 & 0,750 \\
& 364 & 1,303 & 0,181 & 0,816 \\
& 386 & 5,496 & 0,092 & 0,180 \\
\hline & 259 & $-0,660$ & 0,107 & 0,779 \\
Cc x Dho & 340 & 0,048 & 0,093 & 0,670 \\
& 364 & $-0,427$ & 0,107 & 0,721 \\
& 386 & 1,661 & 0,061 & 0,267 \\
\hline
\end{tabular}

Tabela II.3. Maurolicus: valores médios e intervalos de confiança $(\alpha=0,05)$ do comprimento da cabeça $(\mathrm{Cc})$, altura do corpo (Ac) e diâmetro da órbita (Dho) em relação ao comprimento padrão, por lance de pesca.

\begin{tabular}{|c|cc|cc|cc|}
\cline { 2 - 7 } \multicolumn{1}{c|}{} & \multicolumn{2}{c|}{ Cc x Cp } & \multicolumn{2}{c|}{ Ac x Cp } & \multicolumn{2}{c|}{ Dho x Cp } \\
\hline Lances & Média & I.C. & Média & I.C. & Média & I.C. \\
\hline 259 & 30,62 & 0,25 & 22,42 & 0,20 & 9,10 & 0,10 \\
340 & 30,18 & 0,22 & 22,67 & 0,30 & 9,41 & 0,16 \\
364 & 31,09 & 0,55 & 22,63 & 0,33 & 9,24 & 0,24 \\
386 & 31,46 & 0,27 & 22,26 & 0,31 & 10,02 & 0,14 \\
\hline Total & 30,84 & 0,19 & 22,49 & 0,15 & 9,44 & 0,10 \\
\hline
\end{tabular}


A

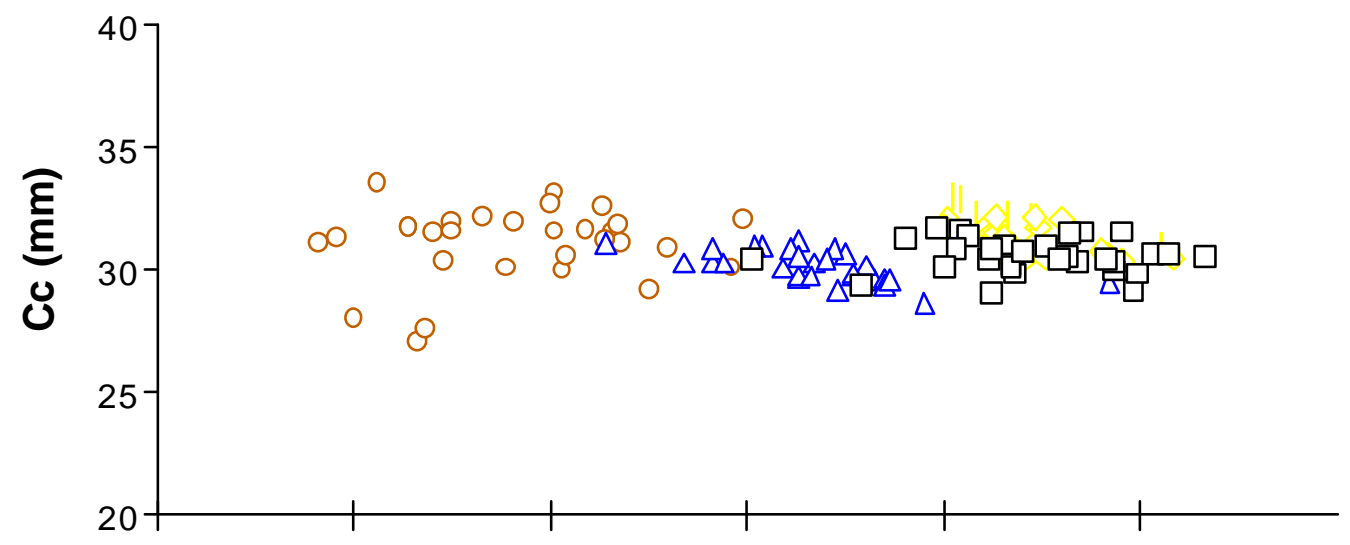

B

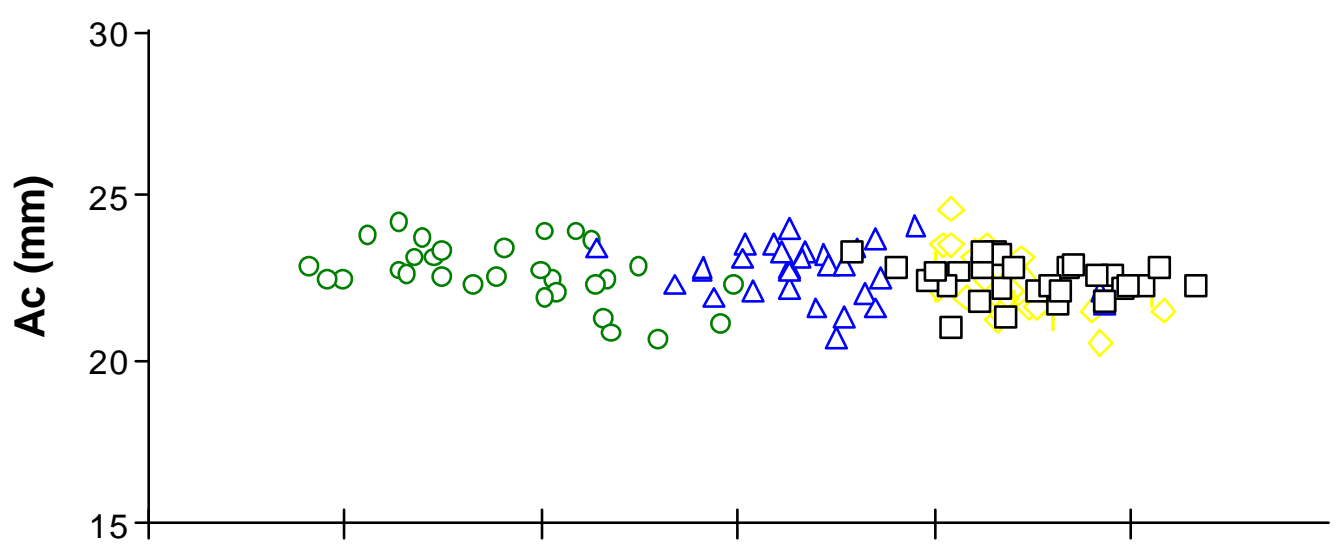

C

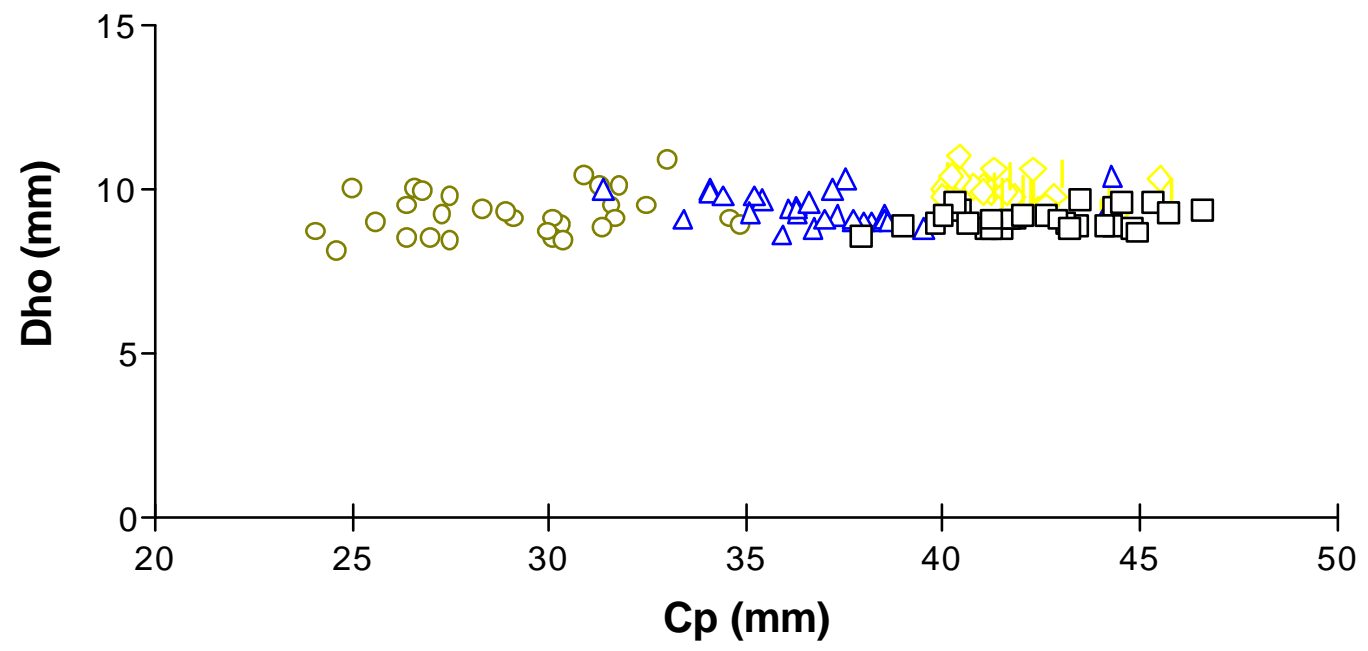

\section{$259 \triangle 340 \quad \circ 364 \quad 386$}

Figura II.5. Maurolicus: Variação, em porcentagem, da relação entre o comprimento da cabeça (A), altura do corpo (B) e diâmetro da órbita (C) e o comprimento padrão em função do tamanho do peixe. 


\section{3b: Características merísticas}

O número de vértebras, de rastros branquiais, de fotóforos $\mathrm{AC}$, e dos raios das nadadeiras dorsal, peitoral e ventral não variaram em função do tamanho do peixe ou do sexo (figuras II.6 A, B, C, D, E e F).

$\mathrm{Na}$ figura II.7. apresentam-se os valores destas características, para os quatro lances de pesca, com dados de machos e fêmeas agrupados. Verificou-se que os valores mais freqüentes foram os mesmos para os diferentes lances, exceto para o lance 340, cujos indivíduos analisados apresentaram maior número de raios da nadadeira peitoral.

Certas características apresentaram maior variabilidade em alguns lances. Assim, no lance 386, encontraram-se até 13 raios da nadadeira dorsal, ao passo que nas demais estações de pesca o número máximo de raios foi 12. Porém, exceto no número de raios da nadadeira peitoral do lance 340 , em todos os lances as amplitudes destas características se sobrepõem e os valores mais freqüentes são iguais. Portanto, ao se considerar estas características merísticas não foram encontradas evidências de que ocorra, na área, mais do que uma espécie. 
Número de fotóforos caudais
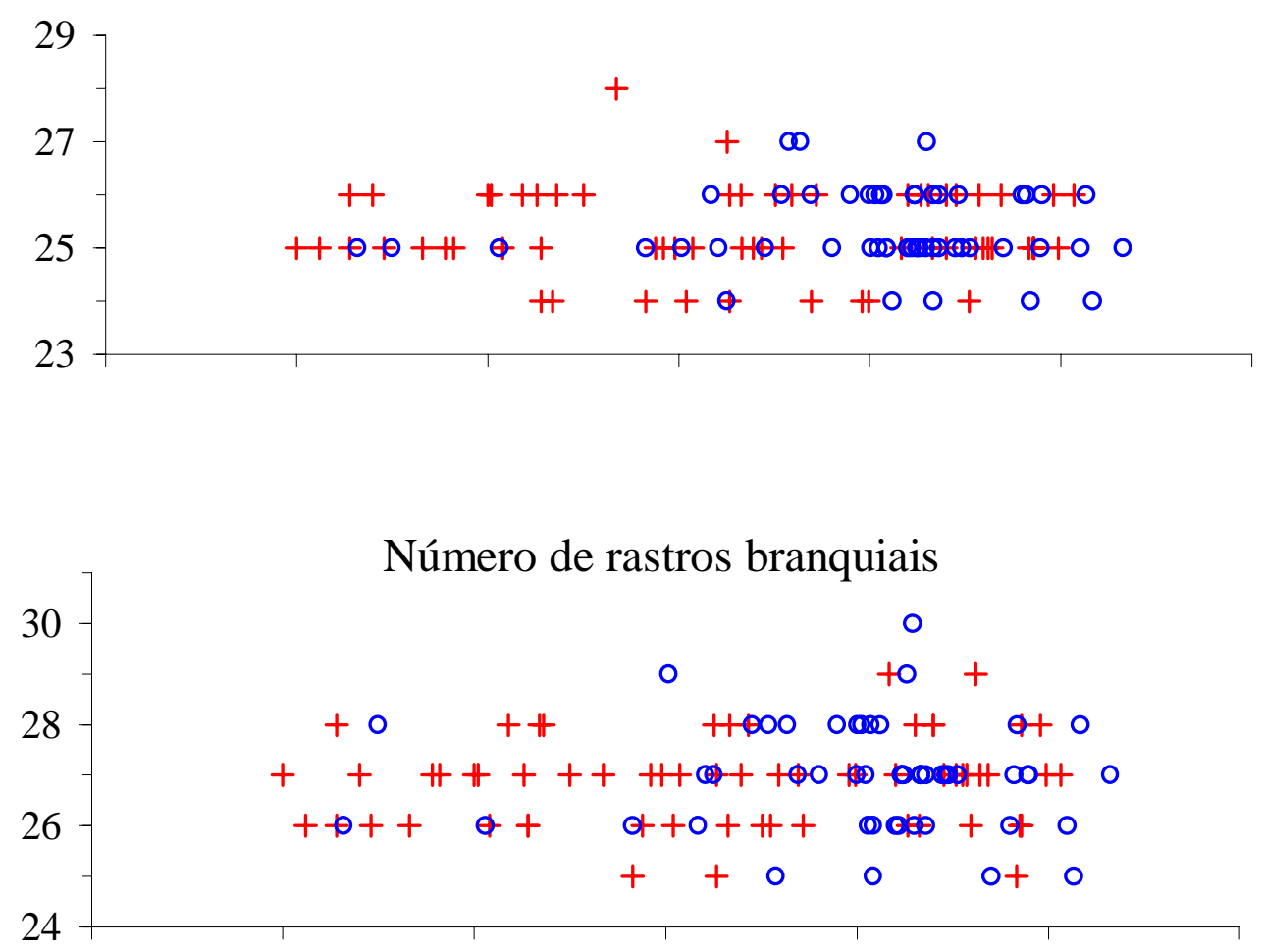

Número de vértebras

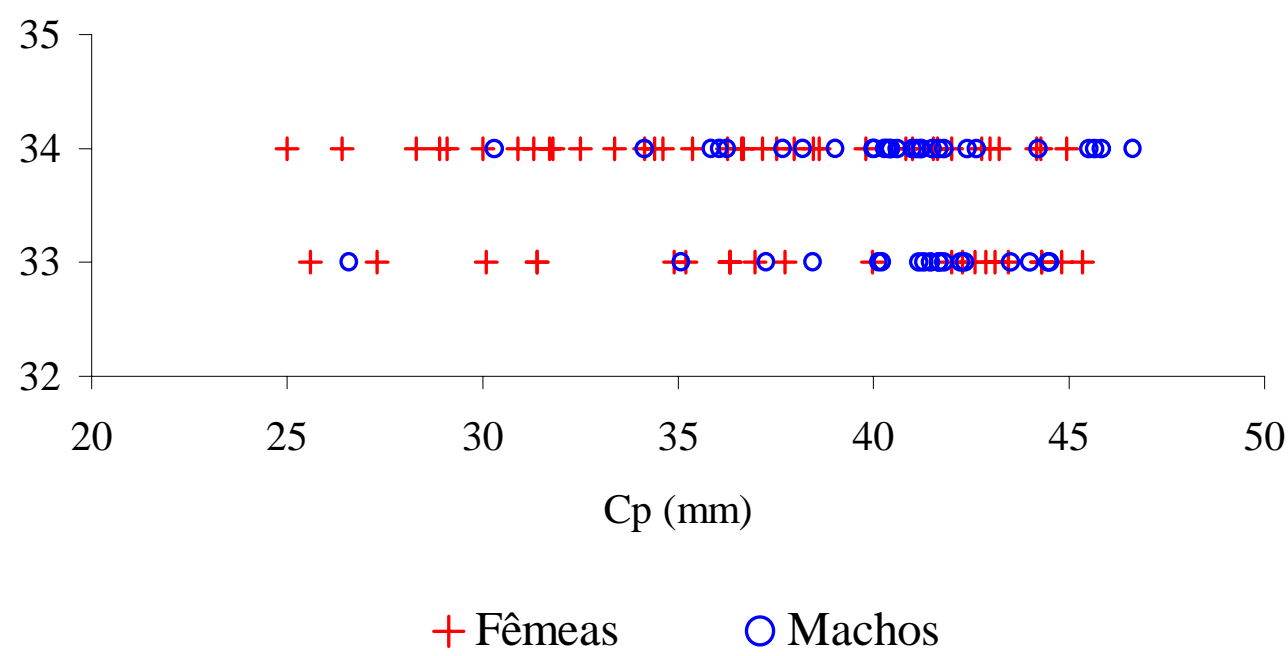

Figura II.6. Maurolicus: Variação do número de fotóforos caudais, número de rastros branquiais e número de vértebras em função do comprimento do corpo, para machos e fêmeas separadamente. 
Número de raios da nadadeira dorsal

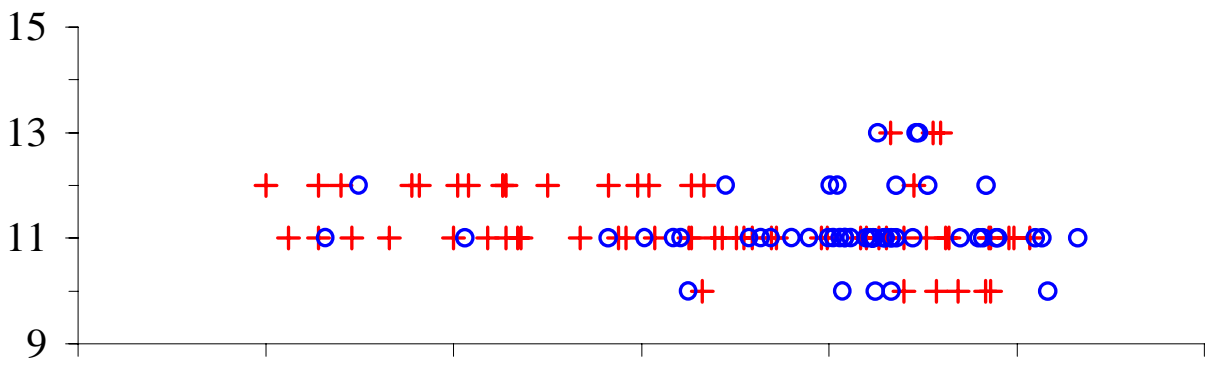

Número de raios da nadadeira ventral

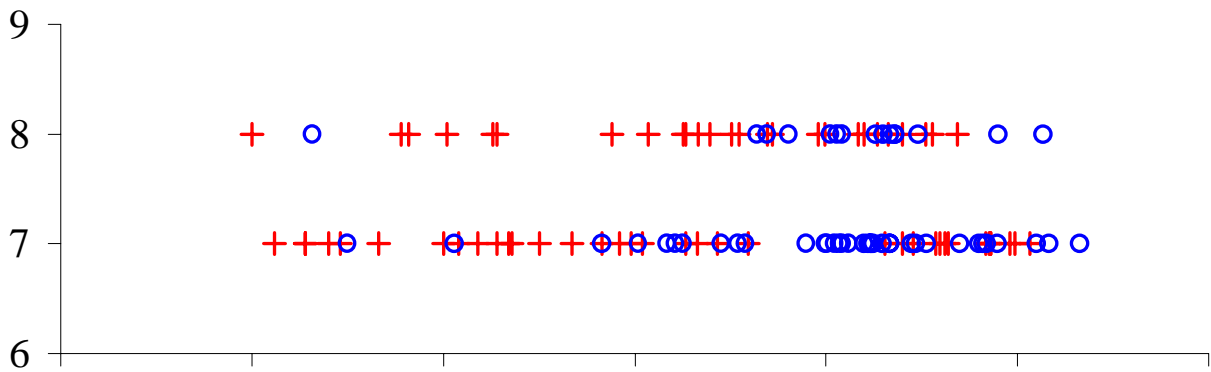

Número de raios da nadadeira peitoral

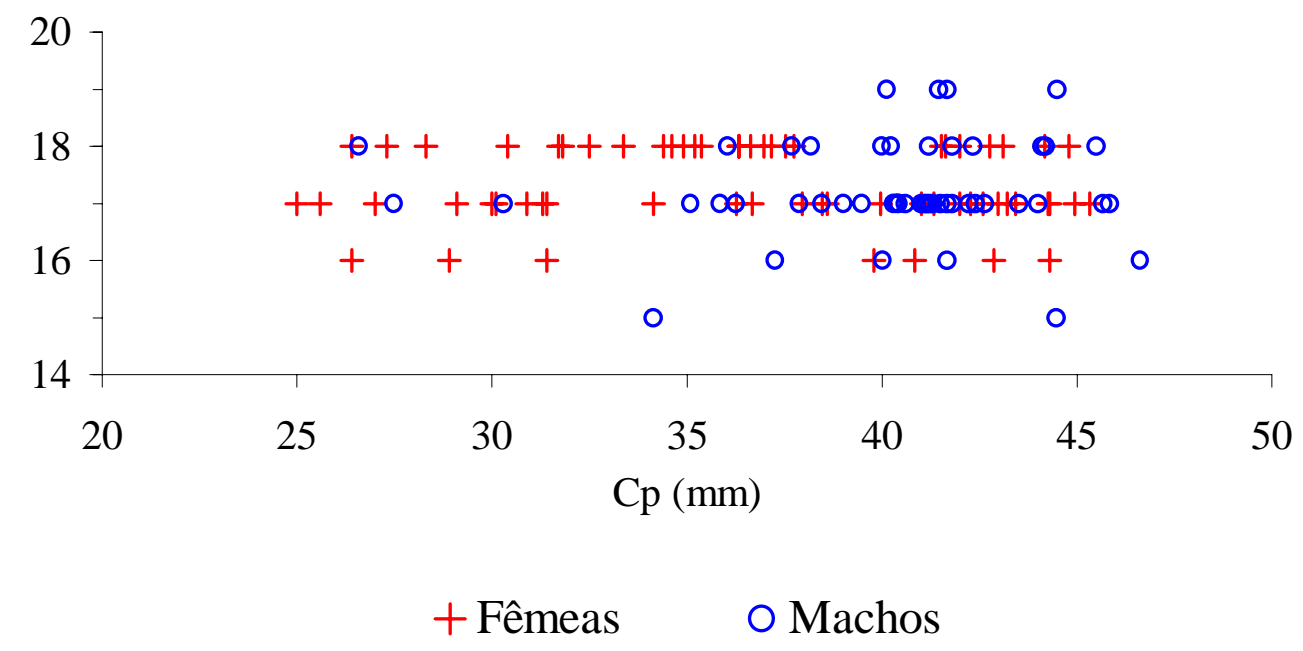

Figura II.6. (cont.) Maurolicus: Variação do número de raios da nadadeira dorsal, número de raios da nadadeira ventral e número de raios da nadadeira peitoral em função do comprimento do corpo, para machos e fêmeas separadamente. 
Fotóforos AC

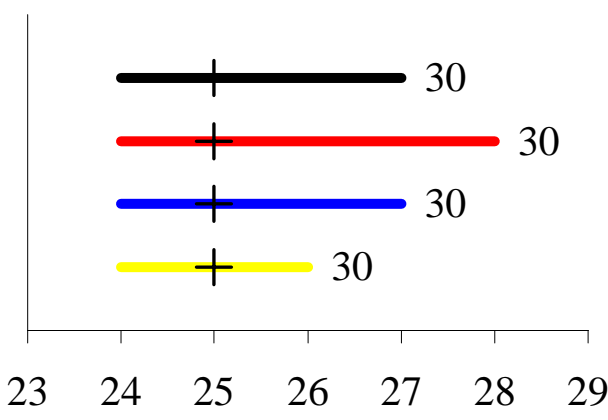

Número
Raios de nadadeira dorsal

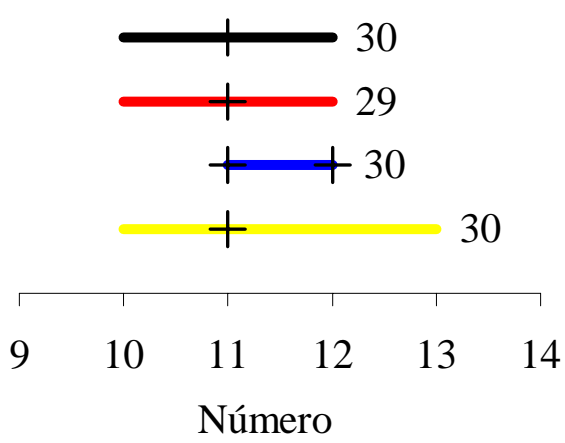

Raios de nadadeira peitoral
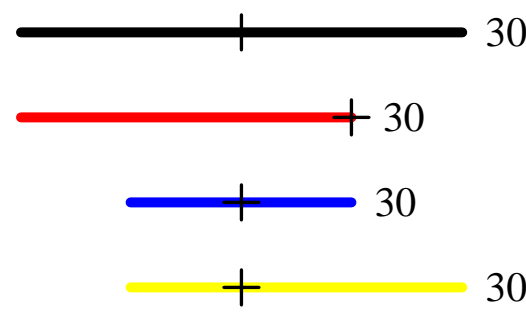

Vértebras
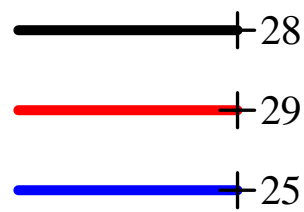

$+29$

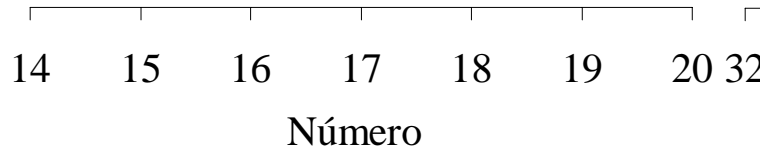

Rastros branquiais
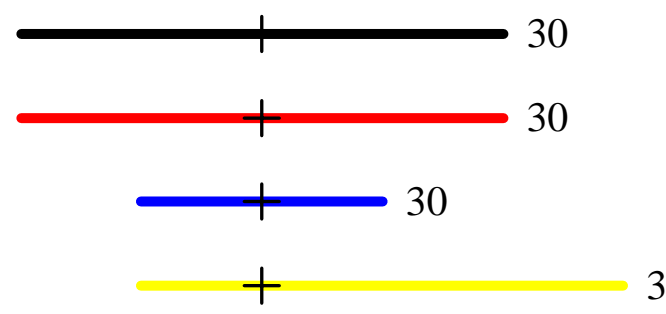

$\begin{array}{lllll}24 & 25 & 26 & 27 & 28\end{array}$

$29 \quad 30$

Número

Número

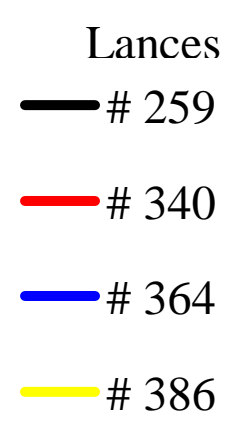

Figura II.7. Maurolicus: resultados das análises sobre características merísticas para os quatro lances de pesca. Os valores ao lado das barras horizontais representam o número de peixes analisados. A cruz preta representa o valor mais freqüente. 


\section{3c: Identificação da espécie:}

As características utilizadas neste estudo, para a espécie de Maurolicus que ocorre na ZEE brasileira entre Cabo Frio e Arroio Chuí, constam da tabela II.4., na qual também foram incluídas as características para mais quatro espécies do gênero Maurolicus apresentadas por Parin \& Kobyliansky (1996).

Verificou-se que a espécie deste estudo é diferente de $M$. muelleri no que tange às relações $\mathrm{Ac} / \mathrm{Cp}$ e $\mathrm{Cc} / \mathrm{Cp}$, ao número de rastros do $1^{\circ}$ arco branquial e ao tamanho máximo. Quando comparada com $M$. weitzmanni apresentou diferenças no número de vértebras, de rastros do $1^{\circ}$ arco branquial e de fotóforos AC. A figura II.8. ilustra as diferenças merísticas citadas. As espécies que mais se assemelharam à deste estudo foram M. stehmanni e M. parvipinnis.

Levando em conta a afirmação de Parin \& Kobyliansky (op. cit.) de que M parvipinnis ocorre no Pacífico sudeste enquanto M. stehmanni se encontra no sudoeste do Atlântico e o conceito de alopatria, é possível afirmar que a espécie de Maurolicus presente entre as latitudes de $22^{\circ}$ e $35^{\circ} \mathrm{S}$ é $M$. stehmanni.

Recentemente, prospecções hidroacústicas realizadas na ZEE, acima de Cabo de São Tomé (Madureira, com. pessoal ${ }^{1}$ ) mostraram a substituição, na comunidade mesopelágica, desta espécie por outras.

Bonecker \& Hubold (1990) verificaram diminuição no número de larvas abaixo de $35^{\circ}$ $\mathrm{S}$ da área do presente estudo, sugerindo que os processos hidrográficos de convergência e alta descarga pluvial do Rio da Prata promovem uma descontinuidade na distribuição de Maurolicus. Dados de hidroacústica obtidos na mesma área do presente trabalho apresentaram menores densidades de Maurolicus na porção sul (Greig, 2000). Por outro lado Figueroa et al. (1998) não constataram a ocorrência de Maurolicus em uma série de arrastos de meia água realizados entre 1988 e 1995, próximos à quebra de plataforma, entre $36^{\circ}$ e $45^{\circ} \mathrm{S}$ no Atlântico sudoeste (área adjacente à do presente estudo), sendo que as espécies de peixes mesopelágicos que predominaram naquelas amostras pertenciam, principalmente, à família Mycthophidae.

Estes fatos sugerem que os limites norte e sul de distribuição da espécie, ora identificada como M. stehmanni, no Atlântico Sudoeste estejam, portanto, entre as latitudes de $22^{\circ} \mathrm{e} 35^{\circ} \mathrm{S}$. 
Tabela II.4. Valores das características merísticas e morfométricas obtidos neste trabalho e aqueles apresentados na revisão de Parin \& Kobyliansky (1996). Os números representam as médias e os valores entre parênteses os valores máximos e mínimos. V - vértebras; RB - rastros do $1^{\circ}$ arco brânquial; FAC - fotóforos caudais; RNP - raios da nadadeira peitoral; $\mathrm{Cc} / \mathrm{Cp}$ - relação $(\%)$ entre comprimento da cabeça e o comprimento padrão; Dho/Cp - relação (\%) entre o diâmetro da órbita e o comprimento padrão; $A \mathrm{c} / \mathrm{Cp}$ - relação (\%) entre altura do corpo e o comprimento padrão; $T_{\text {max. }}$ tamanho máximo e $L$ - localidade pesquisada.

\begin{tabular}{|c|c|c|c|c|c|}
\hline & $\begin{array}{l}\text { Presente } \\
\text { estudo }\end{array}$ & $\begin{array}{c}\text { M. stehmanni } \\
\text { (Parin \& } \\
\text { Kobyliansky, } \\
\text { 1993) }\end{array}$ & $\begin{array}{c}\text { M. muelleri } \\
\text { (Gmelin ,1789) }\end{array}$ & $\begin{array}{l}\text { M. parvipinnis } \\
\text { (Valliant, 1888) }\end{array}$ & $\begin{array}{l}\text { M. weitzmani (Parin } \\
\text { \& Kobyliansky. } \\
\text { 1993) }\end{array}$ \\
\hline $\mathrm{V}$ & $34(33)$ & $33(34)$ & $34(33-35)$ & $34(33-35)$ & $33(32-33)$ \\
\hline $\mathrm{RB}$ & $27(25-30)$ & $28-29(27-29)$ & $29-31(28-32)$ & $27-28(26-29)$ & $22-24(21-26)$ \\
\hline FAC & $26(25-28)$ & $25-26(24-26)$ & $25-26(23-27)$ & $24-25(23-27)$ & $23-24(22-26)$ \\
\hline NP & $17(15-19)$ & $17-19$ & $17-19$ & $16-18$ & $17-19$ \\
\hline $\mathrm{Cc} / \mathrm{Cp}$ & $27-33 \%$ & $27-29 \%$ & $26-29 \%$ & $28,5-32 \%$ & $29,5-33 \%$ \\
\hline Dho/Cp & $8-11 \%$ & $8,5-10 \%$ & $8-10 \%$ & $9,5-12,5 \%$ & $9,5-11,5 \%$ \\
\hline $\mathrm{Ac} / \mathrm{Cp}$ & $20,5-24,5 \%$ & $23-25 \%$ & $19-22 \%$ & $22-25 \%$ & $22,5-25,5 \%$ \\
\hline $\mathrm{T}_{\max }$ & 52 & 46 & 65 & 54 & 52 \\
\hline $\mathrm{L}$ & $\begin{array}{l}\text { Oeste do } \\
\text { Atlântico Sul } \\
\left(22 \text { a } 35^{\circ} \mathrm{S}\right)\end{array}$ & $\begin{array}{c}\text { Oeste do } \\
\text { Atlântico Sul }(34 \\
\left.\text { a } 40^{\circ} \mathrm{S}\right)\end{array}$ & $\begin{array}{l}\text { Leste do Atlântico } \\
\text { Norte }\left(40-45^{\circ} \mathrm{N}\right)\end{array}$ & $\begin{array}{l}\text { Leste do Pacífico } \\
\text { Sul (Chile) }\end{array}$ & $\begin{array}{l}\text { Oeste do Atlântico } \\
\text { Norte até Golfo do } \\
\text { México e leste do } \\
\text { Atântico tropical ao } \\
\text { longo do talude } \\
\text { africano. }\end{array}$ \\
\hline
\end{tabular}


Números de rastros do $1^{\circ}$ arco branquial

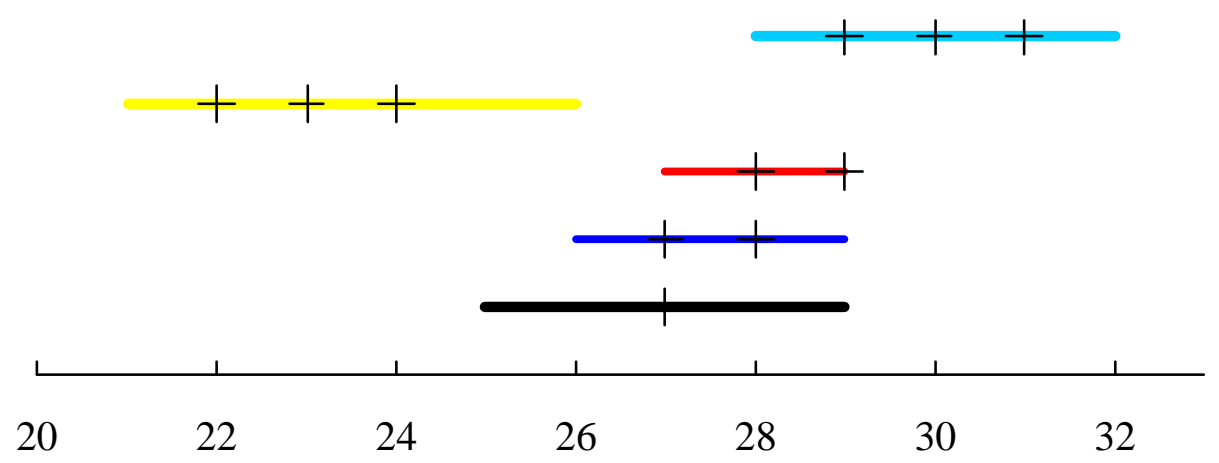

Números de Fotóforos AC
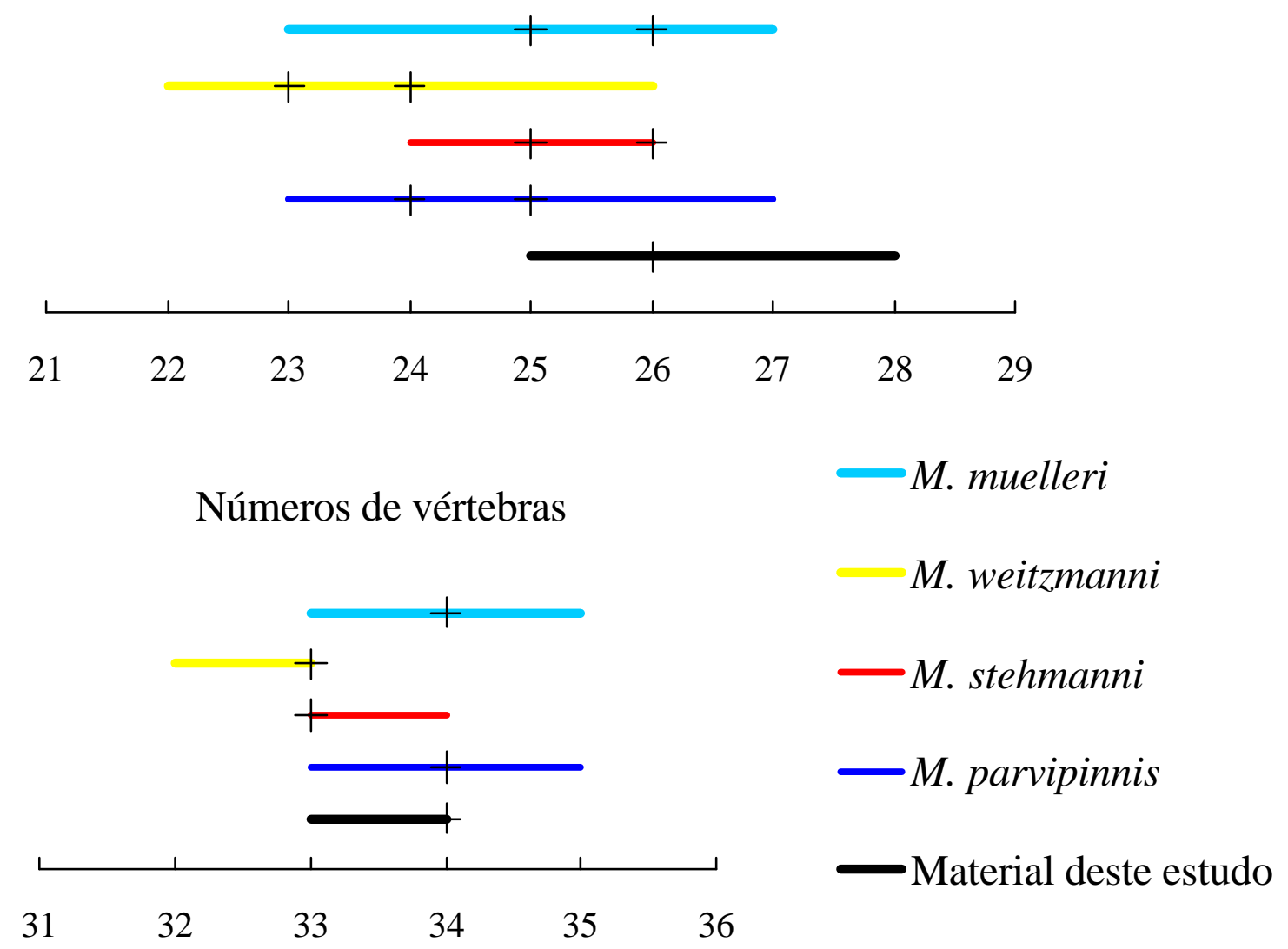

Figura II.8. Variação das características merísticas para as espécies do gênero Maurolicus apresentadas por Parin \& Kobyliansky (1996) e neste trabalho. A cruz preta representa o valor mais freqüente. 


\section{CAPÍTULO III. ESTRUTURA TERMOHALINA e DISTRIBUIÇÃO de Maurolicus stehmanni na ÁREA}

\section{1 INTRODUÇÃO}

Sparre \& Venema (1997) entendem como estoque pesqueiro ("manancial") um subconjunto de uma espécie que possui os mesmos parâmetros de crescimento e mortalidade e que ocupa uma área geográfica particular. Os autores sugerem que, no caso de não haver indícios de que ocorram diferentes estoques dentro de uma área, a sua avaliação deve ser iniciada considerando-se toda a área de distribuição e, caso se perceba, no futuro, que há diferenças, torna-se necessário proceder as analises destes parâmetros separadamente.

Mann (1993) opina que há uma correlação entre os processos oceanográficos de larga escala na dinâmica dos estoques pesqueiros, e procura relacionar os processos de produção com estes fatores.

Neste sentido, os objetivos específicos deste capítulo foram:

- Apresentar a distribuição horizontal de M. stehmanni na ZEE Sudeste-Sul brasileira e sua relação com a estrutura termohalina.

- Apresentar a distribuição vertical de M. stehmanni em função da hora do dia e das condições de temperatura da coluna de água. 


\section{2 MATERIAL E MÉTODOS}

Para as análises apresentadas neste capítulo foram utilizados os dados obtidos nas coletas de inverno (cruzeiro I), outono (cruzeiro II) e primavera (cruzeiro III), pois nestes períodos toda a área entre $22 \mathrm{e} 35^{\circ} \mathrm{S}$ foi pesquisada.

\section{2a: Condições oceanográficas da área durante os cruzeiros}

Procurando analisar a estrutura termohalina da área nas três épocas foram obtidos perfis de temperatura, condutividade e pressão (CTD Sea-bird SBE-9) a cada 20 milhas náuticas, entre as isóbatas de 100 e 2000 metros, totalizando 160 estações hidrográficas em cada cruzeiro (figura I.2.).

Esses dados foram analisados pela equipe do Laboratório de Oceanografia Física do Departamento de Física da Fundação Universidade do Rio Grande, sob a coordenação da MSc. Meyre P. Silva. Foram entregues à Coordenação do Score Sul do Programa REVIZEE três relatórios preliminares apresentando os resultados sobre as características termohalinas, a identificação das massas de água presentes e a estimativa da contribuição volumétrica de cada uma delas para toda a região entre Cabo de São Tomé e Arroio Chuí (Silva \& Freitas, 1999; Silva et al., 1999a e Silva et al., 1999b).

No presente estudo, para facilitar o entendimento sobre a distribuição de M. stehmanni e, a título de exemplificar as condições oceanográficas vingentes, foram traçados perfis verticais de temperatura e salinidade para quatro radiais localizadas ao longo da área (figura III.1.), para cada um dos cruzeiros. Nas análises de temperatura a isoterma de $18^{\circ} \mathrm{C}$ foi destacada, pois este valor está próximo do máximo de temperatura da ACAS. Segundo Campos et al. (1999) os limites inferiores e superiores de temperatura e salinidade da ACAS são os seguintes: $6^{\circ}<\mathrm{T}$ $<18,5^{\circ} \mathrm{C}$ e $34,5<\mathrm{S}<36,0$. Os resultados destas análises e daquelas realizadas sob a coordenação de MSc. Meyre P. Silva foram apresentados em conjunto.

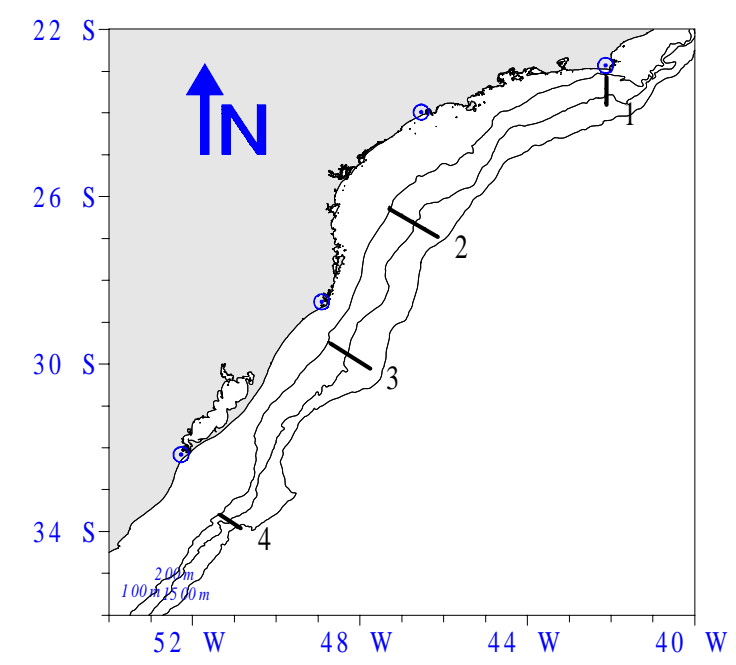

Figura III.1. Localização das radiais 1, 2, 3 e 4, para as quais foram traçados os perfis verticais de temperatura e salinidade. 


\section{2b: Distribuição espaço-temporal de M. stehmanni}

Para a análise da distribuição espacial e temporal de M. stehmanni, no plano horizontal, utilizou-se a distribuição dos registros provenientes dos estudos de ecointegração preparados pelo Laboratório de Hidroacústica do Departamento de Oceanografia da Fundação Universidade do Rio Grande e também foram lançados em mapas a localização dos lances de pesca para os três cruzeiros.

Com vistas a identificar a distribuição vertical de $M$. stehmanni nas diferentes épocas de coleta em função da hora do dia, os valores da profundidade de operação da rede e do horário de início da mesma, para todas as capturas, foram lançados em gráficos de dispersão, destacando-se os arrastos com a presença de M. stehmanni.

Para verificar se a distribuição vertical dos cardumes de $M$. stehmanni na coluna de água apresentava um padrão influenciado pelas condições de temperatura da coluna de água foram representados, graficamente, para cada lance de pesca, a profundidade de operação da rede, a profundidade do início da termoclina e a profundidade na qual o valor de temperatura era de $18^{\circ} \mathrm{C}$. Estes dois últimos valores foram obtidos após a análise dos perfis verticais de temperatura provenientes das estações oceanográficas mais próximas aos lances com ocorrência de M. stehmanni, como apresentado na figura III.2.

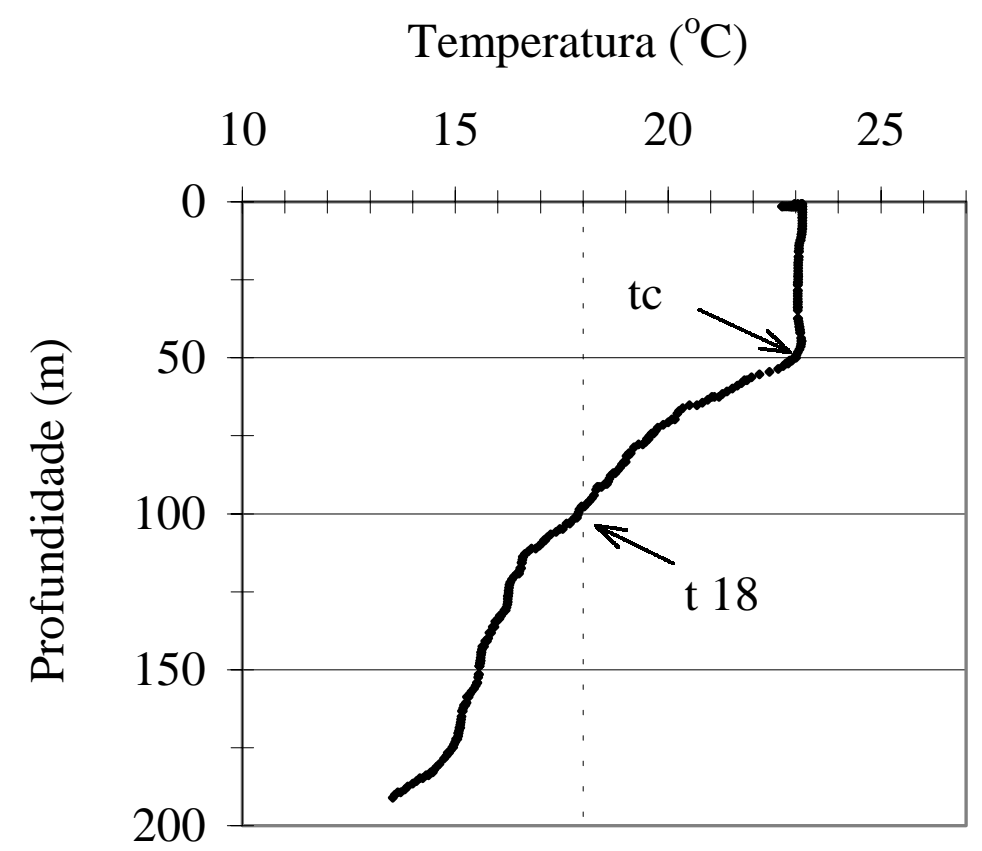

Figura III.2. Perfil vertical da temperatura de uma estação oceanoagráfica. As setas indicam o início da termoclina (tc) e a isoterma de $18^{\circ} \mathrm{C}$ (t 18). 


\section{3 RESULTADOS:}

\section{3a: Condições oceanográficas na área durante os cruzeiros}

De maneira geral, a estratificação de temperatura e salinidade das estações oceânicas foi semelhante nos três cruzeiros (Silva \& Freitas, 1999; Silva et al., 1999a e Silva et al., 1999b).

No cruzeiro de inverno a temperatura variou entre 19 e $22^{\circ} \mathrm{C}$, a 10 metros de profundidade, diminuindo em direção ao sudoeste e a salinidade esteve em torno de 36,5. A isolinha de $18^{\circ} \mathrm{C}$ ficou próxima aos 100 metros, onde se iniciou um forte gradiente vertical de temperatura e salinidade (figura III.3.). Exceção foi encontrada nas estações localizadas no extremo sudoeste, onde foram observados os menores valores de temperatura e salinidade a 10 metros ( $16^{\circ} \mathrm{C} \mathrm{e} 34$ respectivamente); estes valores aumentaram em direção ao fundo, alcançando $18^{\circ} \mathrm{C} \mathrm{e} 36$ aos $50 \mathrm{~m}$ e permanecendo assim até $120 \mathrm{~m}$ (Silva \& Freitas, 1999).

Nos cruzeiros de outono e primavera, a 10 metros de profundidade, a temperatura variou entre $25^{\circ} \mathrm{C}$ (na porção nordeste) e $21^{\circ} \mathrm{C}$ (na porção sudoeste) e a salinidade esteve em torno de 36,5. Observou-se o início da termoclina próximo aos 50 metros, ou seja, em profundidades menores que as encontradas no cruzeiro de inverno. A isolinha de $18^{\circ} \mathrm{C}$ ficou próxima ou abaixo dos 100 metros nestes dois cruzeiros, assim como no inverno. Quanto à variação vertical da salinidade, via de regra, a haloclina ocorreu a partir dos 50 metros de profundidade (figuras III.4. e III.5.).

Segundo Silva \& Freitas (1999), Silva et al. (1999a) e Silva et al. (1999b) estas condições, provavelmente, foram reflexo da predominância da AT nas camadas superiores da CB. Abaixo destas camadas houve predomínio da ACAS (porção inferior da CB), observandose, a partir dos 100m, um gradiente de temperatura e salinidade. Além disso, constatou-se diminuição da influência da CB na medida em que a mesma se deslocava para o sul, acompanhada do aumento da contribuição da corrente de plataforma que transporta águas de baixa temperatura e salinidade; este processo foi mais intenso no inverno.

Sobre a plataforma continental (PC), nas estações mais próximas à costa, as variações foram mais acentuadas:

No cruzeiro de inverno ocorreu um forte gradiente horizontal nos campos da temperatura e da salinidade. Os menores valores $\left(16^{\circ} \mathrm{C}\right.$ e 34$)$ foram encontrados na porção sudoeste da área, enquanto que os maiores valores $\left(21^{\circ} \mathrm{C}\right.$ e 37$)$ na porção nordeste (figura III.3.). Estes resultados refletiram os processos atuantes sobre a distribuição espacial e volumétrica das massas de água presentes na área (Silva \& Freitas, 1999).

A Água Costeira (AC), com baixos valores de temperatura e salinidade, esteve presente em algumas estações costeiras ao longo de toda a área, chegando a atingir a Quebra de Plataforma (QP) ao sul do Cabo de Santa Marta (figura III.3.). De acordo com Silva (1999) esta massa de água ocupou as camadas superficiais até 50 metros de profundidade e sua contribuição 
Inverno

Temperatura $\left({ }^{\circ} \mathrm{C}\right)$

Radial 1

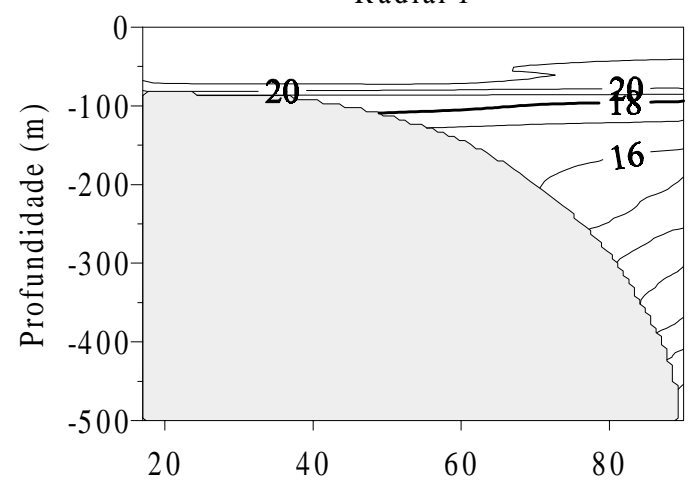

Radial 2

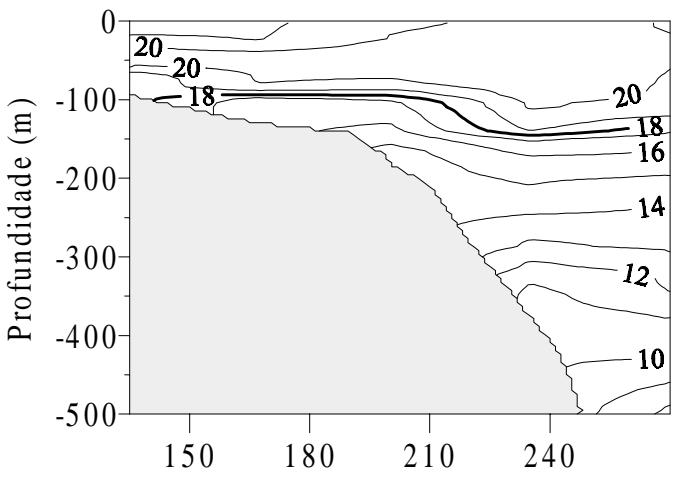

Radial 3

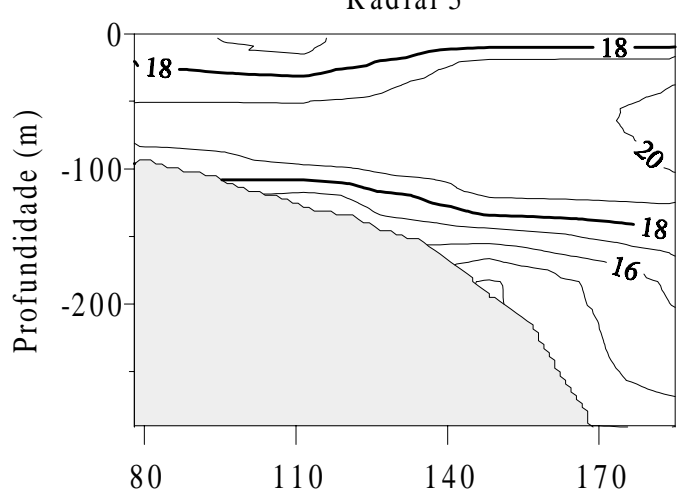

Radial 4

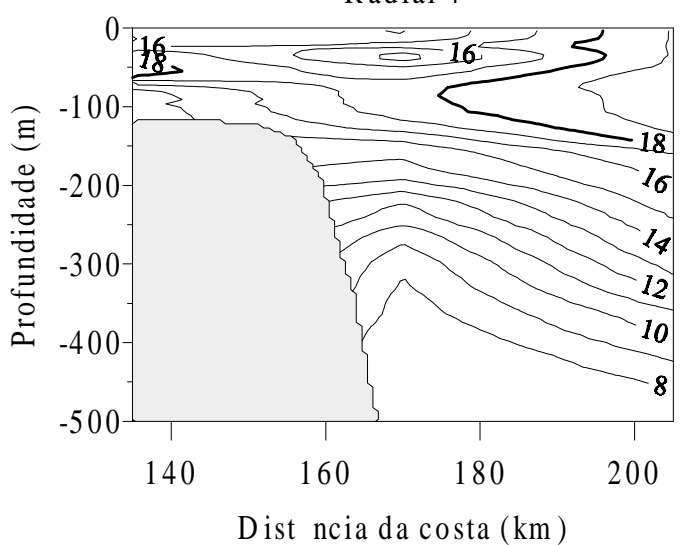

Salinidade

Radial 1

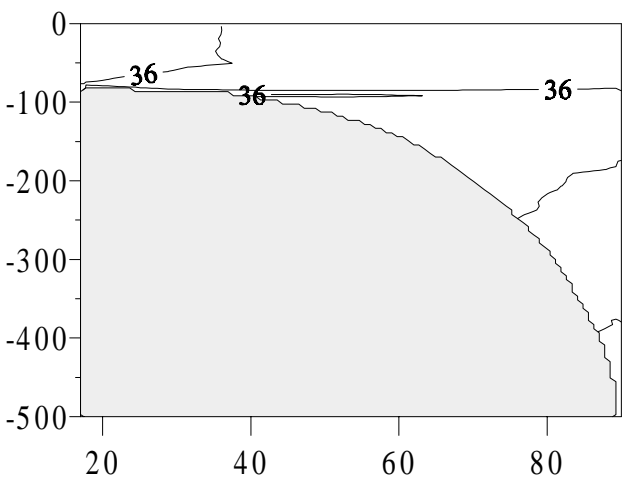

Radial 2
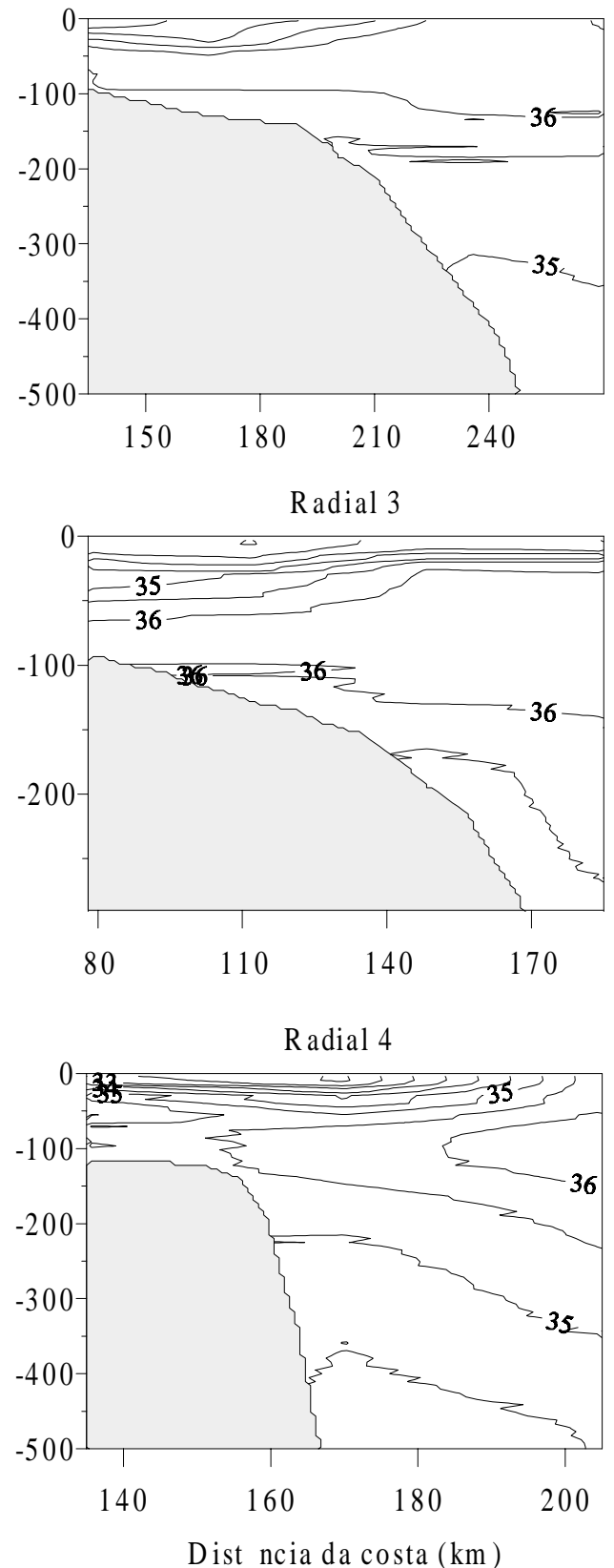

Figura III.3. Distribuição vertical de temperatura e salinidade para as radiais 1, 2, 3 e 4 no cruzeiro de inverno. 


\section{Outono}

Tempretura $\left({ }^{\circ} \mathrm{C}\right)$

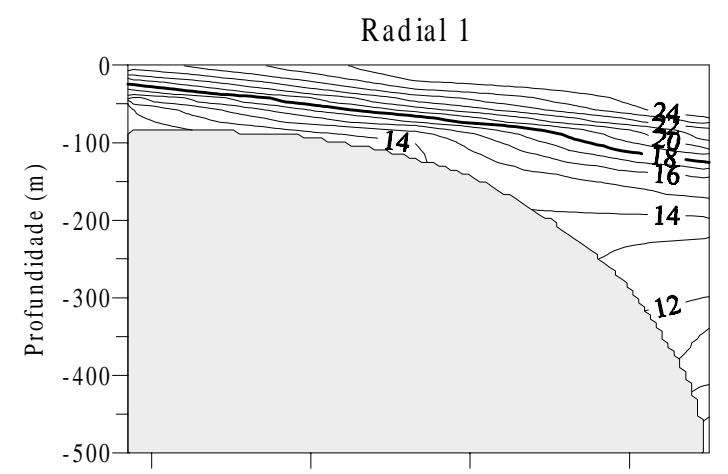

20

40

60

Radial 2
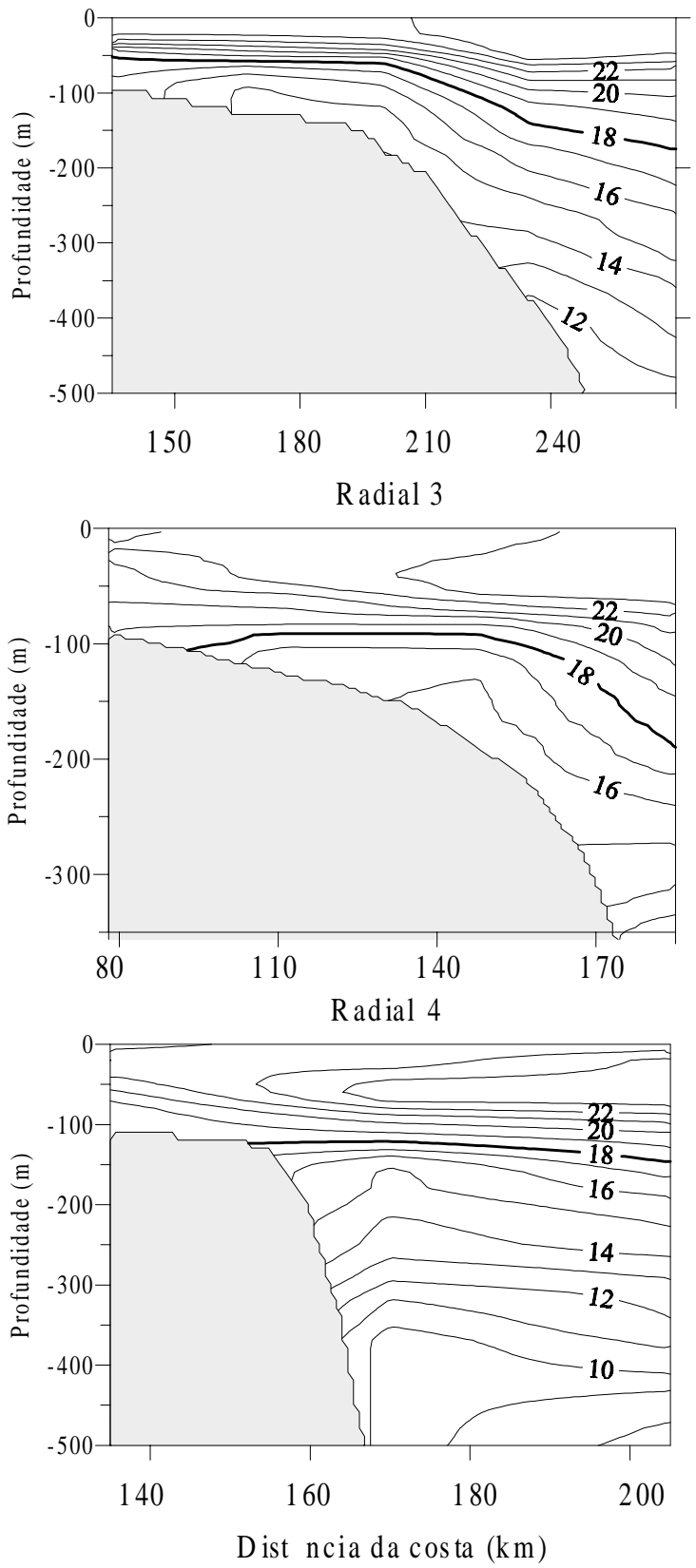

Salinidade

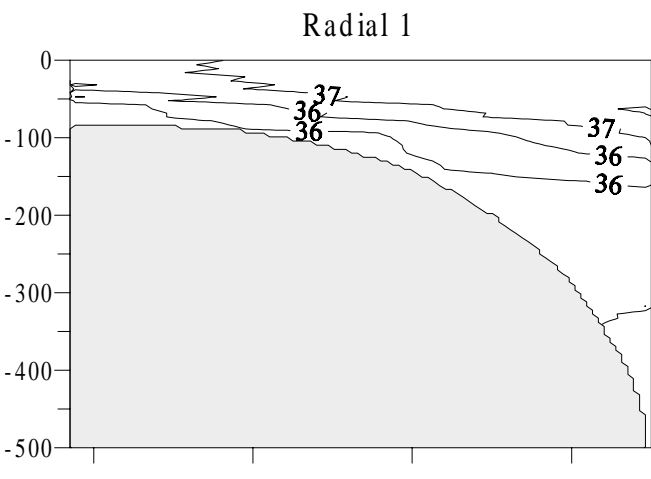

20

40

60

80

Radial 2
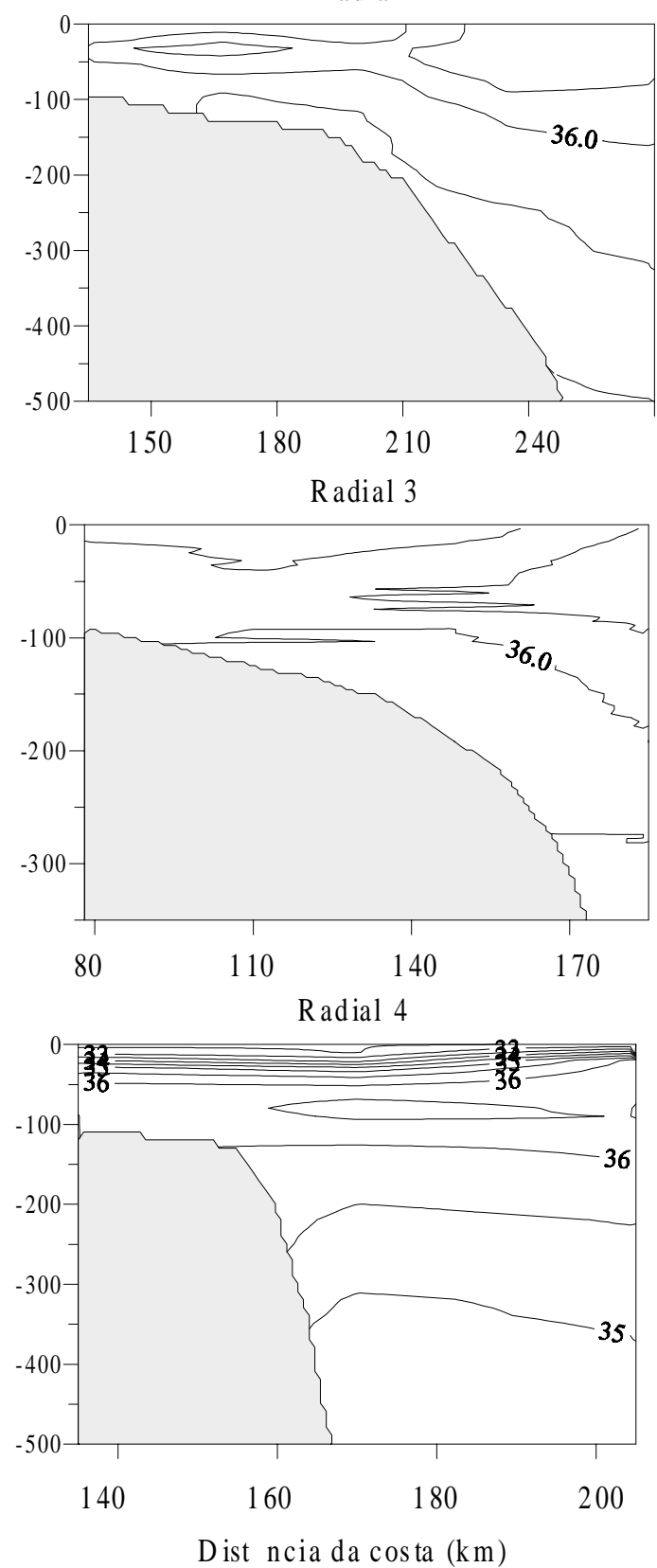

Figura III.4. Distribuição vertical de temperatura e salinidade para as radiais 1, 2, 3 e 4 no cruzeiro de outono. 


\section{Primavera}
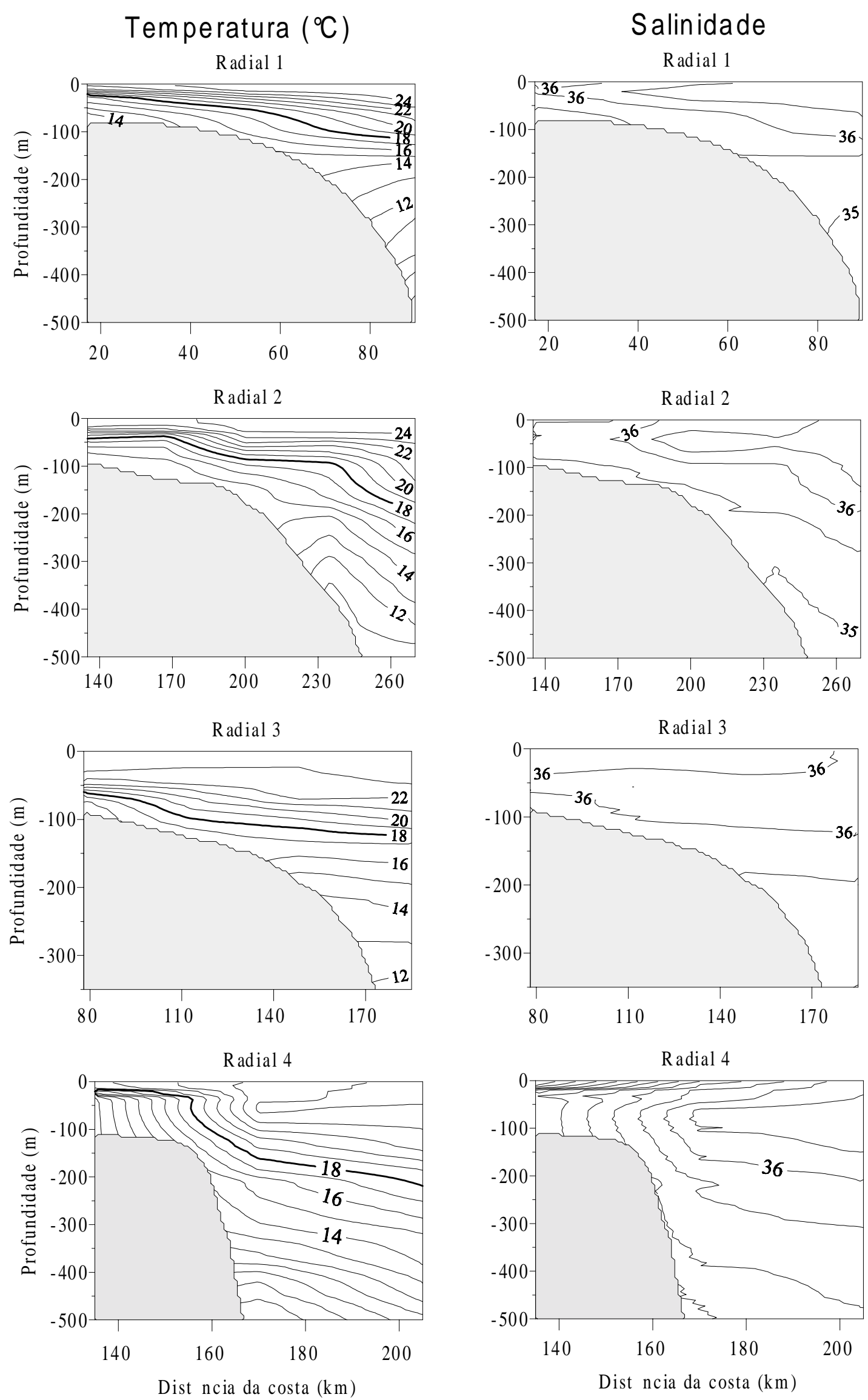

Figura III.5. Distribuição vertical de temperatura e salinidade para as radiais 1, 2,3 e 4 no cruzeiro de primavera. 
volumétrica foi máxima, cerca de $5 \%$, entre Itajaí e Rio Grande. Nas demais áreas, não passou de $5 \%$.

A Água Tropical (AT) apresentou a maior contribuição na formação das águas na região. Porém, sua participação foi maior ao norte decrescendo na medida que era carregada para a direção sul. Sabendo que a AT é transportada pela Corrente do Brasil (CB), pode-se inferir que a CB se afastou em direção ao oceano na porção sul da área nesta ocasião (Silva \& Freitas, 1999).

Silva et al. (1999b) verificaram que no cruzeiro de outono a contribuição da AC sobre a Plataforma Continental (PC) foi ainda menor, restringindo-se apenas à área abaixo de Rio Grande, sendo que nesta região os gradientes verticais de temperatura e salinidade foram altos e invertidos, devido a influência da CP. Observou-se a intrusão da Água Central do Atlântico Sul (ACAS) sobre a PC de maneira intensa, chegando a atingir camadas superficiais nas estações mais próximas ao litoral do Rio de Janeiro, fato observável pela figura III.4. Mais ao sul, na Bacia de Santos, a ACAS esteve sobre a PC, mas próxima ao fundo, provocando um forte gradiente vertical de temperatura nas camadas mais profundas. Ao sul do Cabo de Santa Marta a diminuição da salinidade, indicou influência da Corrente de Plataforma, que se intensificou em direção sudoeste, porém em menor intensidade que nos demais cruzeiros (Silva et al., 1999a) (figura III.4.).

No Cruzeiro de primavera ocorreu penetração da ACAS sobre a PC entre Cabo Frio e Rio Grande, sendo que ao norte de Santos este processo ocorreu com maior intensidade. Nas proximidades de Rio Grande foi, novamente verificada menor influência da CB, em detrimento de uma maior contribuição da CP (Silva et al., 1999b) (figura III.5.).

\section{3b: Distribuição espaço-temporal de M. stehmanni}

Na figura III.6. está representada a ocorrência de M. stehmanni para os três cruzeiros dentro da malha amostral, obtida a partir de dados hidroacústicos e na figura III.7. estão indicadas as localizações dos lances de pesca com captura. Verificou-se que a espécie ocorreu ao longo de toda a área nas três épocas de pesquisa, sendo que próximo a Cabo Frio esteve presente após a isóbata de 200 m, ao passo que entre Santos e Arroio Chuí ocorreu a partir da isobáta de $100 \mathrm{~m}$. No outono a distribuição de M. stehmanni foi um pouco mais ampla que nos demais cruzeiros, estendendo-se até o extremo sul da área.

As capturas de $M$. stehmanni efetuadas durante o dia se deram em profundidades maiores que aquelas realizadas nos horários de menor iluminação (nascer e pôr-do-sol) e noturnos (figura III.8.).

Em todos os arrastos realizados durante o dia a espécie não foi capturada em profundidades inferiores a $80 \mathrm{~m}$, sendo que no inverno predominaram as capturas entre os 100 e $150 \mathrm{~m}$, no outono ao redor dos $150 \mathrm{~m}$ e na primavera entre 140 e $230 \mathrm{~m}$ (figura III.8.).

A análise da figura III.9., que é uma representação gráfica das profundidades dos 
lances de pesca com presença de M. stehmanni, das respectivas profundidades de início da termoclina e da isoterma $18^{\circ} \mathrm{C}$, considerando-se o horário, mostrou que:

- As capturas de M. stehmanni realizadas nos horários diurnos se deram abaixo do início da termoclina nas três épocas. Em relação à isoterma de $18^{\circ} \mathrm{C}$ nota-se, que no inverno, os cardumes estavam próximos a esta, enquanto que no outono e na primavera ocorreram abaixo dela (exceto pelo lance \#208, efetuado acima da isoterma de $18^{\circ} \mathrm{C}$ ).

- Nos horários próximos ao nascer e pôr-do-sol, as capturas se deram em menores profundidades, sempre acima da isoterma de $18^{\circ} \mathrm{C}$ e próximas do início da termoclina (exceção feita ao lance \#258, efetuado a $200 \mathrm{~m}$ )

- Durante o período noturno não houve captura da espécie no inverno, enquanto que na primavera e outono os lances ocorreram em pequenas profundidades, próximo ao início da termoclina e acima da temperatura de $18^{\circ} \mathrm{C}$ (exceto para o lance \#373, realizado a $150 \mathrm{~m}$ ).

Estes resultados confirmaram que $M$. stehmanni realiza migração vertical diariamente, ocupando camadas menos profundas na coluna de água durante os horários de menor iluminação. 


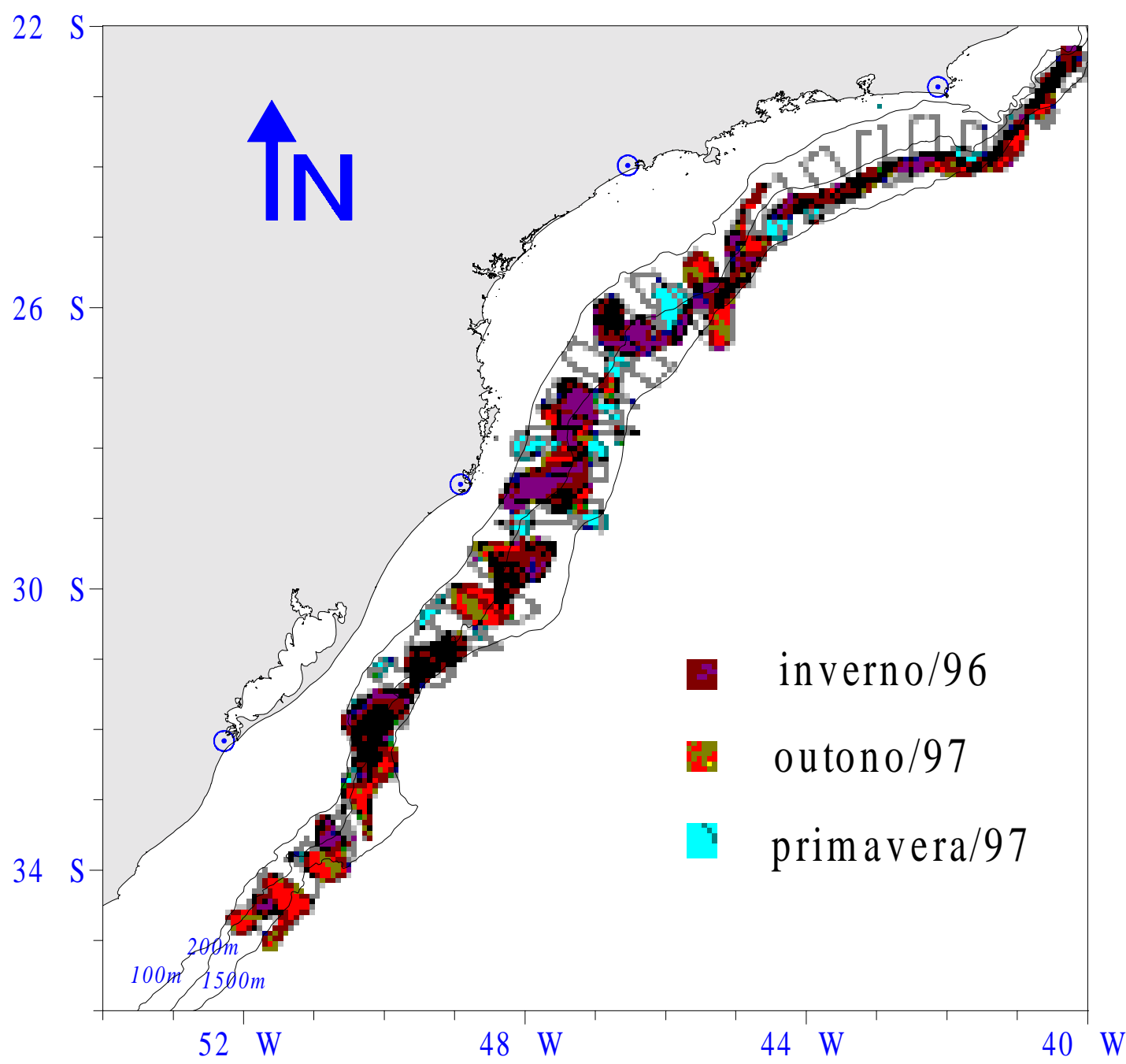

Figura III.6. Distribuição dos cardumes de M. stehmanni, a partir das análises dos registros hidroacústicos durante os cruzeiros de estudo. Figura fornecida pelo Laboratório de Hidroacústica, do Departamento de Oceanografia da Fundação Universidade do Rio Grande. 


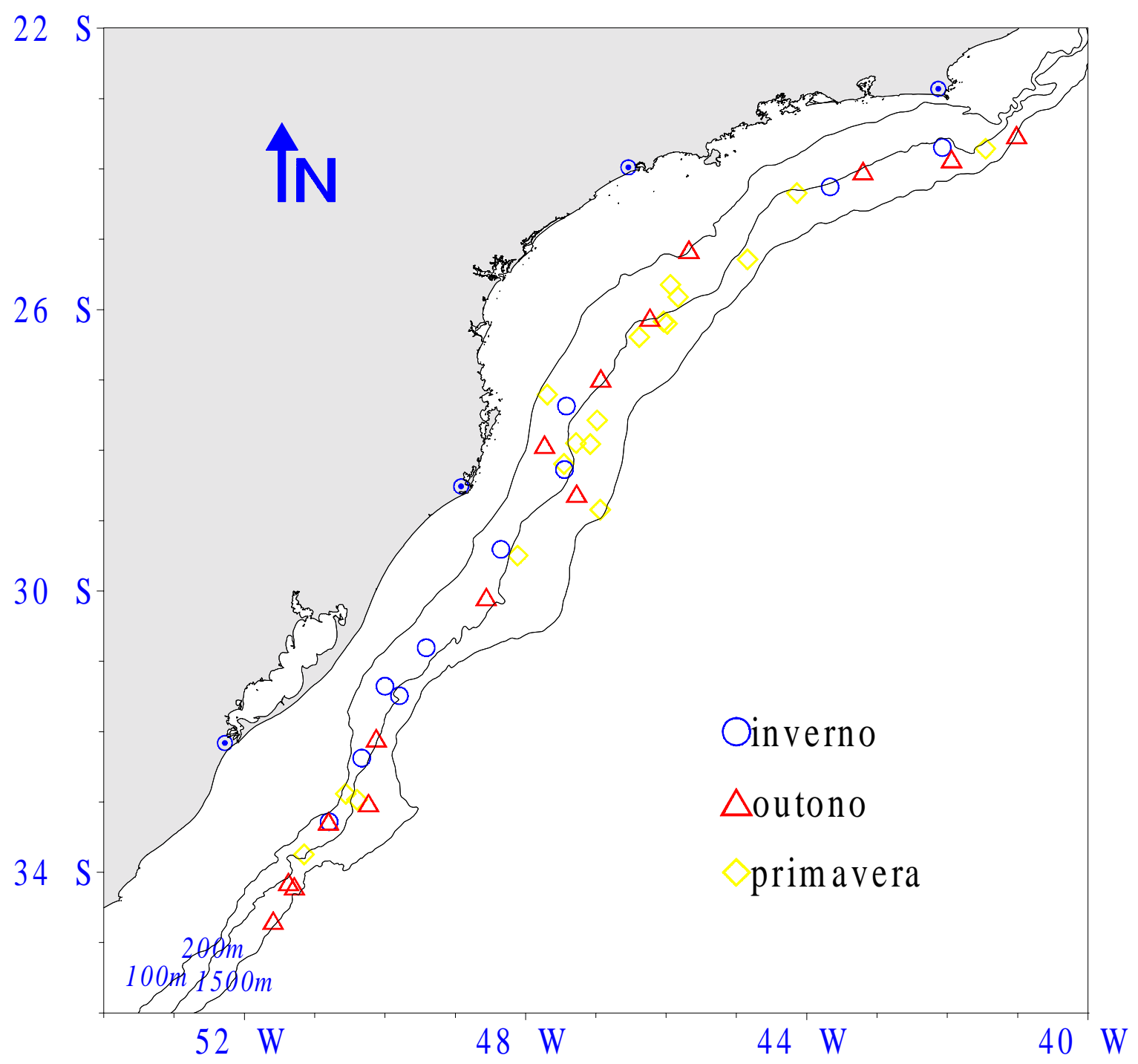

Figura III.7. Distribuição dos lances de pesca com ocorrência de M. stehmanni para os três cruzeiros realizados. 

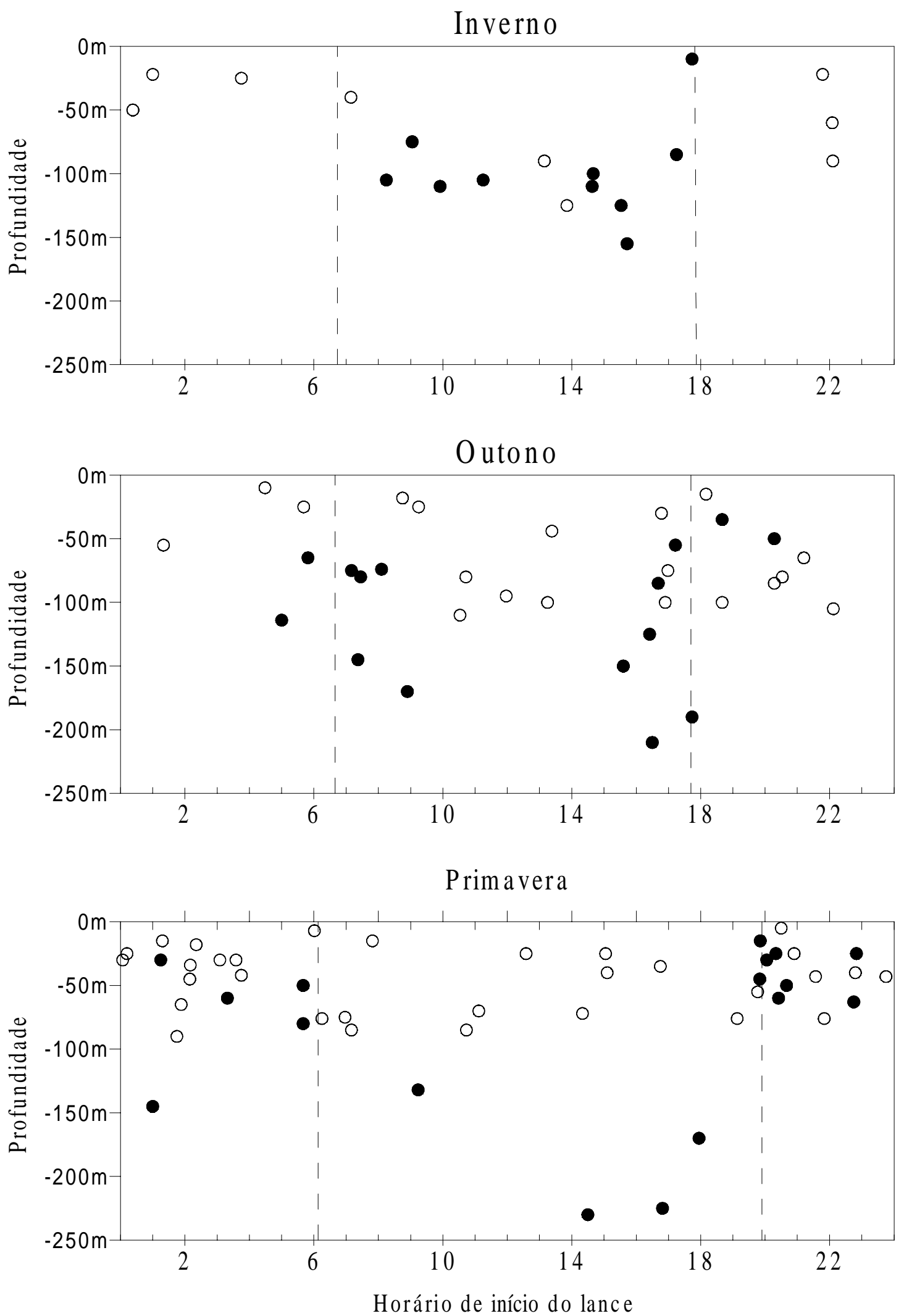

Figura III.8. Profundidade e horário de operação de todos os lances de pesca, com presença $(\bullet)$ ou ausência (o) de $M$. stehmanni. 
$\stackrel{\mathrm{N}}{\longleftarrow}$
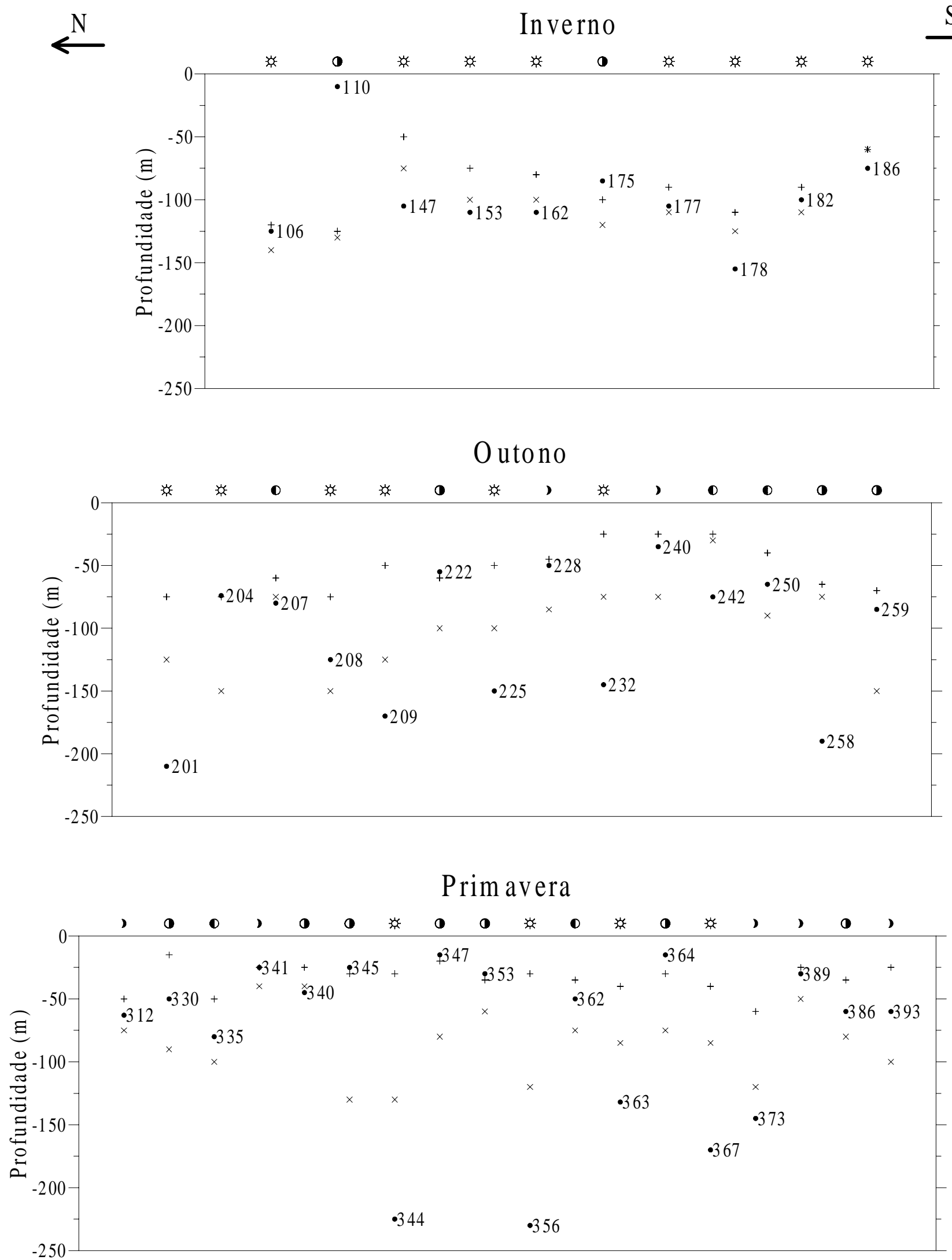

Figura III.9. Profundidade de operação da rede (•); profundidade do início da termoclina (+); isoterma de $18{ }^{\circ} \mathrm{C}(\times)$ e o momento do dia em que foi efetuada a captura ( ) - noite; $\bigcirc$ - nascer do sol; $\not \subset$ - dia e $\bigcirc$ - pôr-dosol), por lance de pesca, para os três cruzeiros (o número ao lado da profundidade de operação representa o lance de pesca). 


\section{4 DISCUSSÃO:}

Os resultados apresentados evidenciaram que $M$. stehmanni ocupa a ZEE brasileira Sudeste-Sul de maneira intensa e que a espécie está intimamente ligada à quebra da plataforma e ao talude continental, corroborando os resultados de vários autores (Weiss et al., 1988; Bonecker \& Hubold, 1990; Ribeiro, 1996 e Greig, 2000).

Clarke (1982); Hulley \& Prosch (1987) e Boehlert et al. (1994) mostraram que as espécies do gênero Maurolicus que ocorrem, respectivamente, no sudeste da Austrália, no Atlântico sudeste e em montes submarinos ("seamounts") no Pacífico são espécies mesopelágicas associadas a massas de terra ("land masses"), tais como talude continental, montes submarinos, ilhas e fiordes. Hulley \& Prosch (op. cit.) e Boehlert et al. (op. cit.) as classificaram como pseudo-oceânicas, isto é, habitam a interface entre a zona nerítica e oceânica, como parece ser o caso de M. stehmanni.

Reid et al. (1991) classificaram como comunidade mesopelágica-limite ("mesopelagicboundary") a comunidade de micronécton associada à terra entre os limites oceânicos e neríticos do Hawaí, a qual é composta por peixes (Argentinidae, Myctophidae e Sternoptychidae), crustáceos e lulas. Ao que parece, M. stehmanni é a principal espécie de peixe que compõe o micronécton da comunidade de quebra de plataforma.

Caldeira (1999), ao estudar a distribuição da espécie de Maurolicus que ocorre na área do presente estudo, em relação às massas de água, constatou que a mesma é capaz de suportar diferenças de temperatura de até $10^{\circ} \mathrm{C}$, sendo encontrada tanto na AT, como na ACAS e na AC. Os resultados do presente trabalho indicaram esta espécie ocupa a ACAS durante os horários diurnos, migrando para camadas menos profundas nos horários de menos luz, onde, preferencialmente, ocorre a AT. Durante o outono, no extremo sul da área sob investigação, a ocorrência de $M$. stehmanni e a menor influência da Corrente de Plataforma (CP), que carrega águas frias e de baixa salinidade (Água Subantártica), indicam que a frente causada pela confluência da CB e da CP pode ser um limite à distribuição da espécie, como sugeriram Weiss et al. (1988). Esta afirmação é ainda corroborada pelos trabalhos de Figueroa et al. (1998) e Greig (2000); os primeiros não constataram a ocorrência de Maurolicus em uma série de arrastos realizados entre $36^{\circ}$ e $45^{\circ} \mathrm{S}$, área adjacente à do presente estudo e verificaram que as principais espécies de peixes mesopelágicos que aí ocorrem pertencem à família Mycthophidae, enquanto que Greig (op. cit) verificou menor densidade nos registros hidroacústicos de Maurolicus nas proximidades do limite sul da área do presente estudo na primavera de 1997.

A realização de um deslocamento diário na coluna de água por $M$. stehmanni foi confirmada por Caldeira (1999) e Greig (2000), que estudaram registros hidroacústicos de Maurolicus na ZEE Sudeste-Sul brasileira no inverno e na primavera, respectivamente. Estes autores constataram que a espécie se mantém próxima aos $300 \mathrm{~m}$ de profundidade durante o dia, formando cardumes densos; à noite estes peixes se movem para camadas superiores da 
coluna de água, muitas vezes se misturando com outras espécies. Greig (2000) acrescenta que no pôr-do-sol (início da migração) os cardumes de M. stehamnni se dirigem à superfície (cerca de $10 \mathrm{~m}$ ), permanecendo fora da amostragem acústica por um curto espaço de tempo (10 a 20 minutos) e depois a camada de dispersão de M. stehmanni se estabiliza em torno dos 50 metros.

Wootton (1990) atribui três funções à migração vertical diária em peixes pelágicos zooplanctívoros: A) acompanhar o movimento vertical diário realizado por sua presa; B) evitar ser predado por peixes maiores, dirigindo-se a camadas mais escuras e mais profundas durante o dia e C) após se alimentar em profundidades menores com temperaturas mais elevadas, o peixe se direcionaria a camadas mais profundas, com valores de temperatura mais reduzidos, $\mathrm{o}$ que conseqüentemente reduziria sua taxa metabólica. Longhurst \& Pauly (1987) consideraram que algumas espécies mesopelágicas permanecem em camadas mais profundas durante o dia, distribuídos em grandes e densos cardumes, aparentemente com pouca mobilidade, associados às baixas temperaturas para a redução de gasto energético.

Clark \& Levy (1988) discutiram o valor adaptativo da migração vertical diária para peixes zooplantívoros visuais e, a partir de estudos sobre o comportamento de salmões juvenis, propuseram um modelo no qual um dos principais fatores determinantes da posição vertical destes peixes na coluna da água seria a intensidade luminosa. Segundo estes autores a tomada de alimento depende da luz, uma vez que se trata de predadores visuais; em contrapartida, com o aumento da intensidade luminosa a ação dos predadores (ictiófagos visuais) é intensificada. Assim, o que rege a migração vertical de espécies zooplanctófagas seria a razão entre a tomada de alimento e o risco de predação. Os curtos períodos de tempo entre o amanhecer e o anoitecer, quando a intensidade luminosa alcança níveis intermediários, seriam os momentos onde esta razão estaria otimizada. Os autores denominam estes momentos de "janela antipredação".

Giske et al. (1990) e Kaartvedt et al. (1998) afirmaram que M. muelleri é um predador visual que realiza migração vertical diária, discutindo o conceito de "janela antipredação" (Clark \& Levy, op. cit.) para explicar o comportamento da espécie no mar da Noruega. Giske et al. (op. cit.) verificaram, em registros hidroacústicos, um rápido ajuste na distribuição vertical dos cardumes de $M$. muelleri durante o dia em resposta às variações na cobertura de nuvens e, portanto, da intensidade luminosa.

Os resultados do presente trabalho sobre a migração diária de $M$. stehmanni não descartam a hipótese de janela antipredação apresentada por Clark \& Levy (op. cit.), embora sejam necessários outros estudos para confirmá-la. Neste sentido, seriam necessários a realização de cruzeiros de prospecção com coletas periódicas de exemplares ao longo de 24 horas, seguida de análise da atividade alimentar

A alta ocorrência de ovos e larvas em todas as épocas estudadas por Weiss et al. (op. cit.), Hubold \& Bonecker (op. cit.) e Ribeiro (op. cit.), a alta estimativa de biomassa apresentada por Greig (2000) e a alta ocorrência de M. stehmanni encontrada nos três cruzeiros realizados durante o presente estudo, permitem afirmar que esta espécie está ajustada à região de quebra 
de plataforma. Segundo Lowe-McConnel (1999), esta região é uma interface entre o ambiente oceânico, com produção primária baixa e constante, e o ambiente nerítico, com produção mais elevada e mais sensível às variações ambientais.

É importante lembrar que a amostragem (arrastos de meia água) não foi realizada de maneira aleatória e, portanto, a sua análise teve caráter especulativo, no sentido de evidenciar padrões de deslocamento verticais e horizontais da espécie em função das condições ambientais. Além disso, foi possível saber as profundidades de operação do aparato de pesca e do registro acústico, permitindo inferir sobre a representatividade do lance em relação ao registro, mas permaneceu a incerteza se ocorreu captura durante a descida ou subida da rede nos momentos de seu lançamento ou recolhimento, respectivamente. Outra possível fonte de erro é que não foi possível avaliar se a captura se deu em uma porção específica do registro, isto é, se foi amostrada apenas uma porção da população visualizada no ecorregistro. 


\section{CAPÍtulo IV. ESTRUTURA da POPUlaÇÃo e REPRODUÇÃO de Maurolicus stehmanni}

\section{1 INTRODUÇÃO}

Para um monitoramento adequado de um estoque é importante conhecer os seus limites físicos, assim como o de suas áreas específicas de desova e de crescimento (Pitcher \& Hart, 1996).

Segundo Potts \& Wootton (1984) e Wootton (1990), reprodução é o processo que garante a perpetuação de uma espécie, sendo que a estratégia reprodutiva é a gama de características que esta espécie manifesta, a fim de manter a população; ela é moldada por uma série de condições ecológicas e é única para uma mesma espécie ou população. Variações nas condições ecológicas podem determinar mudanças nas estratégias reprodutivas, conduzindo a uma reprodução bem sucedida. Estas mudanças são denominadas táticas reprodutivas, apresentam diferentes graus de plasticidade e, como as estratégias, também são adaptativas.

Levando-se em conta estas afirmações, o estudo das táticas reprodutivas de Maurolicus stehmanni, tais como local (is) e época (s) de desova e o tamanho médio de primeira maturação gonadal se faz importante por uma série de razões, das quais talvez as mais pertinentes sejam:

1) Devido ao fato de M. stehmanni ser uma espécie de vida curta, crescimento rápido e fecundidade elevada, alterações no meio ambiente, em termos físicos e/ou biológicos, podem acarretar mudanças rápidas nestes parâmetros (Salvanes \& Stockley, 1996).

2) Sendo esta espécie um dos principais elos entre os componentes produtores e de topo da cadeia pelágica de quebra de plataforma (Greig, 2000), torna-se importante a compreensão de seu ciclo de vida, em especial da manutenção da espécie neste ecossistema.

3) Devido a sua elevada biomassa Maurolicus stehmanni é um potencial pesqueiro e como tal, sua explotação deve ser precedida (e mantida) por estudos que permitam o monitoramento da espécie.

Neste sentido, os objetivos específicos deste capítulo foram:

- Verificar a composição da população de M. stehmanni em relação ao tamanho;

- Verificar as proporções entre jovens e adultos e entre machos e fêmeas de M. stehmanni dentro dos diferentes lances de pesca, em relação ao comprimento, ao estádio de maturidade gonadal e à época do ano;

- Estimar a relação entre o peso total e o comprimento padrão de $M$. stehmanni;

- Estimar o tamanho médio de primeira maturação gonadal;

- Investigar possíveis épocas e áreas de desova de M. stehmanni na ZEE Sudeste-Sul do Brasil

- Verificar o tipo de desenvolvimento ovocitário da espécie. 


\section{2 MATERIAL E MÉTODOS:}

Utilizou-se o material procedente dos três Cruzeiros de Prospecção Pelágica do PROGRAMA REVIZZE, Score Sul (cruzeiros I, II e III) para as análises referentes à estrutura da população em tamanho; relação entre o peso e o comprimento; proporção entre jovens e adultos; proporção entre machos e fêmeas; tamanho de maturação gonadal e áreas e épocas de desova, pois estes cruzeiros abrangeram toda a área de estudo (figura I.1.). A este material acrescentou-se o de mais dois cruzeiros, realizados com a mesma metodologia, porém, proveniente de uma área restrita, próxima à Itajaí (figura I.2.), para estudo de detalhes em nível histológico dos ovários da espécie.

\section{2a: Captura e composição da população:}

As capturas de $M$. stehmanni em peso foram anotadas imediatamente após os lances de pesca. O número de exemplares $(\mathbf{N})$ de $M$. stehmanni de cada arrasto foi estimado a partir da regra de três:

$$
\mathbf{N}=\mathbf{P} * \mathbf{n} / \mathbf{p a} \text { onde, }
$$

$\mathbf{n}=$ tamanho da amostra, $\mathbf{P}=$ peso total capturado e $\mathbf{P a}=$ peso total da amostra.

Para analisar a composição em comprimento da população foi calculada a distribuição de freqüência dos exemplares capturados por classe de comprimento padrão (DFCC) de $2 \mathrm{~mm}$, para cada lance de pesca.

Para obter a DFCC por época do ano, os valores absolutos de ocorrência por classes de comprimento padrão de cada lance foram multiplicados pela razão $\mathbf{N} / \mathbf{n}$ do próprio lance e a seguir, os valores estimados para todos os lances de cada cruzeiro foram somados.

A soma dos valores obtidos para cada classe, em todos os lances forneceu a DFCC para os três períodos em conjunto.

Sabe-se que a proporção sexual pode variar em função do espaço, do tempo e do comprimento, indicando modificações no comportamento reprodutivo dos peixes (Wootton, 1990). Neste sentido, foram realizados cálculos sobre a proporção entre machos e fêmeas por lance de pesca e em relação ao comprimento, para cada época do ano, segundo metodologia descrita por Vazzoler (1996). A hipótese de que a proporção entre machos e fêmeas era 1:1 foi averiguada pelo teste do $x^{2}$ (Zar, 1996). Para estes cálculos, devido à dificuldade de se identificar macroscopicamente qual o sexo dos peixes jovens, foram considerados apenas os peixes adultos, com exceção do cálculo da proporção sexual em função do comprimento padrão.

A proporção entre jovens e adultos entre as diferentes épocas e locais de coleta pode indicar períodos e áreas de recrutamento; assim, foram elaboradas figuras representando esta proporção por época do ano e por lance de pesca. Foram considerados peixes jovens aqueles que tiveram o estádio de maturidade gonadal classificado como imaturo (A) e peixes adultos aqueles nos demais estádios. 


\section{2b: Relação entre o peso total e o comprimento padrão e fator de condição}

Para estimar o peso total do peixe (Wt) a partir do seu comprimento padrão $(\mathbf{C p})$ e vice versa, os parâmetros (a e b) desta relação foram calculados pela equação: $\mathbf{W}_{\mathbf{t}}=\mathbf{a}^{*} \mathbf{C} \mathbf{p}^{\mathbf{b}}$ (onde, $\mathbf{a}=$ coeficiente linear da regressão e $\mathbf{b}=$ coeficiente angular da regressão), utilizando o método dos mínimos quadrados, a partir dos valores de Wt e Cp logaritmizados (log natural).

Os dados foram lançados em gráficos de dispersão e os possíveis erros durante a amostragem ou a transcrição dos dados, foram verificados e corrigidos ou retirados das análises.

Inicialmente os cálculos da relação peso/comprimento foram realizados para machos e fêmeas separadamente, aplicando-se teste t para verificar a homogeneidade entre os parâmetros dessa relação e a possibilidade de agrupar os dados, como sugere Vazzoler (1981).

Para comparar a relação Wt/Cp entre os três cruzeiros, calculou-se os parâmetros desta relação para cada época, aplicando-se o teste F para verificar a existência, ou não, de diferenças significativas entre os parâmetros obtidos. A título de comparação, as curvas obtidas para cada época do ano, foram traçadas em um mesmo gráfico.

O fator de condição $(\mathbf{K})$ foi calculado para cada exemplar, pela seguinte fórmula:

$$
\mathbf{K}=\mathbf{W}_{\mathbf{t}} / \mathbf{C} \mathbf{p}^{\mathrm{b} * 10^{4}} \text { onde, }
$$

$\mathrm{W}_{\mathrm{t}}=$ peso total;

$\mathrm{W}_{\mathrm{c}}=\mathrm{W}_{\mathrm{t}}-\mathrm{W}_{\mathrm{o}}=$ peso do corpo;

$\mathrm{Cp}=$ comprimento padrão;

$\mathrm{b}=$ coeficiente angular da regressão linear dos dados logaritmizados de peso e comprimento.

Na verdade, K é igual ao valor de $\mathbf{a} * 10^{4}$ (intercepção da regressão linear dos dados logaritmizados do peso e comprimento); assim, quanto maior o valor de $\mathbf{K}$ maior será o peso do peixe para um determinado tamanho (King, 1996).

Para verificar a variação do valor de K em função do comprimento padrão, os valores foram lançados em gráficos de dispersão para todos os peixes e, para analisar sua variação entre as épocas de coleta, os valores médios de $\mathbf{K}$ também foram lançados em gráficos. Nestes gráficos foi traçada uma reta que representa o valor de $\mathbf{a} * 10^{4}$, no sentido de averiguar se os valores de K estavam acima ou abaixo dele, pois a representaria a condição média da população.

\section{2c: Tamanho de maturação gonadal:}

Segundo Vazzoler (1996), este é o tamanho médio em que $50 \%$ dos peixes atingiram a maturidade gonadal.

A partir da proporção de indivíduos adultos (estádios B, C, D e E), por classe de comprimento padrão, foi estimado o tamanho médio de $1^{\mathrm{a}}$ maturação gonadal $\left(\mathrm{L}_{50 \text { médio }}\right)$. $\mathrm{O}$ ajuste de uma curva média aos pontos obtidos foi realizado através do método proposto por King (1996), utilizando-se a equação de uma curva logística. O cálculo foi realizado para machos e fêmeas, em conjunto, devido à dificuldade de se identificar o sexo dos peixes imaturos (estádio 
A).

Com o intuito de realizar uma comparação entre os dados da literatura e do presente trabalho foram ainda estimados o tamanho mínimo de maturação $\left(\mathrm{T}_{\text {min }}\right)$ e o tamanho máximo de maturação $\left(\mathrm{T}_{\max }\right)$ para machos e fêmeas separadamente, que representam, respectivamente, os tamanhos mínimos e máximos dos peixes com as gônadas maduras, ou seja, no estádio C (Dalpadado \& Gjøsæter, 1987; Young et al., 1987; Prosch, 1991 e Rasmussen \& Giske, 1994).

\section{2d: Local e época de desova}

Com a finalidade de verificar a existência de local (is) e época (s) de desova para $M$. stehmanni na área prospectada foram analisados:

- A freqüência dos estádios de maturidade gonadal, que pode indicar desova pela presença de peixes maduros (West, 1990), foi calculada por lance de pesca e por época do ano, para todos os peixes (machos e fêmeas agrupados).

- A relação gonadossomática (RGS) que expressa a razão, em porcentagem, entre a peso da gônada e o peso do peixe (total ou somático). Sua variação, ao longo do tempo, pode indicar o período de maior atividade reprodutiva, na medida em que esta razão deve aumentar com o aumento do desenvolvimento ovariano, indicando maior atividade reprodutiva (Wootton, 1990 e King, 1996).

RGS foi calculada a partir das expressões abaixo apresentadas por Vazzoler (1996), considerando-se os lances, o comprimento padrão, as épocas de coleta, os sexos e os estádios de maturidade gonadal (neste caso, machos e fêmeas foram analisados separadamente).

$$
\mathbf{R G S}_{1}=100 * \mathbf{W}_{\mathrm{o}} / \mathbf{W}_{\mathrm{t}} \text { e } \mathbf{R G S}_{2}=100 * \mathbf{W}_{\mathrm{o}} / \mathrm{W}_{\mathrm{c}} \text { onde }
$$

$\mathbf{W}_{\mathbf{0}}=$ peso dos ovários;

$\mathbf{W}_{\mathbf{t}}=$ peso total;

$\mathbf{W}_{\mathbf{c}}=\mathbf{W}_{\mathbf{t}}-\mathbf{W}_{\mathbf{o}}=$ peso somático.

Também foi calculado o $\Delta$ RGS, através da seguinte equação:

$\Delta \mathrm{RGS}=\mathrm{RGS}_{2}-\mathrm{RGS}_{1}$

- Delta $\mathbf{K}(\boldsymbol{\Delta} \mathbf{K})$, este índice pode revelar, em termos relativos, quanto da energia obtida o peixe está direcionando para o desenvolvimento gonadal, podendo ser um indicador do período reprodutivo (Vazzoler, 1996), pois trata-se da subtração do fator de condição (K) (item IV.2B) pelo fator de condição somático (K') calculado pelo peso corporal menos o peso gonadal.

Foi calculado para as fêmeas adultas, por estádio de maturidade, por época de coleta e utilizando-se as fórmulas abaixo apresentadas:

$$
\Delta \mathrm{K}=\mathrm{K}-\mathrm{K}^{\prime} \text { onde, } \mathrm{K}^{\prime}=\mathrm{W}_{\mathrm{c}} / \mathrm{Cp}^{\mathrm{b}} * \mathbf{1 0}^{4}
$$

$\mathrm{b}=$ coeficiente angular da regressão linear dos dados logaritmizados obtidos da relação peso comprimento (Item IV.2b). 


\section{2e: Histologia das gônadas:}

Usando a metodologia sugerida por Vazzoler (1996) foram montadas preparações permanentes de cortes de ovários e testículos. Este detalhamento teve o objetivo de verificar a acuidade da classificação macroscópica dos estádios de maturidade gonadal.

O número de gônadas examinadas variou entre os lances de pesca, procurando-se realizar, pelo menos, três preparações para cada estádio de maturidade encontrado.

Por meio da análise dos cortes foi confirmado o sexo e, no caso das fêmeas, verificadas as fases do desenvolvimento ovocitário, sendo os ovócitos classificados segundo a escala de Vazzoler (op. cit.).

Nos cruzeiros IV e V uma amostra de peixes de cada um dos lances de pesca foi fixada em solução de formaldeído a $4 \%$ logo que coletada, a fim de preservar melhor as células e estruturas ovarianas. Além disso, alguns espécimes tiveram suas gônadas classificadas a bordo, as quais, logo em seguida foram fixadas. Este material recebeu o mesmo tratamento para a montagem das preparações permanentes conforme indicado acima. 


\section{3 RESULTADOS E DISCUSSÃO:}

\section{IV.3a: Captura e composição da população:}

A captura em peso de Maurolicus stehmanni durante os cruzeiros I, II e III foi de 949.563g, correspondendo ao total estimado de 1,5 milhões de peixes. A maior captura (em número e peso) ocorreu no outono de 1997 (cruzeiro II), seguida da primavera de 1997 (cruzeiro III). Porém, o número de lances de pesca com a presença de $M$. stehmanni foi maior na primavera (18) do que no outono (15), Assim, a captura de M. stehmanni por lance de pesca foi, em média, maior no outono. Em relação à captura de inverno, não foi possível realizar comparações devido à falta do sobressaco ao aparato de pesca (tabela IV.1.).

Tabela IV.1. Captura e tamanho da amostra de Maurolicus stehmanni referente aos cruzeiros I, II e III (inverno de 1996, outono de 1997 e primavera de 1997, respectivamente). Na - número de exemplares amostrados; Nc - número estimado de indivíduos capturados; $\mathrm{P}$ - peso total capturado; $\mathrm{Nl}$ - número de lances com ocorrência de $M$. stehmanni. * Ausência de sobressaco ao aparato de pesca.

\begin{tabular}{|c|cccc|}
\hline & $\begin{array}{c}\text { Cruzeiro I* } \\
\text { Inverno/96 }\end{array}$ & $\begin{array}{c}\text { Cruzeiro II } \\
\text { Outono/97 }\end{array}$ & $\begin{array}{c}\text { Cruzeiro III } \\
\text { Primavera/97 }\end{array}$ & Total \\
\hline $\mathrm{Na}$ & 1684 & 1926 & 2522 & 6132 \\
\hline $\mathrm{Nc}$ & 46084 & 779847 & 581144 & 1407075 \\
\hline $\mathrm{P}(\mathrm{g})$ & 33107 & 506149 & 410307 & 949563 \\
\hline $\mathrm{Nl}$ & 10 & 15 & 18 & 43 \\
\hline $\mathrm{P} / \mathrm{Nl}$ & 4608 & 51990 & 32286 & 32723 \\
\hline $\mathrm{Nc} / \mathrm{Nl}$ & 3311 & 33743 & 22795 & 22083 \\
\hline
\end{tabular}

Na figura IV.1. está representada a composição em comprimento de M. stehmanni para os três cruzeiros em conjunto. A amplitude de comprimento padrão foi de 12 a $50 \mathrm{~mm}$, observando-se duas modas, em 34 e 44mm.

Em relação à distribuição de freqüência de classes de comprimento padrão (DFCC) por cruzeiro (figura IV.2.): a maior amplitude de tamanhos ocorreu no outono (12 a 50mm), ao passo que, nos cruzeiros de inverno e primavera os limites máximos e mínimos foram iguais, sendo de 14 e $48 \mathrm{~mm}$, respectivamente.

Conforme representado na figura IV.2., no inverno verificou-se que o valor modal ficou na classe de comprimento de $36 \mathrm{~mm}$, com esta classe representando cerca de $30 \%$ da amostragem. No outono constatou-se 2 modas em 34 e em $44 \mathrm{~mm}$, classes de comprimento 


\section{Total}

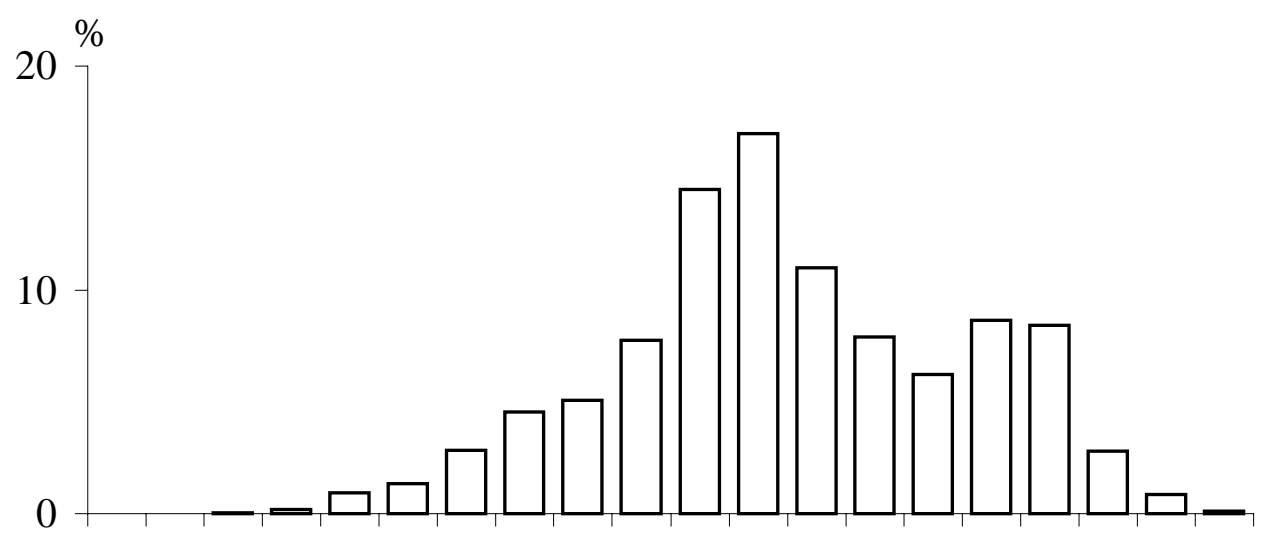

1214161820222426283032343638404244464850

$\mathrm{CP}(\mathrm{mm})$

Figura IV.1. Distribuição de freqüência de classes de comprimento padrão (Cp) de M. stehmanni para os cruzeiros I, II e III em conjunto.

que representaram cerca de 20 e $8 \%$ do total capturado, respectivamente. Na primavera os valores modais nas classes de 30 e $40 \mathrm{~mm}$ de comprimento representaram menos que $15 \%$ da captura total.

Em relação às distribuições de frequiência de classes de comprimento, por lance de pesca (figuras IV.3, IV.4. e IV.5.), verificou-se que:

- A maior parte dos cardumes apresentou exemplares distribuídos em poucas classes de comprimentos (pequena amplitude), com valores modais variáveis.

- No inverno, ao norte da área de estudo, os dois lances efetuados eram compostos de peixes grandes com pouca variação em comprimento, ficando o valor modal em $36 \mathrm{~mm}$, valor que representou quase $50 \%$ da captura. $\mathrm{Na}$ área central, em geral, as amplitudes de comprimento dos peixes foram maiores e mais variadas, os cardumes eram constituídos ora de peixes de tamanhos grandes, ora de peixes de tamanhos menores. Os cardumes amostrados na região sul apresentaram maior amplitude de comprimento, com peixes de tamanho pequeno, intermediário e grande (figura IV.3.).

- No outono, próximo a Cabo Frio, os cardumes foram compostos de peixes grandes, dois deles apresentaram maior amplitude de comprimento e peixes de tamanho intermediário. Entre Santos e Cabo de Santa Marta ocorreram cardumes com peixes distribuídos em poucas classes de comprimento, com peixes de tamanho grande ou pequeno e cardumes com peixes distribuídos em várias classes de comprimento. Abaixo do Cabo de Santa Marta os cardumes foram compostos de peixes de tamanhos intermediários e pequenos, distribuídos em poucas classes de comprimento (figura IV.4.).

- Na primavera, entre Cabo Frio e Santos ocorreram dois lances com peixes 

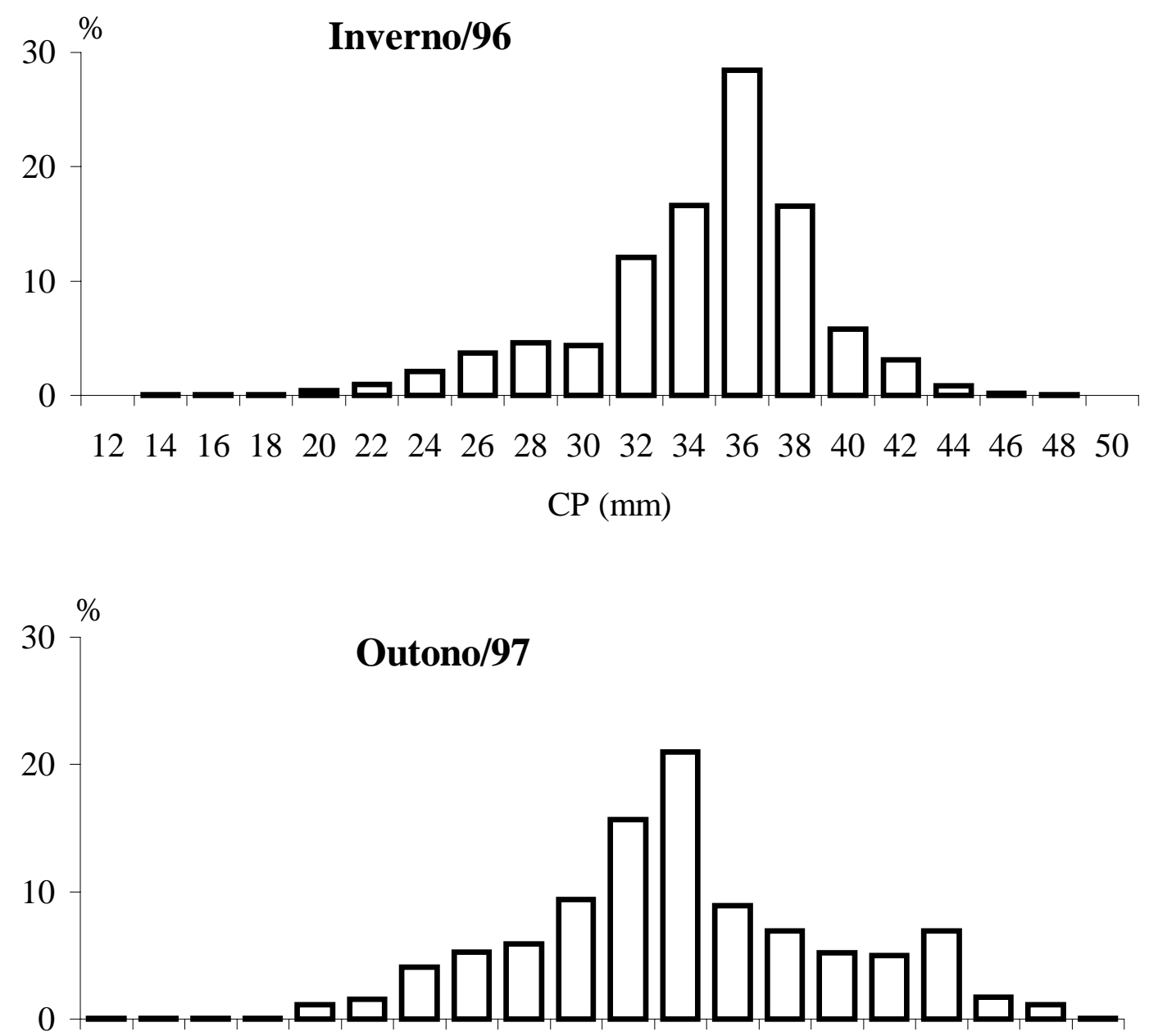

$\begin{array}{llllllllllllllllllll}12 & 14 & 16 & 18 & 20 & 22 & 24 & 26 & 28 & 30 & 32 & 34 & 36 & 38 & 40 & 42 & 44 & 46 & 48 & 50\end{array}$ $\mathrm{CP}(\mathrm{mm})$

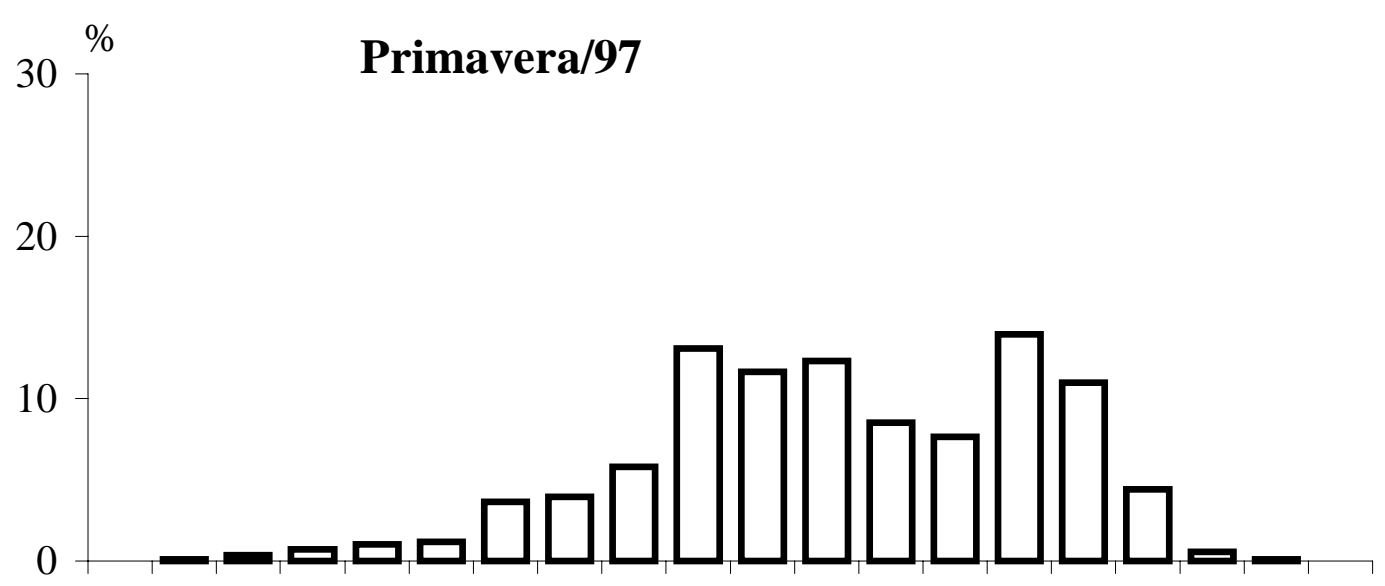

$\begin{array}{llllllllllllllllllll}12 & 14 & 16 & 18 & 20 & 22 & 24 & 26 & 28 & 30 & 32 & 34 & 36 & 38 & 40 & 42 & 44 & 46 & 48 & 50\end{array}$ $\mathrm{CP}(\mathrm{mm})$

Figura IV.2. Distribuição de freqüência de classes de comprimento padrão $(C p)$ de M. stehmanni para as três épocas de estudo. 
Inverno 96
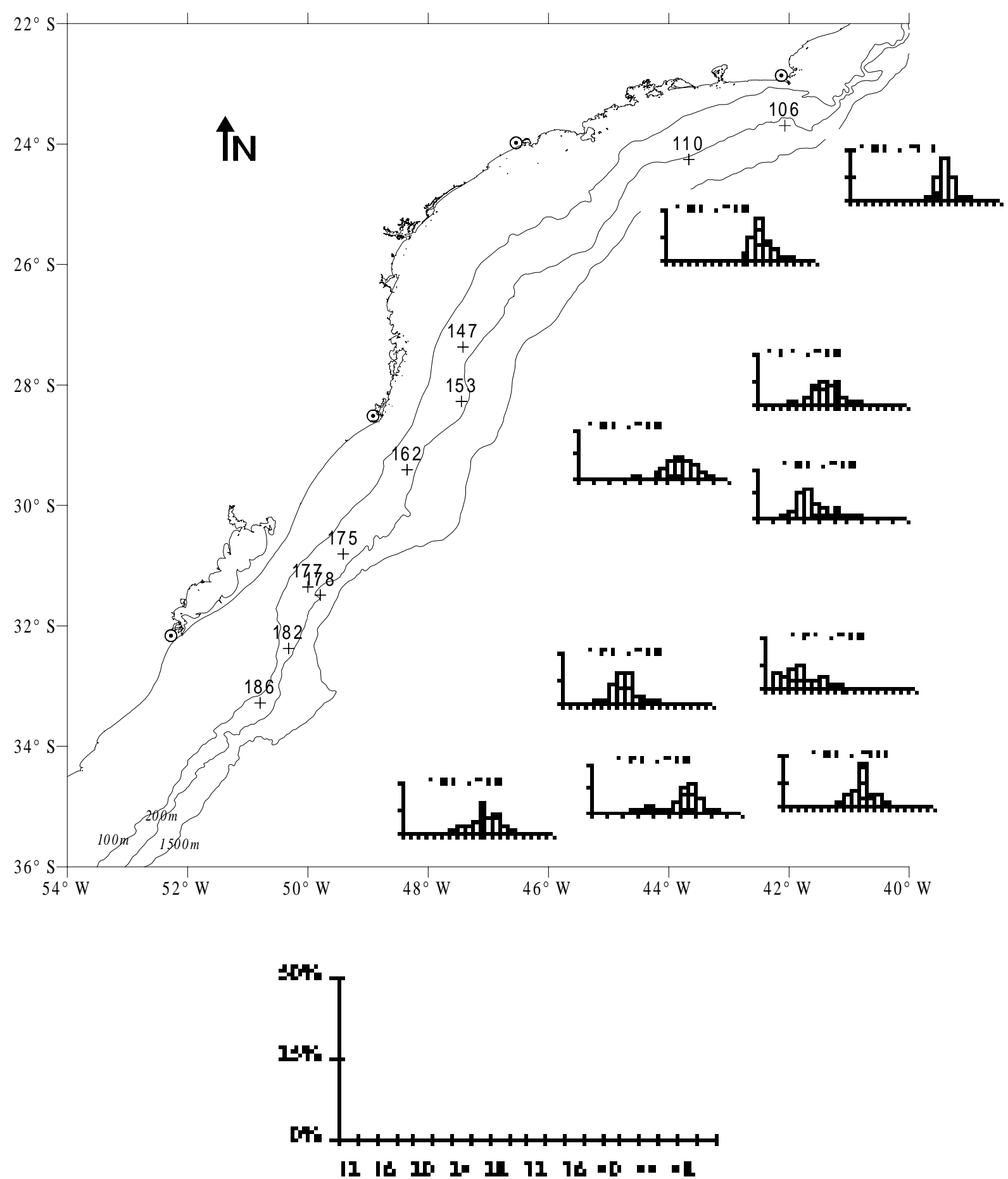

Figura IV.3. Distribuição de freqüência de classes de comprimento padrão $(\mathrm{Cp})$ de $M$. stehmanni, por lance de pesca, para o inverno de 1996. 

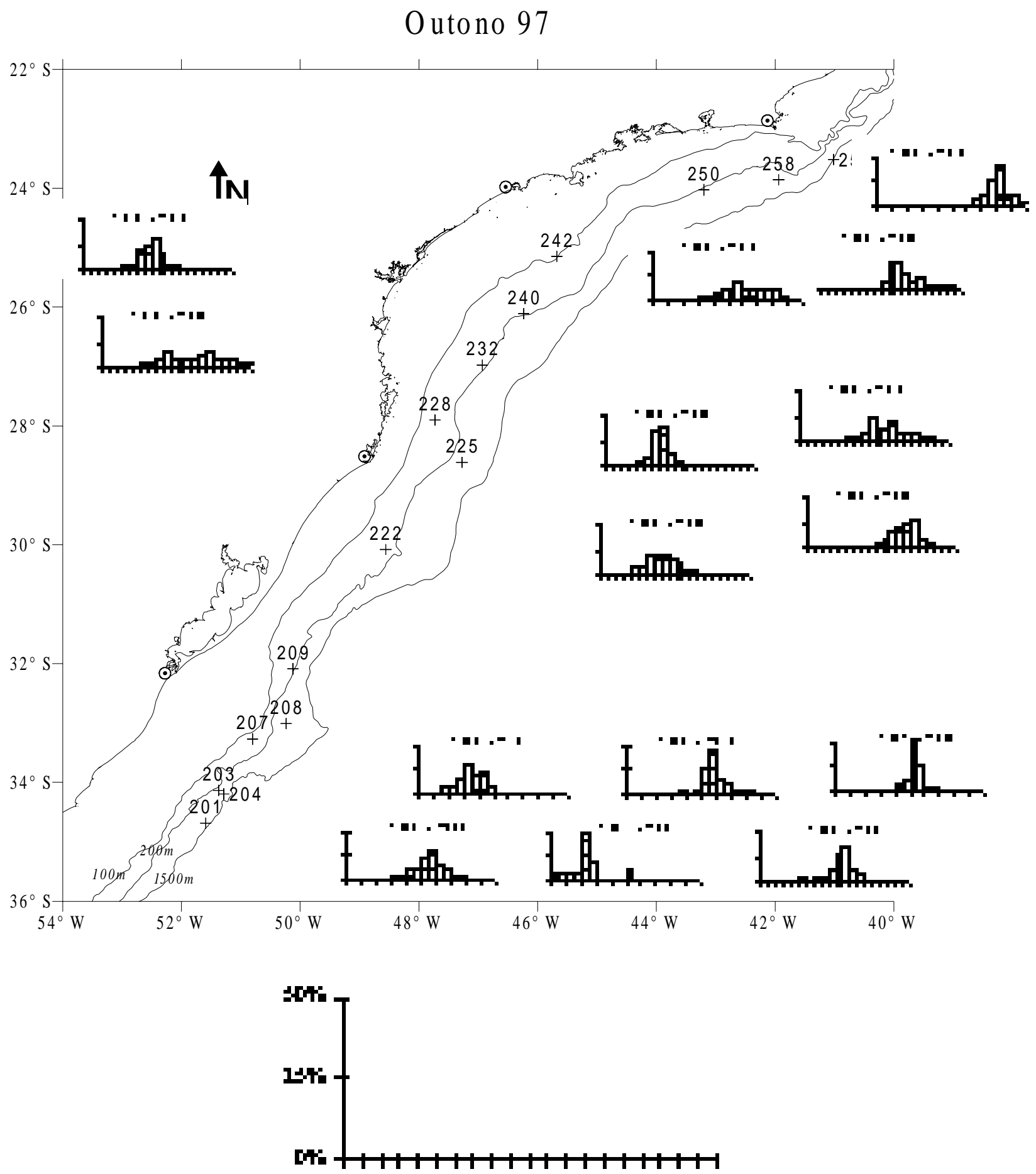

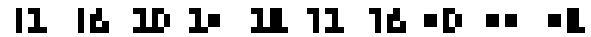

Figura IV.4. Distribuição de freqüência de classes de comprimento padrão $(C p)$ de $M$. stehmanni, por lance de pesca, para o outono de 1997. 


\section{Prim avera 97}
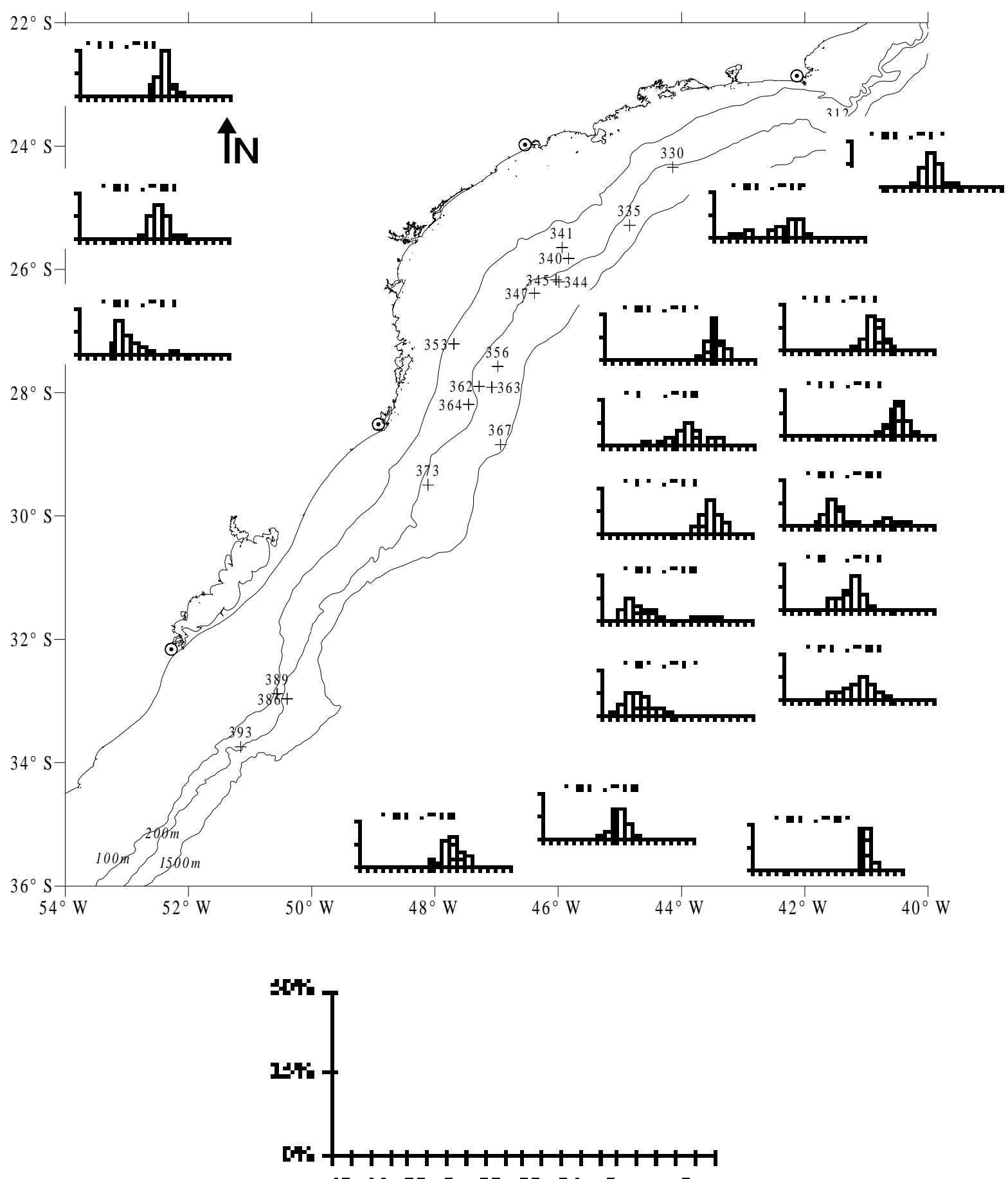

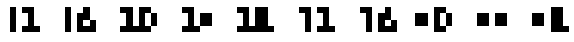

Figura IV.5. Distribuição de freqüência de classes de comprimento padrão $(C p)$ de $M$. stehmanni, por lance de pesca, para a primavera de 1997. 
distribuídos por várias classes de comprimento (moda em 32mm). Entre Santos e Cabo de Santa Marta a variação foi grande: oito capturas tiveram peixes com comprimentos variados com uma moda clara e foram compostos por peixes com tamanhos pequenos, intermediários e grandes. Por outro lado, cinco lances apresentaram até 15 classes de comprimento, predominando ora peixes de tamanho pequeno, ora de tamanho intermediário. Ao sul, abaixo do Cabo de Santa Marta, os cardumes eram constituídos de peixes grandes e com ampla distribuição de classes de comprimento (figura IV.5.).

De uma maneira geral, nos três cruzeiros observou-se que no norte (próximo a Cabo Frio) os cardumes eram compostos de peixes maiores e distribuídos em um número menor de classes de comprimento, sendo que na primavera também ocorreram alguns peixes pequenos; na área central ocorreram cardumes com peixes pequenos, intermediários e grandes, com amplitudes de comprimento maiores e no extremo sul, próximo a Rio Grande, no inverno e primavera os cardumes eram compostos de peixes com tamanhos grandes, enquanto que no outono a captura maior foi de peixes de tamanho intermediário.

Em relação à composição dos cardumes em comprimento, quanto à profundidade do local de captura, constatou-se que sobre a PC, antes da isóbata de $200 \mathrm{~m}$, foram capturados peixes de tamanhos pequenos, médios e grandes, tanto no outono como no inverno, ao passo que na primavera ocorreram apenas peixes de tamanhos grandes e intermediários (figuras IV.3, 4 e 5).

Na tabela IV.2. apresenta-se a proporção sexual dos exemplares capturados em cada lance de pesca, nos três cruzeiros realizados e o resultado do teste $\mathrm{x}^{2}$. Dos 40 lances de pesca, em apenas 8 cardumes houve uma proporção significativamente diferente de 1:1 (p= 0,05), não tendo sido constado qualquer padrão espaço-temporal na distribuição de machos e fêmeas.

No entanto, Rasmussen \& Giske (1994) estudando M. muelleri na Noruega; Prosch (1991) na África do Sul; Dalpadado \& Gjøsæter (1987) no Mar Vermelho; Young et al. (1987) na Tasmânia e Clarke (1982) na Austrália verificaram a existência de um número significativamente maior de fêmeas do que de machos. É importante lembrar que as áreas estudadas por estes autores não foram tão extensas como a do presente estudo.

Prosch (op. cit.) encontrou uma razão de 1,2:1 entre fêmeas e machos e sugeriu que esta diferença poderia estar relacionada com uma estratificação sexual, onde as fêmeas realizariam uma migração (noturna) mais próxima à superfície no verão. Young et al. (op. cit.) verificaram que vários lances de pesca de peixes mesopelágicos continham apenas machos, ou apenas fêmeas, sugerindo a existência de uma segregação sexual espacial. Hunter \& Goldberg (1980) verificaram que os cardumes de Engraulis mordax, pequeno pelágico que habita a costa oeste da América do Norte, apresentavam dominância de machos no momento da desova. Este fato não foi observado para Maurolicus stehmanni, talvez em razão de não terem sido amostrados peixes no momento da desova, pois não foram capturadas fêmeas hidratadas. 
Tabela IV.2. Valores numéricos e proporção sexual de peixes adultos de M. stehmanni, por lance de pesca e época do ano. * - Lances de pesca com proporção sexual significativamente diferente de $1: 1(p=0,05)$.

\begin{tabular}{|c|c|c|c|c|c|c|c|c|}
\hline & Lance & $\mathrm{N}$ machos & $\mathrm{N}$ fêmeas & $\%$ machos & \% fêmeas & $X^{2}$ & $X^{2}$ & RazãoF/M \\
\hline \multirow{7}{*}{$\begin{array}{l}\text { I } \\
\mathbf{n} \\
\mathbf{v} \\
\mathrm{e} \\
\mathbf{r} \\
\mathbf{n} \\
\mathbf{o}\end{array}$} & 106 & 78 & 63 & 55,3 & 44,7 & 1,60 & & \\
\hline & 110 & 76 & 77 & 49,7 & 50,3 & 0,01 & & \\
\hline & 147 & 22 & 9 & 71,0 & 29,0 & 5,45 & $*$ & 0,41 \\
\hline & 153 & 73 & 71 & 50,7 & 49,3 & 0,03 & & \\
\hline & 162 & 0 & 2 & 0,0 & 100,0 & & & \\
\hline & 178 & 39 & 44 & 47,0 & 53,0 & 0,30 & & \\
\hline & 186 & 4 & 2 & 66,7 & 33,3 & 0,67 & & \\
\hline \multirow{13}{*}{$\begin{array}{l}\mathbf{O} \\
\mathbf{u} \\
\mathbf{t} \\
\mathbf{0} \\
\mathbf{n} \\
\mathbf{0}\end{array}$} & 259 & 17 & 33 & 34,0 & 66,0 & 5,12 & $*$ & 1,94 \\
\hline & 258 & 23 & 21 & 52,3 & 47,7 & 0,09 & & \\
\hline & 250 & 33 & 15 & 68,8 & 31,3 & 6,75 & $*$ & 0,45 \\
\hline & 242 & 2 & 7 & 22,2 & 77,8 & 2,78 & & \\
\hline & 240 & 24 & 14 & 63,2 & 36,8 & 2,63 & & \\
\hline & 232 & 10 & 19 & 34,5 & 65,5 & 2,79 & & \\
\hline & 228 & 18 & 7 & 72,0 & 28,0 & 4,84 & $*$ & 0,39 \\
\hline & 225 & 28 & 22 & 56,0 & 44,0 & 0,72 & & \\
\hline & 222 & 13 & 13 & 50,0 & 50,0 & 0,00 & & \\
\hline & 209 & 29 & 21 & 58,0 & 42,0 & 1,28 & & \\
\hline & 207 & 8 & 4 & 66,7 & 33,3 & 1,33 & & \\
\hline & 203 & 23 & 14 & 62,2 & 37,8 & 2,19 & & \\
\hline & 201 & 7 & 6 & 53,8 & 46,2 & 0,08 & & \\
\hline \multirow{18}{*}{$\begin{array}{l}\mathbf{P} \\
\mathbf{r} \\
\mathbf{i} \\
\mathbf{m} \\
\mathbf{a} \\
\mathbf{v} \\
\mathbf{e} \\
\mathbf{r} \\
\mathbf{a}\end{array}$} & 312 & 11 & 18 & 37,9 & 62,1 & 1,69 & & \\
\hline & 330 & 13 & 10 & 56,5 & 43,5 & 0,39 & & \\
\hline & 335 & 29 & 28 & 50,9 & 49,1 & 0,02 & & \\
\hline & 340 & 7 & 49 & 12,5 & 87,5 & 31,50 & $*$ & 7,00 \\
\hline & 341 & 14 & 7 & 66,7 & 33,3 & 2,33 & & \\
\hline & 344 & 24 & 16 & 60,0 & 40,0 & 1,60 & & \\
\hline & 345 & 30 & 29 & 50,8 & 49,2 & 0,02 & & \\
\hline & 347 & 26 & 33 & 44,1 & 55,9 & 0,83 & & \\
\hline & 353 & 26 & 28 & 48,1 & 51,9 & 0,07 & & \\
\hline & 356 & 11 & 11 & 50,0 & 50,0 & 0,00 & & \\
\hline & 362 & 5 & 9 & 35,7 & 64,3 & 1,14 & & \\
\hline & 363 & 4 & 3 & 57,1 & 42,9 & 0,14 & & \\
\hline & 364 & 6 & 4 & 60,0 & 40,0 & 0,40 & & \\
\hline & 367 & 3 & 0 & 100,0 & 0,0 & & & \\
\hline & 373 & 9 & 25 & 26,5 & 73,5 & 7,53 & $*$ & 2,78 \\
\hline & 386 & 18 & 33 & 35,3 & 64,7 & 4,41 & $*$ & 1,83 \\
\hline & 389 & 1 & 17 & 5,6 & 94,4 & 14,22 & $*$ & 17,00 \\
\hline & 393 & 3 & 4 & 42,9 & 57,1 & 0,14 & & \\
\hline
\end{tabular}


Quanto à proporção sexual por classes de comprimento padrão $(\mathrm{Cp})$, devido à dificuldade na identificação do sexo dos peixes jovens, o número de exemplares pequenos foi reduzido. Observou-se oscilação de valores em torno de $50 \%$ de adultos, sem um padrão definido, até os $48 \mathrm{~mm}$, quando ocorreram apenas fêmeas (figura IV.6.).

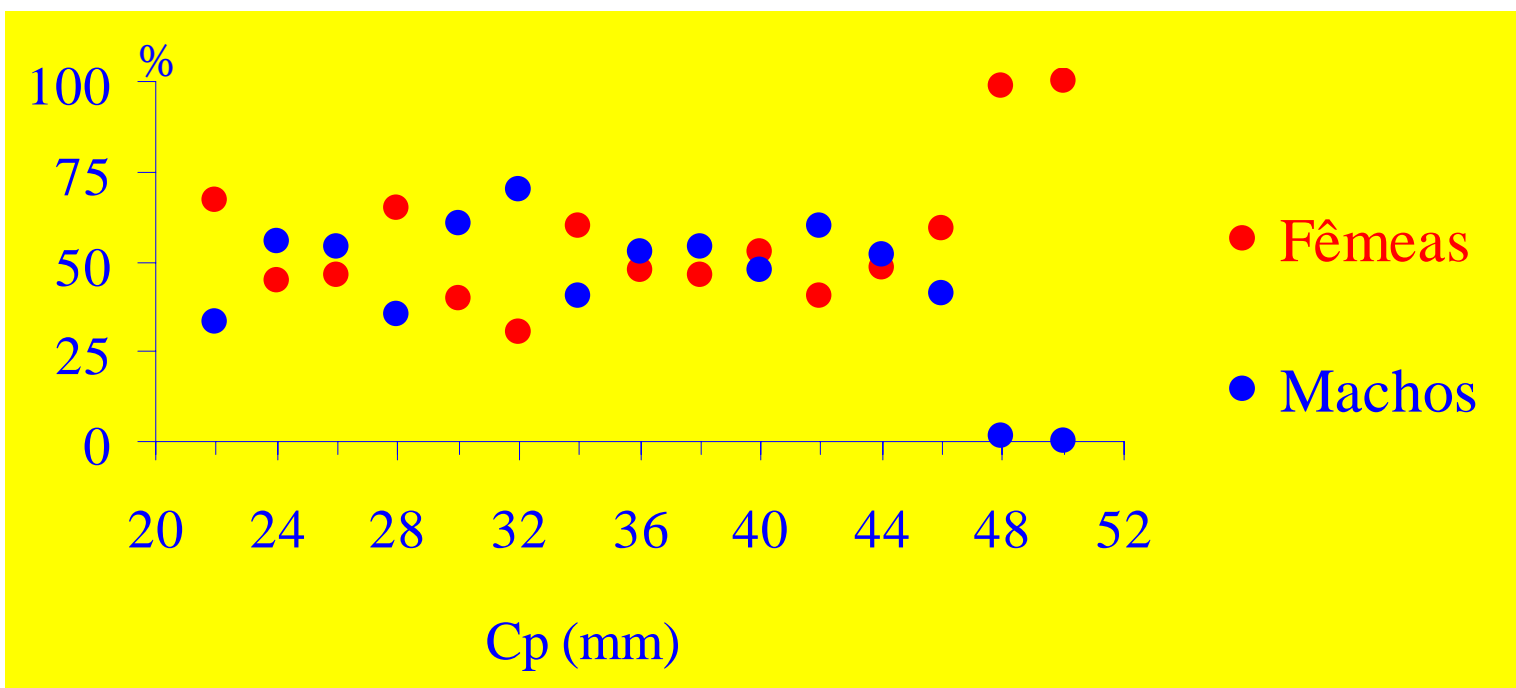

Figura IV.6. Porcentagem de machos e fêmeas de M. stehmanni, por classe de comprimento padrão $(\mathbf{C p})$.

A observação de que a partir de um determinado tamanho só ocorrem fêmeas é corroborada pelos estudos de Rasmussen \& Giske (1994); Prosch (1991); Young et al. (1987); e Dalpadado \& Gjøsæter (1987) para diferentes espécies de Maurolicus. Rasmussen \& Giske (op. cit.) atribuem este fato a uma maior taxa de mortalidade dos machos, que apresentam padrões de crescimento diferentes das fêmeas.

A proporção entre jovens e adultos para cada uma das épocas de coleta está representada na figura IV.7, constatando-se a ocorrência de peixes jovens e adultos nos três períodos, embora a proporção de peixes jovens tenha sido menor no outono (26\%) e maior na primavera $(38 \%)$, sugerindo que houve recrutamento nas três épocas.

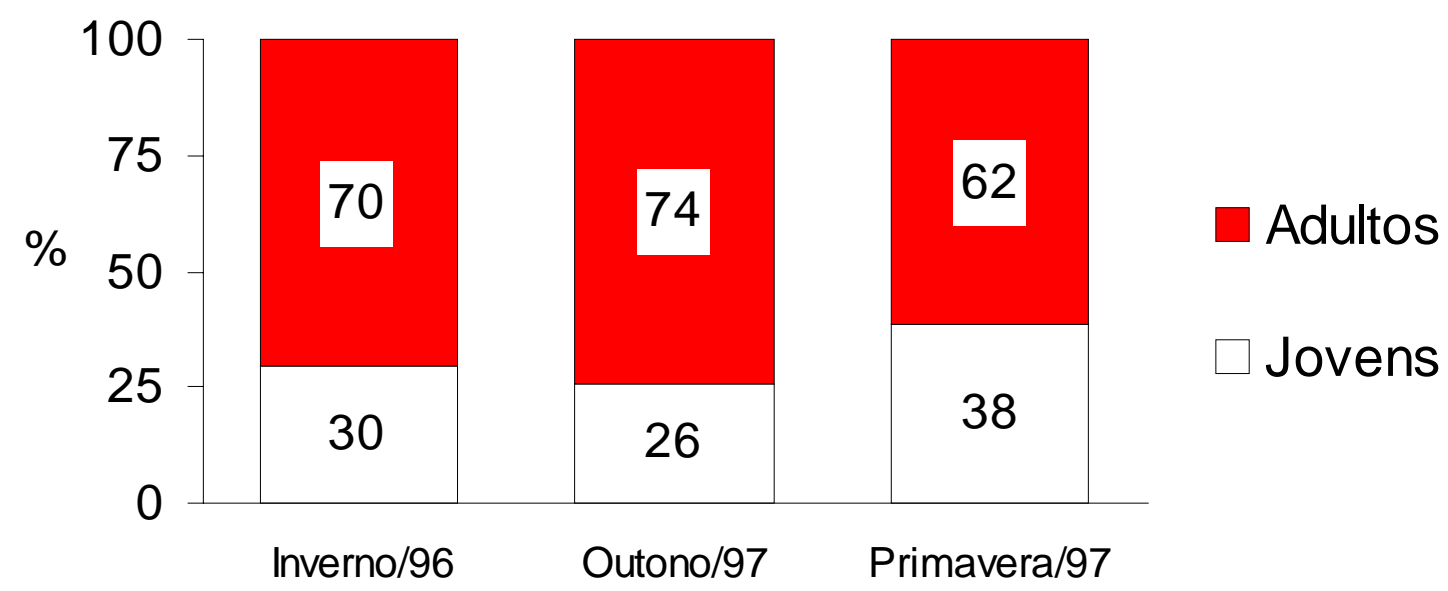

Figura IV.7. Proporção entre jovens e adultos de Maurolicus stehmanni por época de coleta. 
Nas figuras IV.8, IV.9 e IV.10 estão representadas as proporções entre jovens e adultos por lance de pesca, em cada um dos períodos. Verificou-se que:

- Acima de Santos houve predomínio de peixes adultos nas três épocas, embora na primavera tenham ocorrido peixes jovens.

- No inverno, abaixo de Santos, predominaram peixes jovens, com exceção de dois lances (\#153 e \#178).

- No outono e na primavera predominaram ora peixes jovens, ora adultos ao longo da área.

- Em relação à profundidade, entre os 100 e 200 m, no inverno e no outono houve predomínio de jovens, enquanto que na primavera, as poucas capturas foram de adultos. Após os 200 m não houve predominância de nenhum dos grupos.

Vale ressaltar que nos cruzeiros de outono e primavera foi acrescentado ao aparato de pesca um sobressaco, o que poderia explicar a menor captura de peixes pequenos e jovens no inverno.

\section{3b: Relação entre o peso total e o comprimento padrão (Wt/Cp)}

Os valores dos coeficientes (a e b) das regressões Wt/Cp, obtidos para machos e fêmeas, foram comparados, não tendo sido verificadas diferenças significativas. Assim, o cálculo da relação peso/comprimento foi feito para todos os indivíduos, obtendo-se os valores de $\mathbf{b}=$ 2,8877, de $\mathbf{a}=2,3 \times 10^{-5}$ e, do coeficiente de correlação $\left(\mathrm{r}^{2}\right)=0,963$ (figura IV.11.).

A tabela IV.3. apresenta os valores dos parâmetros das regressões entre o peso total e o comprimento padrão para as três épocas, além do valor de $\mathrm{r}^{2}$. O teste $\mathrm{F}$, utilizado para comparar os parâmetros obtidos para cada uma das épocas, apontou diferenças significativas. $\mathrm{Na}$ figura IV.12. apresentam-se as curvas obtidas, verificando-se que para os peixes com comprimentos padrão menores que $35 \mathrm{~mm}$ as diferenças praticamente não existem. Entretanto, a partir dos $35 \mathrm{~mm}$ observa-se tendência diferente entre as curvas. Assim, um peixe de $50 \mathrm{~mm}$ teve, em média um peso de $1,9 \mathrm{~g}$ na primavera, $1,8 \mathrm{~g}$ no inverno e $1,75 \mathrm{~g}$ no outono.

Tabela IV.3. Parâmetros (a e b) da relação Wt/Cp e o coeficiente de determinação $\mathbf{r}^{2}$, para as épocas de coleta.

\begin{tabular}{|c|ccc|}
\hline & Inverno & Outono & Primavera \\
\hline $\mathbf{a}$ & $2,49 \times 10^{-5}$ & $4,02 \times 10^{-5}$ & $1,76 \times 10^{-5}$ \\
\hline $\mathbf{b}$ & 2,862 & 2,729 & 2,966 \\
\hline $\mathbf{r}^{\mathbf{2}}$ & 0,962 & 0,946 & 0,971 \\
\hline
\end{tabular}

Haimovici \& Velasco (2000) estimaram os parâmetros da relação entre o peso total e o comprimento total para Maurolicus capturado em arrastos de fundo, na região sul da ZEE brasileira, obtendo um valor de $\mathbf{b}$ mais elevado $(3,96)$ e de a menor $\left(1,79 \times 10^{-7}\right)$ do que os 


\section{Inverno 96}

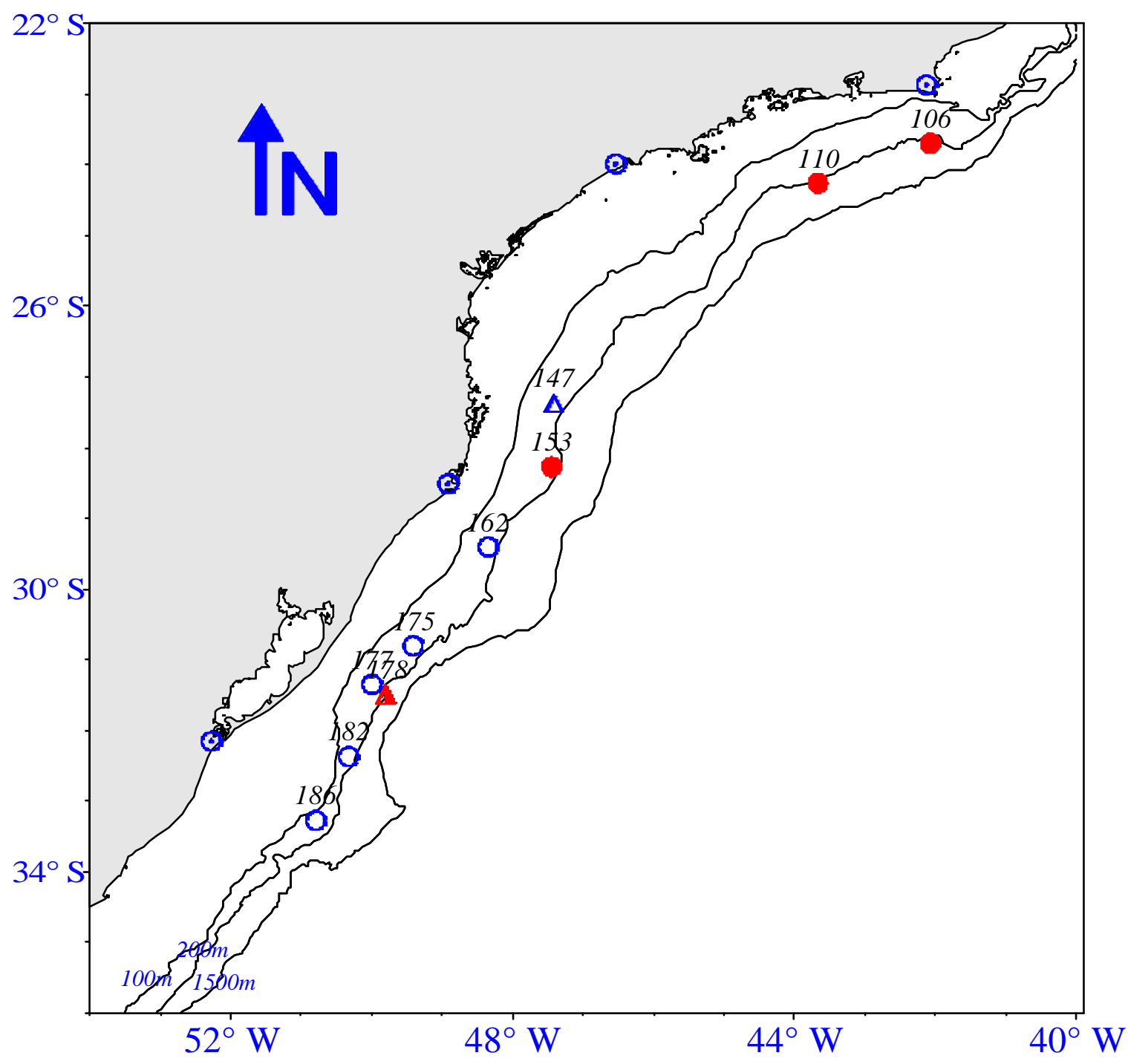

Proporção de adultos

O entre 0.0 e $19.9 \%$

$\Delta$ entre 20.0 e $39.9 \%$

$\Delta$ entre 40.0 e $59.9 \%$

- entre 60.0 e $79.9 \%$

- entre 80.0 e $100.0 \%$

Figura IV.8. Proporção de peixes adultos de Maurolicus stehmanni, por lance de pesca, para o inverno de 1996. 
Outono 97

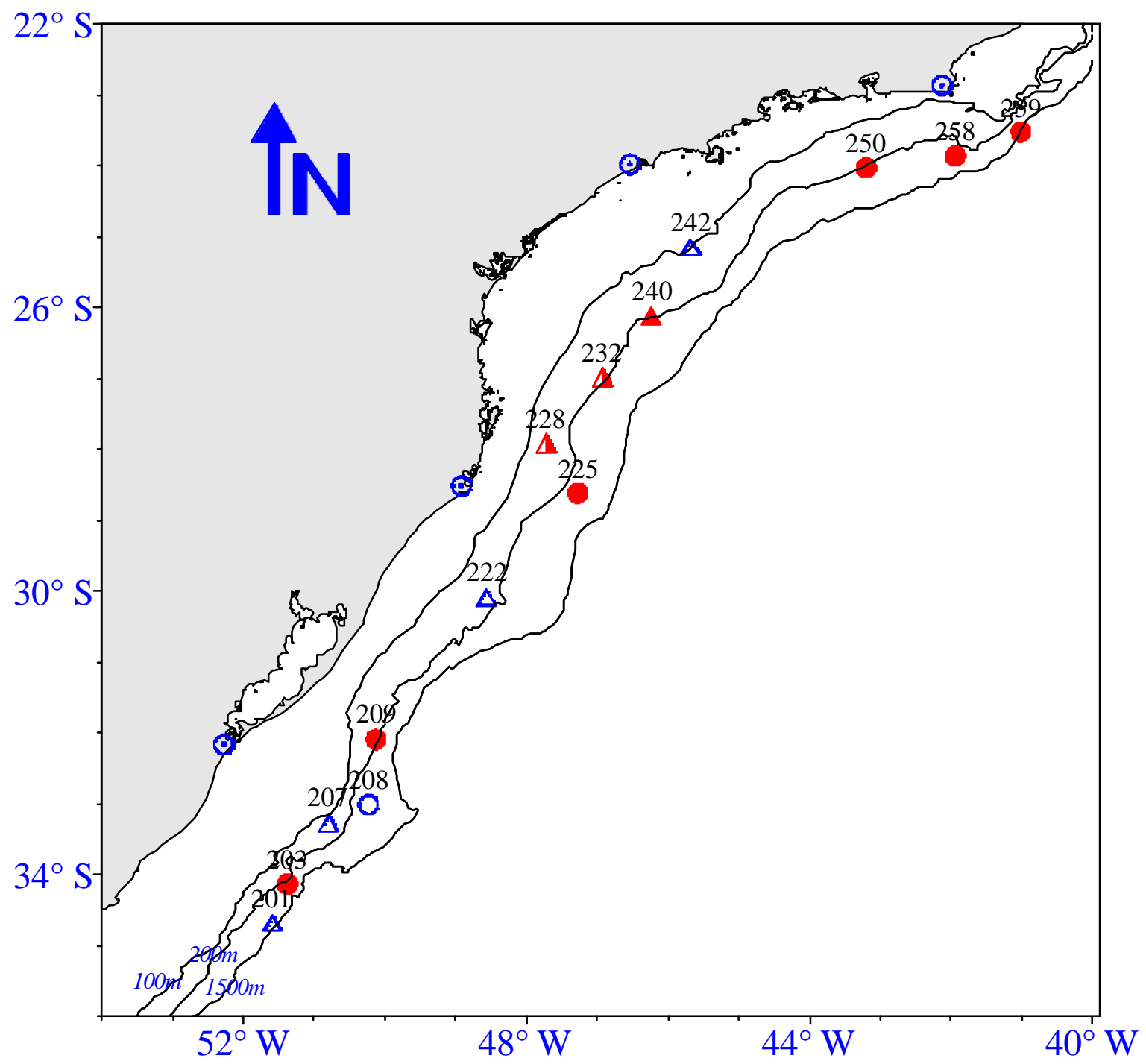

Proporção de adultos

o entre 0.0 e $19.9 \%$

$\Delta$ entre 20.0 e $39.9 \%$

$\Delta$ entre 40.0 e $59.9 \%$

$\Delta$ entre 60.0 e $79.9 \%$

- entre 80.0 e $100.0 \%$

Figura IV.9. Proporção de peixes adultos de Maurolicus stehmanni, por lance de pesca, para o outono de 1997. 


\section{Primavera 97}

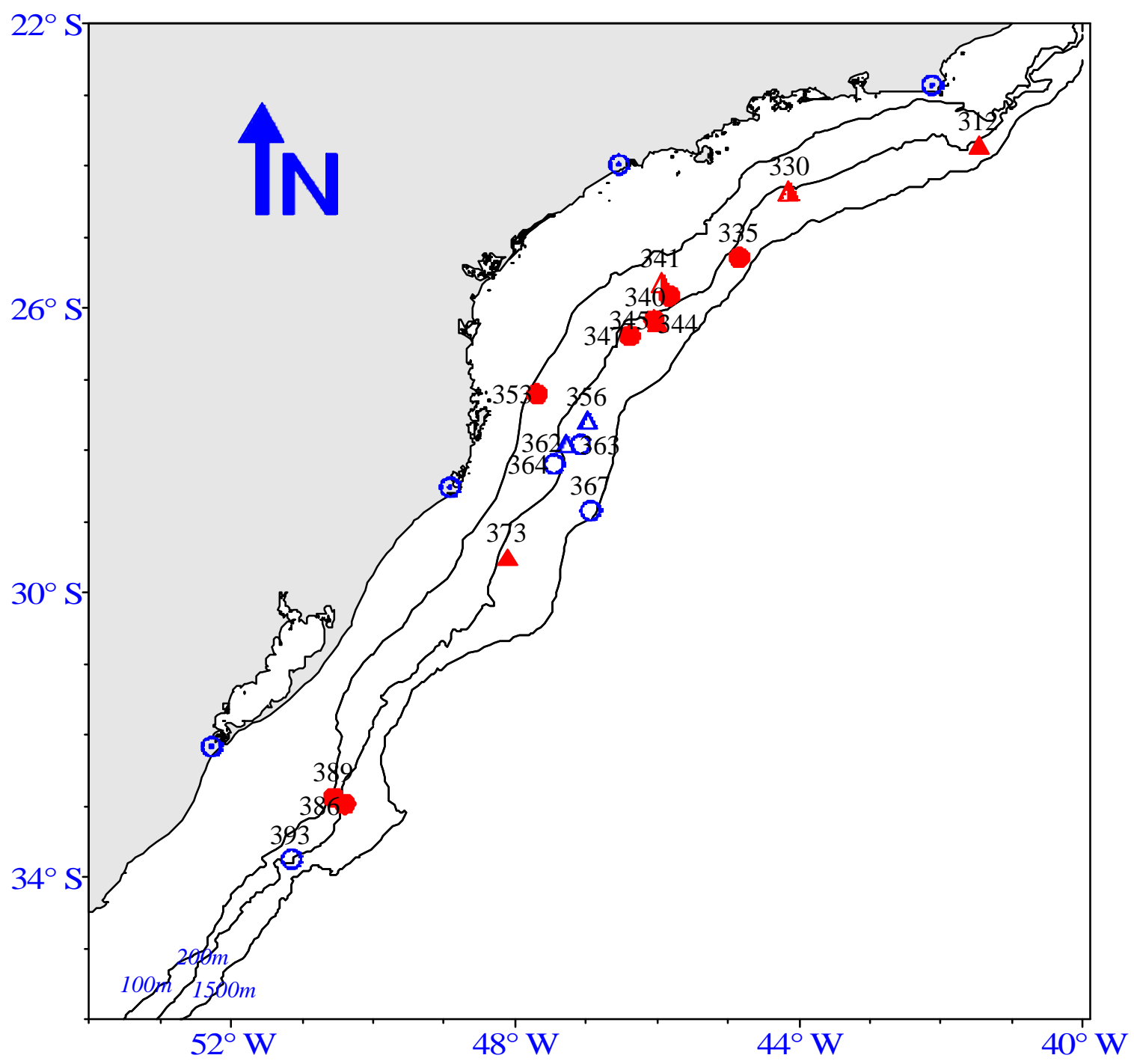

\section{Proporção de adultos}

O entre 0.0 e $19.9 \%$

$\Delta$ entre 20.0 e $39.9 \%$

$\Delta$ entre 40.0 e $59.9 \%$

$\triangle$ entre 60.0 e $79.9 \%$

- entre 80.0 e $100.0 \%$

Figura IV.10. Proporção de peixes adultos de Maurolicus stehmanni, por lance de pesca, para a primavera de 1997. 


\section{Peso total X Comprimento padrão}

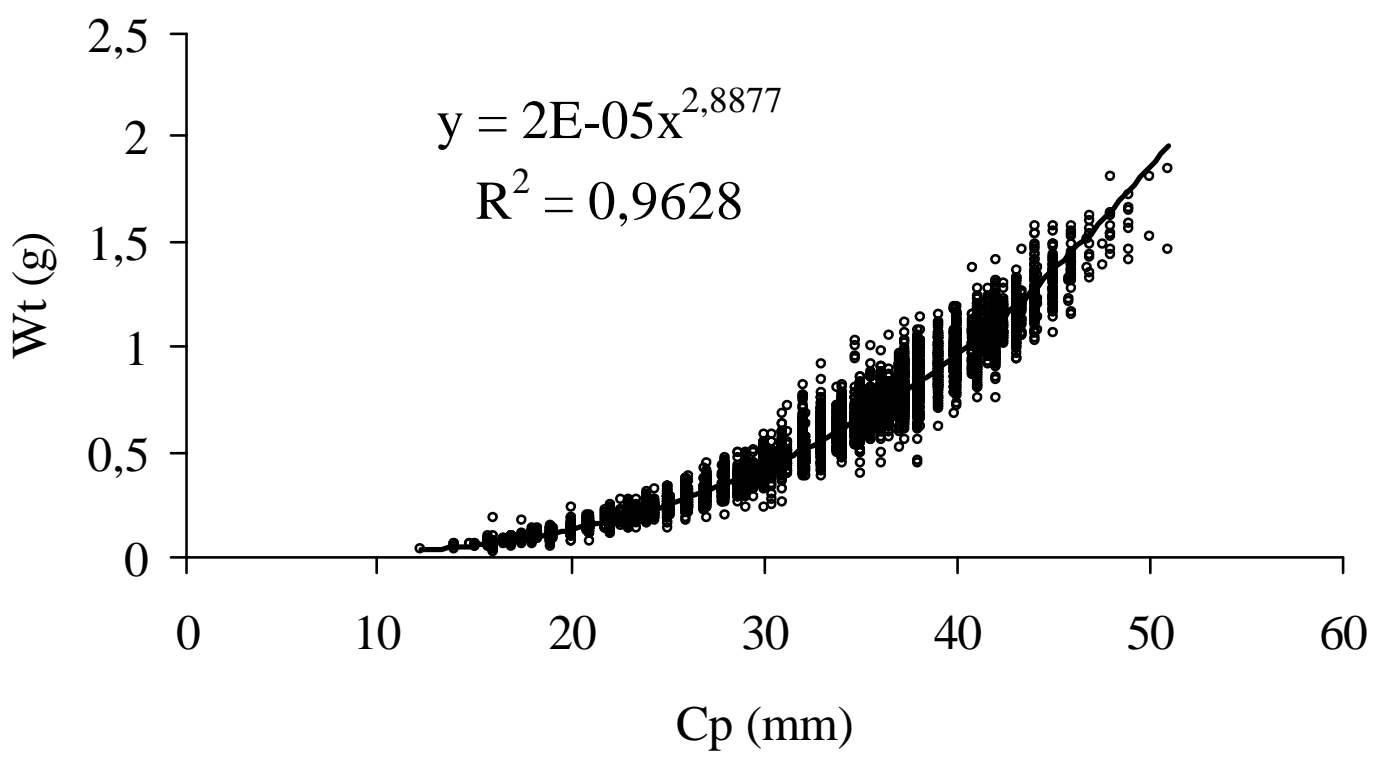

Figura IV.11. Valores de peso total (Wt) e comprimento padrão (Cp) de M. stehmanni. A equação representa a relação entre estas variáveis.

\section{Wt x Cp por época}

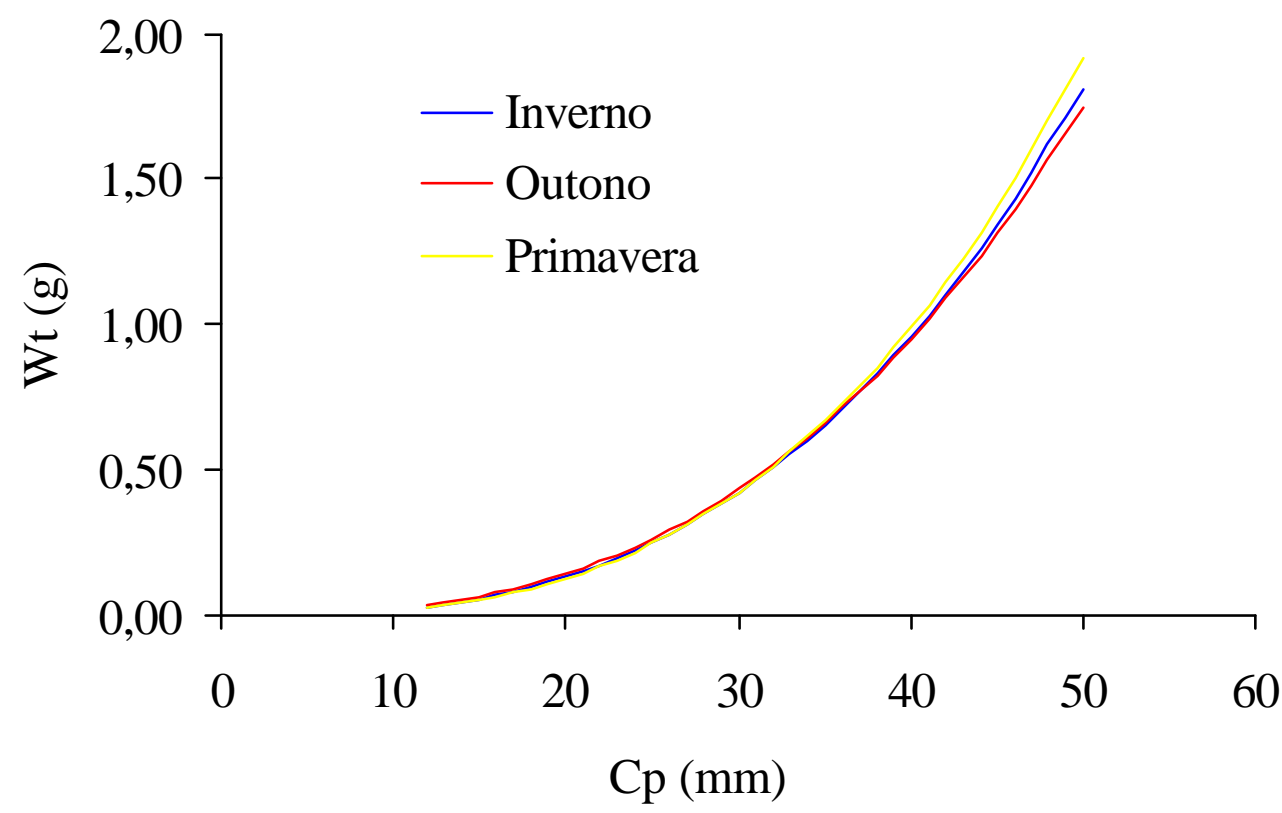

Figura IV.12. Representação gráfica das curvas das relações entre o peso total (Wt) e o comprimento padrão (Cp) de M. stehmanni, por época do ano. 
valores obtidos no presente trabalho. Apesar do elevado coeficiente de determinação encontrado por estes autores $(0,92)$, a comparação com os resultados do presente estudo não é aconselhável, devido ao pequeno número de indivíduos utilizados naquela análise (43) e a pequena amplitude de comprimento (39 a $43 \mathrm{~mm}$ ). Por outro lado, Haimovici \& Velasco (2000) usaram para cálculo o valor de comprimento total e não do comprimento padrão.

A literatura apresenta a relação entre o peso o comprimento para espécies de Maurolicus apenas para o Atlântico Norte, mais especificamente para o Mar da Noruega e os fiordes noruegueses. Gjøsæter (1981) encontrou valores de b diferentes para as coletas realizadas em mar aberto (3,33 - primavera) e dentro de fiordes (2,42 - primavera e 2,97 - outono), sendo os valores de a obtidos da ordem de $10^{-5}$. Rasmussen \& Giske (1994), com amostras coletadas dentro do fiorde Masfjorden, estimaram em 3,03 o valor de b e da ordem de $10^{-5}$ o valor de $\mathbf{a}$.

Em relação aos resultados do presente estudo, os valores estimados de a por Gjøsæter (op. cit.) e Rasmussen \& Giske (op. cit.) foram semelhantes; quanto ao valor de b, exceto para os fiordes na primavera (Gjøsæter, op. cit.), o valor obtido foi menor. Desta forma, para um mesmo comprimento padrão, M. muelleri apresenta maior peso que $M$. stehmanni.

Na figura IV.13. estão representados os valores do fator de condição (K) em relação ao comprimento padrão dos exemplares capturados. Verifica-se que esse valor não variou com o tamanho do peixe.

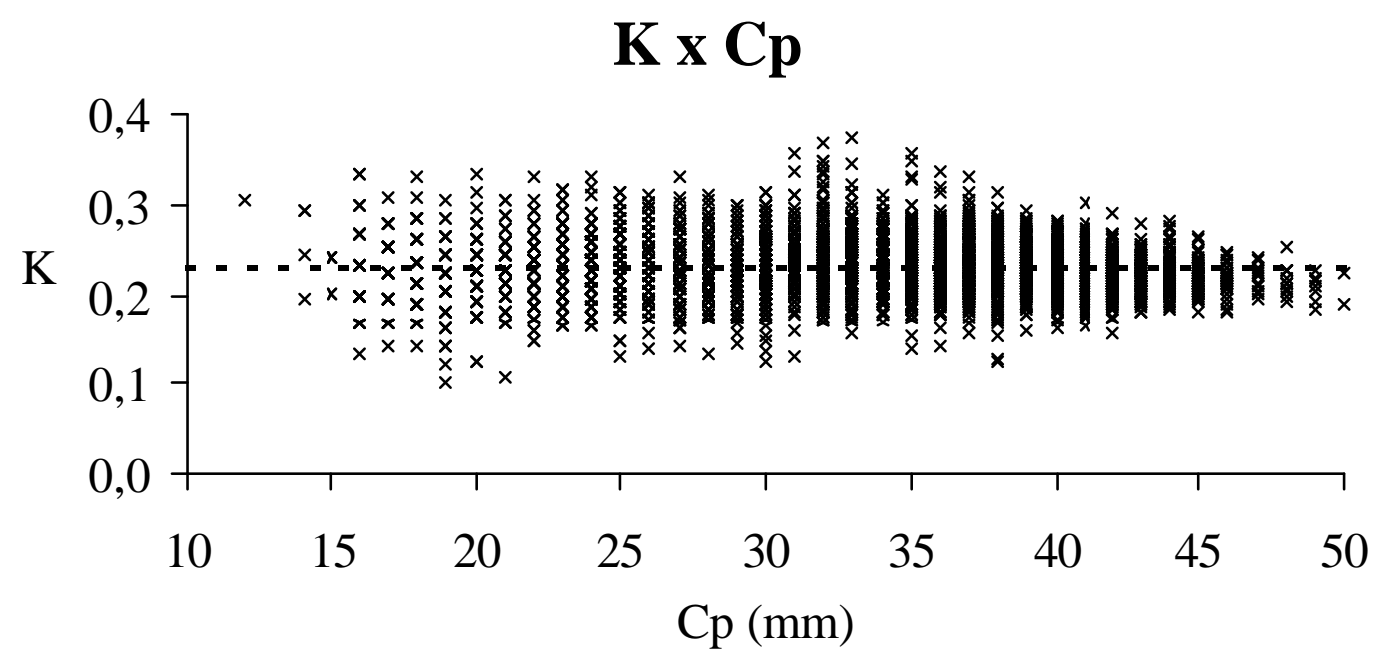

Figura IV.13. Valores do fator de condição (K) em função do comprimento padrão de M. stehmanni. A reta tracejada representa o valor de "a" da relação peso/comprimento.

A inexistência de dependência entre o $\mathrm{K}$ e o tamanho do peixe foi discutida por Braga (1986), o qual mostrou que este fato tende a acontecer quando se utiliza para o cálculo do fator de condição o valor alométrico da relação peso/comprimento, diferentemente do fator de condição de Fulton, que aplica aos dados de comprimento um expoente com valor pré-fixado de 3. 
Os valores médios de $\mathbf{K}$ por época do ano estão representados na figura IV. 4, observase que a maior média foi obtida no outono e a mais baixa no inverno, sendo que, apenas nesta época o valor médio de $\mathbf{K}$ esteve logo abaixo do valor de $\mathbf{a}$ da relação peso/comprimento.

\section{Fator de condição}

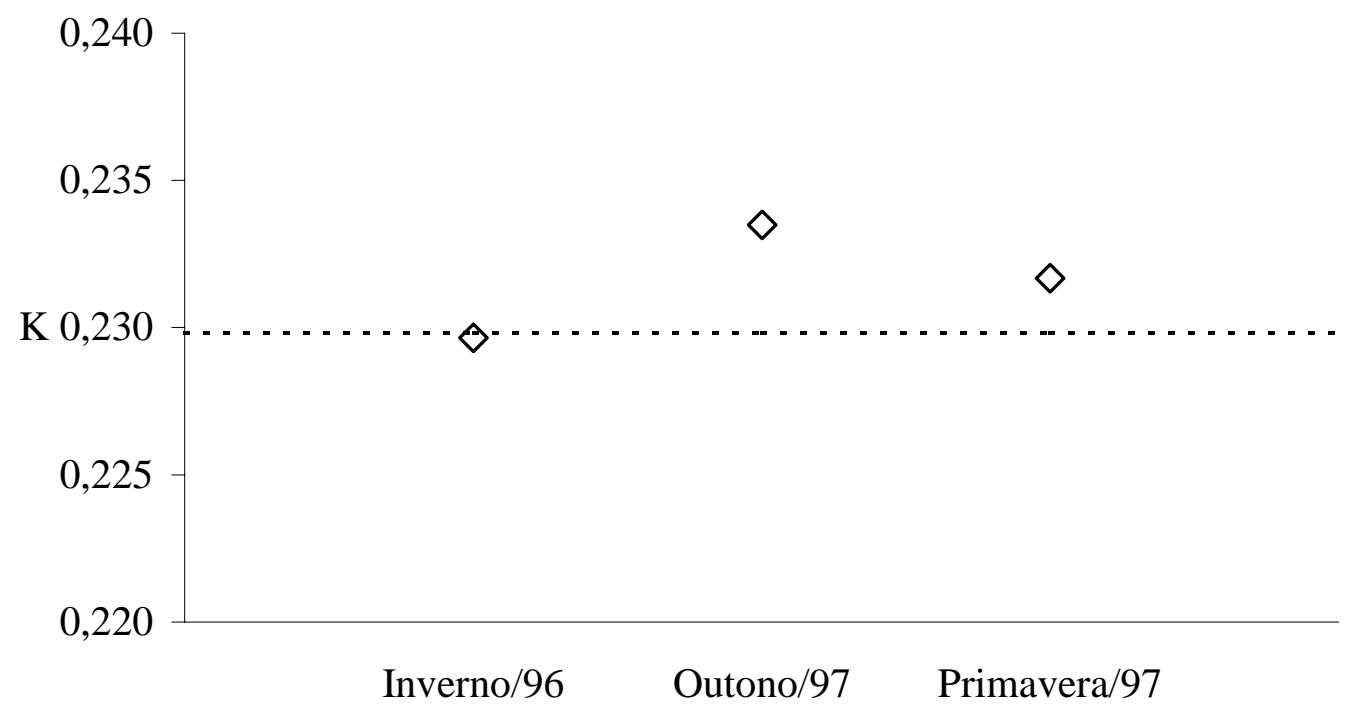

Figura IV.14. Valores médios do fator de condição (K) de $M$. stehmanni por época do ano. A reta tracejada representa o valor de "a" da relação peso/comprimento.

O Fator de condição (K) evidencia quando o peso do peixe é grande (valor de K alto) ou pequeno (valor de K baixo) em relação ao seu tamanho e pode revelar condições nutricionais e/ou gastos de energia em atividades cíclicas relacionadas às condições ambientais e/ou reprodutivas (Wootton, 1990 e Vazzoler, 1996).

Weatherley \& Gill (1987) mostraram que populações de peixes apresentam alterações no fator de condição ao longo do tempo, refletindo flutuações sazonais no balanço metabólico, e também na atividade reprodutiva.

Verificou-se que M. stehamnni apresentou maior peso para um determinado tamanho no outono e na primavera, indicando a possibilidade de um maior investimento reprodutivo e/ou diferenças nas condições ambientais (por exemplo: disponibilidade de alimento) nestas épocas.

\section{3c: Tamanho de maturação gonadal:}

Na figura IV.15. está representada a proporção de indivíduos adultos por classe de comprimento padrão e a estimativa do $\mathrm{L}_{50 \text { médio }}$. O tamanho médio de 1 a maturação gonadal, ou seja, o comprimento em que $50 \%$ dos peixes apresentam gônadas em maturação, foi estimado em $32 \mathrm{~mm}$. 


\section{Tamanho médio de $1^{\circ}$ maturação}

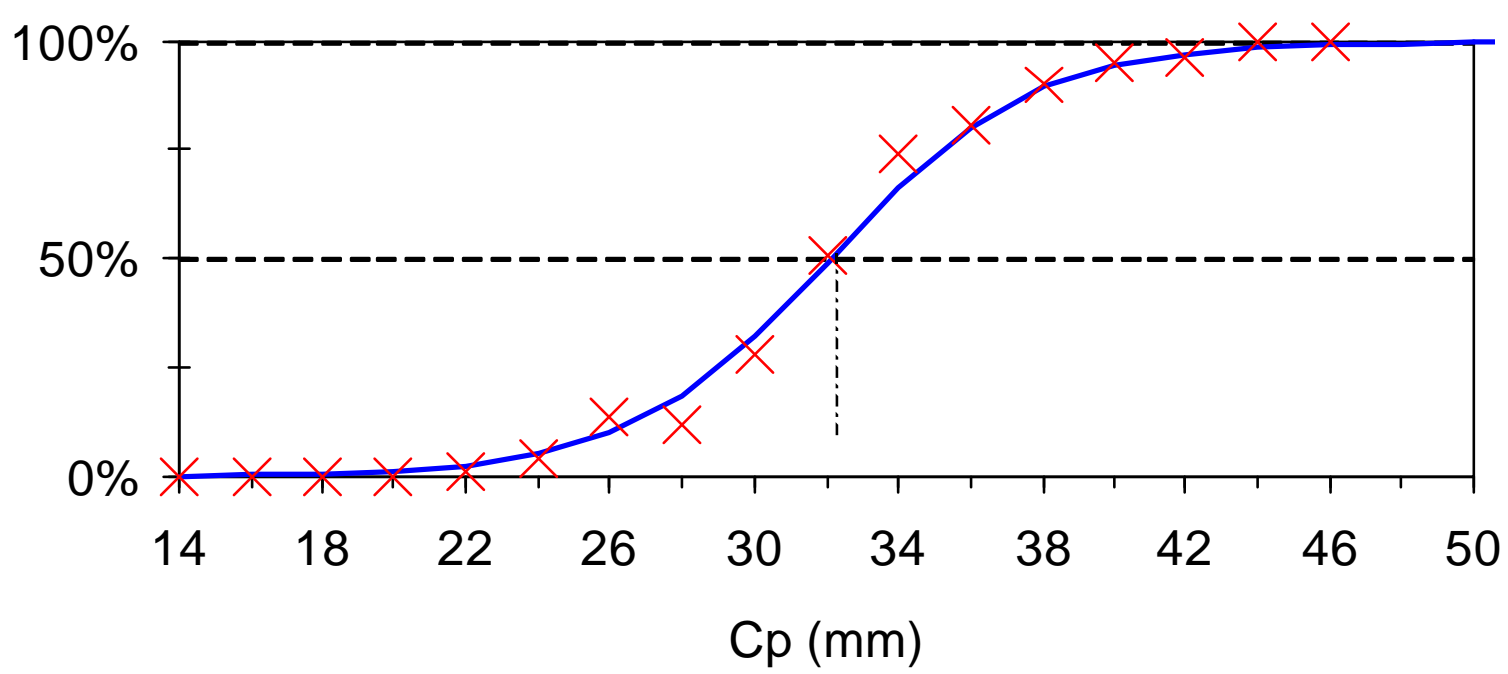

Figura IV.15. Porcentagem de indivíduos adultos por classe de comprimento padrão (Cp) para M. stehmanni. $\mathrm{L}_{50}$ - Tamanho médio de $1^{\text {a }}$ maturação gonadal; $\mathrm{X}$ Valores amostrados; a curva foi traçada segundo King (1996).

O fato de ter-se calculado este parâmetro com dados agrupados (machos e fêmeas), devido à dificuldade de se identificar macroscopicamente o sexo dos indivíduos imaturos, não permitiu verificar diferenças nos tamanhos médios de $1^{\text {a }}$ maturação entre sexos. Entretanto, outros estudos (Young et al., 1981; Dalpadado \& Gjøsæter, 1987; Prosch, 1991 e Rasmussen \& Giske, 1994), mostraram que há diferentes taxas de crescimento e maturação entre machos e fêmeas.

Na tabela IV.4. estão indicados os valores de $\mathrm{T}_{\min }$ e $\mathrm{T}_{\max }$ para machos e fêmeas de $M$. stehmanni, além de resultados de outros estudos realizados com espécies congêneres. Em termos de valores máximos e mínimos de maturação, constatou-se que os machos de $M$. stehmanni apresentaram tamanhos menores que as fêmeas, fato corroborado por estudos realizados para outras espécies do gênero (Young et al., op. cit.; Dalpadado \& Gjøsæter, op. cit.; Prosch, op. cit. e Rasmussen \& Giske, op. cit.).

Stearns \& Crandall (1984) e Wootton (1990) destacam que, dentro de uma mesma espécie, a idade e/ou o tamanho de maturação pode variar e que esta plasticidade seria determinada geneticamente e moldada pelas variáveis ambientais que se refletiriam em diferentes taxas de crescimento e mortalidade, acarretando idades (ou tamanhos) distintos de maturação. Wootton (1973) verificou experimentalmente que fêmeas de Gasterosteus aculeatus amadurecem com idade e peso menores quando o fornecimento de alimento é maior. Stearns \& Crandall (op. cit.) constataram que a maturação ocorre ao longo de uma trajetória de idade e comprimento que depende das condições demográficas da população (densidade). King (1996) salienta que, apesar da maturação gonadal e a desova dependerem de estímulos ambientais, os indivíduos precisam alcançar um certo tamanho (ou idade) antes de se tornarem aptos à reprodução. 
Tabela IV.4. Tamanhos (comprimento padrão) máximos $\left(T_{\max }\right)$ e mínimos $\left(T_{\min }\right)$ de machos e fêmeas com gônadas maduras de espécies do gênero Maurolicus deste estudo e outros localizados em diferentes áreas. $\mathrm{Cp}_{\max }$ é o comprimento padrão máximo encontrado. Notar que os trabalhos foram publicados antes da última revisão do gênero (Parin \& Kobyliansky, 1993 e 1996), exceto a publicação de Rasmunsen \& Giske (1994).

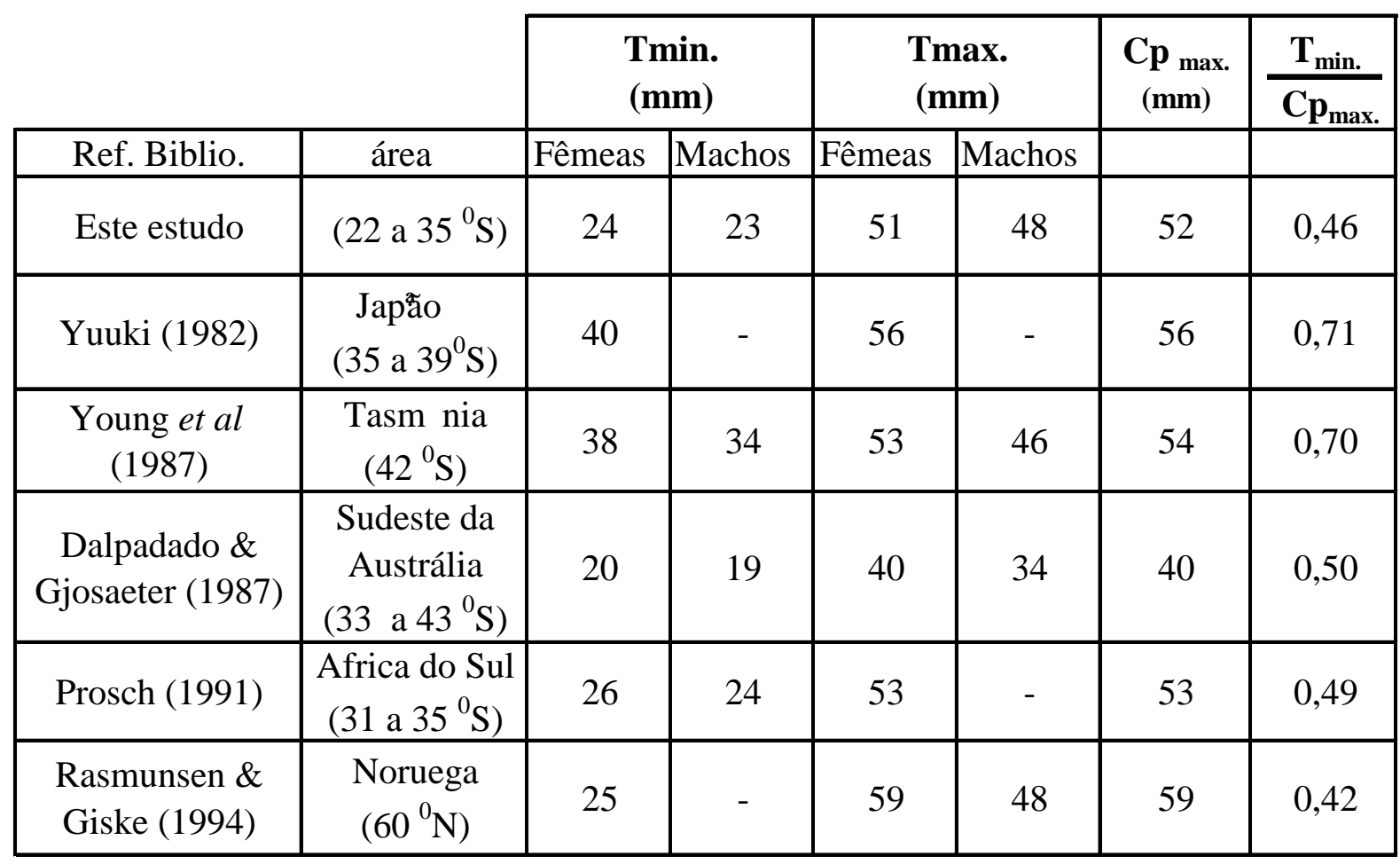

Vazzoler (1996) discute o conceito de "tamanho mínimo crítico", que representaria o tamanho no qual se iniciam os processos de produção reprodutiva; a autora ainda sugere que espécies com ciclo de vida curto e L $\infty$ pequeno (r-estrategistas) atingem estádios gonadais maduros mais cedo do que espécies de vida longa e $\mathrm{L} \infty$ maiores (k-estrategistas).

Longhurst \& Pauly (1987) apresentaram a hipótese de que o tamanho assintótico (L $\infty$ ou $\mathrm{W} \infty)$ e o tamanho médio de primeira maturação $\left(\mathrm{L}_{50 \text { médio }}\right)$ são determinados, principalmente, pela interação entre o fornecimento e a demanda de $\mathrm{O}_{2}$ (ou aquisição e gasto de energia), e que esta relação está limitada pela área das brânquias, que garantem o fornecimento de $\mathrm{O}_{2}$. Estas brânquias não crescem na mesma proporção que o volume do corpo, responsável pela demanda de $\mathrm{O}_{2}$. Segundo estes autores, o amadurecimento das gônadas deveria ocorrer enquanto há "sobras" no fornecimento de energia e que o metabolismo total (metabolismo ativo + metabolismo de manutenção) deveria ser 1,4 vezes maior que o metabolismo de manutenção. Assim, dentro de um mesmo grupo taxonômico, a relação $\mathrm{L}_{50 \text { médio }} / \mathrm{L} \infty$ se mantém constante e alterações ambientais podem acarretar variações no $\mathrm{L}_{50 \text { médio }}$ e no $\mathrm{L} \infty$, mas não na relação entre estes 
parâmetros. Finalmente, eles mostraram que a relação varia entre 0,4 e 0,9 e que há uma tendência dela ser menor nos peixes de grande porte e maior nos peixes de pequeno porte. Todavia, o resultado da relação $\mathrm{L}_{50 \text { médio }} / \mathrm{L} \infty$ neste estudo foi de 0,6 (o L $\infty$ foi estimado pela utilização da equação de Taylor, apresentada no item V.2a5).

Com vistas a verificar a hipótese de Longhurst \& Pauly (1987) acima apresentada, não dispondo na literatura de dados de $\mathrm{L}_{50 \text { médio }}$ e Lo para o gênero Maurolicus, mas contando com dados de $\mathrm{T}_{\text {min }}$, e assumindo que o $\mathrm{T}_{\max }$ está próximo de $\mathrm{L} \infty$, foi calculada a razão entre $\mathrm{o} \mathrm{T}_{\min }$ das fêmeas e o tamanho máximo dos peixes de cada espécie apresentada na tabela IV.4.. Os valores obtidos ficaram em torno de 0,5, exceção para os trabalhos de Young et al. (1987) e Yuuki (1982) cujos valores foram 0,70 e 0,71 , respectivamente.

Comparativamente $M$. stehmanni matura com comprimento mínimo próximo ao das espécies congêneres da África do Sul e da Noruega, mas bastante inferior ao das espécies ocorrentes no Japão e na Tasmânia. Estas diferenças não devem estar relacionadas à latitude, mas sim à aspectos ecológicos característicos de cada ecossistema, como por exemplo: físicos (estrutura térmica) e biológicos (exemplo: competição e predação), que podem implicar em alterações nos parâmetros populacionais como tamanho de maturação, taxa de crescimento e taxa de mortalidade.

\section{3d: Local e época de desova}

Pela análise das freqüências dos estádios de maturidade foram encontrados altos valores de indivíduos A (jovens), B e C (adultos), nas três épocas de coleta (figura IV.16.). No inverno ocorreu alta porcentagem de peixes em maturação (46\%), mas também foram elevados os percentuais de peixes maduros (24\%) e de jovens (30\%). Na primavera dominaram indivíduos jovens (38\%), estando 36\% dos peixes em maturação e $25 \%$ maduros. Vale ressaltar que nas amostragens de primavera houve dominância de peixes imaturos em relação aos demais cruzeiros. No outono os valores relativos para peixes jovens e em maturação foram semelhantes: $26 \mathrm{e}$ $28 \%$, respectivamente, enquanto que a porcentagem de maduros foi a mais alta encontrada, $47 \%$.

A análise das frequiências dos estádios de maturidade por lance de pesca (figuras IV.17, IV.18. e IV.19.), mostrou que foram poucos os lances com a co-ocorrência dos três estádios (A, B e C), sendo: três lances na primavera, cinco no outono e dez na primavera.

Em todas as épocas de amostragem foram encontrados peixes nos diferentes estádios de maturidade gonadal, ao longo de toda a área. Porém, verificou-se que no inverno peixes jovens predominaram ao sul de Santos, enquanto que peixes em maturação e maduros predominaram nas proximidades de Cabo Frio.

Em relação à profundidade do local observou-se que nas três épocas os cardumes com predomínio de peixes maduros ocorreram próximos à isóbata de $200 \mathrm{~m}$, sendo que na primavera foram capturados peixes maduros sobre a plataforma continental, logo após a isóbata de $100 \mathrm{~m}(\# 353)$. 
$\% \quad$ Estádios de maturidade gonadal

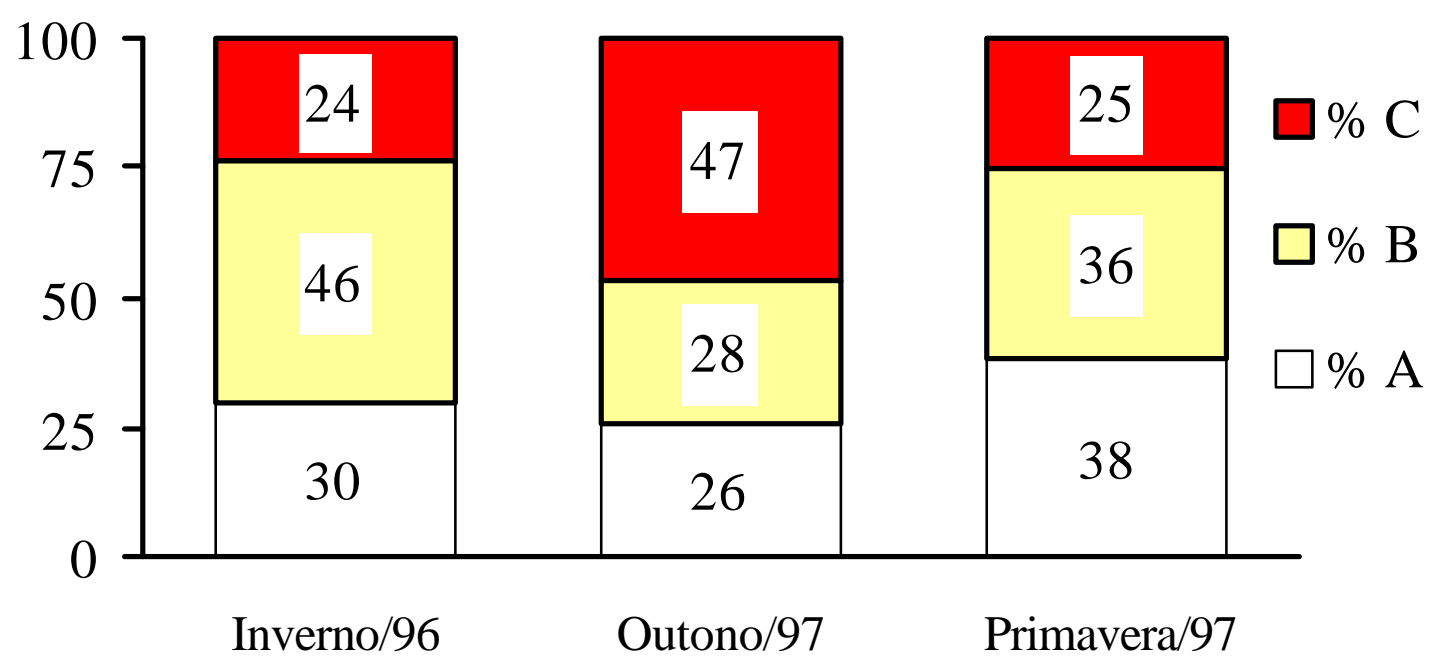

Figura IV.16. Freqüência relativa (em porcentagem) dos estádios de maturidade gonadal de M.stehmanni, por época do ano. A - peixes imaturos (jovens); B - peixes em maturação (adultos) e C - peixes maduros (adultos).

West (1990) afirma que a estimativa das frequiências dos estádios de desenvolvimento gonadal permite o estudo do tamanho de maturação, época da desova e duração do período reprodutivo. Por sua vez, Vazzoler (1996) explica que o desenvolvimento ovariano é um processo contínuo e cíclico, sendo sua divisão em estádios artificial, mas, que a proporção entre estes estádios é importante nos estudos sobre tamanho de primeira maturação, período reprodutivo e área de reprodução.

Levando em conta que um certo número de peixes classificados como imaturos (A) estavam na realidade em maturação (B) e que peixes identificados como em maturação estavam maduros (item IV. 3e), pode-se dizer que as porcentagens de peixes em maturação e maduros eram superiores às estimadas para toda a área e nos três períodos de amostragem.

Embora não haja dados relativos ao verão, a alta porcentagem de indivíduos maduros e em maturação, bem como a presença de jovens em quaisquer dos períodos sugere que Maurolicus stehmanni desova ao longo de toda a área e ao longo do ano, com um pico no outono devido à maior porcentagem de peixes maduros (estádio C).

$\mathrm{Na}$ figura IV.20. estão representados os valores individuais e as médias da relação gonadossomática $\left(\mathrm{RGS}_{1}\right)$ para todos os peixes de cada lance de pesca, observando-se que houve uma grande variação com valores mínimos e máximos próximos a 0 e $9 \%$, respectivamente, nas três épocas de pesquisa. No inverno os maiores valores médios de RGS $\mathrm{f}_{1}$ foram obtidos para os peixes das estações localizadas próximas a Cabo Frio e Cabo de Santa Marta, no outono naquelas localizadas ao norte, próximo a Cabo Frio e na primavera entre Paranaguá e Cabo de Santa Marta.

Na figura IV.21 está representada a variação da relação gonadossomática em função do tamanho dos indivíduos, mostrando que os valores de $\mathrm{RGS}_{1}$ foram maiores para os peixes maduros (máximo de 9\%), seguindo-se daqueles em maturação (máximo de 6\%), enquanto que 


\section{Inverno 96}

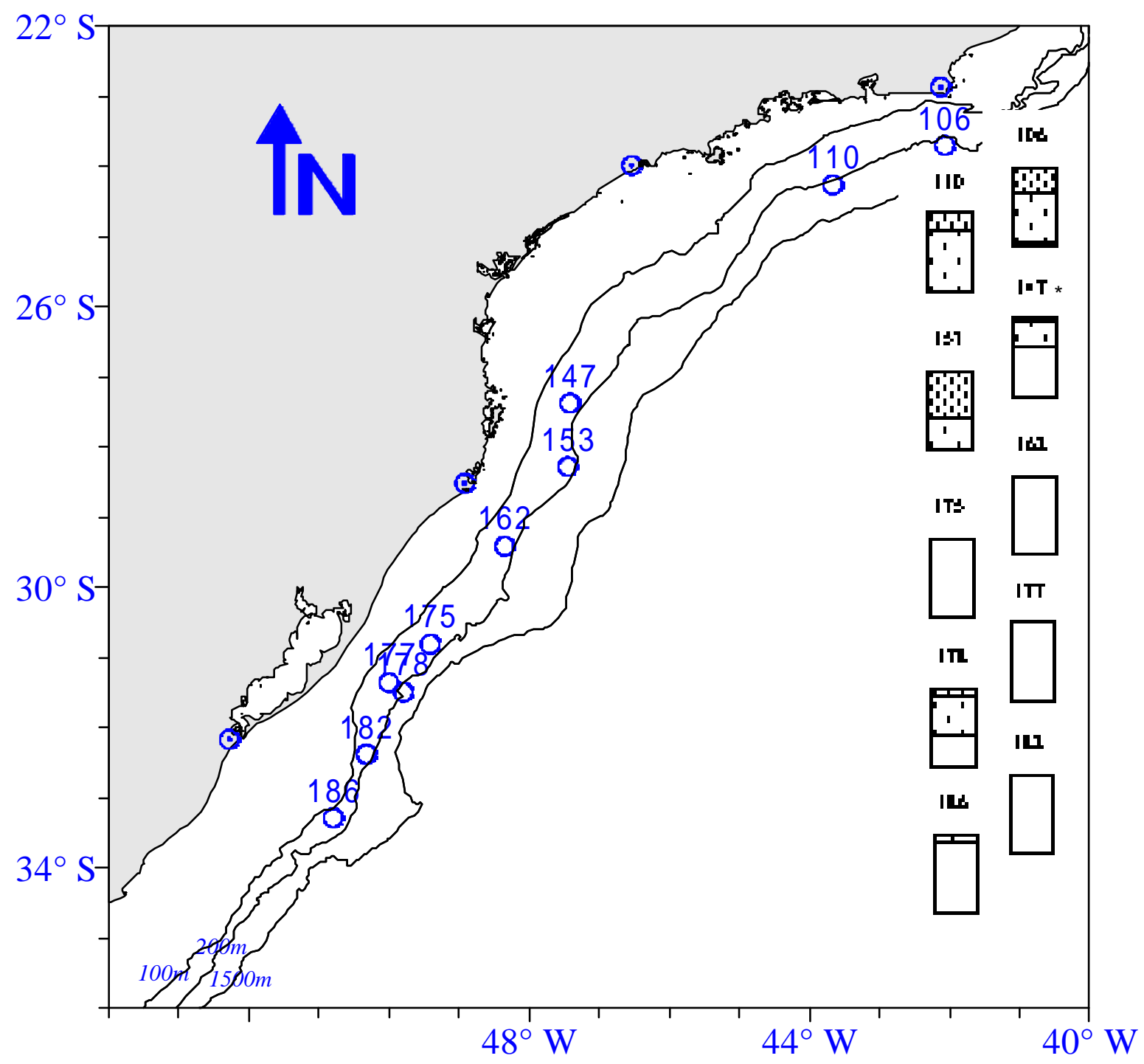

Lances

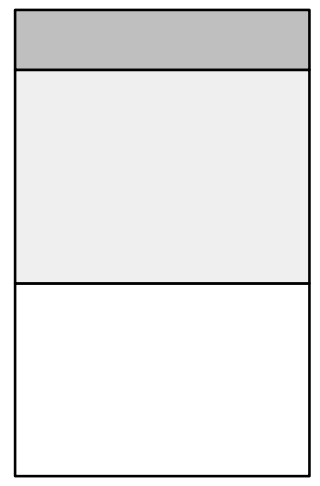

Maduros (C)

$\square$ Em maturação (B)

$\square$ Imaturo (A)

Figura IV.17. Freqüência dos estádios de maturidade gonadal M. stehmanni por local de coleta no inverno de 1996. 


\section{Outono 97}

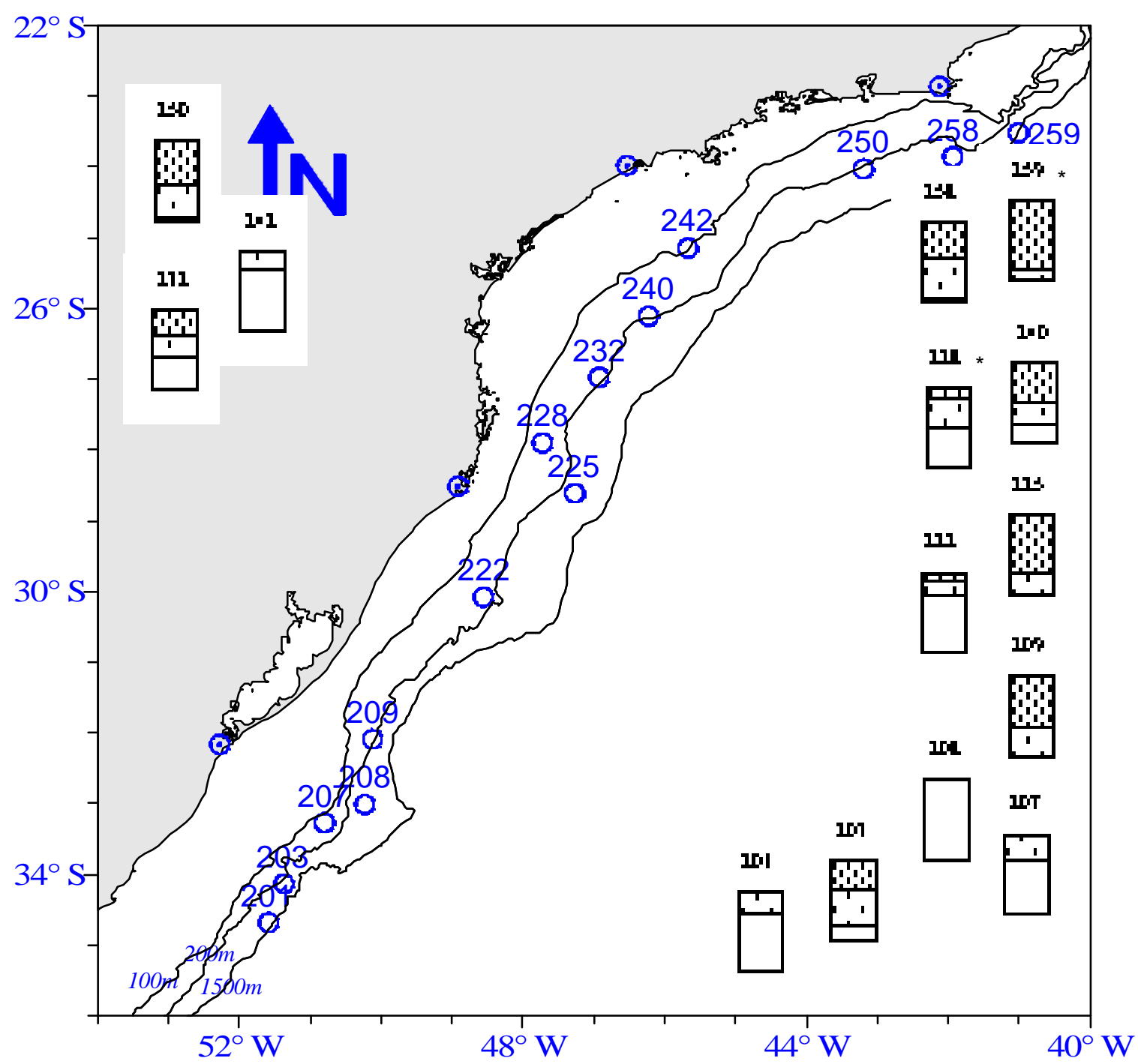

Lances

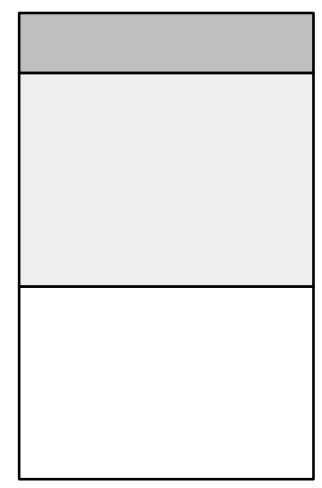

Maduros (C)

$\square$ Em maturação (B)

$\square$ Imaturo (A)

Figura IV.18. Freqüência dos estádios de maturidade gonadal M. stehmanni por local de coleta no outono de 1997. 


\section{Primavera 97}

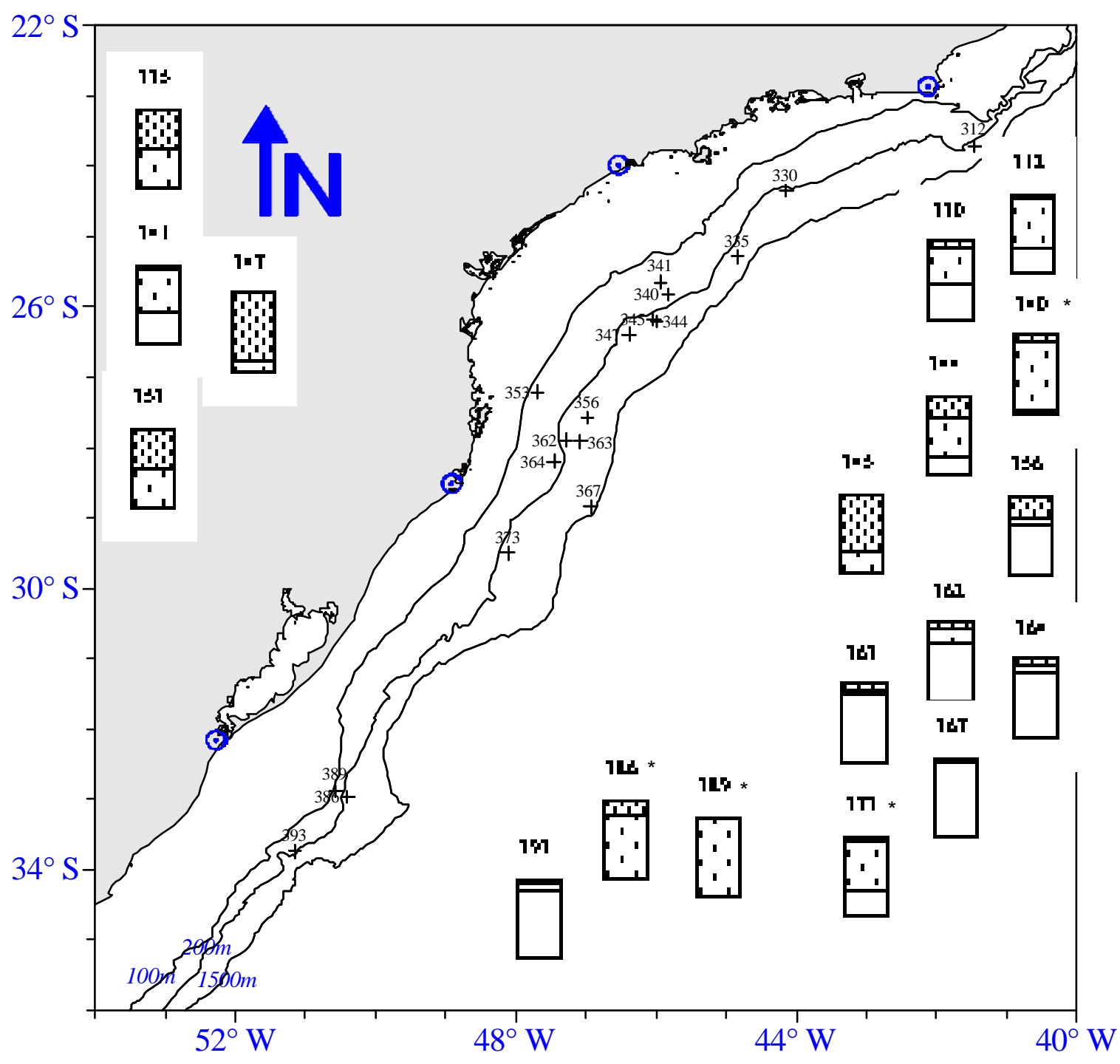

\section{Lances}

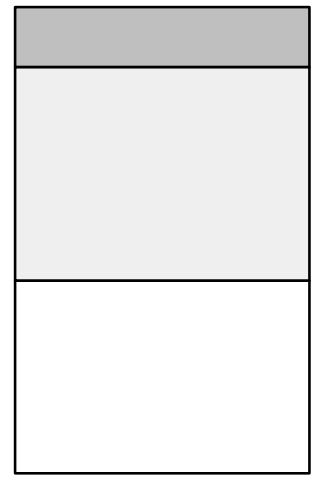

Maduros (C)

$\square$ Em maturação (B)

$\square$ Imaturo (A)

Figura IV.19. Freqüência dos estádios de maturidade gonadal M. stehmanni por local de coleta na primavera de 1997. 

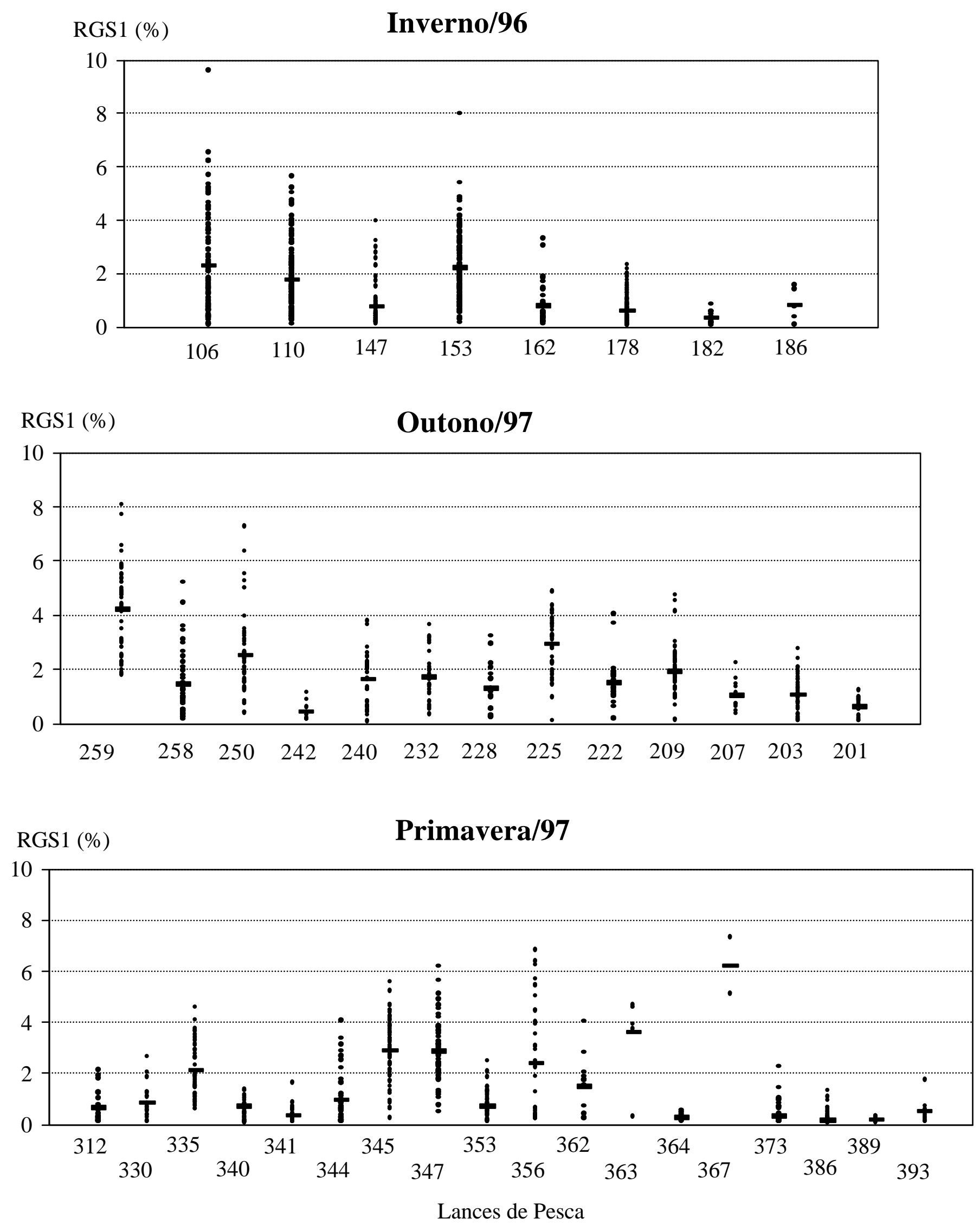

Figura IV.20. Valores individuais de RGS $_{1}$ de $M$. stehmanni para peixes de todos os lances de pesca. A barra horizontal representa o valor médio encontrado. 
Fêmeas

Estádio A

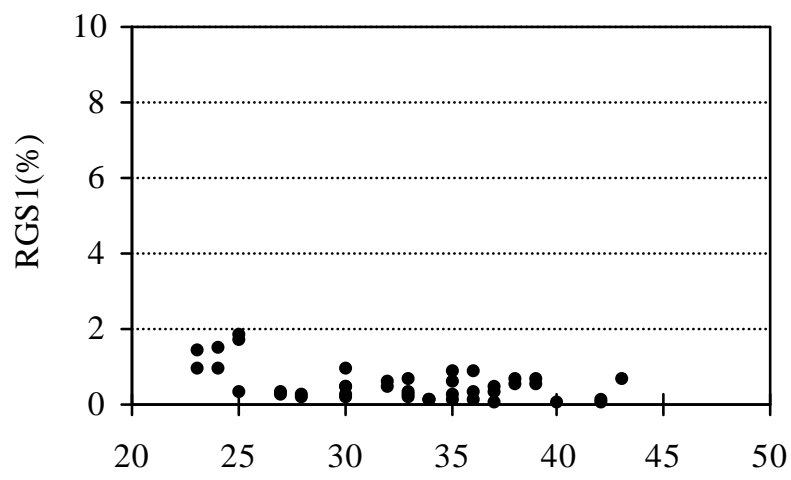

Estádio B

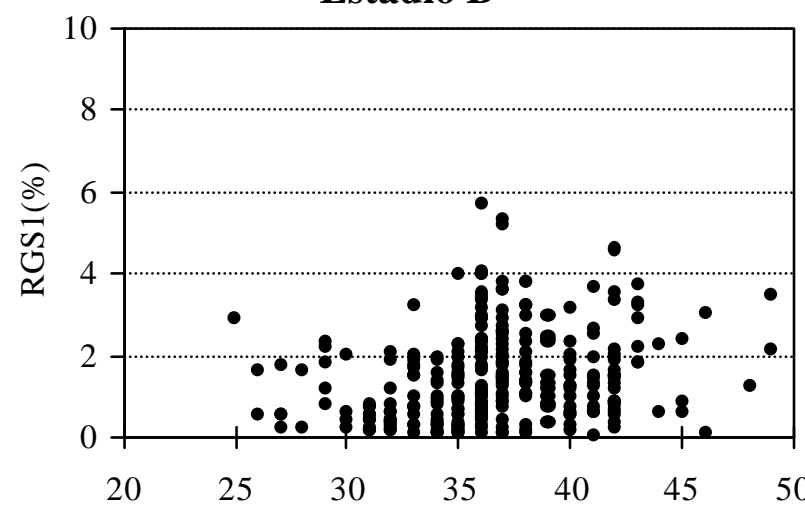

Estádio C

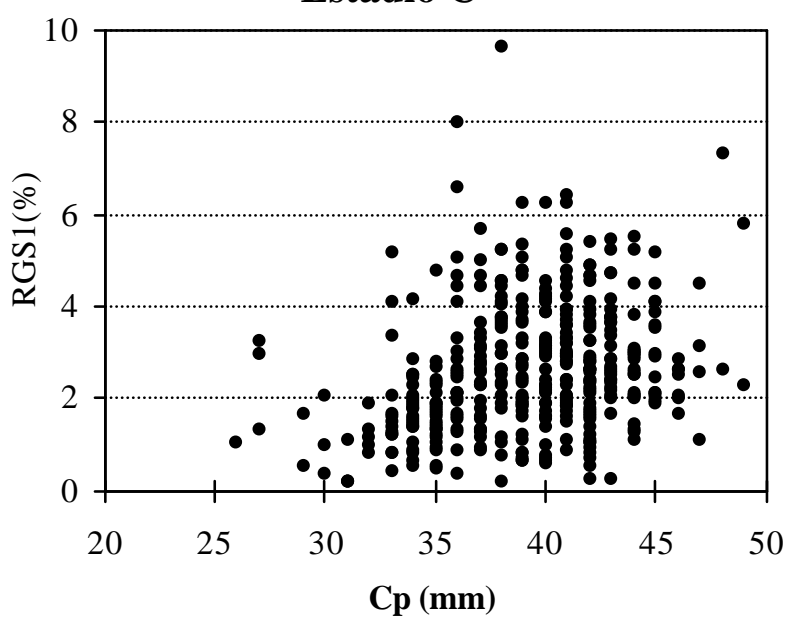

Machos

Estádio A

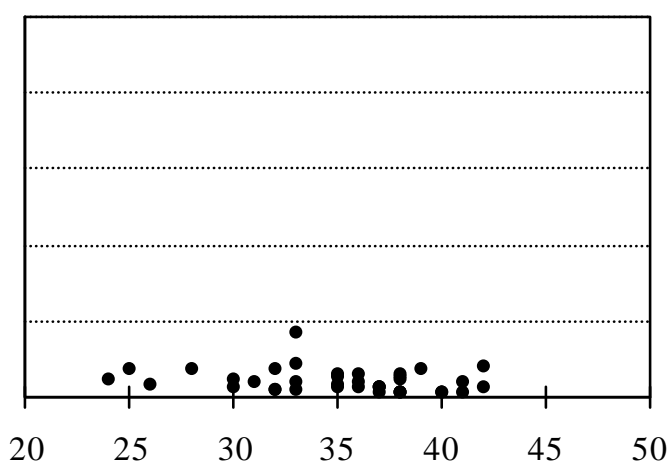

Estádio B

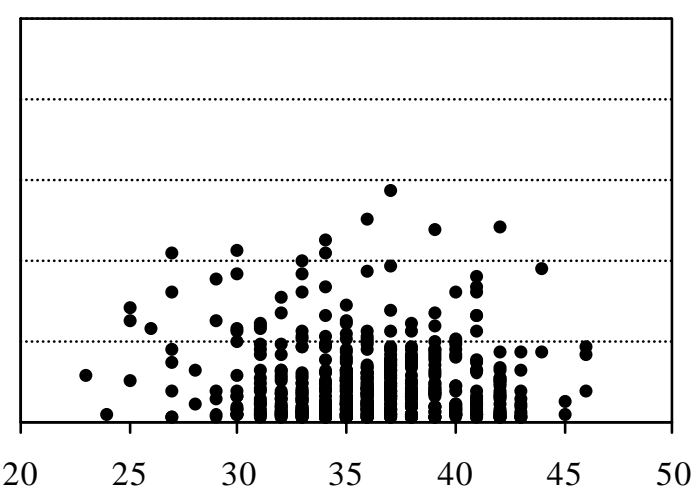

Estádio C

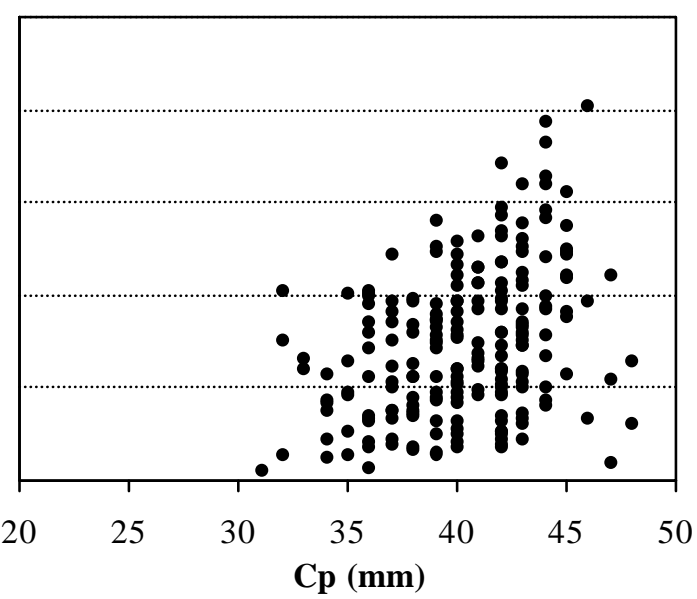

Figura IV.21. Valores de RGS 1 em relação ao comprimento padrão (Cp) dos indivíduos em maturação de $M$. stehmanni, para os diferentes sexos e por estádios de maturidade. 
para os jovens o valor máximo foi de $2 \%$. Estes resultados evidenciaram um aumento do peso da gônada com a maturação gonadal, independente do comprimento.

Resultado diferente foi obtido por Rasmussen \& Giske (1994), estudando Maurolicus muelleri, mostrando que a massa gonadal aumenta em relação ao tamanho do corpo, e que os valores de RGS 1 aumentam até os $40 \mathrm{~mm}$, quando então, ocorre uma estabilização entre 2 e $4 \%$.

As médias e os desvios padrão de $\mathrm{RGS}_{1}$ e $\mathrm{RGS}_{2}$ para as fêmeas estão apresentados na tabela IV.5.. Verificou-se que para as fêmeas maduras (C) os valores médios destes índices estiveram em torno de 3,3 \%, e para as fêmeas em maturação (B) ao redor de 1,9 \%. Na primavera estes valores ficaram próximos a 2,4 e abaixo de $0,8 \%$, respectivamente. No outono os valores médios foram os mais baixos, sendo de 2,4 para as fêmeas C e 1,2\% para as fêmeas B.

Tabela IV.5. Valores médios e desvios padrões de RGS1 e RGS2 das fêmeas em maturação (B) e maduras (C) de M. stehmanni, para as três épocas de amostragem.

\begin{tabular}{|l|l|c|c|c|c|}
\cline { 3 - 6 } \multicolumn{2}{c|}{} & \multicolumn{1}{c|}{$\mathrm{RGS}_{1}$} & \multicolumn{2}{c|}{$\mathrm{RGS}_{2}$} \\
\cline { 3 - 6 } & \multicolumn{1}{c|}{$\mathrm{B}$} & $\mathrm{C}$ & $\mathrm{B}$ & $\mathrm{C}$ \\
\hline Inverno & Média & 1,923 & 3,229 & 1,976 & 3,364 \\
\hline & Desvio & 1,171 & 1,567 & 1,227 & 1,697 \\
\hline Primavera & Média & 0,769 & 2,397 & 0,779 & 2,478 \\
\hline & Desvio & 0,590 & 1,410 & 0,603 & 1,498 \\
\hline Outono & Média & 1,239 & 2,391 & 1,261 & 2,463 \\
\hline & Desvio & 0,810 & 1,123 & 0,835 & 1,191 \\
\hline
\end{tabular}

A figura IV.22. evidencia que no inverno os valores médios de $\Delta$ RGS foram maiores que na primavera e outono, tanto para as fêmeas maduras, $(\mathrm{C})$ como para as fêmeas em maturação (B).

Pelo exposto os valores de $\mathrm{RGS}_{1}, \mathrm{RGS}_{2}$ e $\Delta \mathrm{RGS}$ foram sempre maiores para as fêmeas $\mathrm{C}$ em relação às demais, fato que permite dizer que, as avaliações macroscópicas dos estádios de maturidade, o peso das gônadas e seu valor em relação ao peso do corpo podem ser ferramentas utilizadas na avaliação da maturação gonadal da espécie.

Os valores de $\mathrm{RGS}_{1}$ encontrados na literatura para espécies do gênero Maurolicus foram semelhantes aos deste estudo. Na Noruega, Rasmussen \& Giske (1994) encontraram um valor máximo de $7 \%$, além de constatarem que peixes menores que 30mm nunca tiveram valores maiores que $2 \%$. Clarke (1982), na Austrália, apresentou uma amplitude de valores de 
$\Delta$ RGS

Fêmeas adultas

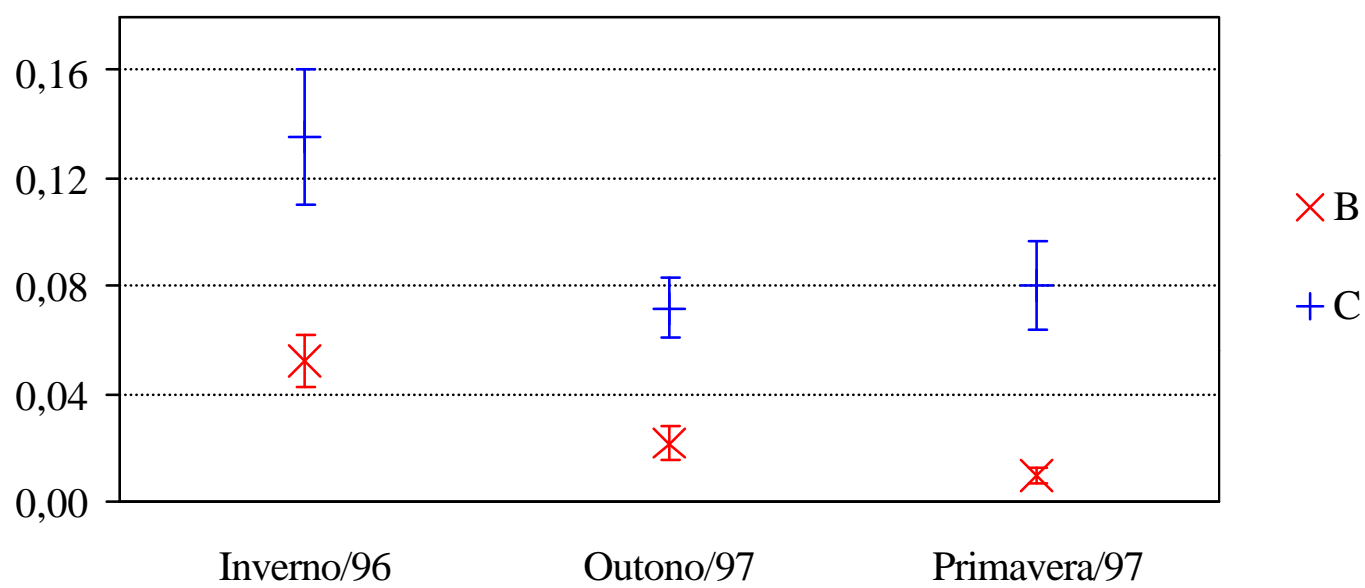

Figura IV.22. Valores médios de $\triangle$ RGS das fêmeas adultas (B e C) de M. stehmanni, por época de coleta. As barras verticais representam os intervalos de confiança $(\mathbf{p}=\mathbf{0 , 0 5})$.

RGS $_{1}$ entre 1,6 a 9,6\%, valor máximo semelhante ao deste estudo. Salvanes \& Stockley (1996), estudando peixes de áreas de oceano aberto e fiordes na Noruega encontraram valores médios de $\mathrm{RGS}_{1}$, para peixes de diferentes localidades, variando entre 1,21 e 5,26\% e que as maiores médias estavam intimamente relacionadas ao diâmetro do ovócito, ou seja, os maiores valores de RGS 1 ocorreram em fêmeas que apresentaram graus de maturidade ovariana mais avançados. Young et al. (1987), na Tasmânia - Austrália, encontraram uma relação direta entre a RGS 1 e o desenvolvimento ovariano e, além disso, valores médios de $\mathrm{RGS}_{1}$ nas épocas de pico de desova variando entre 4 e $4,5 \%$.

No presente trabalho, os valores médios de $\Delta$ RGS, RGS e $_{1} \mathrm{RS}_{2}$, tanto para as fêmeas $\mathrm{C}$ como para as fêmeas $\mathrm{B}$, foram mais elevados no inverno, diminuindo nos demais períodos. A ocorrência de peixes com valores da $\mathrm{RGS}_{1}$ elevados (em torno de 6\%) nas três épocas de estudo indica que $M$. stehmanni apresentou atividade reprodutiva em todos estes períodos. No entanto, os valores médios de $\Delta \mathrm{RGS}, \mathrm{RGS}_{1}$ e $\mathrm{RGS}_{2}$, tanto para as fêmeas $\mathrm{C}$ como para as fêmeas $\mathrm{B}$, foram mais elevados no inverno, revelando um pico de atividade reprodutiva neste período.

A análise da variação das médias de delta $\mathbf{K}(\Delta \mathbf{K})$ para fêmeas em maturação (B) e maduras $(\mathrm{C})$ ao longo do tempo evidenciou que as médias mais elevadas ocorreram no inverno e a mais baixa na primavera (figura IV.23.), o que sugere que houve um maior investimento reprodutivo no inverno, possivelmente um pico de maturação.

Ainda pela figura IV.23. observa-se que os valores de $\Delta \mathbf{K}$ foram sempre maiores para as fêmeas $\mathrm{C}$ do que para as fêmeas $\mathrm{B}$, mostrando que o peso da gônada revelado por este índice é adequado para a avaliação da maturidade.

Estudos sobre o ictioplâncton realizados na região sul (Weiss et al., 1988 e Bonecker 


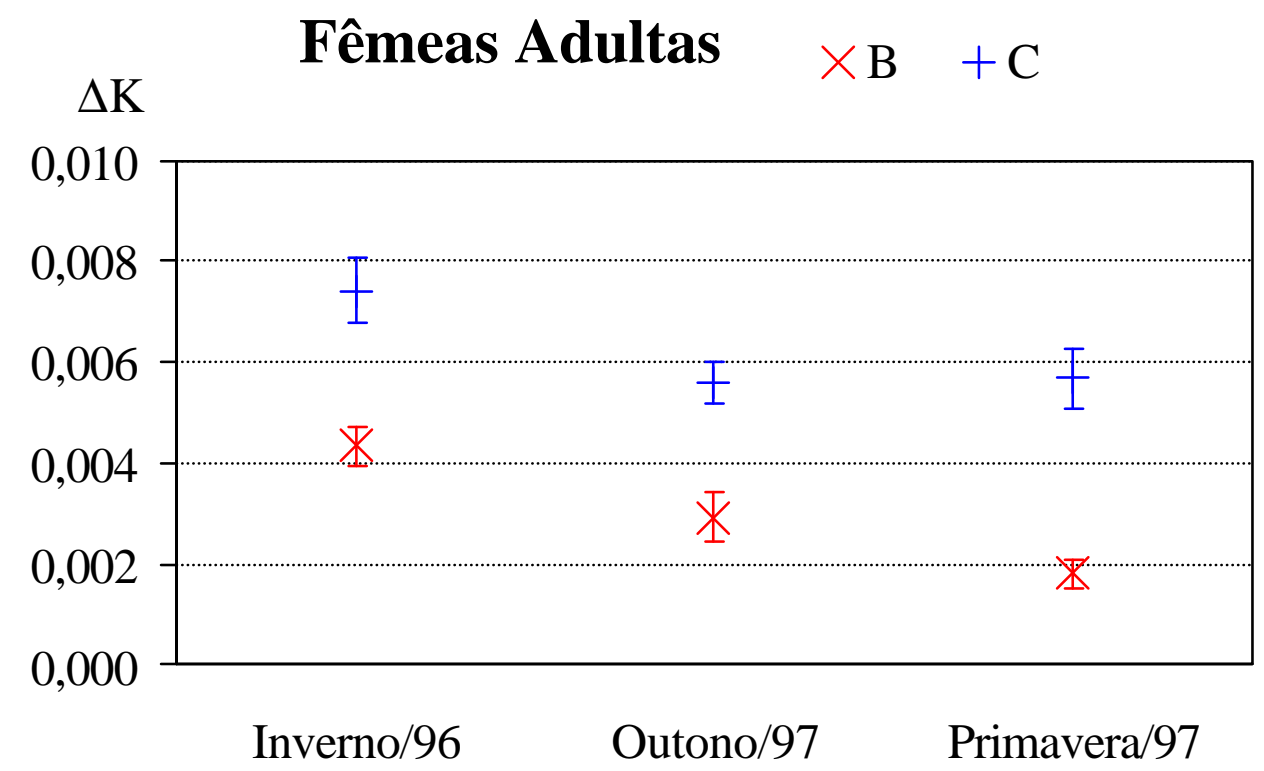

Figura IV.23. Valores médios de $\Delta K$ para fêmeas em maturação (B) e maduras (C), por época do ano. As barras verticais representam os intervalos de confiança $(\mathbf{p}=\mathbf{0 , 0 5})$.

\& Hubold, 1990) e região sudeste (Ribeiro, 1996) do Brasil, ou seja, na mesma área do presente estudo, mostraram a ocorrência de ovos e larvas em todas as épocas analisadas e Ribeiro (op. cit.) concluiu que a espécie desova ao longo de todo o ano, com pico na primavera/verão. Valores mais elevados de $\mathrm{RGS}_{1}, \Delta \mathrm{RGS}$ e $\Delta \mathrm{K}$ no inverno indicariam que neste período a espécie apresentou maturação máxima, podendo nesta época ocorrer um pico de desova.

Apesar de não terem sido encontrados ovários hidratados, o que indicaria desova iminente, os resultados sugerem que $M$. stehmanni apresentou atividade reprodutiva nas três épocas de coleta, corroborando os estudos de Weiss et al. (op. cit.), Bonecker \& Hubold (op. cit.) e Ribeiro (op. cit.), embora durante o presente trabalho, não tenha sido possível realizar coleta de verão, impedindo afirmações sobre a atividade reprodutiva nesta época.

Prosch (1991) concluiu que na África do Sul Maurolicus desova ao longo do ano com um pico na primavera/verão. Foi demonstrado no Japão (Yuuki, 1982) e na Noruega (Gjøsæter, 1981; Dalpadado \& Gjøsæter, 1987) que espécies deste gênero apresentam desova prolongada na primavera. Na Tasmânia, Young et al. (1987) constataram que a desova se inicia na primavera, estendendo-se até o verão e Clarke (1982), no sudeste da Austrália, verificou que este processo começa no inverno, prolongando-se até a primavera. Estes resultados indicam que Maurolicus apresenta alta plasticidade em relação à época de desova, isto é, todas as espécies apresentam atividade reprodutiva na primavera, podendo se iniciar no verão e/ou se estender até o inverno, o que evidencia diferentes táticas para condições ambientais (físicas e biológicas) distintas. 


\section{3e: Histologia das gônadas:}

$\mathrm{Na}$ tabela IV.6. apresentam-se as características das fases do desenvolvimento ovocitário encontradas para M. stehmanni.

O congelamento dos ovários não permitiu que fossem identificadas e descritas com precisão as fases do desenvolvimento ovocitário. Foi possível visualizar os diferentes tamanhos dos ovócitos, porém seu citoplasma estava homogêneo, impedindo uma avaliação clara do processo de vitelogênese.

Quanto à identificação dos sexos, as preparações permanentes com cortes das gônadas indicaram que a escala macroscópica adotada foi adequada para os peixes adultos, mas não para os peixes imaturos e em maturação, com comprimento padrão em torno de $30 \mathrm{~mm}$, devido ao diminuto tamanho das gônadas que, muitas vezes, apresentaram valores em peso menores que $0,001 \mathrm{~g}$.

Em relação aos estádios de maturidade, a análise das preparações dos ovários provenientes dos materiais dos cruzeiros de maio/99 e novembro/99 mostrou:

- Ovócitos nas fases II, III, IV e V, além de folículos pós ovulatórios (POs) e atresia folicular (figura IV.24.) nas gônadas femininas, macroscopicamente definidas como fêmeas maduras (estádio C).

- Não foram observados ovócitos com hidratação pré-ovulatória.

A figura IV.24. evidencia a presença de ovócitos IV e V, revelando tratar-se de gônadas maduras, mas a ocorrência de POs mostrou que havia ocorrido desova, fato não detectado durante a análise macroscópica.

A ausência de fêmeas com ovário em hidratação indicou que estas não estavam no processo de desova, pois a hidratação é o fenômeno caracterizado pelo aumento substancial do volume do ovócito e ocorre horas antes de sua liberação para o meio externo e, cuja ocorrência indicaria desova iminente (Chaves, 1989, Vazzoler, 1996 e Dias et al., 1998).

Constatou-se ainda, que a metade dos peixes com comprimento padrão próximo à 30 mm, provenientes do cruzeiro de novembro de 1997, foi classificada, sob aumento máximo do estereomicroscópio, como fêmeas em maturação (estádio B). Fêmeas provenientes dos três primeiros cruzeiros nestas mesmas condições, haviam sido identificadas como imaturas (A), devido ao diminuto tamanho das gônadas, ao aspecto filiforme dos ovários e à presença de ovócitos de pequeno diâmetro. Nas preparações permanentes, embora prejudicadas devido à dimensão do material, foram encontrados ovócitos nas fases II, III e IV (figura IV.24E), constatando-se o processo de maturação (estádio B), apesar da aparência semelhante a do estádio A.

Dias et al. (1998) constataram diferenças entre as classificações macro e microscópicas dos ovários em várias espécies de Teleósteos. Os autores concluem que atenção especial deve ser dada à análise macroscópica de espécies com fecundidade parcial baixa, cuja liberação de ovócitos pode ser macroscopicamente imperceptível e sua ocorrência só pode ser indicada com 
Tabela IV.6. Características das fases de desenvolvimento ovocitário de M. stehmanni observadas neste estudo.

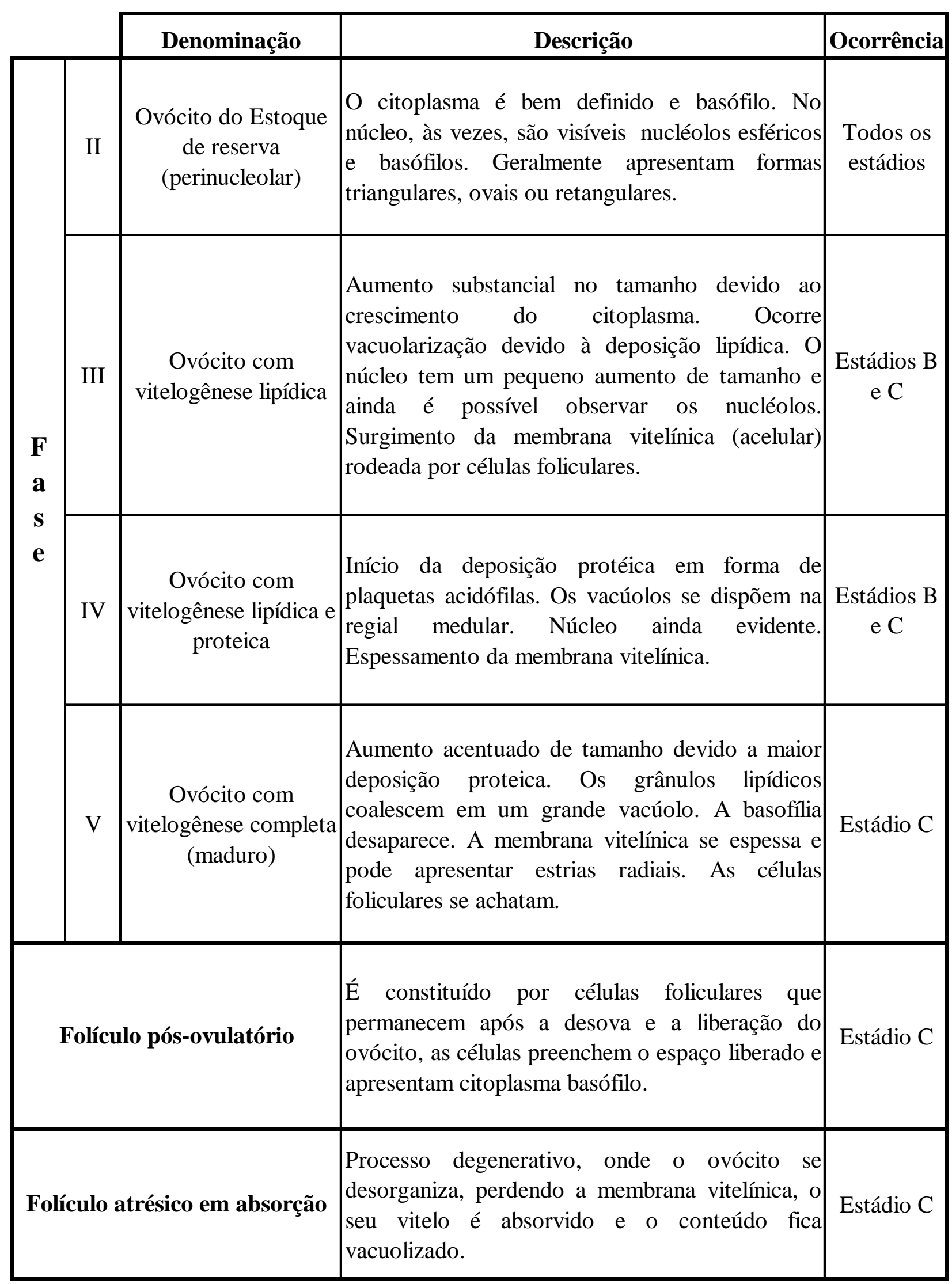


A

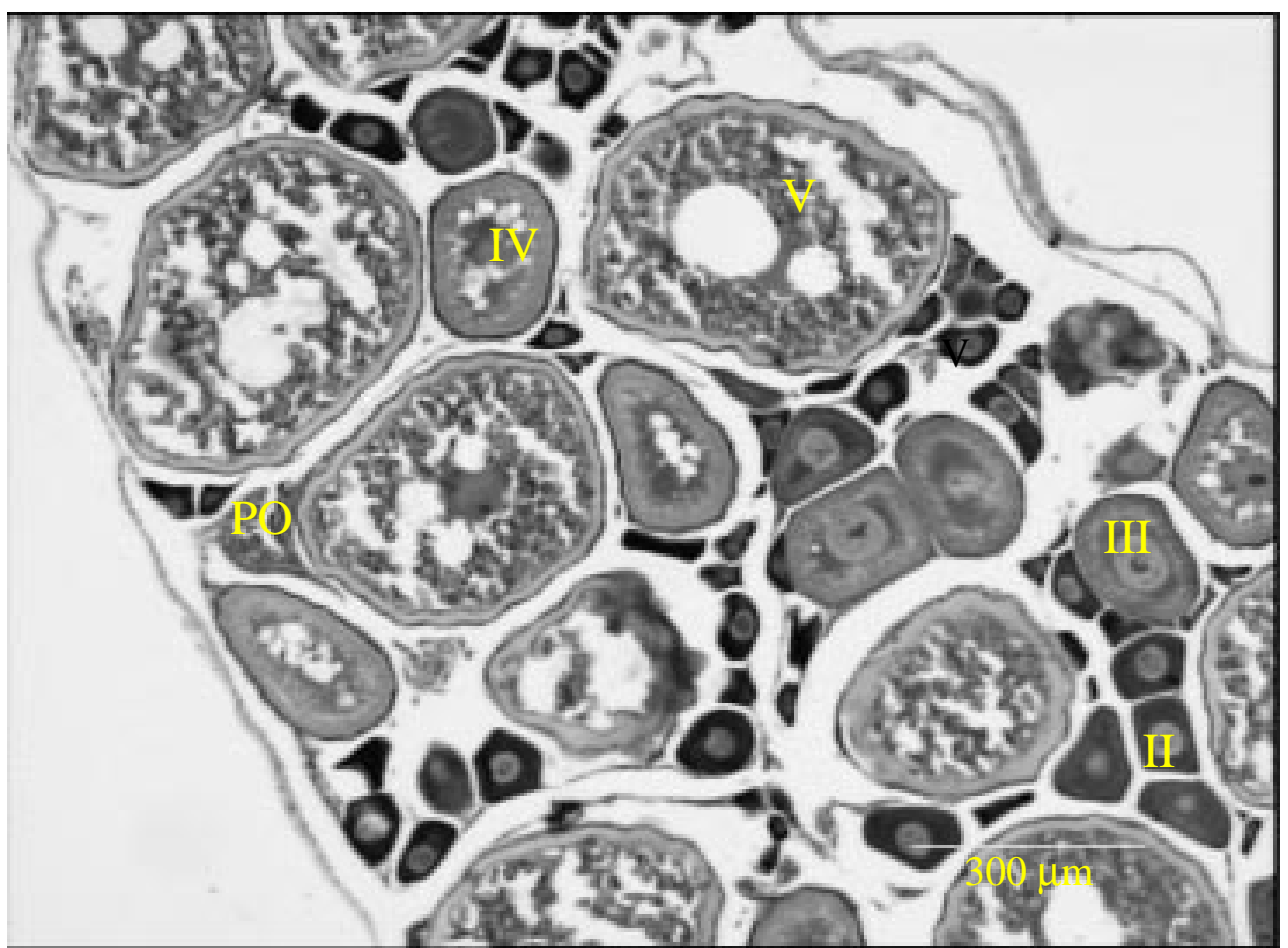

B

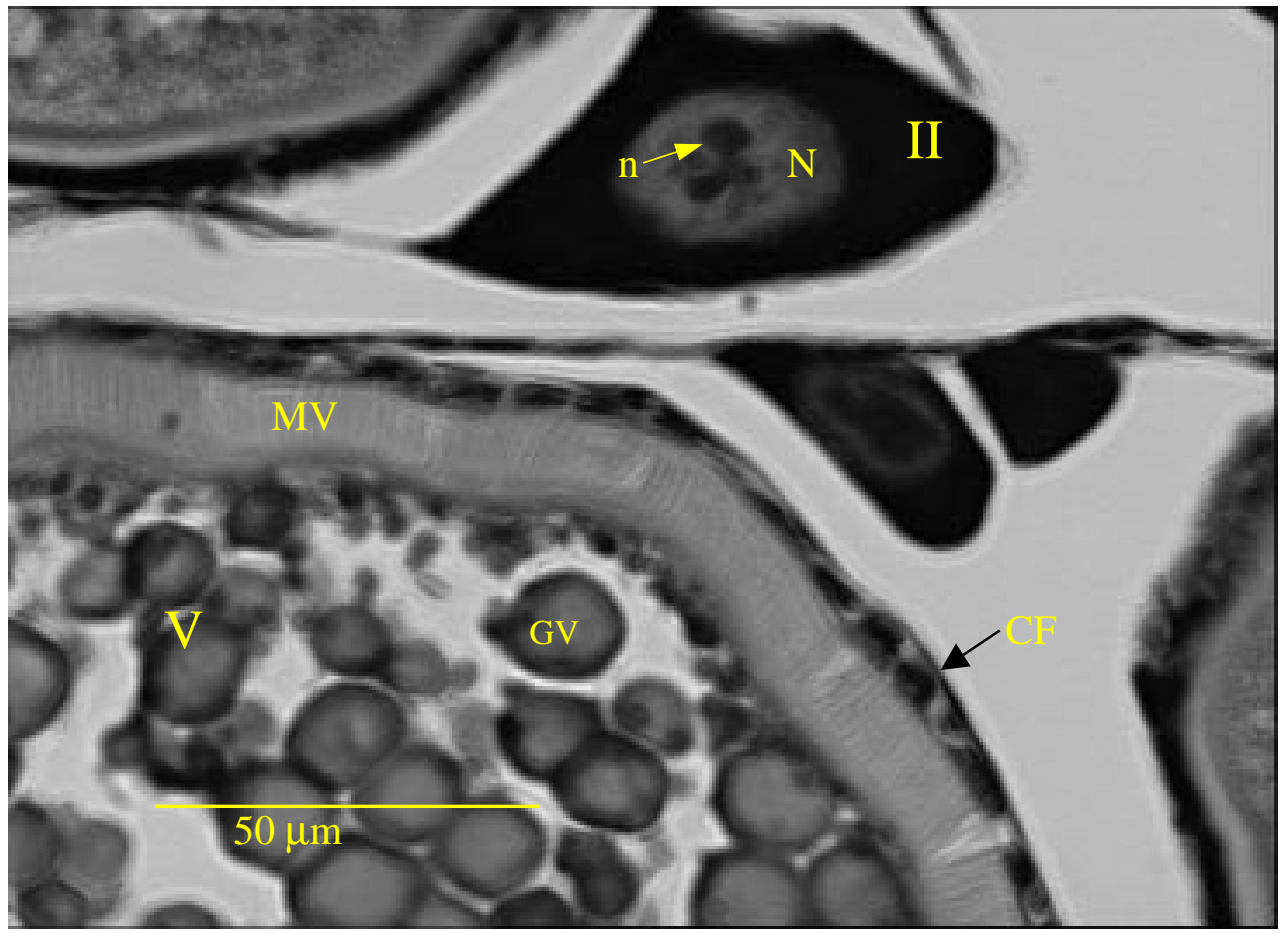

Figura IV.24. Cortes de ovários de fêmeas de Maurolicus stehmanni:

A) Ovário no estádio maduro (C), com ovócitos em diferentes fases de desenvolvimento (II, III, IV e V) e folículo pós-ovulatório (PO).

B) Ovócito na fase V, com vitelogênese completa (V); MV - membrana vitelínica; GP - grânulo proteico e CF - células foliculares e ovócitos na fase II, do estoque de reserva (II): $\mathbf{N}$ - núcleo e $\mathbf{n}$ - nucléolos. 


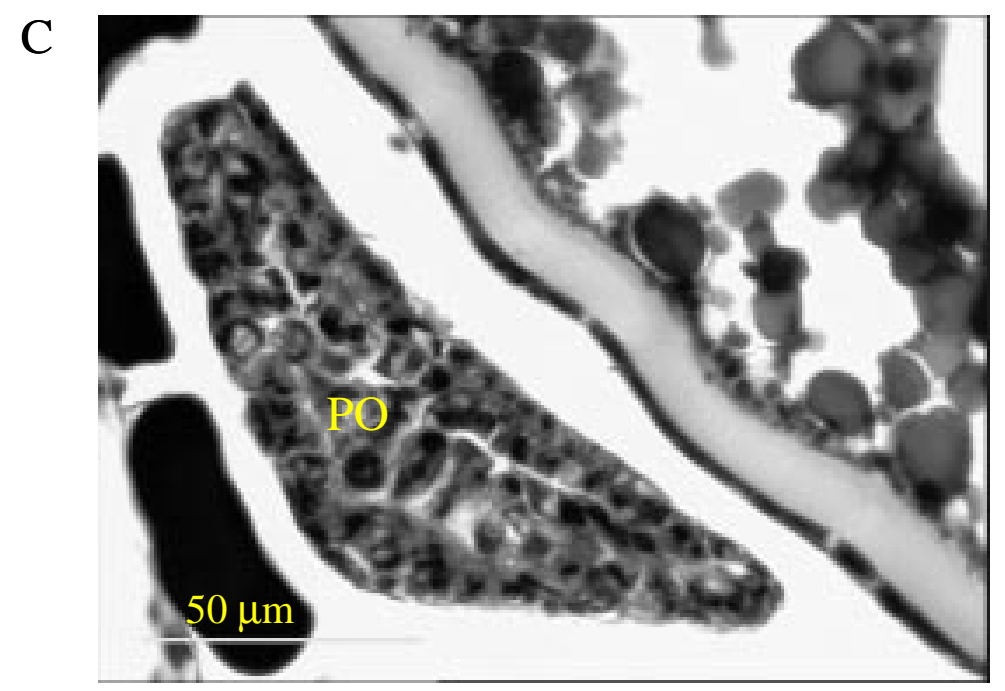

D

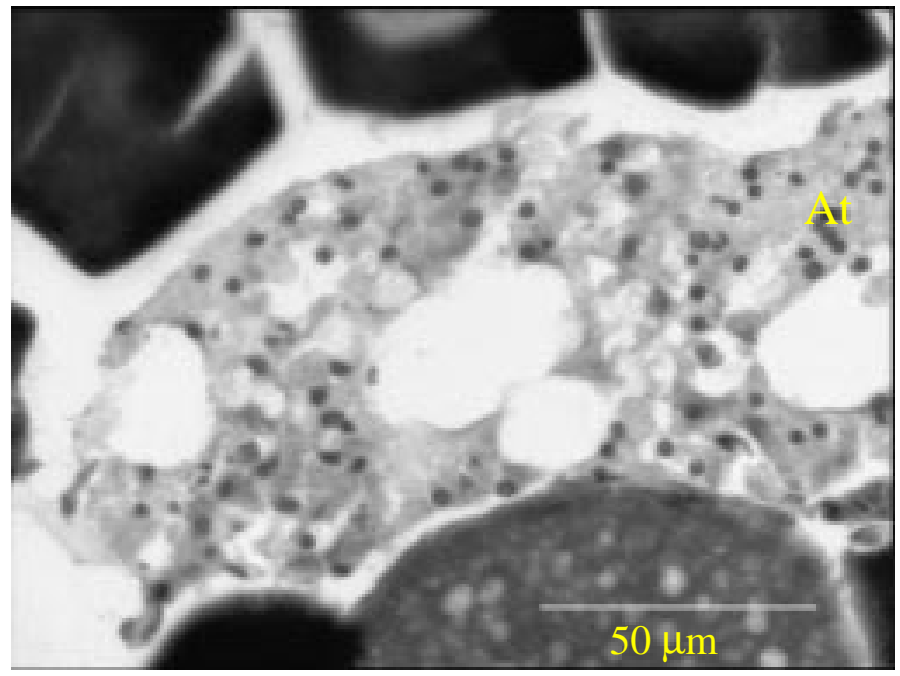

$\mathrm{E}$

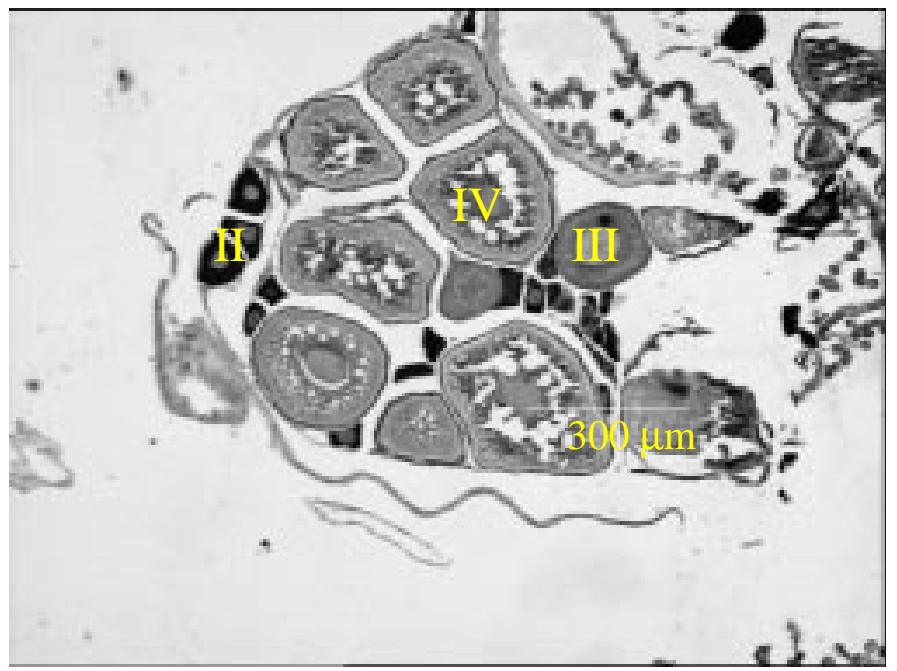

Figura IV.24. (cont.): Cortes de ovários de fêmeas de Maurolicus stehmanni:

C) Folículo pós-ovulatório (PO).

D) Folículo atrésico (At).

E) Ovário no estádio maduro (C) de um peixe com comprimento padrão de $30 \mathrm{~mm}$, apresentando ovócitos em diferentes fases de desenvolvimento (II, III e IV). 
segurança pela presença de PO (desova recente) ou de ovócitos hidratados (desova iminente).

De maneira geral, as classificações dos estádios de maturidade, efetuados sob estereomicroscópio, subestimaram o desenvolvimento ovariano. Verificou-se que o tamanho relativo da gônada de M. stehmanni, bem como sua irrigação, turgidez, o tamanho e opacidade dos ovócitos, não são características adequadas para estimar os estádios de maturidade gonadal. A experiência demonstrou a absoluta necessidade de análise de preparações permanentes com cortes de gônadas para uma definição correta dos mesmos.

Uma vez que os estudos histológicos (item IV.3e) mostraram que houve uma subestimativa nas análises macroscópicas do desenvolvimento gonadal, o valor de $\mathrm{L}_{50 \text { médio }}$ pode ter sido superestimando.

A presença, em um mesmo ovário, de células em várias fases de desenvolvimento e de folículos pós ovulatórios (figura IV.24A) demonstrou que o desenvolvimento ovocitário de $M$. stehmanni é assincrônico.

Melo \& Armstrong (1991), ao estudarem o comportamento reprodutivo da espécie do gênero Maurolicus que ocorre na África do Sul, concluíram haver desova parcelada. Chegaram a esta conclusão após um estudo microscópico das gônadas, onde verificaram a presença de folículos pós ovulatórios, a existência de várias modas na distribuição das frequiências de diâmetro de ovócitos e que o número de ovócitos jovens era sempre maior do que o número de ovócitos mais velhos. Esta é uma característica de peixes que desovam freqüentemente, mas em pequenos intervalos (Prabhu, 1956 apud Melo \& Armstrong, op. cit.), sendo muito comum em espécies com desova prolongada (Hickiling \& Rutemberg, 1936, apud Melo \& Armstrong, op. cit.).

Hunter et al. (1985) mostram que peixes que realizam desova parcelada apresentam gônadas com ovócitos distribuídos em muitas fases de desenvolvimento, variando seu diâmetro de maneira contínua entre ovócitos sem vitelo e ovócitos maduros. West (1990) acrescenta que a presença de várias modas de desenvolvimento ovocitário pode indicar que mais de um lote de ovócitos irá amadurecer, porém são necessárias informações adicionais para confirmar a desova parcelada.

Um peixe que apresenta desenvolvimento ovocitário assincrônico pode apresentar desova total, e os ovócitos não amadurecidos seriam absorvidos (atresia) ou a desova só se daria após o desenvolvimento completo de todos ovócitos nas fases de desenvolvimento mais avançadas. Neste caso, muito provavelmente, a desova seria perceptível pela sua avaliação macroscópica dos ovários, pois estes estariam esvaziados, com aspecto flácido e menor peso, fato não observado.

Assim, os aspectos acima citados e os resultados do presente trabalho sugerem que M. stehmanni realiza desova parcelada. 


\section{CAPITULO V: CRESCIMENTO}

\section{1 INTRODUÇÃO:}

O termo crescimento significa mudança em magnitude, a qual pode ser representada pela variação de uma dimensão física de um organismo (Weatherley \& Gill, 1987). Neste trabalho considerou-se como crescimento o incremento corporal de um indivíduo ao longo do tempo, expresso em tamanho (comprimento padrão).

De toda a energia adquirida pela ingestão de alimentos, uma pequena parte é direcionada para o crescimento somático, enquanto que a maior parte é gasta em manutenção, atividade e reprodução. Do ponto de vista da biologia pesqueira, este crescimento (aliado ao recrutamento), influencia a captura sustentável de um determinado estoque (King, 1996).

Segundo Weatherley \& Gill (op. cit.) o crescimento do peixe apresenta alto grau de plasticidade, sendo que as taxas de crescimento de uma população respondem a diferenças ambientais como temperatura da água, quantidade de alimento disponível e densidade populacional.

Assim, o conhecimento de como se dá o crescimento de Maurolicus stehmanni é interessante não só pelo fato desta espécie ser um potencial pesqueiro da ZEE brasileira, como também por seu importante papel na produtividade e na transferência de energia entre os componentes iniciais e finais da cadeia trófica no ecossistema de quebra de plataforma.

O objetivo específico deste capítulo foi o de estimar os parâmetros de crescimento de Maurolicus stehmanni por meio de 1) Anéis em otólitos (método direto) e 2) Dados de distribuição de freqüência de comprimento (método indireto) o que viabilizaria a identificação da composição das capturas em idade e a avaliação do estoque. 


\section{2 MATERIAL E MÉTODOS}

Nos estudos sobre crescimento apenas o material coletado durante os cruzeiros I, II e III foi utilizado.

\section{2a: Método direto:}

\section{2a1: Análise de otólitos e obtenção de dados:}

Foram realizadas análises preliminares nos otólitos sagittae, que serviram tanto como treinamento para o observador como para identificar: a melhor forma de leitura em relação ao tipo de luz (incidente ou refletida); a necessidade de utilização de meio de imersão (foram experimentados álcool e xilol); o plano de leitura e a orientação do eixo de leitura para a tomada de medidas.

O otólito sagitta de M. stehmanni é achatado lateralmente, sendo que sua face interna é relativamente plana e, a externa, convexa, com o centro determinando a porção mais lateral do otólito (em sua posição natural) ou a sua altura (na posição de leitura). Apresenta um rostro (região anterior) proeminente e pontiagudo, muito delicado, com várias irregularidades na sua face ventral, que tende a aumentar em complexidade conforme os indivíduos aumentam de

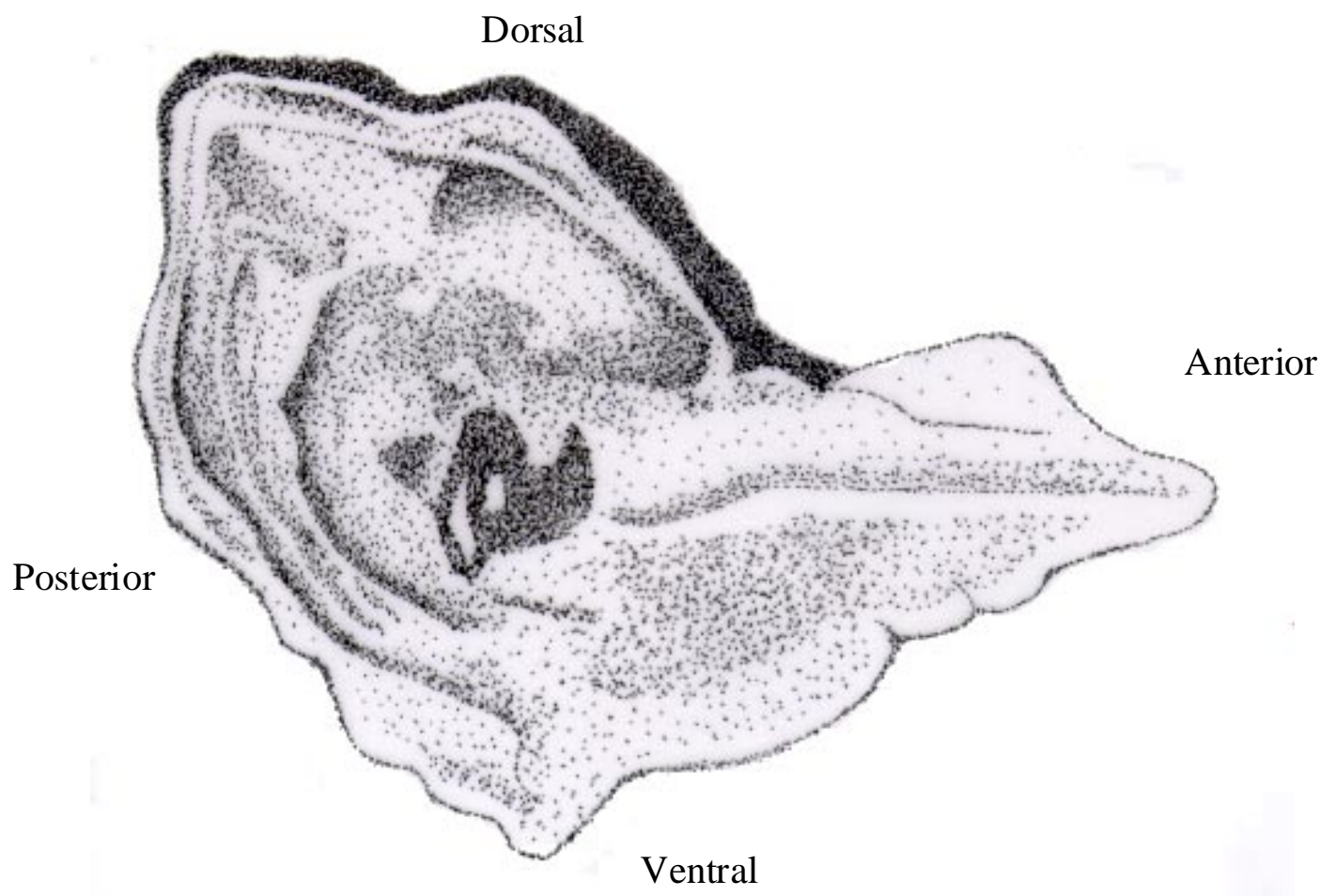

Figura V.1. M. stehmanni: Esquema da face externa do otólito sagitta. 
tamanho (figura V.1.).

Os otólitos direitos, imersos em álcool a $70 \%$, dentro de um cadinho de cor preta, com sua face externa voltada para cima, foram examinados sob esteremicroscópio de luz equipado com escala micrométrica, sob iluminação incidente.

O padrão mais comum encontrado nestas estruturas foi o de um núcleo opaco e espesso e, nas porções mais externas, zonas translúcidas (escuras) e opacas (claras) alternadas.

Foi considerado anel completo a seqüência de uma zona opaca e uma zona translúcida, seguida de uma zona opaca (esta última indicando o início de um novo anel). Os indivíduos foram separados em grupos, em função do número de anéis completos encontrados, da seguinte forma: sem anel completo - grupo de 0 anéis $\left(G_{0}\right), 1$ anel completo - grupo de de 1 anel $\left(G_{1}\right)$ e assim por diante.

Além da contagem do número de anéis, foram tomadas as medidas do raio do otólito (Ro): distância entre o centro e a borda externa do otólito; e dos raios dos anéis completos $\left(\mathrm{R}_{\mathrm{i}}\right)$ : distância entre o centro e a borda externa de cada anel, ou seja, o extremo da zona translúcida.

Todas as medidas foram realizadas sobre o eixo de leitura correspondente à reta traçada a partir do centro do núcleo até a projeção da margem posterior e dorsal, conforme ilustrado na figura V.2.

Também foi analisada a borda do otólito, no sentido de apresentar-se opaca ou

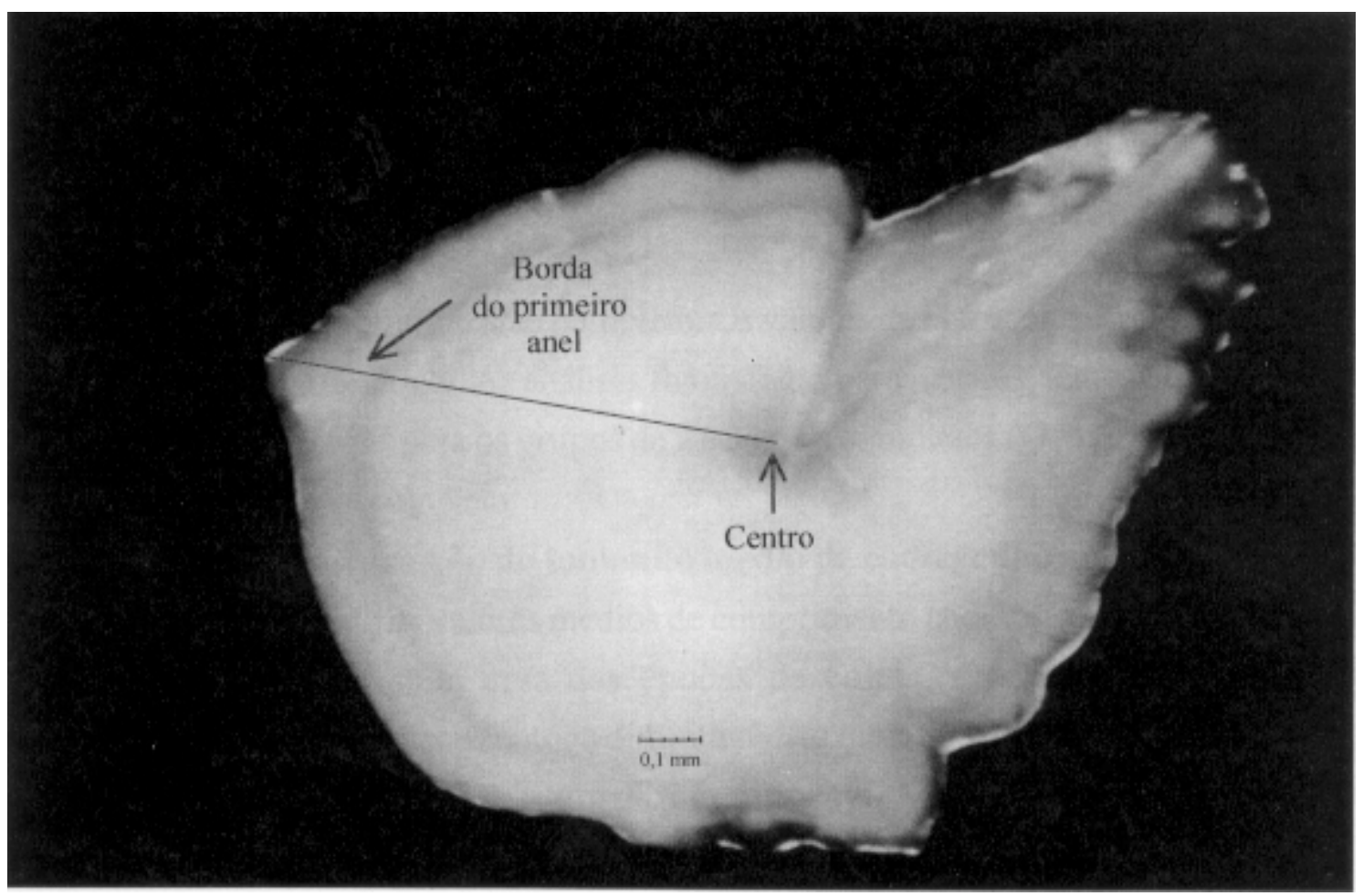

Figura V.2. Otólito de Maurolicus stehmanni. A reta representa o eixo de leitura adotado. 


\section{translúcida.}

A ocorrência de finas zonas translúcidas, sem continuidade ao longo de todo o otólito foi considerada como falso anel.

Procurou-se ler cerca de 6 otólitos por classe de comprimento para cada época de coleta, abrangendo toda a área. Cada otólito foi analisado duas vezes e quando houve diferença entre as leituras uma terceira foi realizada; permanecendo a incerteza, o otólito foi desconsiderado para análises.

\section{2a2: Periodicidade e época de formação dos anéis:}

Análises que levem ao conhecimento sobre a periodicidade e, portanto, sobre a época de formação dos anéis, são fundamentais para validá-los, permitindo atribuir, aos mesmos, idades absolutas. Foram realizadas cinco tipos de análises:

- Análise da frequiência da ocorrência de bordas opacas e translúcidas no tempo. Foi calculada a frequiência de ocorrência (em porcentagem) de cada tipo de borda nos períodos de estudo. As análises foram feitas por grupo de anel separadamente e para todos os grupos em conjunto.

- Estudo da variação sazonal do incremento marginal (IM). Lançou-se em gráficos de dispersão os valores deste índice para cada grupo de anel; os cálculos foram realizados separadamente para machos, fêmeas e para a amostra total, para cada época de coleta. O IM foi calculado usando a seguinte equação:

$$
\begin{gathered}
\mathbf{I M}=\left(\mathbf{R o}-\mathbf{R}_{\mathrm{n}}\right) / \mathbf{R o} \text { onde, } \\
\mathrm{Ro}=\text { raio do otólito e } \mathrm{R}_{\mathrm{n}}=\text { raio do último anel completo. }
\end{gathered}
$$

- Estudo da variação sazonal do índice de crescimento marginal (G), que é dado pela formula:

$$
\mathbf{G}=\left(\mathbf{R o}-\mathbf{R}_{\mathbf{n}}\right) /\left(\mathbf{R o}-\mathbf{R}_{\mathrm{n}-1}\right) \quad \text { onde, }
$$

$\mathrm{R}_{\mathrm{n}-1}=$ raio do penúltimo anel completo. Os valores de $\mathbf{G}$ foram lançados em gráficos de dispersão por época de coleta. As análises foram feitas para machos, fêmeas e amostra total e só puderam ser realizadas para os grupos de 2 e 3 anéis completos $\left(\mathrm{G}_{2}\right.$ e $\left.\mathrm{G}_{3}\right)$, já que só estes possuíam mais de um anel completo.

- Estudo da variação do tamanho médio de cada grupo ao longo do tempo: foram lançados em gráfico os valores médios de comprimento padrão de cada grupo de anéis $\left(\mathbf{G}_{\mathbf{0}}, \mathbf{G}_{\mathbf{1}}, \mathbf{G}_{\mathbf{2}}\right.$ e $\left.\mathbf{G}_{\mathbf{3}}\right)$ para cada uma das épocas de coleta, procurando-se identificar descontinuidades em seu crescimento; a diminuição no tamanho médio de um grupo etário representaria o intervalo de tempo da formação de um novo anel. Estas análises foram realizadas separadamente para machos, fêmeas e amostra total.

- Estudo da variação sazonal do fator de condição. Os valores médios de K obtidos para cada época de coleta (item III. 2B) foram lançados em gráfico com o intuito de se 
observar possíveis descontinuidades deste fator ao longo do tempo.

\section{2a3: Relação entre o raio do otólito e o comprimento padrão.}

Procurando verificar qual o tipo de relação existente entre o raio do otólito (Ro) e comprimento padrão (Cp) e se esta estrutura era adequada para estudar o crescimento desta espécie, os valores destas variáveis foram lançados em gráficos de dispersão. Os valores discrepantes, quando identificados, foram averiguados e corrigidos ou retirados das análises. Aos dados de Ro e Cp foi ajustada equação do tipo linear, pelo método dos mínimos quadrados, e calculado o coeficiente de determinação $\left(\mathrm{r}^{2}\right)$.

Este procedimento foi adotado inicialmente para os dados de machos e fêmeas separadamente, realizando-se teste t para verificar a existência de diferenças significativas entre os sexos para os parâmetros obtidos.

\section{2a4: Retrocálculo}

Retrocálculo é uma técnica empregada para estimar o tamanho do peixe em idades pretéritas. A partir de um conjunto de dados representativos da população contendo o (s) tamanho (s) da (s) zonas (s) em partes duras (anéis em otólitos, escamas, espinhos etc.) e o comprimento atual do peixe, calcula-se o tamanho médio que este peixe teria no momento da formação de cada marca (Francis, 1990).

O retrocálculo dos comprimentos padrões em cada grupo de anel foi efetuado para cada indivíduo e em seguida foi obtida a média para cada grupo utilizando-se os seguintes métodos:

- "Body Proportional Hypotesis" (BPH), calculado pela fórmula:

$$
\mathbf{C} \mathbf{p}_{\mathrm{i}}=\left(\left(\mathbf{c}+\mathbf{d} * \mathbf{R o}_{\mathrm{i}}\right) /(\mathbf{c}+\mathbf{d} * \mathbf{R o}) * \mathbf{C p}\right.
$$

- "Scale Proportional Hypotesis" (SPH), utilizando a fórmula:

$$
\mathbf{C} \mathbf{p}_{\mathbf{i}}=(\mathbf{a} / \mathbf{b})+(\mathbf{C p}+\mathbf{a} / \mathbf{b}) *\left(\mathbf{R o}_{\mathbf{i}} / \mathbf{R o}\right), \text { onde, }
$$

$\mathbf{C p}=$ comprimento padrão do peixe no momento da captura

$\mathbf{C} \mathbf{p}_{\mathbf{i}}=$ comprimento padrão estimado do peixe na idade $i$.

$\mathbf{R o}=$ raio total do otólito.

$\mathbf{R o}_{\mathrm{i}}=$ raio do anel correspondente a idade $\mathrm{i}$.

$\mathbf{a}$ e $\mathbf{b}=$ parâmetros da relação linear entre $\mathbf{R o} \times \mathbf{C p}$ (item anterior).

$\mathbf{c}$ e $\mathbf{d}=$ parâmetros da relação linear entre $\mathbf{C p} \times \mathbf{R o}$, que foram estimados pelo método dos mínimos quadrados.

As hipóteses SPH e PBH assumem que há proporcionalidade (constante ao longo da vida do peixe) no desvio da média dos tamanhos da estrutura e do corpo, respectivamente (Francis, 1990). 


\section{2a5: Parâmetros de crescimento}

Buscando descrever o crescimento de M. stehmanni foi adotado o modelo de crescimento de von Bertalanffy, representado pela seguinte equação:

$$
\mathbf{C p}=\mathbf{L} \infty *\left(1-\mathbf{e}^{-\mathrm{k}(\mathrm{t}-\mathrm{to})}\right) \text { onde, }
$$

Cp e t - tamanho e idade do peixe - são as variáveis da equação, enquanto que $\mathbf{L} \infty$, k e $\mathbf{t}_{\mathbf{0}}$ são os chamados parâmetros da equação.

Lo é o comprimento assintótico, tamanho que o peixe teria na idade infinita; $\mathbf{k}$ é a taxa de crescimento, representando a velocidade com que o peixe se aproxima de $\mathbf{L} \boldsymbol{\infty}$; e $\mathbf{t}_{\mathbf{0}}$ que em termos biológicos representa a idade (teórica) do peixe com tamanho igual a zero.

Os parâmetros da curva de crescimento foram calculados utilizando-se duas séries de valores: 1) Tamanhos médios dos indivíduos em cada grupo de anéis $\left(\mathbf{G}_{\mathbf{0}}, \mathbf{G}_{\mathbf{1}}, \mathbf{G}_{\mathbf{2}}\right.$ e $\left.\mathbf{G}_{\mathbf{3}}\right)$ no momento da captura $\left(\mathbf{C p}_{\mathbf{c}}\right)$ e 2) Tamanhos retrocalculados médios dos mesmos grupos $\left(\mathbf{C p}_{\mathbf{i}}\right)$.

Os métodos de cálculo foram três:

- Método de Ford-Walford (Ford, 1993 e Walford, 1946 apud Sparre \& Venema, 1997) trata-se de um método gráfico simples e para cálculo foi realizada a seguinte rotina, baseada em Vazzoler (1981):

1) Os valores de comprimento médio do peixe na idade $\mathrm{t}\left(\mathrm{Cp}_{\mathrm{t}}\right)$ e o comprimento médio dos peixes na idade seguinte $\left(\mathrm{Cp}_{\mathrm{t}+1}\right)$ foram lançados em gráficos de dispersão e a seguir calculado, pelo método dos mínimos quadrados, os parâmetros (a e b) da regressão:

$$
C p_{t+1}=a+b^{*} C p_{t}
$$

2) Estimou-se o L $\infty$ considerando, na equação acima, $\mathrm{Cp}_{\mathrm{t}+1}=\mathrm{Cp}_{\mathrm{t}}$, ou seja, o momento em que cessa (ou fica constante) o crescimento, assim:

$$
\mathbf{L} \infty=\mathbf{a} /(\mathbf{1 - b})
$$

3) Lançou-se em gráfico de dispersão os valores do logaritmo natural de $\left(\mathrm{L} \infty-\mathrm{C} \mathrm{p}_{\mathrm{t}}\right) \mathrm{e}$ a idade (t), estimando-se os parâmetros ( $\mathbf{c}$ e d) da regressão abaixo, também pelo método dos mínimos quadrados.

$$
\operatorname{Ln}\left(\mathbf{L} \infty-\mathbf{C p}_{\mathbf{t}}\right)=\mathbf{c}+\mathbf{d} * \mathbf{t} \text { onde, }
$$

a taxa de crescimento $(\mathrm{k})$ será igual ao valor, em módulo, da inclinação da reta (d) e o $\mathrm{t}_{0}$, corresponde ao tempo $(\mathrm{t})$ em que o peixe teria $\mathrm{Cp}$ igual a 0 , assim:

$$
\begin{aligned}
& k=/ b / e \\
& t_{0}=(c-\operatorname{Ln}(\operatorname{L} \infty)) / k
\end{aligned}
$$

- Método de Bayley: (Bayley, 1997).

Foram executados os seguintes passos:

1) A partir do $\mathbf{C} \mathbf{p}_{\mathbf{t}}$, foi calculado o peso médio $\left(\mathbf{W}_{\mathbf{t}}\right)$ para cada grupo de anel, utilizando 
os dados da equação da relação entre o peso e o comprimento padrão (item III. 2 B).

2) Cálculo do crescimento instantâneo $(\mathrm{G})$,

$$
\mathbf{G}=\mathbf{L n}\left(\mathbf{W}_{t+1}\right)-\mathbf{L n}(\mathbf{W t}) \text { onde, }
$$

$\mathrm{W}_{\mathrm{t}}$ é o peso médio do peixe na idade $\mathrm{t}$ e $\mathrm{W}_{\mathrm{t}+1}$ é o peso médio do peixe na idade seguinte.

3) Lançamento, em gráfico de dispersão, dos valores de $\mathbf{G}$ e 1/C $\mathbf{p}_{\mathbf{t}}$, calculando-se a seguir os parâmetros da regressão linear $(u$ e $v)$ entre estas variáveis, pelo método dos mínimos quadrados.

$$
\mathbf{G}=u+v^{*} \mathbf{C p}
$$

4) Cálculo de L $\infty$ e k pelas equações:

$$
\begin{aligned}
& \mathbf{L} \infty=-v / u \\
& \mathbf{k}=-\boldsymbol{u} / \mathbf{b} \text { onde, }
\end{aligned}
$$

b é o coeficiente angular da regressão peso/comprimento padrão.

5) Para estimar do valor de $\mathbf{t}_{\mathbf{0}}$ lançou-se mão da equação de crescimento de von Bertalanffy transformada:

$$
t_{0}=t+(1 / k)\left(\operatorname{Ln}\left(\left(\operatorname{L} \infty-C_{p}\right) / L \infty\right)\right.
$$

Utilizando os valores de $\mathbf{k}$ e L $\boldsymbol{\infty}$ obtidos e os valores de comprimento médio de cada grupo de anel $\left(\mathbf{C p}_{\mathbf{t}}\right)$ calculou-se o $\mathbf{t}_{\mathbf{0}}$ para cada um destes grupos, considerando-se a média dos valores de $\mathbf{t}_{\mathbf{0}}$ obtidos.

- Método de von Bertalanffy: este método estima o valor de $\mathbf{t}_{\mathbf{0}} \mathrm{e} \mathbf{k}$, porém $\mathbf{o}$ valor de Lo deve estar disponível (King, 1996).

Inicialmente calculou-se os parâmetros da regressão linear entre a idade te o logaritmo natural de $1-\mathrm{Cp} / \mathrm{L} \infty$.

$$
\operatorname{Ln}(1-C p / L \infty)=a+b * t
$$

$\mathrm{O}$ valor de $\mathrm{k}$ corresponde à inclinação da reta $(\mathbf{b})$ e o valor de $\mathrm{t}_{0}$ foi estimado a partir da equação:

$$
\mathbf{t}_{\mathbf{0}}=-\mathbf{a} / \mathbf{b}
$$

Foi utilizada a formula de Taylor (Taylor, 1962) para estimar o L $\infty:$

$$
\mathbf{L} \infty=\mathbf{C p}_{\max } / \mathbf{0 , 9 5} \text { onde, }
$$

$\mathbf{C} \mathbf{p}_{\max }$ é o tamanho do maior peixe amostrado (em comprimento padrão). 


\section{2b: Método indireto}

No sentido de comparar os resultados obtidos pelo método direto foram aplicados às séries de dados de freqüência de comprimento a rotina ELEFAN I e o método Bhattacharya, ambos inseridos no pacote computacional FISAT (Gayanilo \& Pauly, 1997).

\section{2b1: Rotina ELEFAN I:}

Este software estima os parâmetros Lo e k da curva de crescimento de von Bertalanffy, a partir de dados de distribuição de freqüência de classes de comprimento. O método se baseia na análise de progressão modal, onde várias amostras de distribuição de freqüência de comprimento são dispostas seqüencialmente e as progressões das modas servem para inferir sobre o crescimento (Longhurst \& Pauly, 1987).

O método foi aplicado a duas séries de dados.

1) Distribuição de frequiência das classes de comprimento padrão para cada um dos três cruzeiros (apresentada na figura IV.2.) e;

2) Distribuição de freqüência das classes de comprimento para os três cruzeiros agrupados (apresentada na figura IV.1.).

A seguir descreve-se brevemente os procedimentos executados pelo programa:

1) Reestruturação dos dados: tem por objetivo identificar os picos (valores positivos) que representam diferentes coortes. Neste momento são realizados os seguintes passos: A) Cálculo da média móvel das frequiências de cada classe de comprimento, sobre 5 classes. B) Divisão do valor da frequiência da classe (valor observado) pela média móvel desta classe obtendose a frequiência ajustada. C) Cada freqüência ajustada é dividida pela média das frequiências ajustadas da amostra e subtraída de 1. D) Reajuste final dos valores. E) Os valores iguais a -1 são substituídos por 0 e os valores negativos multiplicados pela razão entre a soma dos valores positivos e a soma dos valores negativos (Sparre \& Venema, 1997). O software apresenta os resultados em forma de planilha.

2) Utilizando estas planilhas o pesquisador deve escolher o (s) ponto (s) inicial (ais) chamado (s) de (s) 'Starting Point" (SP) representado (s) por uma determinada amostra (SS) e classe de comprimento (SL). A partir do SP são traçadas curvas de crescimento. Deve-se aplicar como SP os maiores valores obtidos após a reestruturação, que representam as maiores modas. Segundo Issac-Nahum (1989), uma vez que as idades das coortes são desconhecidas, o programa não é capaz de estimar o $\mathbf{t}_{\mathbf{0}}$, parâmetro que fixa a curva de crescimento ao eixo da abcissa; assim a curva é projetada a partir de $\mathbf{S P}$, que tem o papel de substituir $\mathrm{t}_{0}$.

3) A partir dos dados reestruturados, do SP e, de valores iniciais para os parâmetros L $\infty$ e k ("seed values") o programa projeta uma nova planilha realçando os maiores valores de $\mathrm{Rn}$ para valores de $\mathrm{k}$ e $\mathrm{L} \infty$. Rn é um índice de ajuste, e é dado pela equação: 


$$
\mathbf{R n}=\mathbf{1 0}^{(\mathrm{ESP} / \mathrm{ASP})} / \mathbf{1 0} \text { onde, }
$$

ASP (“available sum of peaks") representa a soma dos picos (valores positivos) presentes em todas as amostras e ESP (“explained sum of peaks”) é a soma de todos os pontos (negativos e positivos) sobre os quais cada curva passa. Este passo deve ser repetido várias vezes, para diferentes SPs.

O procedimento foi realizado para as duas séries de dados descritas utilizando-se diferentes SPs. Foram escolhidas as curvas que apresentaram os maiores valores de Rn e maior número de coincidências entre os picos e as curvas, considerando-se também aspectos como: os resultados obtidos da leitura de otólitos; os resultados disponíveis na literatura sobre o gênero; que um número excessivo de coortes causa uma sobreposição das coortes de maior idade; o tamanho do peixe no primeiro ano de vida e sua data de nascimento.

O valor de $\mathbf{t}_{\mathbf{0}}$ foi estimado utilizando-se a fórmula empirica de Pauly (1979):

$$
\log \left(-t_{0}\right)=-0,3922-0,2753 * \log L \infty-1.038 * \log k
$$

\section{2b2: Método Bhattacharya (1967 apud Sparre \& Venema, 1997)}

Este método consiste na decomposição das distribuições de comprimento em curvas normais sobrepostas, que representariam diferentes coortes (Sparre \& Venema, 1997). Aplicouse o método, contido no pacote computacional FISAT (Gayanilo \& Pauly, 1997), aos dados da amostra total e, a seguir, a partir das médias de Cp obtidas para cada coorte, foram calculados os parâmetros de crescimento $\mathbf{k}$ e $\mathbf{t}_{\mathbf{0}}$ pelo método de von Bertalanffy (King, 1996) e Lo pela fórmula de Taylor (Taylor, 1962), descrito no item V. 2 a5.

\section{2c: Comparação entre os resultados deste estudo e os da literatura.}

Foi calculado o índice de performance de crescimento $(\Phi)$ com o intuito de comparar os parâmetros de crescimento obtidos pelos diferentes métodos e valores apresentados pela literatura para espécies do gênero Maurolicus. Como sugere Issac-Nahum (1989) este índice busca identificar possíveis diferenças entre estoques em relação a características energéticas, nicho ecológico e também erros de estimativas. Utilizou-se a seguinte equação:

$$
\Phi=\log (k)+2 * \log (\operatorname{L} \infty)
$$

Os valores de $\mathrm{k}$ e $\mathrm{L} \infty$ obtidos neste estudo e aqueles encontrados na literatura foram lançados em gráfico de dispersão. Também foram traçadas curvas auximétricas de valores de $\boldsymbol{\Phi}$, de modo semelhante ao apresentado por Issac-Nahum (op. cit.).

A comparação entre espécies e diferentes estudos também foi feita pela análise das diferentes curvas de crescimento, levando-se em consideração aspectos como o tempo necessário para se alcançar o L $\infty$ e o tamanho no primeiro ano de vida. 


\section{3 RESULTADOS:}

\section{3a: Método direto:}

\section{3a1: Análise dos otólitos}

Foram analisados 872 otólitos, mas 165 não foram considerados nas análises devido à dificuldade de identificação dos anéis ou do centro da estrutura. Foram encontrados até 3 anéis completos nos otólitos, totalizando 4 grupos $\left(\mathrm{G}_{0}, \mathrm{G}_{1}, \mathrm{G}_{2}\right.$ e $\left.\mathrm{G}_{3}\right)$ (figura V.3A, B, C e D). Da amostra utilizada constaram peixes com comprimentos padrão máximos e mínimos de 50 e $14 \mathrm{~mm}$, respectivamente.

Os valores dos comprimentos padrão médios e dos raios médios dos otólitos, obtidos por grupo de anel estão apresentados na tabela V.1. Verificou-se que as médias de Cp e Ro aumentaram de acordo com o grupo, embora as diferenças de comprimento padrão e dos raios entre os grupos $\mathrm{G}_{2}-\mathrm{G}_{1}$ e $\mathrm{G}_{3}-\mathrm{G}_{2}$ tenham sido semelhantes.

Tabela V.1. M. stehmanni: Valores médios de comprimento padrão e raio dos otólitos por grupo de anel. $\mathrm{N}$ - número de otólitos analisados em cada grupo; $\mathrm{Cp}$ comprimento padrão médio; Ro - raio médio do otólito e dp - desvios padrão.

\begin{tabular}{|c|c|c|c|c|c|}
\hline Grupo de anel & $\mathbf{N}$ & $\mathbf{C p}(\mathbf{m m})$ & $\mathbf{d p}$ & $\mathbf{R o}(\mathbf{m m})$ & $\mathbf{d p}$ \\
\hline $\mathrm{G}_{0}$ & 244 & 25,3 & 5,0 & 0,55 & 0,093 \\
\hline $\mathrm{G}_{1}$ & 245 & 34,3 & 4,1 & 0,73 & 0,065 \\
\hline $\mathrm{G}_{2}$ & 159 & 38,6 & 3,7 & 0,80 & 0,051 \\
\hline $\mathrm{G}_{3}$ & 59 & 42,9 & 2,9 & 0,86 & 0,041 \\
\hline
\end{tabular}

$\mathrm{Na}$ figura V.4. estão representados os valores obtidos para os raios de cada um dos anéis em função do comprimento padrão, observando-se que a dispersão dos valores entre os diferentes grupos foi pequena em relação à dispersão total dos raios dos anéis. Constatou-se que, independentemente do tamanho do peixe, o raio de cada um dos anéis se manteve relativamente constante, embora tenha se verificado alguma sobreposição.

Observou-se em 135 otólitos uma fina zona translúcida com raio médio de $0,46 \mathrm{~mm}$ e amplitude de 0,25 a 0,55 mm. Devido à pequena distância desta zona ao centro do otólito, sua ocorrência em apenas $19 \%$ dos otólitos analisados e a existência de descontinuidade ao longo do otólito, considerou-se esta zona como sendo um falso anel. 
A

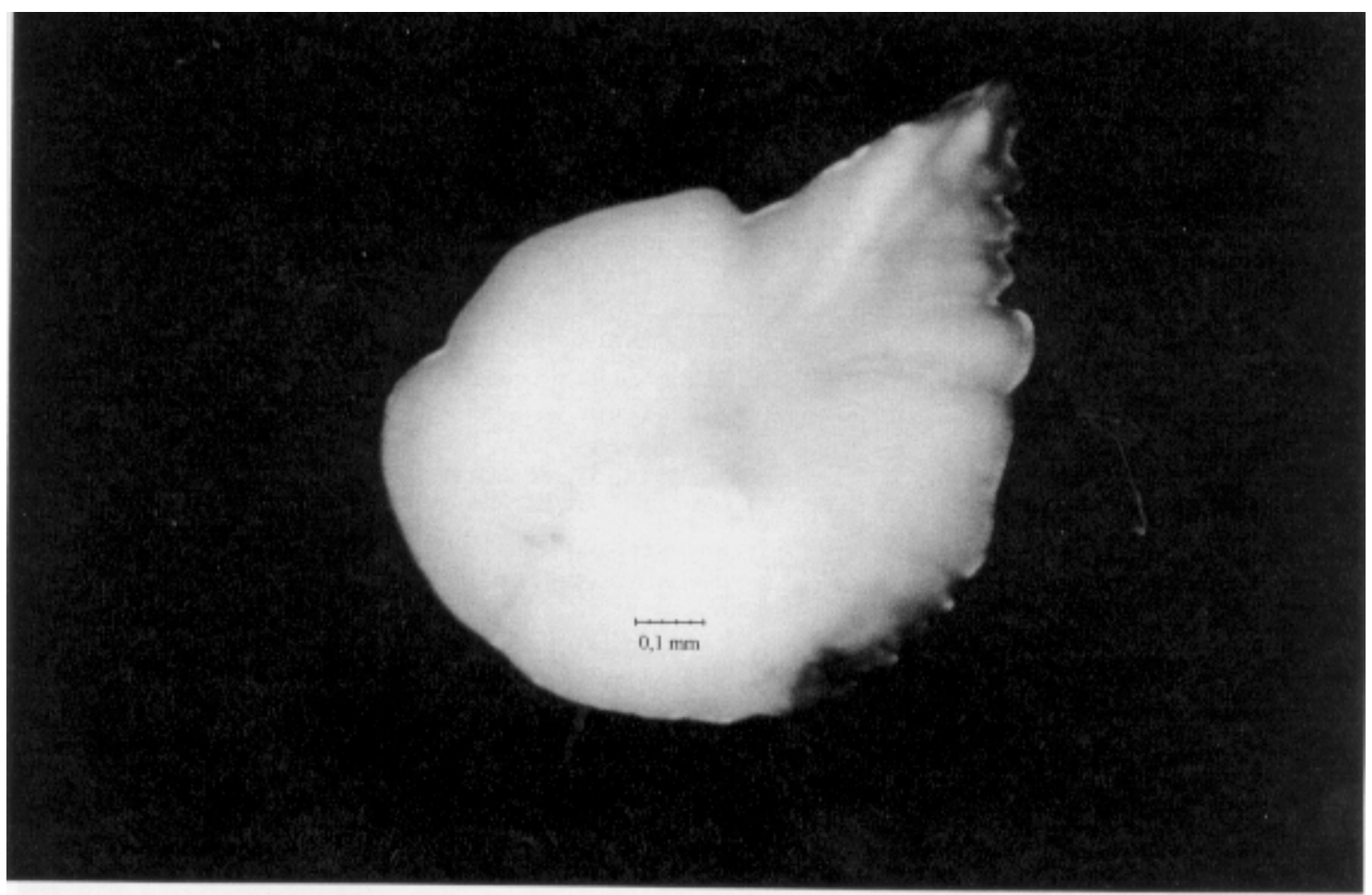

B

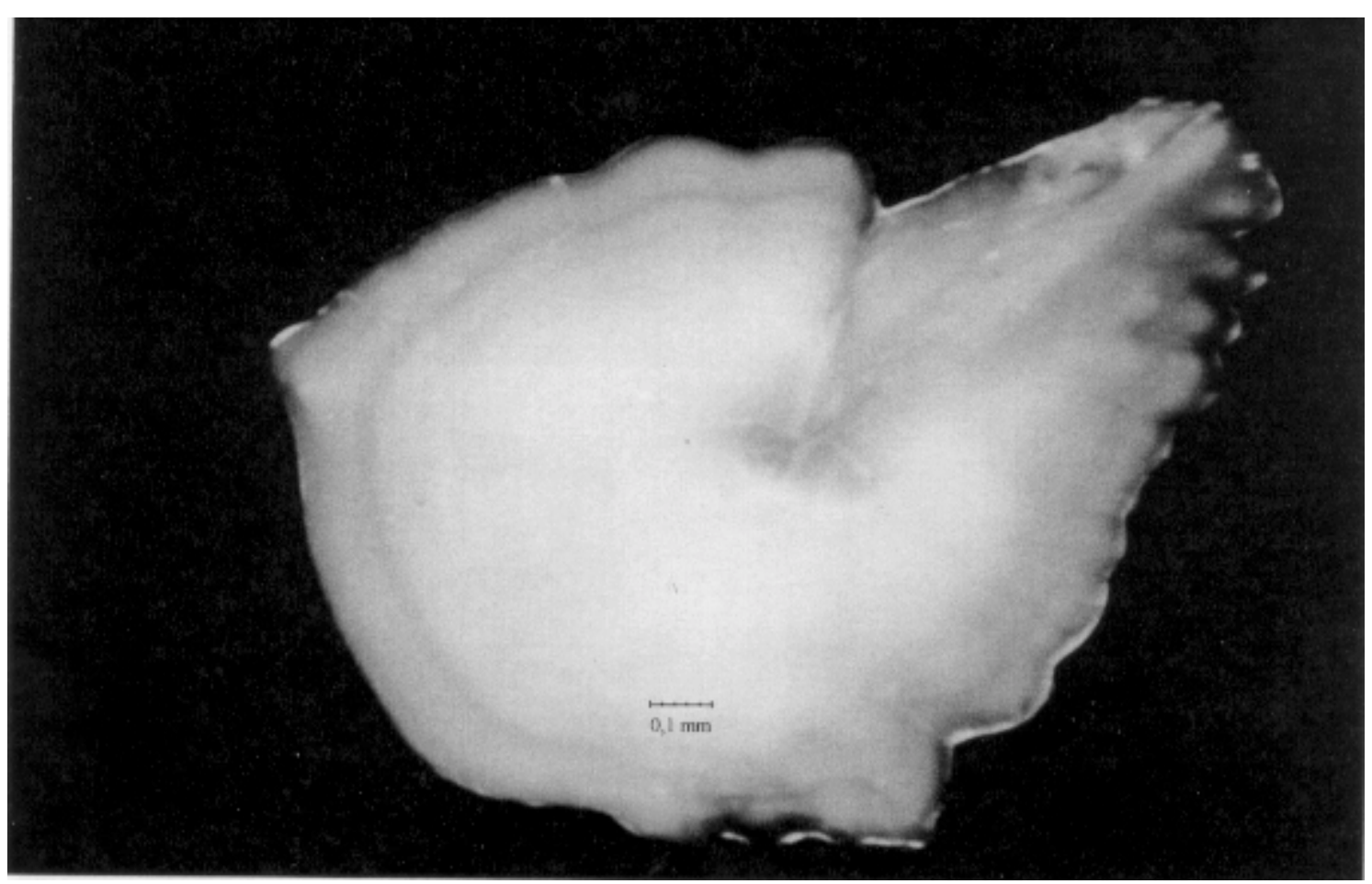

Figura V.3. Otólitos de M. stehmanni mostrando diferentes grupos de anéis. A - 0 anéis, $\mathrm{Cp}=29 \mathrm{~mm}$ e $\mathrm{B}-1$ anel, $\mathrm{Cp}=36 \mathrm{~mm}$. 
C
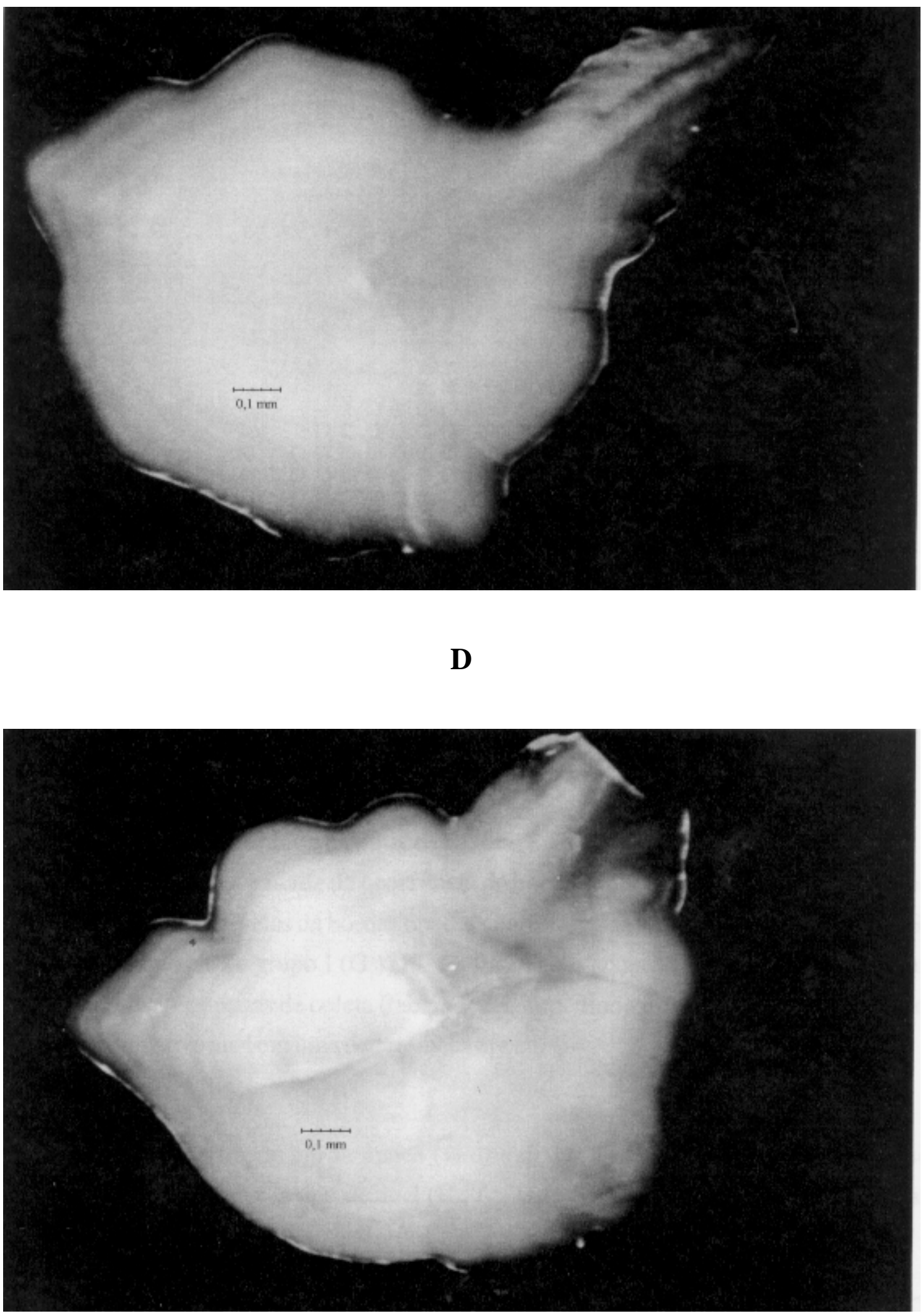

Figura V.3. (continuação) Otólitos de $M$. stehmanni mostrando diferentes grupos de anéis. C- 2 anéis, $C p=41 \mathrm{~mm}$ e $D-3$ anéis, $C p=42 \mathrm{~mm}$. 


\section{Raio do anel x Comprimento padrão}

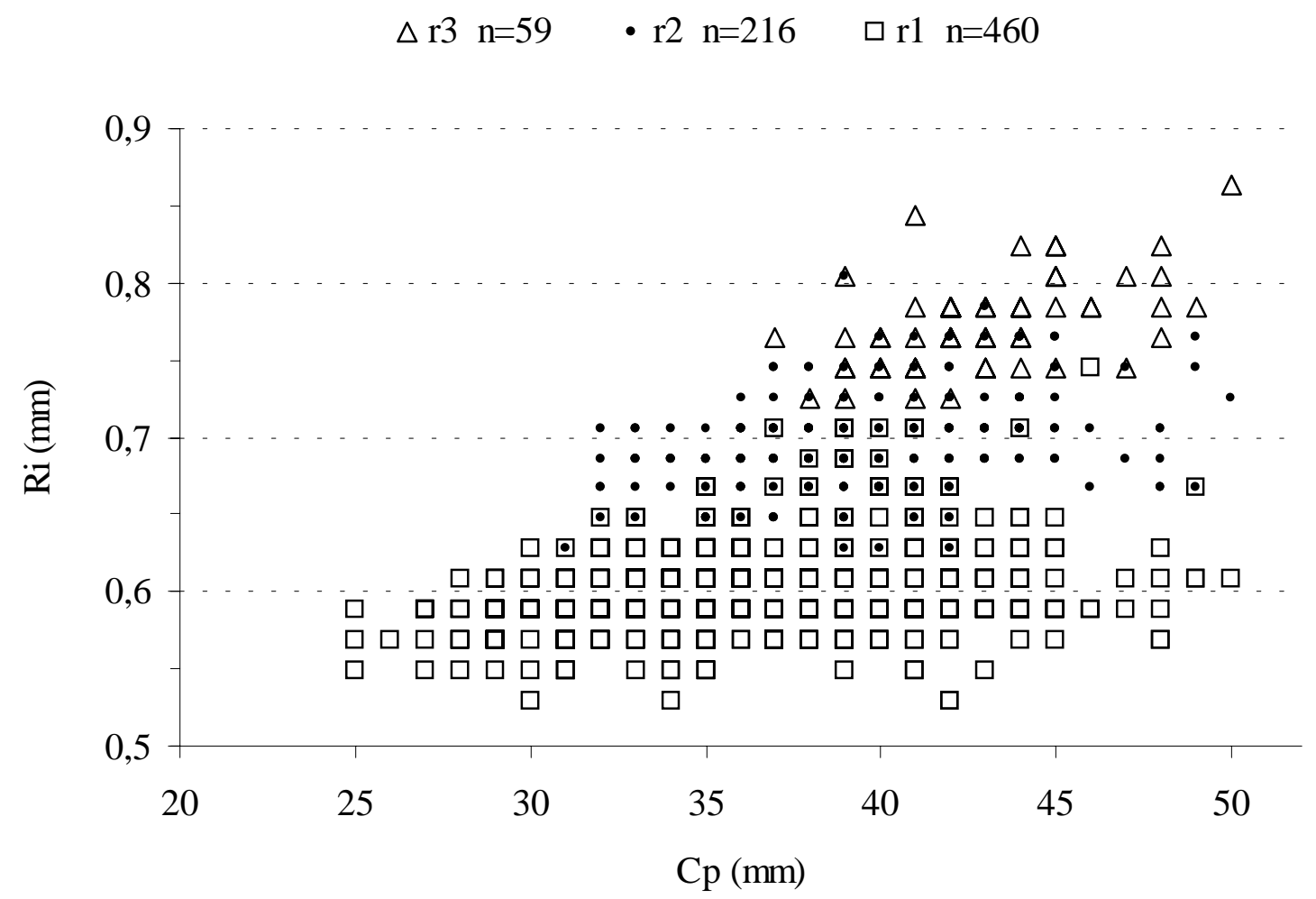

Figura V.4. Raio dos anéis em função do comprimento padrão (Cp). n - tamanho da amostra para M. stehmanni.

\section{3a2: Periodicidade e época de formação dos anéis.}

Quanto à periodicidade da ocorrência de bordas opacas e translúcidas, constatouse que as maiores ocorrências de bordas opacas ocorreram na primavera para o grupo $0\left(\mathrm{G}_{0}\right)$ $(17 \%)$ e no outono para o grupo $1\left(\mathrm{G}_{1}\right)(17 \%)$. Entretanto, mais de $90 \%$ das bordas estavam translúcidas nas três épocas de coleta (tabela V.2.), impedindo inferências sobre o início de formação de um novo anel em uma determinada época.

Tabela V.2. Porcentagem de borda opaca (\% o) e de borda translúcida (\% t) nos otólitos de $M$. stehmanni por grupo de anel $\left(\mathrm{G}_{0}, \mathrm{G}_{1}, \mathrm{G}_{2}\right.$ e $\left.\mathrm{G}_{3}\right)$ para as três épocas de análise; n é o número de otólitos analisados.

\begin{tabular}{|c|c|c|c|c|c|c|c|c|c|}
\hline & \multicolumn{3}{|c|}{ Inverno/96 } & \multicolumn{3}{|c|}{ Outono/97 } & \multicolumn{3}{|c|}{ Primavera/97 } \\
\hline & $\% \mathrm{t}$ & $\%$ & $\mathbf{n}$ & $\% \mathrm{t}$ & $\% 0$ & $\mathbf{n}$ & $\% \mathbf{t}$ & $\% 0$ & $\mathbf{n}$ \\
\hline $\mathbf{G}_{0}$ & 94 & 6 & 79 & 92 & 8 & 63 & 83 & 17 & 102 \\
\hline $\mathbf{G}_{\mathbf{1}}$ & 99 & 1 & 77 & 83 & 17 & 87 & 94 & 6 & 81 \\
\hline $\mathbf{G}_{2}$ & 98 & 2 & 56 & 94 & 6 & 66 & 100 & 0 & 37 \\
\hline $\mathbf{G}_{3}$ & 95 & 5 & 20 & 100 & 0 & 27 & 100 & 0 & 12 \\
\hline Total & 97 & 3 & 232 & 90 & 10 & 243 & 91 & 9 & 232 \\
\hline
\end{tabular}


A variação sazonal do valor médio do Incremento Marginal (IM), por grupo de anéis, para machos, fêmeas e toda amostra está representada na figura V.5. De maneira geral, os valores de IM foram mais elevados no inverno e menores no outono e primavera.

Quanto à variação sazonal do Índice de Crescimento Marginal (G), o grupo $\mathrm{G}_{3}$ apresentou média mais elevada na primavera para machos, fêmeas e toda a amostra, sendo que no outono e no inverno os valores foram mais reduzidos, enquanto que para o grupo $\mathrm{G}_{2} \mathrm{os}$ resultados foram diferentes: as fêmeas e a amostra total apresentaram os maiores valores no outono e os menores no inverno e primavera, respectivamente; para os machos os maiores valores de G ocorreram no inverno, diminuindo nos demais períodos (figura V.6.).

Na figura V.7. está representada a variação do comprimento médio de cada grupo de anel nas épocas de coleta para machos e fêmeas, separadamente, e para a amostra total. Para machos, fêmeas e toda a amostra do grupo de 1 anel $\left(G_{1}\right)$ verificou-se uma tendência dos valores médios de $\mathrm{Cp}$ serem mais baixos no outono e, maiores no inverno, enquanto que para os grupos $\mathrm{G}_{2}$ e $\mathrm{G}_{3}$ os maiores valores de $\mathrm{Cp}$ ocorreram no outono, exceto para as fêmeas do grupo $\mathrm{G}_{2}$, que tiveram o maior valor de $\mathrm{Cp}$ na primavera.

Os valores médios do Fator condição $(\mathrm{K})$ de toda a amostra para as três épocas estão representados na figura V.8. O valor mais elevado foi obtido no outono e o menor no inverno, sendo que nesta época o valor médio de K esteve logo abaixo do valor do parâmetro "a" da relação Wt/Cp (item III.2B). Isto indica que um peixe com determinado tamanho tinha menos massa corpórea no inverno do que na primavera e no outono.

Levando-se em conta as discrepâncias dos resultados obtidos pelos métodos utilizados, não foi possível constatar uma época de formação dos anéis e atribuir a cada anel uma idade absoluta.

No entanto, com caráter especulativo, numa tentativa de obter os parâmetros de crescimento para $M$. stehmanni e compará-los a outras espécies do gênero, levou-se em consideração resultados obtidos com outras espécies de Maurolicus e procedeu-se as análises onde a formação do anel foi considerada anual.

\section{3a3: Relação entre o raio do otólito e o comprimento padrão.}

Na figura V.9. estão apresentadas as retas obtidas da relação entre o raio do otólito e o comprimento padrão (Ro x Cp) para machos e fêmeas, constatando-se suas semelhanças. $\mathrm{O}$ teste $\mathrm{t}$ realizado não indicou diferenças significativas entre os parâmetros obtidos; assim, os dados foram agrupados. A nuvem de pontos, a reta obtida, assim como a equação da reta e o coeficiente de determinação $\left(\mathrm{r}^{2}\right)$ estão apresentadas na figura V.10. O valor do coeficiente de correlação foi elevado, 0,91, indicando que a dependência entre as variáveis é alta, e permitindo afirmar que o crescimento da estrutura acompanhou o crescimento do peixe de maneira linear. 


\section{Grupo de 1 anel}

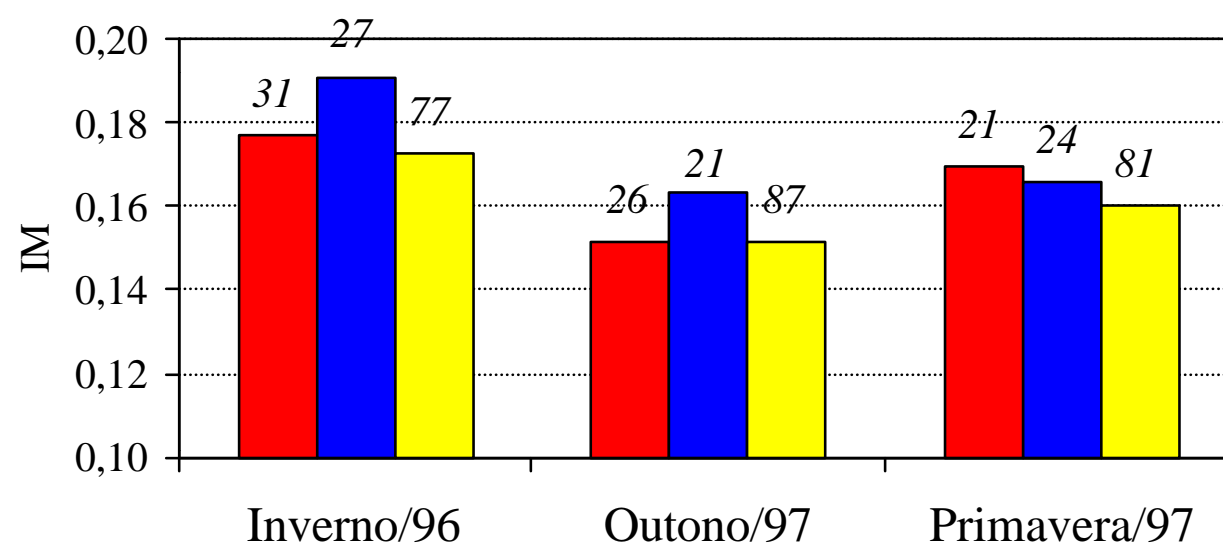

Grupo de 2 anéis

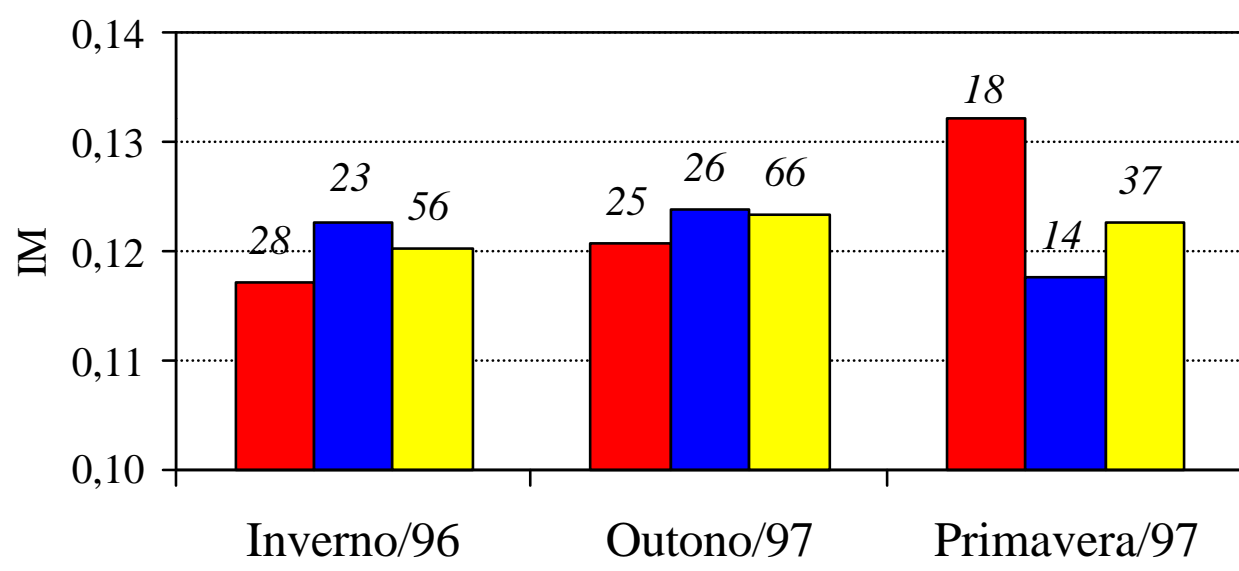

\section{Grupo de 3 anéis}

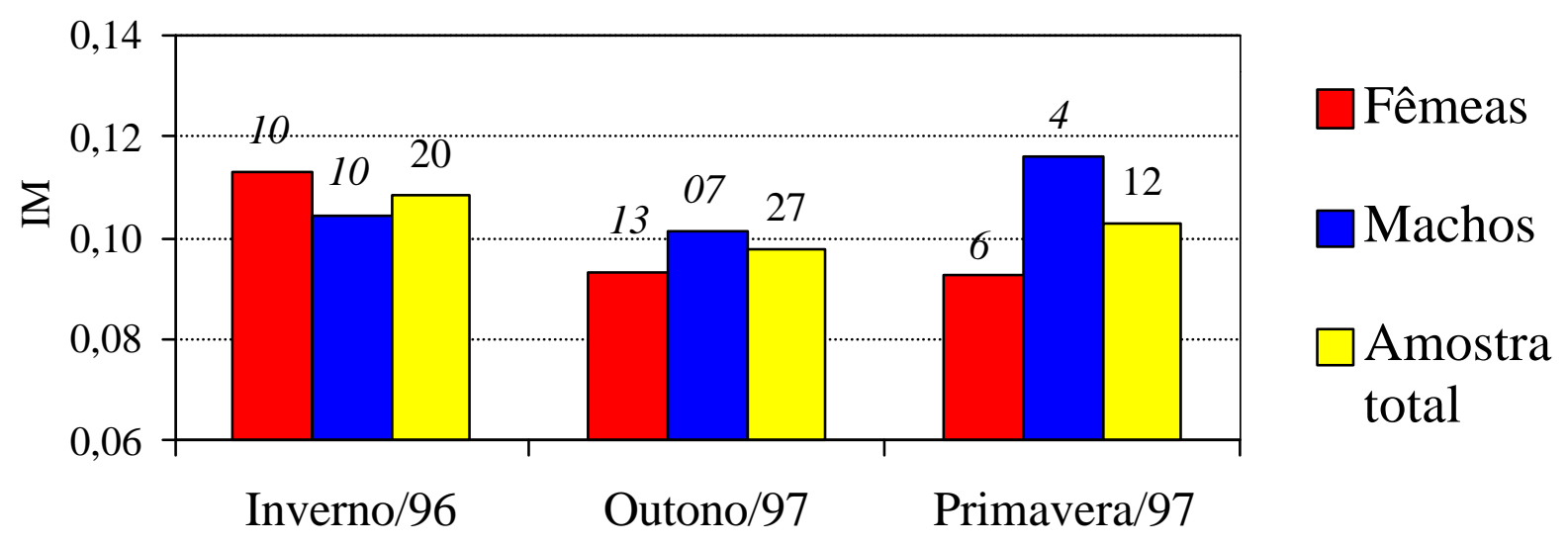

Figura V.5. Valores médios do incremento marginal (IM) dos otólitos de M. stehmanni para os grupos de 1, 2 e 3 anéis, considerando-se fêmeas, machos e a amostra total, por época de coleta. Os números em itálico indicam o tamanho da amostra. 
Grupo de 2 anéis

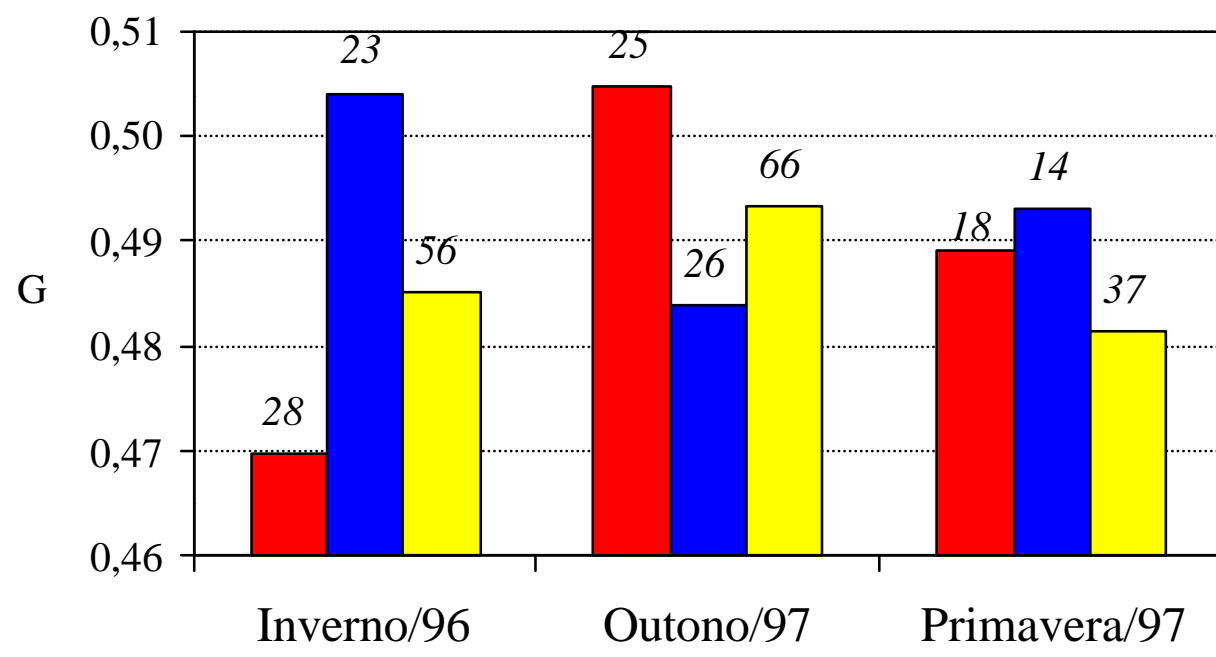

$\square$ Fêmeas

$\square$ Machos

$\square$ Amostra total

Grupo de 3 anéis

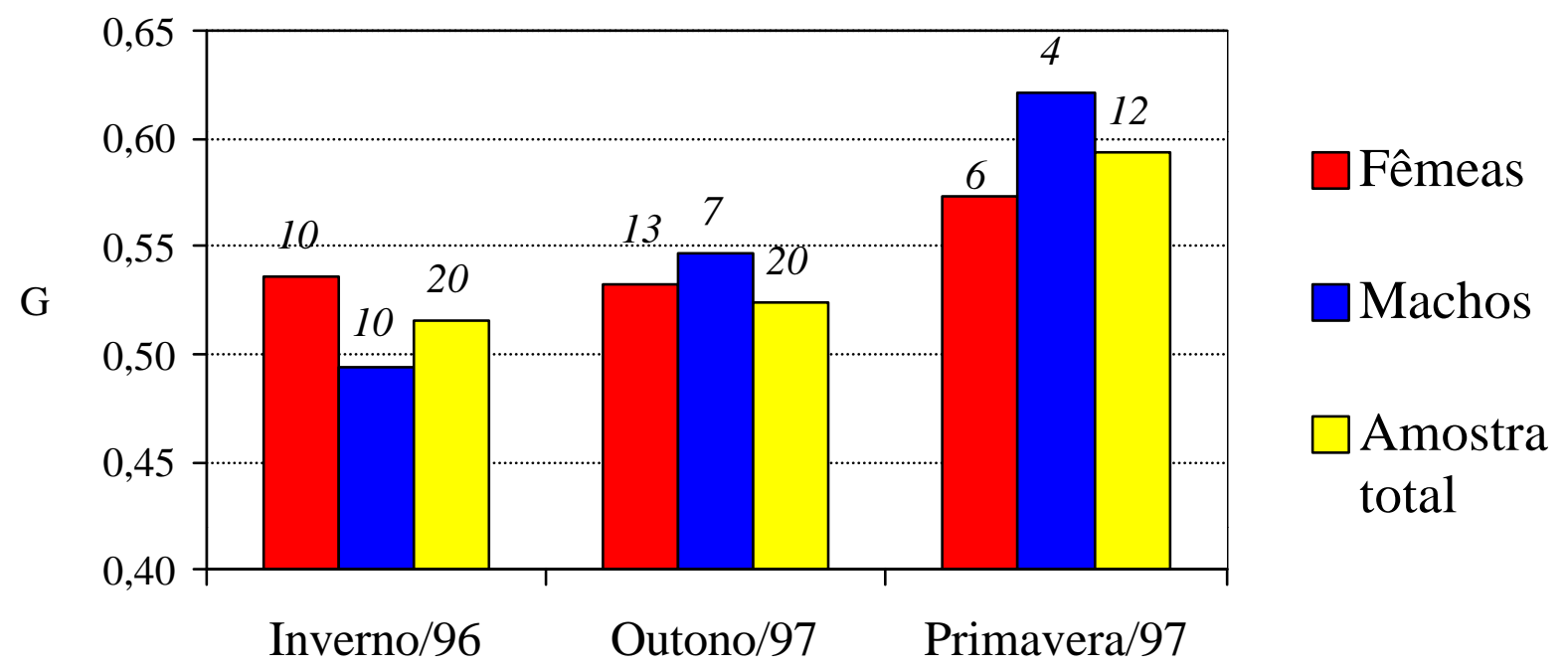

Figura V.6. Valores médios do índice de incremento marginal (G) dos otólitos de $M$. stehmanni para os grupos de 2 e 3 anéis, considerando-se fêmeas, machos e a amostra total, por época de coleta. Os números em itálico indicam o tamanho da amostra. 


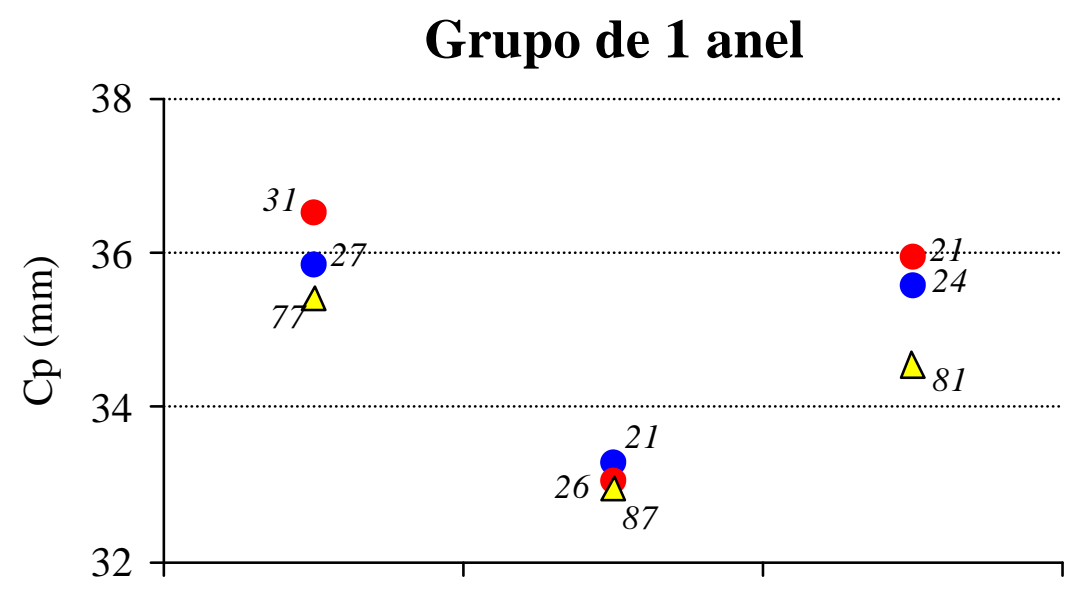

- Machos

- Fêmeas

$\triangle$ Amostra Total

\section{Grupo de 2 anéis}

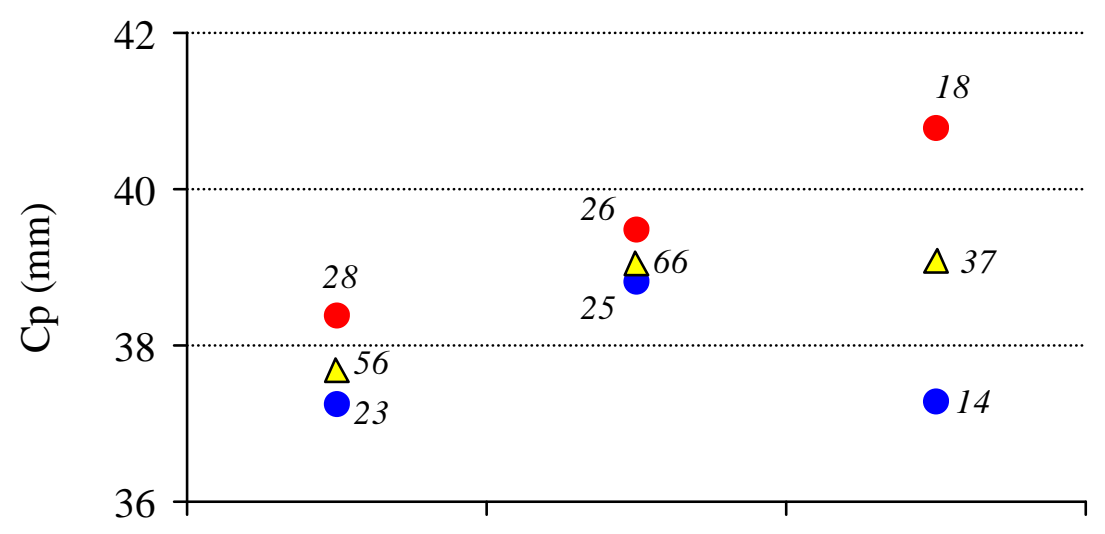

- Machos

- Fêmeas

$\triangle$ Amostra Total

Grupo de 3 anéis

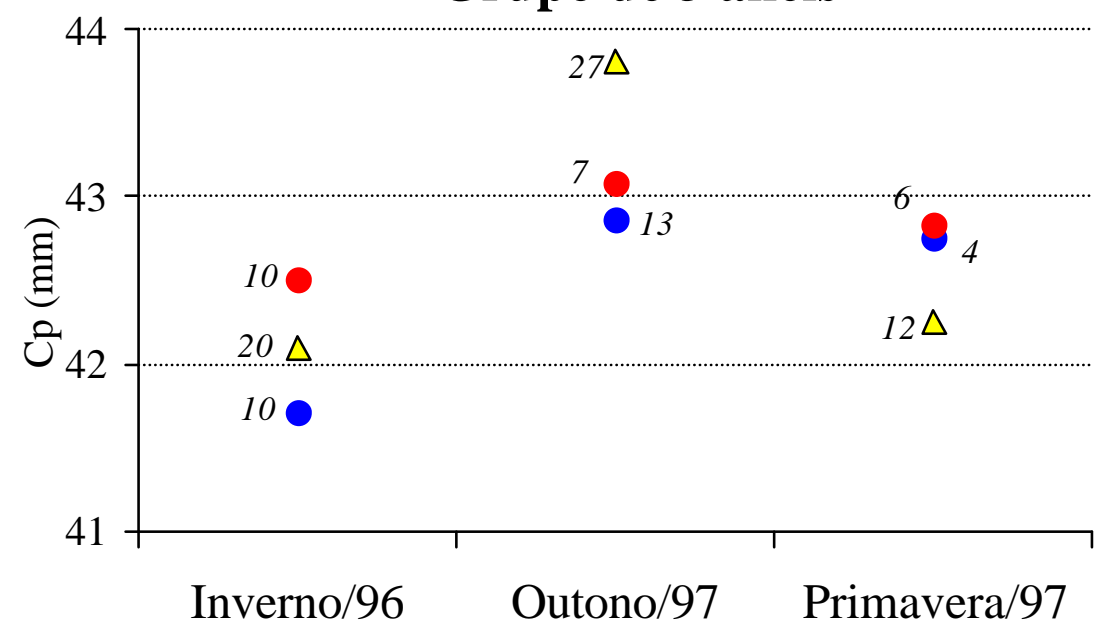

- Machos

- Fêmeas

$\triangle$ Amostra Total

Figura V.7. Comprimento padrão (Cp) médio de M. stehmanni por época do ano para os grupos de anéis, considerando-se fêmeas, machos e a amostra total. Os números em itálico indicam o tamanho da amostra. 


\section{Fator de condição $(K)$}

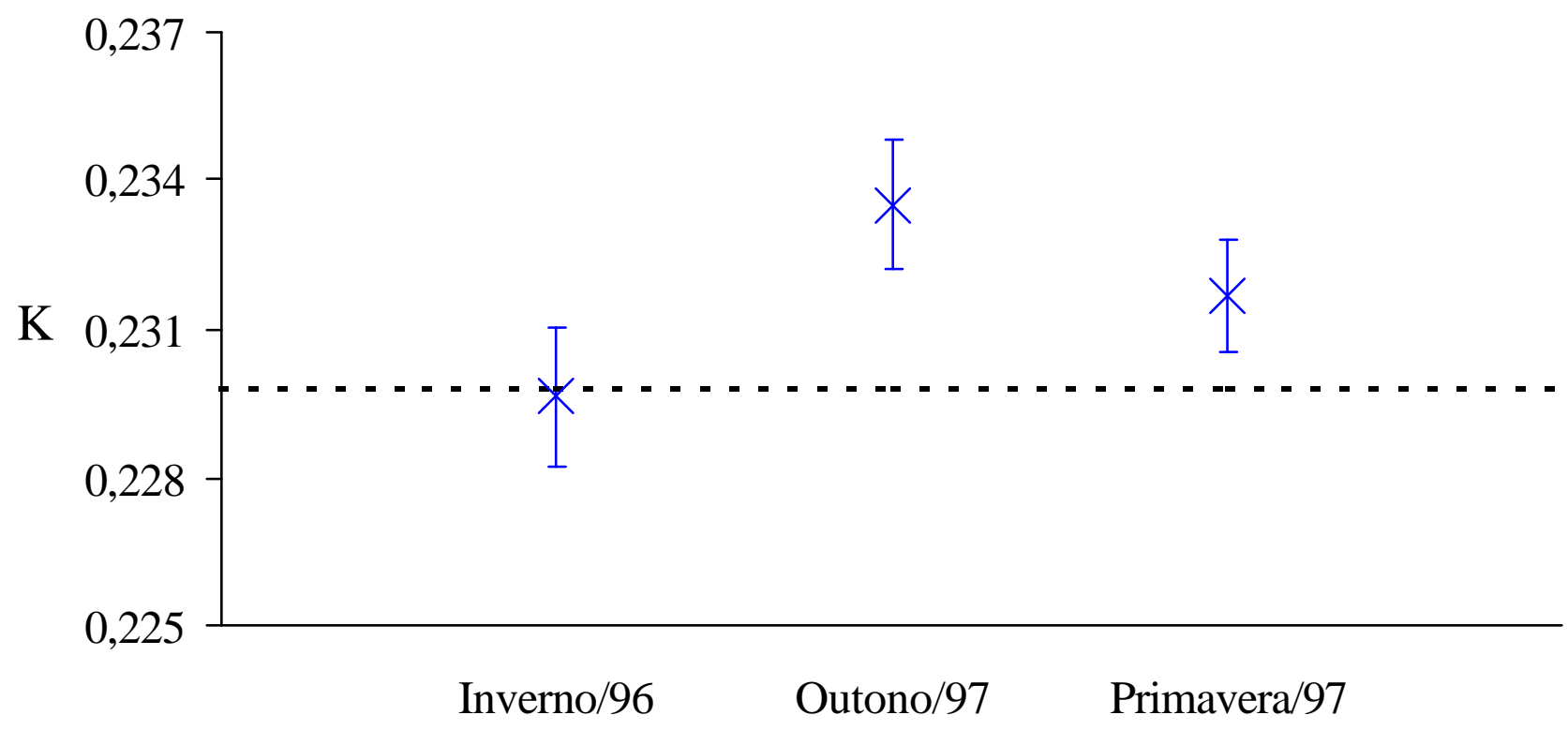

Figura V.8. M. stehmanni: Fator de condição (K) por época do ano. A reta tracejada representa o valor de "a " da relação peso/comprimento.

\section{Ro x Cp}

— Fêmeas, $\mathrm{n}=139$ — Machos, $\mathrm{n}=116$

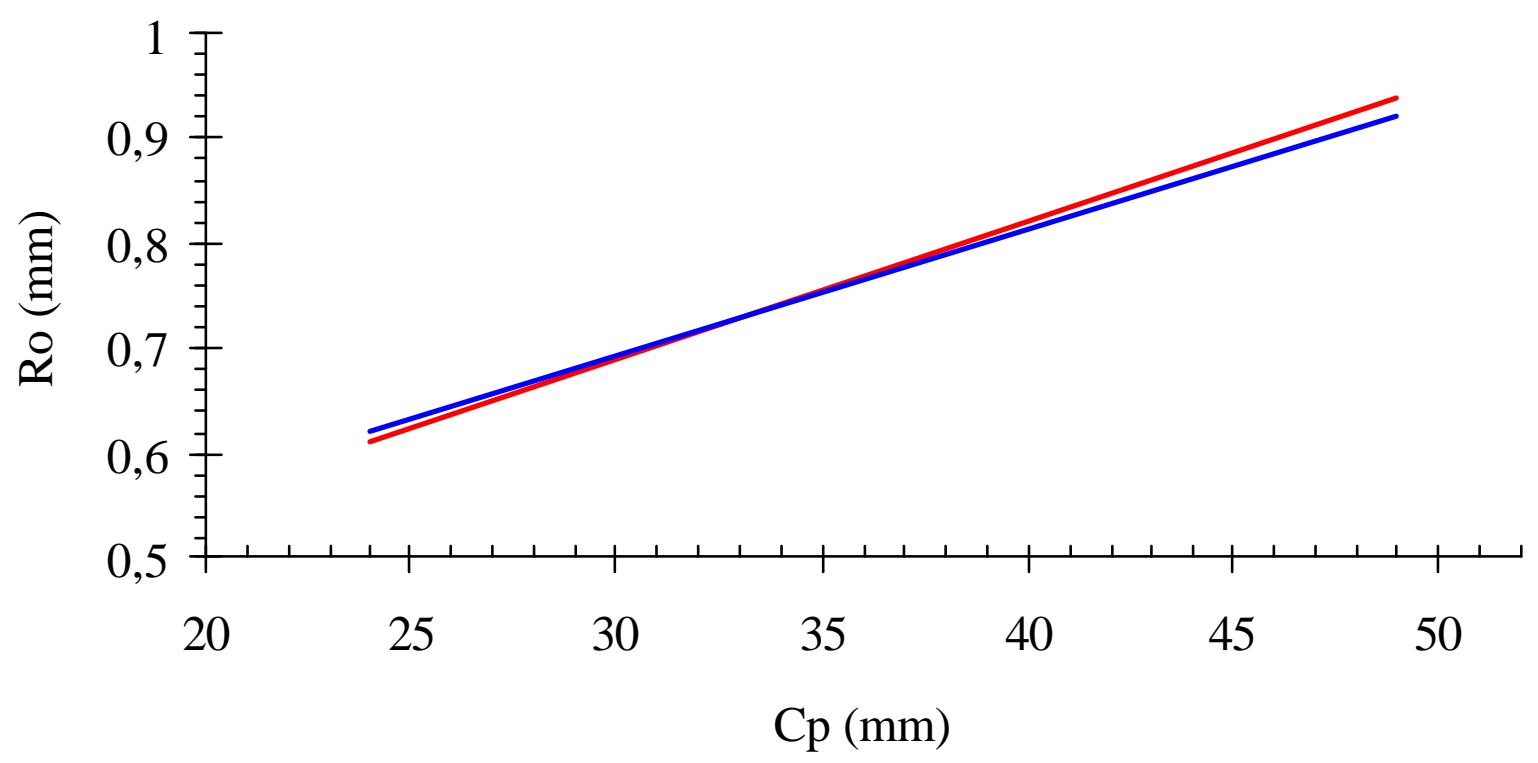

Figura V.9. M. stehmanni: Representação gráfica das relações entre o raio do otólito (Ro) e o comprimento padrão $(\mathrm{Cp})$ de machos e fêmeas. 


\section{Raio do otólito x Comprimento Padrão}

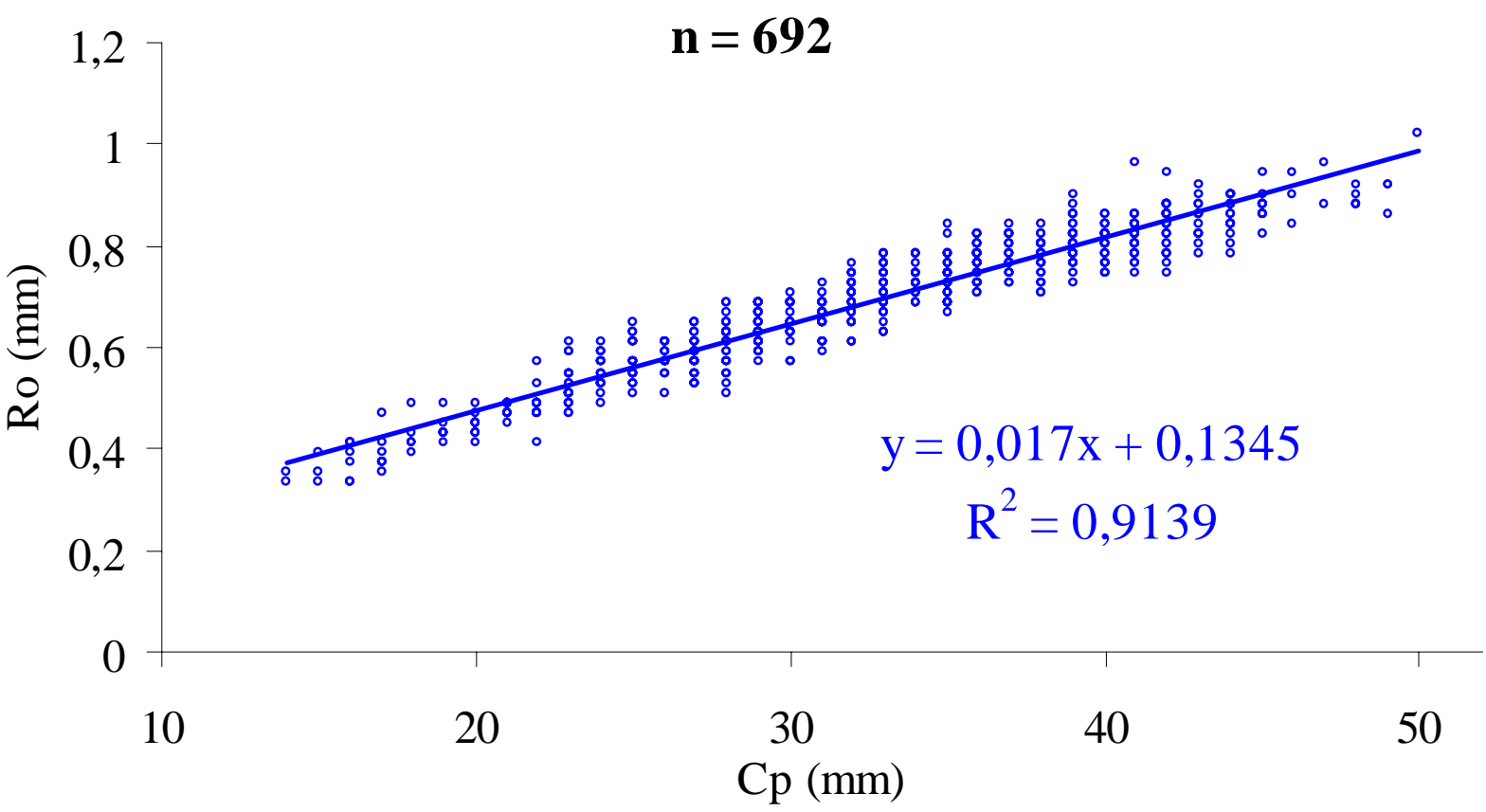

Figura V.10. M. stehmanni: Relação entre o raio do otólito (Ro) e o comprimento padrão (Cp).

\section{3a4: Retrocálculo}

Os valores de comprimento padrão médio dos peixes para cada anel $\left(\mathbf{C} \mathbf{p}_{\mathbf{i}}\right)$, retrocalculados pelos métodos BPH e SPH estão apresentadas na tabela V.3.. Constatou-se que as estimativas dos tamanhos médios dos peixes, no momento de formação dos anéis, foram próximas nos dois procedimentos adotados. Para o cálculo dos parâmetros de crescimento utilizou-se as médias dos comprimentos obtidos.

Constatou-se que o Fenômeno de Lee (Francis, 1990), caracterizado pela diminuição dos tamanhos médios retrocalculados à época de formação de cada anel, na medida em que aumentam as idades de captura, não ocorreu, uma vez que os tamanhos retrocalculados de $M$.

Tabela V.3. M. stehmanni: Valores de comprimento padrão retrocalculados pelos métodos BPH e SPH para cada grupo de anel $G_{1}, G_{2}$ e $G_{3}$. Cpi é o comprimento padrão médio retrocalculado que o peixe teria na formação do anel i, e foi calculado para todos os peixes.

\begin{tabular}{|c|c|ccc|ccc|}
\cline { 3 - 8 } \multicolumn{2}{c|}{} & \multicolumn{3}{c|}{ BPH } & \multicolumn{3}{c|}{ SPH } \\
\hline Grupo de anel & $\mathrm{n}$ & $1^{\mathrm{o}}$ anel & $2^{\mathrm{o}}$ anel & $3^{\mathrm{o}}$ anel & $1^{\mathrm{o}}$ anel & $2^{\mathrm{o}}$ anel & $3^{\mathrm{o}}$ anel \\
\hline $\mathrm{G}_{1}$ & 242 & 27,9 & & & 27,3 & & \\
$\mathrm{G}_{2}$ & 157 & 27,9 & 33,3 & & 27,1 & 32,9 & \\
$\mathrm{G}_{3}$ & 59 & 28,2 & 33,7 & 38,0 & 27,1 & 33,1 & 37,7 \\
\hline & $\mathbf{C p}_{\mathbf{i}}$ & $\mathbf{2 7 , 9}$ & $\mathbf{3 3 , 4}$ & $\mathbf{3 8 , 0}$ & $\mathbf{2 7 , 2}$ & $\mathbf{3 2 , 9}$ & $\mathbf{3 7 , 7}$ \\
\hline
\end{tabular}


stehmanni à época de formação de cada anel não apresentaram variações entre os grupos.

\section{3a5: Parâmetros de Crescimento:}

Com os valores de comprimento médio obtidos pela leitura de anéis (tabela V.1) e retrocalculados (Tabela V.3.) foram calculados os parâmetros de crescimento pelos métodos citados e os resultados de $\mathbf{L} \infty, \mathbf{k}, \mathbf{t}_{\mathbf{0}} \mathbf{e} \boldsymbol{\Phi}$ constam da tabela V.4.

Verificou-se a partir do retrocálculo que os valores de $\mathbf{L} \infty$ foram mais elevados, e os

Tabela V.4. M. stehmanni: Parâmetros de crescimento estimados através de diferentes métodos: 1) valores médios de comprimento padrão por grupo de anel e 2) valores retrocalculados. $\Phi$ - índice de performance.

\begin{tabular}{|c|l|c|c|c|c|}
\cline { 3 - 5 } \multicolumn{2}{c|}{} & Loo $(\mathrm{mm})$ & $\mathrm{k}\left(\right.$ ano $\left.^{-1}\right)$ & $\mathrm{t}_{\mathrm{O}}($ anos $)$ & $\Phi$ \\
\hline \multirow{2}{*}{ Comprimento } & Ford Walford & 48,5 & 0,46 & $-0,59$ & 1,04 \\
médio por anel & Bayley & 50,1 & 0,30 & $-1,66$ & 0,88 \\
& von Bertalanffy & 53,7 & 0,32 & $-1,09$ & 0,96 \\
\hline \multirow{2}{*}{ Comprimentos } & Ford Walford & 62,2 & 0,18 & $-2,32$ & 0,83 \\
retrocalculados & Bayley & 67,9 & 0,13 & $-3,29$ & 0,77 \\
& von Bertalanffy & 53,7 & 0,25 & $-1,86$ & 0,86 \\
\hline
\end{tabular}

de $\mathbf{k}$ e $\mathbf{t}_{\mathbf{0}}$ mais baixos, quando comparados com os valores calculados a partir das médias de comprimento dos peixes no momento da captura.

Com exceção do método de von Bertalanffy, onde o valor de $\mathbf{L} \infty$ foi previamente estimado, com o método de Ford-Walford obteve-se valores de $\mathbf{L} \infty$ menores, valores de $\mathbf{k}$ e $\mathbf{t}_{\mathbf{0}}$ maiores do que quando aplicado o método de Bayley.

Os valores de $\boldsymbol{\Phi}$ foram próximos de 1 e mais baixos quando utilizou-se os valores médios de $\mathrm{Cp}$ retrocalculados, para os três métodos.

A título de comparação, foram traçadas as curvas de crescimento ajustadas aos parâmetros obtidos (figuras V.11. e V.12.), verificando-se que, quando utilizados os valores retrocalculados (figura V.12.) o crescimento é mais lento, necessitando mais de 8 anos para atingir o $\mathbf{L} \infty$, ao passo que, quando aplicados os valores de comprimento médio por anel o crescimento foi mais rápido. Fato a ser ressaltado é que, exceto quando utilizado o método de Ford-Walford, os valores de $\mathrm{t}_{0}$ foram muito baixos, chegando $\mathrm{a}-3$.

\section{3b: Método indireto}

\section{3b1: Rotina ELEFAN I}

Os valores dos parâmetros de crescimento $\left(\mathbf{L} \infty, \mathbf{t}_{\mathbf{0}}\right.$ e $\left.\mathbf{k}\right)$ de $M$. stehmanni, obtidos através desse método, o índice de performance $(\boldsymbol{\Phi})$ para os dados de distribuição de frequiência 
das classes de comprimento por coleta e agrupados estão apresentados na tabela V.5., enquanto as curvas de crescimento estão reprentados nas figuras V.13. e V.14., respectivamente. Para a amostra total foram evidenciadas quatro coortes, um comprimento de $33 \mathrm{~mm}$ no primeiro ano de vida e o mês de nascimento em novembro, quando utilizada a amostra por cruzeiro e obtevese 5 coortes, $30 \mathrm{~mm}$ no primeiro ano de vida e nascimento no mês de fevereiro.

Tabela V.5. Parâmetros de crescimento $\left(L \infty, k, t_{0}\right)$ e o índice de performance $(\Phi)$ de M. stehmanni estimados pela rotina ELEFAN I para a amostra total e por época de coleta.

\begin{tabular}{|c|cccc|}
\hline & $\mathbf{L}_{\boldsymbol{\infty}}(\mathrm{mm})$ & $\mathbf{k}\left(\right.$ ano $\left.^{-1}\right)$ & $\mathbf{t}_{\mathbf{0}}(\operatorname{anos})$ & $\boldsymbol{\Phi}$ \\
\hline Total & 53,0 & 0,90 & $-0,15$ & 1,40 \\
\hline Por época & 53,0 & 0,78 & $-0,18$ & 1,34 \\
\hline
\end{tabular}

\section{3b2: Método Bhattacharya}

A tabela V.6. apresenta os valores médios de Cp estimados pelo método Bhattacharya. O programa forneceu resultados satisfatórios para a decomposição da distribuição em 3 e 4 coortes. Observou-se que, em ambos os resultados, os valores médios de $\mathrm{Cp}$ das duas primeiras coortes foram próximos aos valores de $\mathrm{Cp}$ médio obtido para os grupos de 0 e 1 anel (tabela V.1), enquanto que para as demais coortes os valores estimados foram mais elevados, tanto para o grupo de 2 como de 3 anéis. Os paramêtros de crescimento $\left(\mathbf{L} \infty, \mathbf{k}, \mathbf{t}_{\mathbf{0}}\right)$ e o índice de performance $(\boldsymbol{\Phi})$ obtidos a partir destes valores médios de Cp estão apresentados na tabela V.7..

Tabela V.6. Valores médios de comprimento padrão $(\mathrm{mm})$ das coortes de $M$. stehmanni estimados pelo método Bhattacharya.

\begin{tabular}{|l|cccc|}
\hline & $\mathbf{1}^{\text {a }}$ coorte & $\mathbf{2}^{\mathbf{a}}$ coorte & $\mathbf{3}^{\mathbf{a}}$ coorte & $\mathbf{4}^{\text {a }}$ coorte \\
\hline 3 coortes & 24,6 & 33,8 & 42,5 & - \\
\hline $\mathbf{4}$ coortes & 24,6 & 33,8 & 42,3 & 48,0 \\
\hline
\end{tabular}

Tabela V.7. Parâmetros de crescimento $\left(L \infty, k, t_{0}\right)$ e o índice de performance $(\Phi)$ de M. stehmanni estimados pela método Bhattacharya para a amostra total.

\begin{tabular}{|c|cccc|}
\hline & $\mathbf{L} \boldsymbol{\infty}(\mathrm{mm})$ & $\mathbf{k}\left(\right.$ ano $\left.^{-1}\right)$ & $\mathbf{t}_{\mathbf{0}}($ anos $)$ & $\boldsymbol{\Phi}$ \\
\hline 3 coortes & 53,7 & 0,48 & $-0,22$ & 1,14 \\
\hline 4 coortes & 53,7 & 0,54 & 0,02 & 1,20 \\
\hline
\end{tabular}




\section{Curvas de crescimento de $M$. stehmanni ajustadas aos dados de tamanhos de captura}

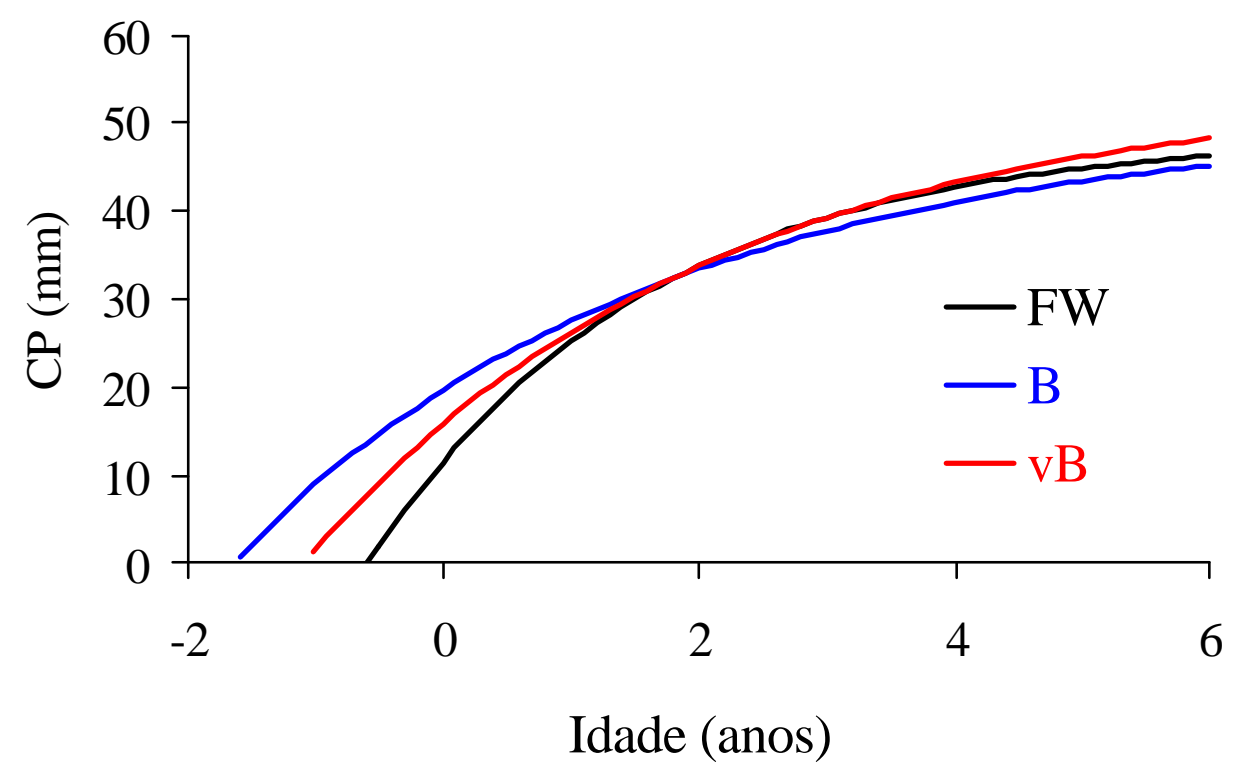

Figura V.11. M. stehmanni: Curvas de crescimento ajustadas aos dados de comprimentos padrão médios por anel. FW: método Ford-Walford; B: método de Baylay; vB: método de von Bertalanffy.

Curvas de crescimento de $M$. stehmanni ajustadas aos dados tamanhos retrocalculados

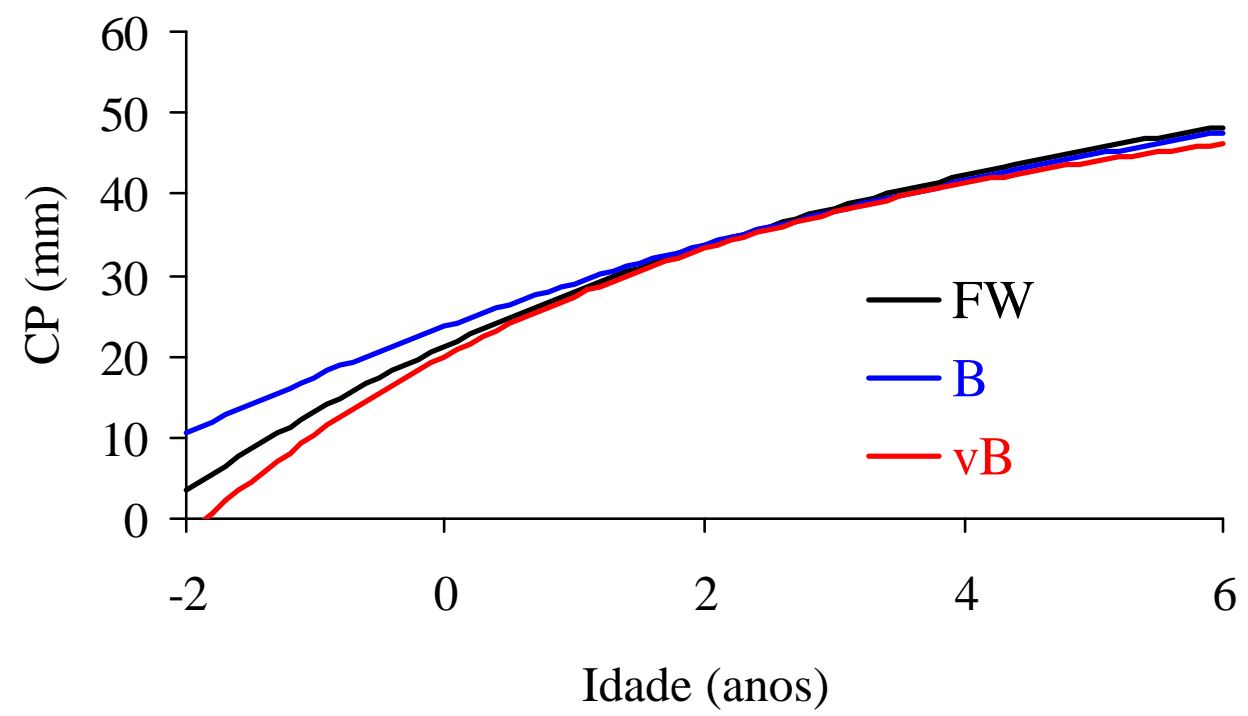

Figura V.12. Curvas de crescimento de $M$. stehmanni ajustadas aos dados de comprimentos padrão médios retrocalculados. FW: método Ford-Walford; B: método de Baylay; vB: método de von Bertalanffy. 


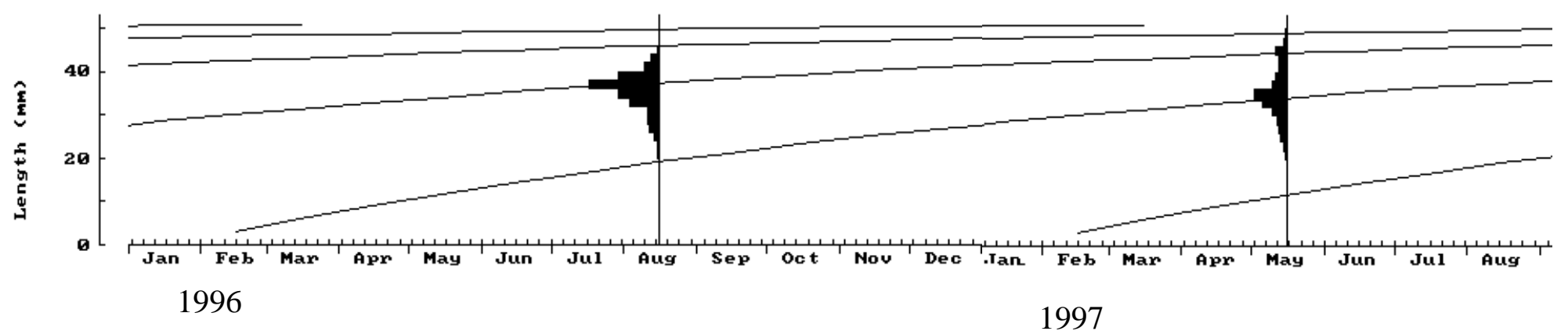

Loo 53.00

H. 0.780

SS -41.00

SL 41.00

Rn 0.146

Figura V.13. Histograma dos valores de freqüência de comprimento padrão, curvas de crescimento e os parâmetros de crescimento obtidos pela rotina ELEFAN I utilizando os dados de cada cruzeiro. 


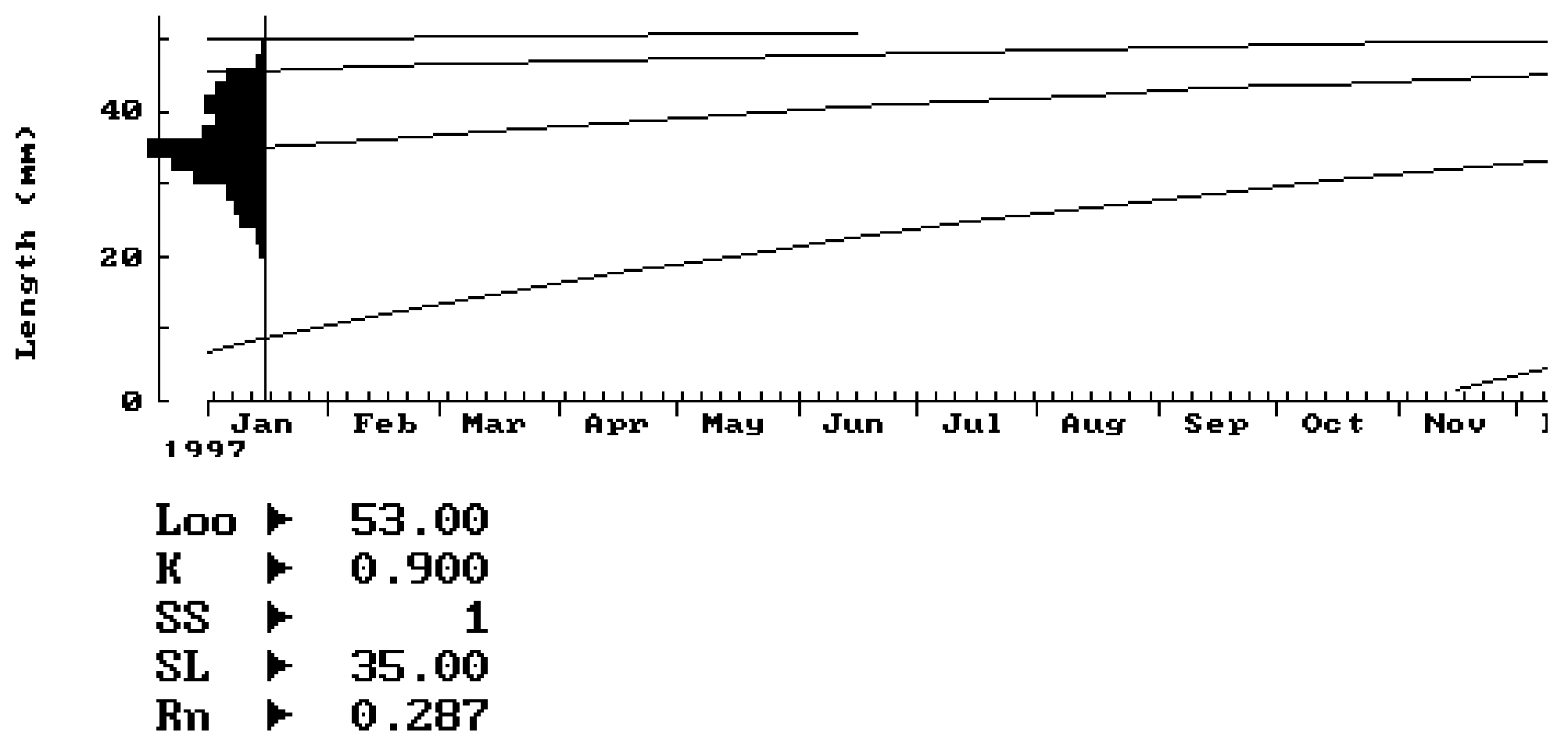

Figura V.14. Histograma dos valores de freqüência de comprimento padrão, curvas de crescimento e os parâmetros de crescimento obtidos pela rotina ELEFAN I utilizando os dados agrupados. 


\section{3c: Comparação entre os métodos direto, indireto e resultados da literatura:}

Os parâmetros $\mathbf{L} \infty, \mathbf{k}, \mathbf{t}_{\mathbf{0}} \mathrm{e} \boldsymbol{\Phi}$ estimados neste trabalho pelos métodos direto e indireto constam das tabelas V.4., V.5., V.7. e da figura V.15. Nesta última são ainda apresentados os resultados para Maurolicus do Japão e da Noruega, título de comparação. Observou-se que o valor de $\mathbf{k}$ mais elevado foi obtido quando aplicada a rotina ELEFAN I (metodo indireto), mas ainda assim este valor é inferior aos dados da literatura.

Com relação ao $\mathbf{L} \boldsymbol{\infty}$, considerando que nas amostragens o valor de comprimento padrão máximo foi $51 \mathrm{~mm}$, constatou-se que o retrocálculo superestimou este parâmetro, que o comprimento médio por anel o subestimou, enquanto que a rotina ELEFAN e o método Bhattacharya forneceram valores coerentes.

Em relação ao $\boldsymbol{\Phi}$, os valores obtidos pelo método ELEFAN colocam $M$. stehmanni próxima a espécies congêneres dos fiordes da Noruega e do Mar do Japão, enquanto que os demais métodos utilizados apresentaram valores baixos, muito distintos das demais espécies estudadas. 


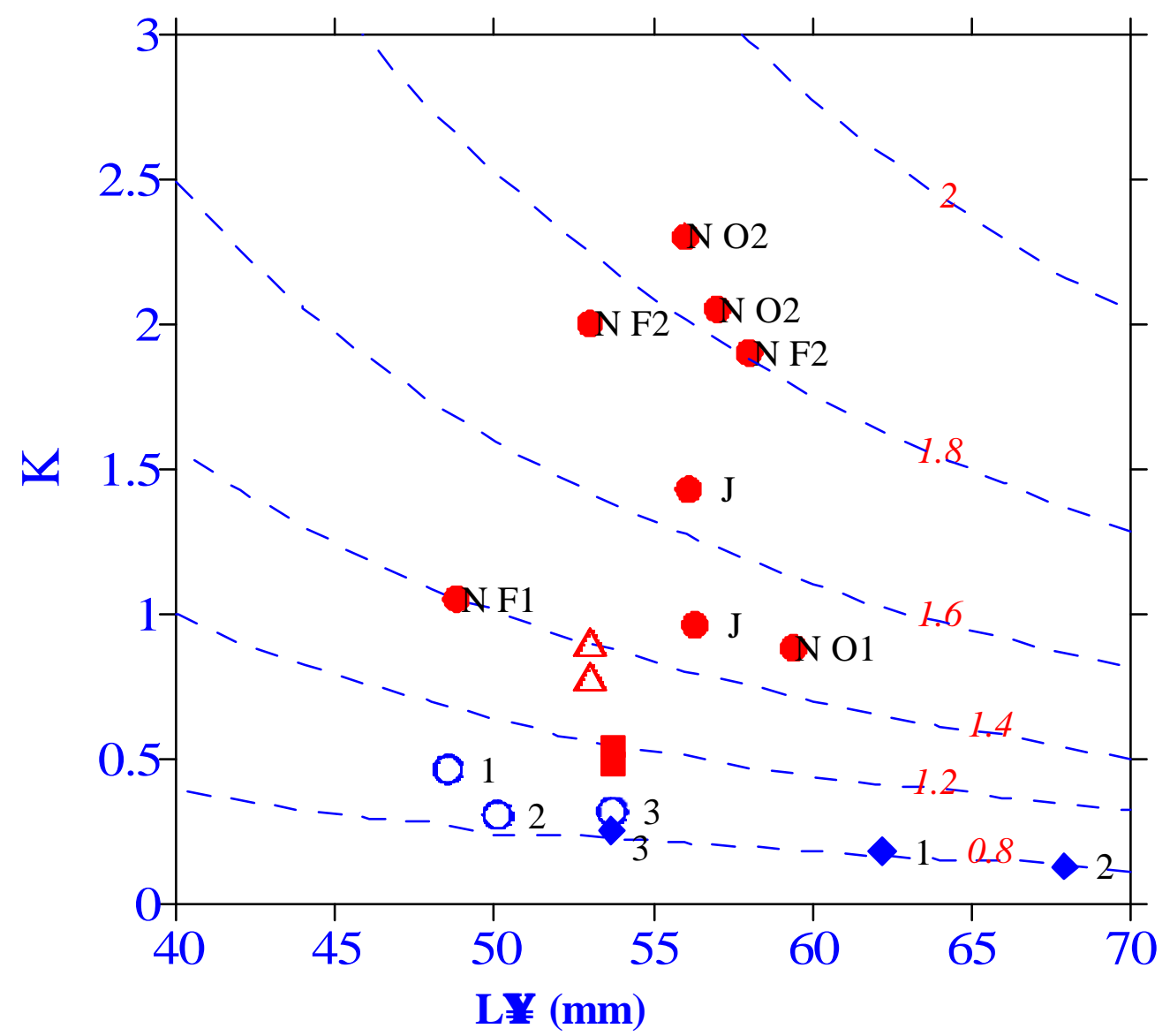

Figura V.15. Grade auximétrica do índice de performance $(\Phi)$ sobre a relação entre a taxa de crescimento (k) e o L $\mathbf{L}^{\bullet} \bullet$ - Valores da literatura: NO1- Noruega, mar aberto (Gjøsæter, 1981); NF1 - Noruega, fiordes (Gjøsæter, 1981); NO2 Noruega, mar aberto (Kristoffersen \& Salvanes, 1996); NF2 - Noruega, fiordes (Kristoffersen \& Salvanes, 1996); J - Japão (Yuuki, 1984); O - Este estudo, dados de comprimento médio por grupo de anel; - Este estudo, dados retrocalculados por grupo de anel (1 - Ford-Walford, 2 - Bayley e 3 - von Bertalanffy); $\Delta$ - Este estudo, ELEFAN I e $\square$ - Este estudo, Bhattacharya. 


\section{4 DISCUSSÃO:}

\section{4a: Análise dos otólitos}

O crescimento é influenciado pelas condições ambientais e qualquer variação nestas condições pode acarretar diferenças na taxa de crescimento. A estas diferenças podem corresponder anéis ou descontinuidades nas partes duras do esqueleto de animais (estruturas de aposição, onde é depositado Carbonato de Cálcio), sendo que em peixes as estruturas mais utilizadas nos estudos de crescimento são otólitos, escamas e ossos (vértebras e urohiais) (King, 1996). Este autor acrescenta que estas mudanças podem ser aleatórias ou regulares, e neste último caso, produzem séries periódicas de marcas, pois foram formadas em intervalos de tempo conhecidos, correspondendo a anéis etários.

Bagenal \& Tesch (1978) mostram que a partir de dados de idade, aliados a valores de peso e tamanho, é possível fornecer informações sobre a composição do estoque, idade de maturação gonadal, mortalidade e produção de uma população. Estes autores acrescentam que o conhecimento da periodicidade de formação dos anéis é fundamental para validar as leituras e atribuir à amostra idades absolutas.

Neste trabalho verificou-se que o raio do otólito acompanhou o comprimento padrão do peixe de maneira linear, mostrando que o otólito representou o crescimento de Maurolicus stehmanni, em termos relativos, podendo ser utilizado em estudos que visem estimar o crescimento da espécie. Fato semelhante foi verificado por Gjøsæter (1981) na Noruega e Yuuki (1984) no Japão.

No entanto, as análises efetuadas não permitiram que fossem identificadas a periodicidade e a época de formação de anel nos otólitos de $M$. stehmanni, apesar de que Gjøsæter (1981) e Yuuki (1984), ao estudarem o crescimento de Maurolicus, lançaram mão de análises de anéis anuais em otólitos, estimando até 2 e 3 anéis anuais respectivamente. Os trabalhos citados foram realizados em regiões temperadas (Noruega e Japão), que apresentam sazonalidade de temperatura e de produtividade bem marcada.

Gjøsæter (op. cit.), ao estudar a porcentagem de bordas opacas e translúcidas em otólitos de M. muelleri na Noruega, verificou que a borda translúcida se formou no inverno e a opaca no verão, porém, constatou diferenças na formação destas zonas entre peixes imaturos e peixes maduros. O autor também analisou anéis diários (microscopia eletrônica e óptica), validando a periodicidade dos anéis.

Yuuki (1984) estimou, através da variação mensal do incremento marginal, a periodicidade de formação dos anéis para Maurolicus no Mar do Japão, sendo que a ZONA translúcida seria formada, anualmente, entre dezembro e abril (inverno).

No presente trabalho, o estudo da frequiência de ocorrência de bordas opacas e translúcidas não foi eficaz, uma vez que altos valores de borda translúcida foram encontrados nas três épocas, para todos os grupos de anéis. A falta de coleta no verão; o número reduzido 
de coletas ao longo do tempo e a dificuldade de identificação da borda opaca, visto que o otólito é muito delicado e nos seus extremos se apresenta pouco espesso (sendo possível que uma deposição diferenciada tenha sido imperceptível) devem ter sido alguns dos motivos da não obtenção de resultados satisfatórios. Por outro lado, a região de estudo não apresenta uma sazonalidade tão acentuada quanto aquelas referidas nos trabalhos acima, $M$. stehmanni apresenta atividade reprodutiva ao longo todo o ano e realiza migrações verticais diárias na coluna de água, tolerando diferenças de temperatura de até $10^{\circ} \mathrm{C}$.

Gartner (1991) lançou mão da análise de anéis diários, validando-os, para estudar o crescimento de três espécies de Myctophidae, grupo mesopelágico que pode apresentar comportamento semelhante a $M$. stehmanni, no que tange à migração vertical. $\mathrm{O}$ autor concluiu que estas espécies formam o anel diário à noite, quando se encontram em menor profundidade onde a temperatura tem importante papel no processo de calcificação: os peixes por ele estudados enfrentam durante o dia temperaturas próximas a $6^{\circ} \mathrm{C}$ o que inibem a deposição de material.

Giragosov \& Ovcharov (1992) compararam a macroestrutura e a microestutura do otólito sagitta de Myctophum nitidulum, espécie mesopelágica, tropical e migradora diária, concluindo que incrementos são depositados diariamente e que são formadas diferentes zonas que correspondem a diferentes estágios do ciclo de vida. Concluiram que a formação de zonas se dá em um ciclo lunar e ocorre na lua cheia, quando o processo de migração vertical cessa ou é diminuído, devido a maior luminosidade nos períodos noturnos.

Linkowski (1996) estudou a microestrutura do otólito de cinco espécies do gênero Hygophum (Myctophidae), procurando relacioná-la com o ritmo lunar e migração vertical. Quatro das espécies estudadas realizam migração vertical diária e apresentaram microincrementos diários em série, formando um padrão cíclico que correspondeu ao ciclo lunar; o autor sugere que a explicação para este padrão está mais relacionada com o ritmo comportamental (migração) do que com variações ambientais, porém não se pode excluir aspectos como maior luminosidade da água no comportamento de espécies mesopelágicas.

Visto que a metodologia aplicada para se avaliar a periodicidade e época de formação dos anéis foi, neste estudo, ineficaz, e que alguns destes métodos apresentaram resultados satisfatórios para espécies do mesmo gênero, mas localizadas em áreas de clima temperado (Japão e Noruega), conclui-se que: salvo deficiências amostrais, a periodicidade de formação de anéis anuais em $M$. stehmanni não segue uma sazonalidade tão marcada como a que ocorre com outras espécies do gênero em áreas de clima temperado.

A sugestão para trabalhos futuros é a aplicação de esforço na identificação de anéis diários por meio de microscopia eletrônica e óptica, como realizado por Gjøsæter (1981), Gartner (1991); Giragosov \& Ovcharov (1992) e Linkowski (op. cit.) em espécies mesopelágicas. 


\section{4b: Parâmetros de Crescimento:}

O modelo adotado para descrever o crescimento de $M$. stehmanni foi o de von Bertalanffy, mas, segundo Pitcher \& Hart (1996) nenhum modelo irá se ajustar perfeitamente a todo o ciclo de vida de um peixe. Portanto, vários modelos deveriam ser aplicados a diferentes fases ("stanzas") do crescimento, embora a equação de von Bertalanffy seja a de maior uso em biologia pesqueira. Os autores acrescentam que este modelo assume que o peixe cresce até um determinado tamanho máximo e quanto mais se aproxima deste tamanho menor é sua taxa de crescimento.

Comparando os resultados obtidos encontrou-se diferença na estimativa dos parâmetros de crescimento quando aplicados os valores de $\mathbf{C p}$ médios dos grupos anéis, assumidos como anuais, no momento da captura $\left(\mathbf{C p}_{\mathbf{c}}\right)$ e os valores de $\mathbf{C p}$ retrocalculados $\left(\mathbf{C p}_{\mathbf{i}}\right)$. Quando utilizados os valores médios dos grupos etários os valores de $\mathbf{k}$ e $\mathbf{t}_{\mathbf{0}}$ foram um pouco mais elevados e o de Lo próximo ao comprimento padrão máximo capturado (figura V.12.). Com os valores retrocalculados foram obtidos valores de $\mathbf{k}$ e $\mathbf{t}_{\mathbf{0}}$ pequenos e em contrapartida os valores de $\mathbf{L} \boldsymbol{\infty}$ ficaram bastante acima do valor máximo de comprimento padrão amostrado. As curvas de crescimento (figura V.11.) mostraram um crescimento muito lento, onde o peixe levaria mais de 8 anos para atingir $\mathbf{L} \mathbf{L}$.

Estes resultados não eram esperados uma vez que $M$. stehmanni é uma espécie de ciclo de vida curto e, portanto, com crescimento rápido. Os trabalhos sobre crescimento de Maurolicus em outras regiões apresentam taxas de crescimento maiores, com uma estimativa de alcance do L $\infty$ em menos de 3 anos segundo Gjøsæter (1981), Yuuki (1984) e Kristoffersen \& Salvanes (1998).

As análises da distribuição dos valores de $\Phi$ (figura 9) indicam que houve uma sub estimativa dos valores de $\mathbf{k}$, ao passo que os valores de $\mathbf{L} \infty$ foram superestimados pelos métodos de Ford Walford e Bayley, quando aplicados aos valores retrocalculados. Sistematicamente, todos os valores de $\boldsymbol{\Phi}$ estimados pelo método direto parecem ter sido subestimados devido aos baixos valores de $\mathbf{k}$ obtidos e isto pode estar associado ao fato de uma atribuição de "idade" não adequada aos anéis encontrados.

O método indireto de estimativa dos parâmetros crescimento se baseia em dados de freqüência de comprimento e têm sido utilizado desde o final do século passado. O método de Petersen baseia-se na identificação de classes modais de uma amostra de freqüência de comprimento. A estas são atribuídas idades relativas, permitindo inferir, sobre estas idades, o crescimento (Longhurst \& Pauly, 1987).

O outro método que lança mão de dados de frequiência de comprimento é a Análise de Progressão Modal, no qual várias amostras de freqüência de comprimento são lançadas em histogramas de modo seqüencial. A técnica consiste na identificação das modas (que representam diferentes coortes dentro de uma população) e da sua progressão (em tamanho) ao longo do tempo (Longhurst \& Pauly, op. cit.). 
Mais recentemente foram desenvolvidos métodos integrados que se baseiam nos métodos de Petersen e Análise de Progressão Modal, como é o caso da rotina ELEFAN I (Longhurst \& Pauly, op. cit.).

Os resultados obtidos neste estudo pela aplicação da rotina ELEFAN I indicaram para M. stehmanni um ciclo de vida curto, atingindo o L $\infty$ em 3 ou 4 anos, sendo que no $1^{\circ}$ ano de vida alcançaria aproximadamente $33 \mathrm{~mm}$. Os valores de $\mathbf{k}$ obtidos foram um pouco abaixo dos apresentados para Maurolicus no Japão (Yuuki, 1984) e Noruega (Gjøsæter, 1981 e Kristoffersen \& Salvanes, 1998) e os valores de L $\infty$ inferiores aos descritos nesses, exceto para Maurolicus que ocorre no fiorde Norueguês (Gjøsæter, op. cit.). Por este método, portanto, foram obtidos parâmetros de crescimento mais coerentes com os da literatura a despeito da espécie apresentar desova o ano todo.

Comparativamente o método de Bhattacharya forneceu valores de $\mathbf{k}$ inferiores aos estimados pela rotina ELEFAN I, mas superiores aos obtidos pelos métodos diretos.

O indicador de performance de crescimento $(\Phi)$ foi apresentado por Munro \& Pauly (1983) com objetivo de comparar a performance de crescimento de peixes e invertebrados cujo crescimento pudesse ser descrito pela equação de von Bertalanffy. Os autores realizaram os cálculos de $\Phi$ para uma série de parâmetros de crescimento publicados para vários estoques de cinco espécies e várias espécies de quatro famílias, verificando que as distribuições de $\Phi$ para cada espécie e família apresentavam valores próximos e distribuídos de forma normal, e concluíram que o valor de $\Phi$ pode representar e quantificar a energia de um habitat ou nicho, pois estaria diretamente relacionado com a performance de crescimento e, portanto, o metabolismo e consumo alimentar. Issac-Nahum (1989) acrescenta que $\Phi$ também pode ser utilizado para identificar erros nas estimativas dos parâmetros de crescimento. Cergole (1993) fez uma comparação dos resultados dos parâmetros de crescimento da sardinha (Sardinella brasiliensis) obtidos para a costa Sudeste do Brasil com os resultados presentes na literatura, sobre a espécie, mostrando que de maneira geral, seus resultados eram semelhantes aos já publicados, o que, de certa maneira, validou suas análises.

No presente estudo os valores de $\Phi$ para os parâmetros obtidos foram muito baixos quando utilizado o método direto, indicando que o crescimento de $M$. stehmanni foi subestimado e ao que parece, isto se deu por falhas na identificação dos anéis de crescimento e sua periodicidade em otólitos.

Quanto ao método indireto os resultados foram mais satisfatórios no sentido de apresentar valores de $\Phi$ próximos aos da literatura; entretanto os valores foram, de maneira geral, mais baixos no presente estudo. Os resultados obtidos da literatura são provenientes de áreas temperadas, onde a temperatura da água é mais fria do que na região Sudeste-Sul do Brasil, o que condicionaria um crescimento mais rápido de $M$. stehmanni, entretanto, isto não foi constatado. 
Longhurst \& Pauly (1987) descrevem um modelo de crescimento que depende da relação entre a demanda e o consumo de $\mathrm{O}_{2}$, e apontam que o crescimento da superfície das brânquias não acompanha o crescimento do corpo em volume e, portanto, com o crescimento do peixe a relação consumo/demanda diminui. Assim, o peixe cresce enquanto há sobra de $\mathrm{O}_{2}$ consumido pelos processos de manutenção; desta forma, peixes tropicais (que habitam águas mais quentes) tendem a apresentar tamanhos assintóticos menores e taxas de crescimentos maiores que suas contrapartes de regiões temperadas.

Cubillos \& Arancibia (1984) realizaram um estudo sobre o indicador performance de crescimento de três espécies do gênero Trachurus baseando-se em dados da literatura e sugerem que T. symmetricus murphyi cresce "melhor", como um todo, do que os outros estoques de Trachurus, pois apresenta o maior valor de $\Phi$; relacionam isto ao fato de $T$. symmetricus murphyi ocorrer em áreas de ressurgência (costa do Chile).

As diferenças constatadas entre o crescimento de $M$ stehmanni e M. muelleri podem estar relacionadas às características dos ecossistemas no qual estas espécies vivem, envolvendo principalmente aspectos relativos à produtividade (primária e secundária), à densidade da população e a características metabólicas da própria espécie. No entanto, mais do que características intrínsicas (genéticas) de cada uma das espécies, acredita-se que estudos mais aprofundados devam ser realizados sobre a formação dos anéis e sua periodicidade; neste sentido, estudos sobre anéis diários se fazem necessários. 


\section{CONSIDERAÇÕES FINAIS}

A espécie de Maurolicus que ocorre na região sudeste-sul brasileira é M. stehmanni (Parin \& Kobyliansky, 1993), não tendo sido encontradas evidências de diferentes estoques.

A espécie encontra-se distribuída ao longo de toda a área, preferencialmente sobre a Plataforma externa e o Talude superior e realiza migrações verticais diárias na coluna de água, suportando variações de temperatura da ordem de $10^{\circ} \mathrm{C}$. Neste sentido, sua ocorrência se dá tanto na Água Central do Atlântico Sul como na Água Tropical.

O limite sul da distribuição desta espécie parece estar ligado à posição da Convergência Subtropical.

A estrutura da população em tamanho, ao longo da área, evidenciou um padrão de ocupação diferencial com maior proporção de peixes maiores ao norte da área, próximo a Cabo Frio.

A espécie tem sua primeira maturação gonadal aos $32 \mathrm{~mm}$ e apresentou atividade reprodutiva durante todo o período de estudo, não tendo sido constatada uma área específica de desova, embora tenha se verificado alta incidência de peixes maduros nas proximidades da Quebra de Plataforma Continental.

Embora o otólito revele o crescimento em comprimento da espécie, a macroanálise de zonas (anéis) nos mesmos não se mostrou adequada para a atribuição de idades, pois não foi possível estabelecer a periodicidade da formação dos anéis. A atribuição de idades absolutas a esses anéis, com base na literatura levou a obtenção de parâmetros de crescimento irreais, deixando evidente a necessidade de estudos da microestrutura (anéis diários) destas estruturas.

Embora fugindo das premissas requeridas pelo método, a obtenção dos parâmetros de crescimento através da freqüência de comprimentos, apresentou resultados coerentes com a estratégia de vida de espécies congêneres. 


\section{REFERÊNCIAS BIBLIOGRÁFICAS:}

Ahlstrom, E. H.; W. J. Richards \& S. H. Weitzman. 1984. Families Gonostomatidae, Sternoptychidae and associated Stomiiformes groups: development and relationships. Amer. Soc. Icthyol., 1: 184 - 198.

Ankenbrandt, L. 1985. Food habits of bait-caught skipjack tuna, Katsuwonus pelamis, from the southwestern Atlantic Ocean. Fish. Bull., 83 (3): 379 - 393.

Bagenal, T. B. \& F. W. Tesch. 1978. Age and growth. In: Bagenal T. B. ed. Methods for assesment of fish in fresh waters. Oxford, Blackwell IBP handbook, 3: 101-136.

Bayley, P. B. 1977. Method for finding of limits of application of von Bertalannffy growth model and statistical estimates of parameters. J. Fish. Res. Board Can., 83 (3): 1079 - 1084.

Boehlert, G.W.; C.D. Wilson \& K. Mizuno. 1994. Populations of the sternoptychid fish Maurolicus muelleri on seamounts in the Central North Pacific. Pac. Sci. 48 (1): 57 69.

Bonecker, A. C. T. \& G. Hubold. 1990. Distribution and abundance of larval gonostomatidae fishes in the southwest Atlantic. Meeresforsch., 33 (1): 38 - 51.

Braga, F. M. S. 1986. Estudo entre fator de condição e relação peso/comprimento para alguns peixes marinhos. Ver. Brasil. Biol., 46 (2): 339 - 346.

Brey, T. \& D. Pauly. 1986. Eletronic length frequency analyses. A revised and expanded user's quide to ELEFAN 0, 1 and 2. Ber. Inst. Meeresfork., 149: 1 - 76.

Caldeira, G. F. 1999. Análise descritiva da ocorrência de cardumes de Trichiurus lepturus (Linnaaeus, 1758) e Maurolicus muelleri (Gmeliim, 1789) em relação às massas d'água durante um cruzeiro de inverno entre Cabo de São Tomé-RJ e Chuí-RS. Monografia. Fundação Universidade do Rio Grande. 52 p.

Campos, E. J. D. 1995. Estudos da circulação oceânica no Atlântico tropical e na região oeste do Atlântico subtropical sul. Tese de livre-docência. Universidade de São Paulo, Instituto Oceanográfico. $114 \mathrm{p}$.

Campos, E. J. D.; A. R. Piola \& J. L. Miller 1999. Water mass distribution on the shelf and shelf-break upwelling in the Southeast Brazil Bigth. In: SYMPOSIUM ON GLOBAL CHANGE STUDIES, 10. Dallas. Anais. Dallas, American Metereology Society. p. $446-449$.

Campos, E. J. D.; D. Velhote \& I. C. A. Silveira. 2000. Shelf break upwelling driven by Brazil Current cyclonic meanders. Geophys. Res. Letts, 27 (6): 751 - 754. 
Castello, J. P.; M. Haimovici; C. Odebrecht \& C. M. Vooren. 1997. The continental shelf and slope. In: Seeliger, U.; Odebrecht, C. \& Castello, J. P., eds Subtropical convergence enviroments: the coast and sea in the southwestern Atlantic. Berlin, Springer - Verlag. p. $171-178$.

Castro-Filho, B. M. 1996. Correntes e massa de água da Plataforma Continental Norte de São Paulo. Tese de livre-docência. Universidade de São Paulo, Instituto Oceanográfico. $248 \mathrm{p}$.

Cergole, M. C. 1993. Avaliação do estoque da sardinha-verdadeira, Sardinella brasiliensis, da costa sudeste do Brasil, período 1977 a 1990. Tese de doutorado. Universidade de São Paulo, Instituto Oceanográfico. 245 p.

Chaves, P. T. C. 1989. Hidratação pré-ovulatória em peixes: Um caráter de origem marinha? Rev. Brasil.Zool., 6 (3): 463 - 472.

Cirano, M. 1995. Utilização de modelo numérico no estudo diagnóstico da circulação oceânica na Bacia de Santos. Tese de mestrado. Universidade de São Paulo, Instituto Oceanográfico. $116 \mathrm{p}$.

Clark, C.W. \& D. A. Levy. 1988. Diel vertical migrations by juvenile sockeye salmon and the antipredation window. Am. Naturalist, 131 (2): 271-290.

Clarke, T. A . 1982. Distribution, growth, and reproduction of the lightfish Maurolicus muelleri (Sternoptychidae) off south-east Australia. CSIRO Mar. Labs Rept., 145: 1 - 12.

Clarke, T. A . 1983. Sex ratios and sexual differences in size among mesopelagic fishes from the Central Pacific Ocean. Mar. Biol., 73 (2): 203 - 209.

Cubillos, L. S. \& H. F. Arancibia. 1994. Comparative growth performance of jack mackerels of the genus Trachurus, with emphasis on T. symmetricus murphyi in Chile. Naga, 17 (2): 32-35.

Dalpadado, P. \& J. Gjøsæter. 1987. Observations on mesopelagic fish from the Red Sea. Mar. Biol., 96 (2): 173 - 183.

Dias, J.F.; E. Peres-Rios, P. D. T. D. C. Chaves \& C. L. D. B. Rossi Wongtschowski.1998. Análise macroscópica dos ovários de teleósteos: Problemas de classificação e recomendações de procedimentos. Rev. Brasil. Biol., 58 (1): 55-69.

Figueroa, D. E.; J. M. D. Astarloa \& P. Martos. 1998. Mesopelagic fish distribution in the southwest Atlantic in relation to water masses. Deep Sea Res., 45 (3-2): 317 - 332.

Fischer, W. ed.. 1978. FAO species identification sheets for fishery purposes. Western Central Atlantic (fishing area 31). Roma, FAO. 7v. 
Francis, R. I. C. C. 1990. Back calculation of fish lenght: a critical review. J. Fish Biol., 36 (6): $883-902$.

Garcia, C. A. E. 1997. Physical oceanography. In: Seeliger, U.; Odebrecht, C. \& Castello, J. P. eds. Subtropical convergence enviroments: the coast and sea in the Southwestern Atlantic. Berlin, Springer - Verlag. p 94-96.

Gartner, J. V. Jr. 1991. Life histories of three species of lanternfishes (Pisces: Myctophidae) from the eastern Gulf of Mexico. 1. Morphological and microstructural analysis of sagittal otoliths. Mar. Biol., 111 (1): 11 - 21.

Gayanilo Jr, F. C. \& D. Pauly. 1997. FAO - ICLARM stock assessment tools (FISAT). Reference manual. FAO computerized information series (Fisheries), nº.. Rome, FAO. 262p.

Gjøsæter, J. 1981. Life history and ecology of Maurolicus muelleri (Gonostomatidae) in Norwegian waters. FiskDir. Skr. Ser. Hav. Unders., 17: 109 - 131.

Gjøsæter, J. \& K. Kawaguchi 1980. A review of the world resources of mesopelagic fish. FAO Fish. tech. Pap., 193. 151 p.

Giragosov, V. Y. \& O. P. Ovcharov. 1992. Age and growth of the lantern fish Myctophum nitidulum (Myctophidae) from the Tropical Atlantic. J. Ichithyol., 32 (6): 34 - 42.

Giske, J.; D. L.Aksnes; B. M. Baliño; S. Kaartvedt; U. Lie; J. T. Nordeide; A . G. V. Salvanes; S. M. Wakili \& A. Aadnesen. 1990. Vertical distribution and trophic interactions of zooplankton and fish in Masfjorden, Norway. Sarsia, 75: 65 - 91.

Goodson, M. S.; J. Giske, \& R. Rosland 1995. Growth and ovarian development of Maurolicus muelleri during spring. Mar. Biol., 124 (2): 185 - 195.

Greig, A. B. 2000. Determinação da distribuição e estimativa da abundância de Maurolicus muelleri (Gmelin, 1789); (Teleostei: Sternoptychidae) por método hidroacústico na região sudeste-sul do Brasil, para a primavera de 1997. Dissertação de mestrado. Fundação Universidade do Rio Grande. 104 p.

Grey, M. 1964. Family Gonostomatidae. In: Fishes of the western North Atlantic. Mem. Sears Fdn. mar. Res., 1: 78 - 240.

Haimovici, M.; A. S. Martins; J. L. Figueiredo \& P. C. Vieira. 1994. Demersal bony fish of the outer shelf and upper slope of the southern Brazil subtropical convergence ecosystem. Mar. Ecol. Prog. Ser., 108 (1-2): 59 - 77.

Haimovici, M. \& G. Velasco. 2000. Lenght-weight relationship of marine fishes from southern Brazil. Naga, 23 (1): 19 - 23.

Hulley, P.A. \& , R.M. Prosch. 1987. Mesopelagic fish derivatives in the southern Benguela upwelling region. S. Afr. J. mar. Sci. 5: 597 - 611. 
Hunter, J. R. \& S. R. Goldberg. 1980. Spawning incidence and batch fecundity in Northern Anchovy, Engraulis mordax. Fish. Bull., 77 (3): 641 - 652.

Hunter, J. R.; N. C. H. Lo, \& R. J. H. Leong. 1985. Batch fecundity in multiple spawning fishes. NOAA Tec Report. 36: 67 - 76.

Issac-Nahum, V. J. 1989. Analyses of methods for the estimation of fish growth parameters, based on data from family Scianidae and on simulated data. Tese de doutorado. Institute für Meereskunde, Universität Kiel. 244 p.

Kaartvedt, S.; T. Knutsen \& J. C. Holst. 1998. Schooling of the vertically migrating mesopelagic fish Maurolicus muelleri in light summer nights. Mar. Ecol. Prog. Ser., 170: 287 - 290.

King, M. G. 1996. Fisheries biology, assessment and management. Oxford, Fishing news book. $146 \mathrm{p}$.

Kristoffersen, J.B. \& A. G. V. Salvanes. 1998. Life history of Maurolicus muelleri in fjordic and oceanic environments. J. Fish Biol., 53 (6): 1324 - 1341.

Linkowski, T. B. 1996. Lunar rhythms of vertical migrations coded in otolith microstructure of North Atlantic lanternfishes, genus Hygophum (Myctophidae). Mar. Biol., 124 (4): $495-508$.

Longhurst, A. R. \& D. Pauly. 1987. Ecology of tropical oceans. San Diego, Academic Press. $407 \mathrm{p}$.

Lowe- McConnel, R. H. 1999. Estudos ecológicos de comunidades de peixes tropicais. Trad. Vazzoler, A. E. A. de M.; A. A. Agostinho \& P. T. M. Cunnhingham. São Paulo, Edusp. 535 p.

Mann, K. H. 1993. Physical oceanography, food chains, and fish stocks: a review. ICES J. mar. Sci., 50 (2): 105 - 119.

Matsuura, Y. 1996. A probable cause of recruitment failure of the Brazilian sardine Sardinella aurita population during the 1974/75 spawning season. S. Afr. J. mar. Sci., 17: 29 35.

Matsuura, Y. \& E. M. Kitahara 1995. Horizontal and vertical distribution of anchovy Engraulis anchoita eggs and larvae off Cape Santa Marta Grande in Southern Brazil. Arch. Fish. Mar. Res., 42 (3): 239 - 250.

Melo, Y.C. \& M. J. Armstrong. 1991. Batch spawning behavior in lightfish Maurolicus muelleri. S. Afr. J. mar. Sci., 10: 125 - 130.

Miranda, L. B. \& M. Katsuragawa 1991. Estrutura térmica na região sudeste do Brasil (outubro/ novembro de 1988). Publção. esp. Inst. Oceanogr., S. Paulo, (8): 1 - 14.

Munro, J. L. \& D. Pauly 1983. A simple method for comparing the growth of fishes and invertebrates. Fishbyte, 1 (1): 5-6. 
Parin, N. V. \& S. G. Kobyliansky 1993. Review of the genus Maurolicus (Sternoptychidae, Stomiiformes), with re-establishing validity of five species considered junior synonyms of M. muelleri and descriptions of nine new species. Trudy Inst. Okeanol., 128: 69 107.

Parin, N. V. \& S. G. Kobyliansky. 1996. Diagnoses and distribution of fifteen species recognized in genus Maurolicus Cocco (Sternoptychidae, Stomiiformes) with a key to their identification. Cybium, 20 (2): 185 - 195.

Piola, A.; E. J. D. Campos; O. O. Moller Jr.; M. Charo \& C. Martinez. 1999. Continental shelf water masses off eastern south america $-20^{\circ}$ to $40^{\circ} \mathrm{S}$. In: SYMPOSIUM ON GLOBAL CHANGE STUDIES, 10. Dallas. Anais. Dallas, American Metereology Society. 9 12.

Pires-Vanin, A. M. S. \& Y. Matsuura. 1993. Estrutura e função do ecossistema da plataforma continental da região de Ubatuba, Estado de São Paulo: uma introdução. Publção. esp. Inst. Oceanogr., S. Paulo, (10): 1 - 8.

Pitcher, T. J. \& P. J. B. Hart 1996. Fisheries Ecology. $9^{\text {a. }}$ edition. Londres, Chapman \& Hall. $414 \mathrm{p}$.

Poots G. W. \& R. J. Wootton. 1984. Fish reproduction: strategies and tactics. London, Academic Press. 409 p.

Prosch, R. M. 1991. Reproductive biology and spawning of the myctophid Lampanyctodes hectoris and the sternoptychid Maurolicus muelleri in the southern Benguela ecosystem. S. Afr. J. mar. Sci., 10: 241 - 252.

Rasmussen, O. I. \& J. Giske 1994. Life-history parameters and vertical distribution of Maurolicus muelleri in Masfjorden in summer. Mar. Biol., 120 (4): 649 - 664.

Reid, S. B.; J. Hirota; R. E. Young \& L. E. Halllacher. 1991. Mesopelagic-boundary community in Hawaii: micronekton at the interface between neritic and oceanic ecosystems. Mar. Biol., 109: 427 - 440.

Ribeiro, M. R. 1996. Estudos sobre o desenvolvimento larval, abundância e distribuição de ovos e larvas de Maurolicus muelleri (Gmelin, 1789) (Teleostei: Sternoptychidae), e possíveis potencialidades ao largo da costa sudeste brasileira, compreedida entre $23^{\circ}$ S. (Cabo Frio-RJ) e 29 S (Cabo de Santa Marta Grande-SC). Tese de mestrado. Universidade de São Paulo, Instituto Oceanográfico. 160 p.

Robertson, D. A. 1976. Planktonic stage of Maurolicus muelleri (Teleostei: Sternoptychidae) in New Zealand waters. N. Z. J1 mar. Freshwat. Res., 10: 311 - 328. 
Salvanes, A. G. V. \& B. M. Stockley. 1996. Spatial variation of growth and gonadal developments of Maurolicus muelleri in the Norwegian Sea and in Norwegian fjord. Mar. Biol., 126 (2): $321-332$.

Silva, M. P. 1995. Caracterização físico-química das massas de água da Bacia de Santos durante o Projeto COROAS. Verão e Inverno de 1993. Tese de mestrado. Universidade de São Paulo, Instituto Oceanográfico. 135 p.

Silva, M. P. \& A. C. Freitas 1999. Projeto REVIZEE SCORE Sul (sub-área Oc. Física) Cruzeiro REVIZEE I - Pelágico. Relatório Técnico. FURG, Laboratório de Oceanografia Física. 8 p.

Silva, M. P.; A. C. Freitas \& M. C. Miranda 1999a. Projeto REVIZEE SCORE Sul (sub-área Oc. Física) - Cruzeiro REVIZEE II - Pelágico. Relatório Técnico. FURG, Laboratório de Oceanografia Física. 26 p.

Silva, M. P.; A. C. Freitas \& M. C. Miranda 1999b. Projeto REVIZEE SCORE Sul (sub-área Oc. Física) - Cruzeiro REVIZEE III - Pelágico. Relatório Técnico. FURG, Laboratório de Oceanografia Física. 26 p.

Sparre, P. \& S. C. Venema 1997. Introduction to tropical fish stock assessment. Part 1. Manual. FAO Fish tech. Pap., 306 (2): 1 - 404.

Stearns, S. C. \& R. E. Crandall. 1984. Plasticity for age at sexual maturity: a life-history responses to inavoidable stress. In: Potts, G. W. \& R. J. Wootton eds. Fish reproduction: strategies and tactics. Londres, Academic Press. p. 13 - 33.

Taylor, C. C. 1962. Growth equations with metabolic parameters. J. Cons. int. Explor. Mer., 23: $366-370$.

Vazzoler, A. E. A. de M. 1981. Manual de métodos para estudos biológicos de populações de peixes: crescimento e reprodução. Brasília, CNPq. Programa Nacional de Zoologia. $108 \mathrm{p}$.

Vazzoler, A. E. A. de M. 1996. Biologia da reprodução de peixes teleósteos: teoria e prática. Maringá, Eduem/SBI. 169 p.

Weatherley, A . H. \& H. S. Gill. 1987. The biology of fish growth. Londres, Academic Press. $443 \mathrm{p}$.

Weiss, G.; G. Hubold \& A. C. T. Bonecker. 1988. Eggs and larvae of Maurolicus muelleri (Gmelin, 1789) (Teleostei, Sternoptychidae) in the southwest Atlantic. Meeresforsch., 32 (1): $53-60$.

Weitzman, S. H. 1974. Osteology and evolutionary relationships of the Sternoptychidae, with a new classification of stomiatoid families. Bull. am. Mus. nat. Hist., 153 (3): 327 - 478. 
West, G. 1990. Methods of assessing ovarian develoment in fishes: a review. Aust. J. mar. Freshwat. Res., 41 (2): 199 - 222.

Wootton, R. J. 1973. The effect of size of food ration on egg production in the female threespined stickleback Gasterosteus aculeatus L. J. Fish Biol., 5 (1): 89 - 96.

Wootton, R. J. 1990. Ecology of teleostei fishes. Londres, Chapman \& Hall. 404 p.

Young, J. W.; S. J. M. Blaber \& R. Rose. 1987. Reproductive biology of three species of midwater fishes associated with the continental slope of Eastern Tasmania, Australia. Mar. Biol., 95 (3): 323 - 332.

Yuuki, Y. 1982. Spawing and maturity of a sternoptychid fish Maurolicus muelleri in the south western of the sea of Japan. Bull. japan. Soc. Scient. Fish., 48 (6): 749 - 753.

Yuuki, Y. 1984. Age and growth of a sternoptychid fish Maurolicus muelleri in the south western waters of the sea of Japan. Bull. japan. Soc. Scient. Fish., 50 (11): 1849 1854.

Zar, J. H. 1996. Biostatistical analysis. New Jersey, Prentice Hall. 662p.

Zavala-Camin, L. A . 1981. Hábitos alimentares e distribuição dos atuns e afins (Osteichthyes Teleostei) e suas relações ecologicas com outras espécies pelágicas das regiões sudeste e sul do Brasil. Tese de doutorado. Universidade de São Paulo, Instituto de Biociências. $237 \mathrm{p}$. 